\title{
Prokaryotic Biodiversity of Lonar Meteorite Crater Soda Lake Sediment and Community Dynamics During Microenvironmental pH Homeostasis by Metagenomics
}

\author{
Dissertation \\ for the award of the degree \\ "Doctor of Philosophy" Ph.D. Division of Mathematics and Natural Sciences \\ of the Georg-August-Universität Göttingen
}

within the doctoral program in Biology of the Georg-August University School of Science (GAUSS)

Submitted by Soumya Biswas from Ranchi (India) Göttingen, 2016 


\section{Thesis Committee}

Prof. Dr. Rolf Daniel

Department of Genomic and Applied Microbiology, Institute of Microbiology and Genetics, Faculty of Biology and Psychology, Georg-August-Universität Göttingen, Germany

PD Dr. Michael Hoppert

Department of General Microbiology, Institute of Microbiology and Genetics, Faculty of Biology and Psychology, Georg-August-Universität Göttingen, Germany

\section{Members of the Examination Board}

Reviewer: $\quad$ Prof. Dr. Rolf Daniel, Department of Genomic and Applied Microbiology, Institute of Microbiology and Genetics, Faculty of Biology and Psychology, Georg-August-Universität Göttingen, Germany

Second Reviewer: PD Dr. Michael Hoppert, Department of General Microbiology, Institute of Microbiology and Genetics, Faculty of Biology and Psychology, Georg-August-Universität Göttingen, Germany

Further members of the Examination Board:

Prof. Dr. Burkhard Morgenstern, Department of Bioinformatics, Institute of Microbiology and Genetics, Faculty of Biology and Psychology, Georg-August-Universität Göttingen, Germany

PD Dr. Fabian Commichau, Department of General Microbiology, Institute of Microbiology and Genetics, Faculty of Biology and Psychology, Georg-August-Universität Göttingen, Germany

Prof. Dr. Kai Heimel, Department of Molecular Microbiology and Genetics, Institute of Microbiology and Genetics, Faculty of Biology and Psychology, Georg-August-Universität Göttingen, Germany

PD Dr. Wilfried Kramer, Department of Molecular Genetics, Institute of Microbiology and Genetics, Faculty of Biology and Psychology, Georg-August-Universität Göttingen, Germany

Date of the oral examination: 04.08.2016 
"A man should look for what is, and not for what he thinks should be."

- $\quad$ Albert Einstein 


\section{TABLE OF CONTENTS}

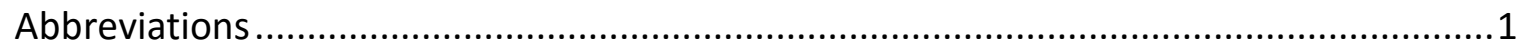

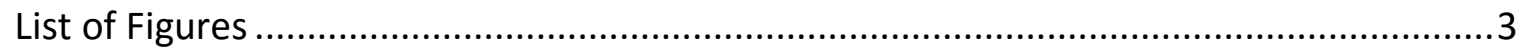

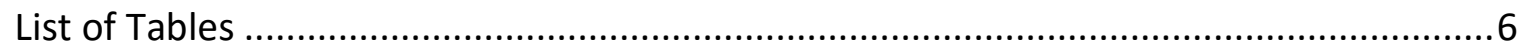

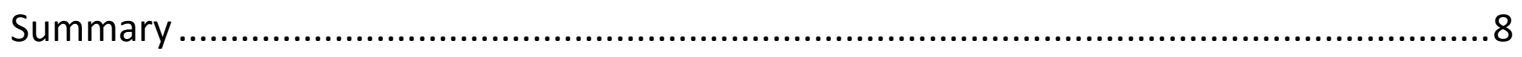

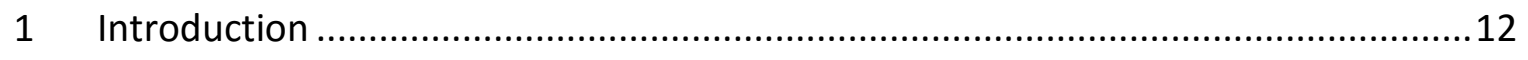

1.1 State Of The Research On Prokaryotes Inhabiting Soda Lakes........................12

1.1.1 Prokaryotes Isolated From Soda Lakes ................................................ 14

1.1.1.1 Prokaryotic Biodiversity And Biogeochemical Cycles In Soda Lakes ....15

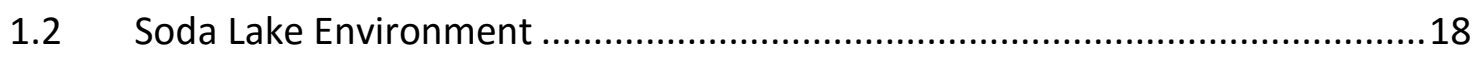

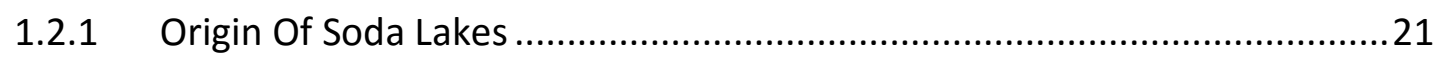

1.2.2 pH As A Major Environmental Variable ..............................................21

1.3 Element Cycling In The Soda Lake Environment.........................................22

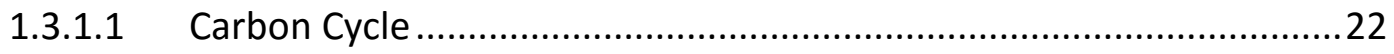

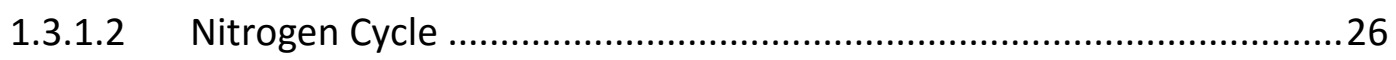

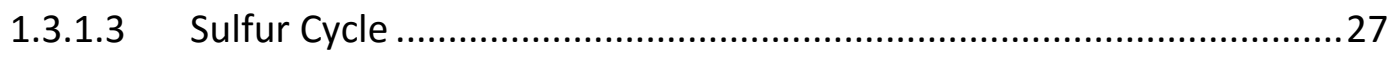

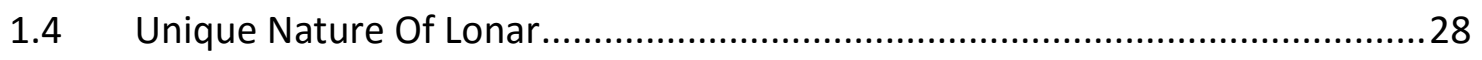

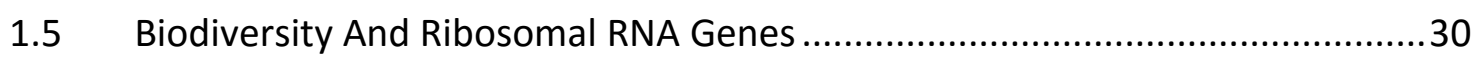

1.6 Community Dynamics And Microenvironmental ph Homeostasis....................31

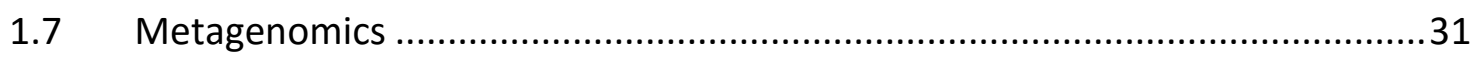

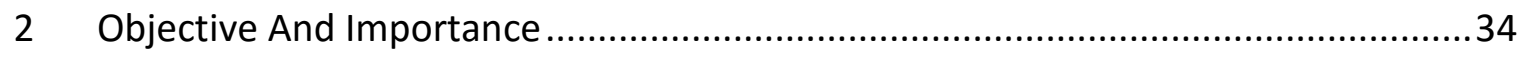

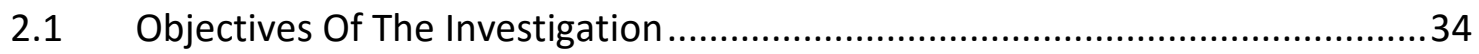

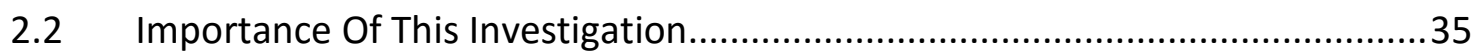

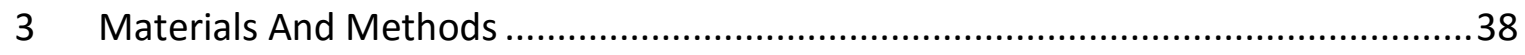

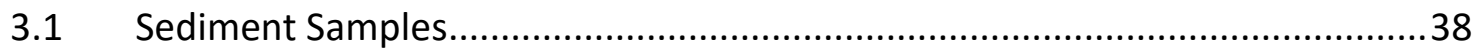

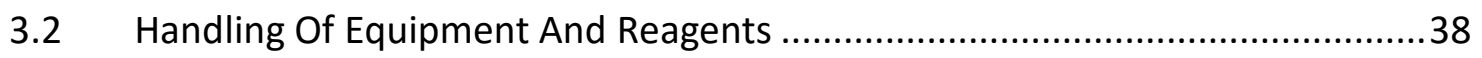




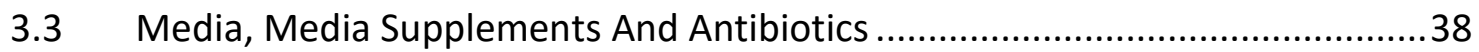

3.4 Organisms, Oligonucleotides, Enzymes, And Buffers ......................................41

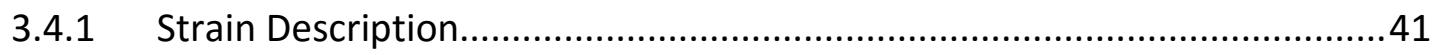

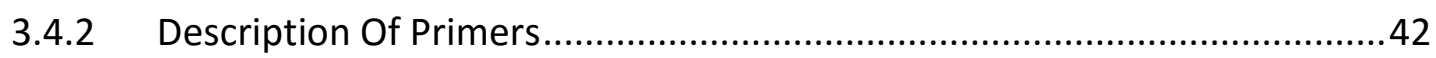

3.4.2.1 Primers For Roche Platform Sequencing ..................................... 42

3.4.2.2 Primers For Illumina Platform Sequencing .....................................42

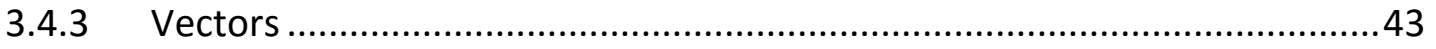

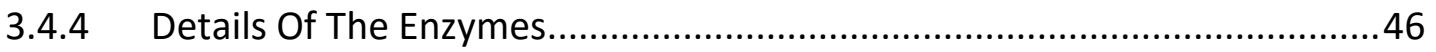

3.4.5 Composition Of Buffers And Stock Solutions..........................................46

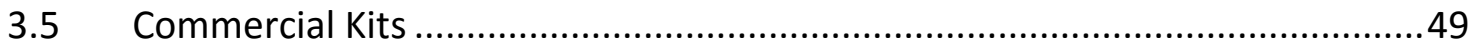

3.6 Computational And Statistical Analysis Tools ...............................................50

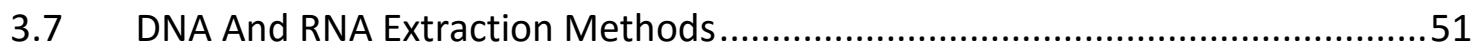

3.7.1 Extraction Of DNA And RNA For The Total And The Active Prokaryotic Biodiversity Assessment By Illumina Platform ....................................................51

3.7.2 Extraction Of DNA For Additional Biodiversity Assessment By Roche Platform 52

3.7.3 Extraction Of DNA From Agarose Gel .....................................................53

3.7.4 Extraction Of DNA For Direct Metagenome Analysis ................................54

3.7.5 Extraction Of DNA For The Study Of Community Dynamics During Microenvironmental pH Homeostasis ...................................................................54

3.7.6 Extraction Of DNA For Construction Of Metagenomic Libraries................55

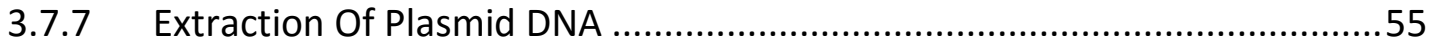

3.7.7.1 Isolation Of Plasmid Using Peqgold Plasmid Miniprep Kit ...................55

3.7.7.2 Isolation Of Plasmid Using QIAGEN Plasmid Plus Midi Kit ...................56

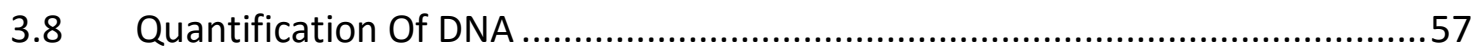

3.8.1 Determination Of DNA Concentration By Nano-Drop Spectrophotometer 57 
3.8.2 Determination Of DNA Concentration By Qubit Fluorometer .58

3.9 Construction And Screening Of Metagenomic Libraries ...............................58

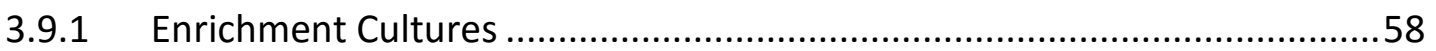

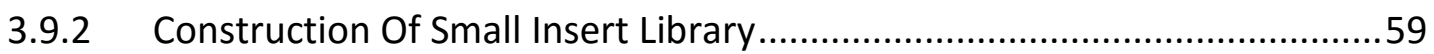

3.9.2.1 Preparation Of Electrocompetent Cells...........................................59

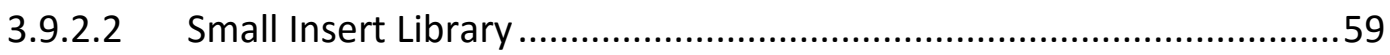

3.9.2.2.1 Transformation Of E. Coli TOP10 And E. Coli DH5 $\alpha$ Cells By

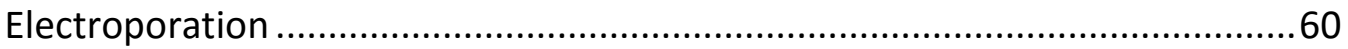

3.9.2.2.2 Detection Of Recombinant Cells By Blue-White Screening .............61

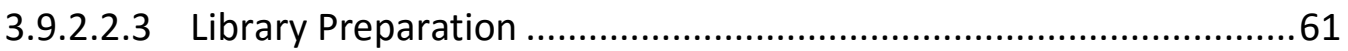

3.9.2.3 Screening Of Small Insert Libraries.................................................62

3.9.2.3.1 Protease Activity Screening ….................................................62

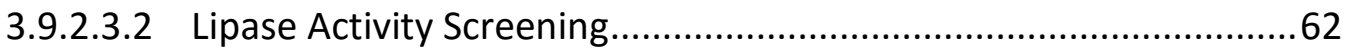

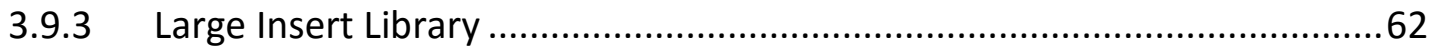

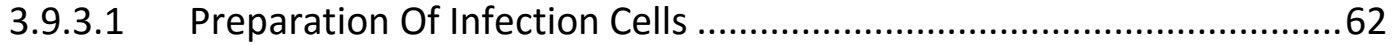

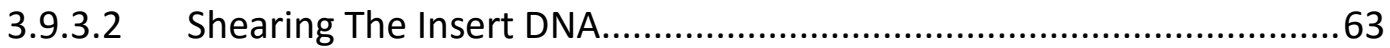

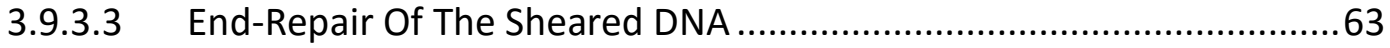

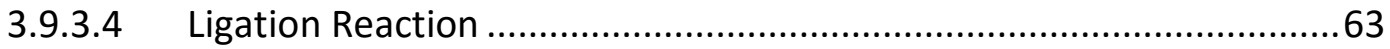

3.9.3.5 Packaging Of Fosmid Clones..............................................................63

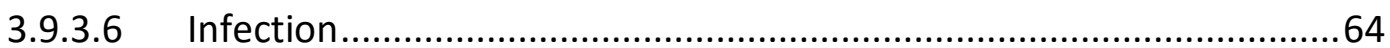

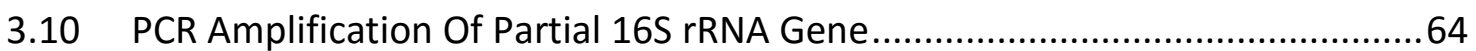

3.10.1 Amplification Of Partial 16S rRNA Gene For The Total And The Active

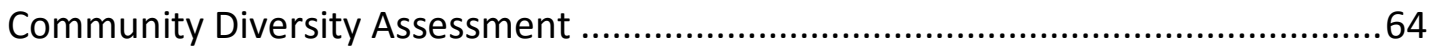

3.10.2 Amplification Of Partial 16S rRNA Gene For Additional Total Diversity Assessment ..... .66

3.10.3 Amplification Of Partial 16S rRNA Gene For Community Dynamics Study During Microenvironmental $\mathrm{pH}$ Homeostasis ..... 67 
3.11 Nonoptimal Microenvironmental pH Exposure

3.12 HPLC Analysis Of Culture Filtrate From Nonoptimal pH Exposure By Varian Star Platform .68

3.13 Sequencing. .69

3.13.1 Sequencing By Illumina Miseq .69

3.13.2 Sequencing By Roche GS-FLX 454 Pyrosequencer. .70

3.14 Analysis Of Sequencing Data .70

3.14.1 Analysis Of Sequencing Of Partial 16S rRNA Gene Data From Illumina Platform .70

3.14.2 Analysis Of Sequencing Of Partial 16S rRNA Gene Data From Roche Platform 71

3.14.3 Analysis Of Direct Metagenome Sequencing Data From Illumina Platform 72

4 Results And Discussion .74

4.1 Description Of Sediment Samples From Lonar Crater Lake ............................74

4.2 The Total And The Active Prokaryotic Diversity Of Lonar Crater Lake ...............76

4.2.1 General Analyses Of The Total And The Active Community Sequencing Data 76

4.2.2 Prokaryotic Diversity And Richness ....................................................... 77

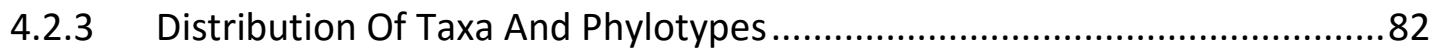

4.2.3.1 The Total And The Active Community Diversity Of Archaea.................82

4.2.3.2 The Total And The Active Community Diversity Of Bacteria.................90

4.2.3.3 Relative Coverage Of The Total And The Active Community .............100

4.3 General Analyses Of The Additional Sequencing Of The Total Diversity Data From Lonar 102

4.4 Comparison Of Present And Previous Investigations On Prokaryotic Diversity Of Lonar Crater Lake. .105 
4.4.1 Genera Detected In Lonar Crater Soda Lake With Significance In

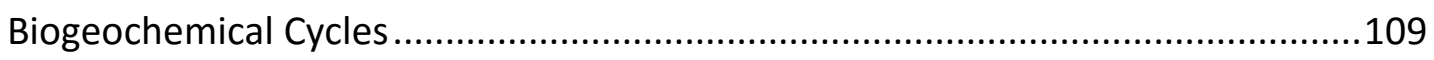

4.5 Diversity Of Functional Genes With Emphasis On Ecological Role..................112

4.5.1 General Analysis Of The Metagenome From The Sediments Of Lonar Lake 112

4.5.1.1 Relative Abundance Of Functional Category. .113

4.5.2 Biogeochemical Cycle And Metabolism Of Methane, Nitrogen, And Sulfur 114

4.5.2.1 Methane Metabolism 115

4.5.2.2 Nitrogen Metabolism. 118

4.5.2.3 Sulfur Metabolism 121

4.6 Community Dynamics During Microenvironmental pH Homeostasis. .125

4.6.1 Shift Of Extracellular pH. 125

4.6.2 Differential Utilization Of Different Amino Acids In Suboptimal And Superoptimal $\mathrm{pH}$ 126

4.6.3 Prokaryotic Diversity, Richness And Distribution Of Taxa ........................127

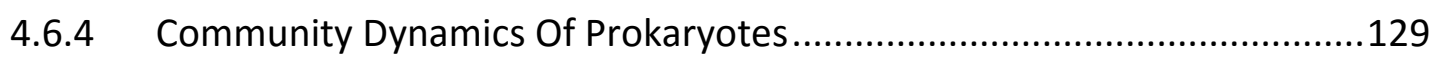

4.6.4.1 Dynamics Of Archaeal Genera:....................................................131

4.6.4.1.1 Dynamic Group Type-Al: .........................................................132

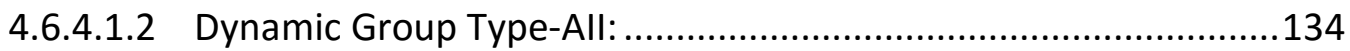

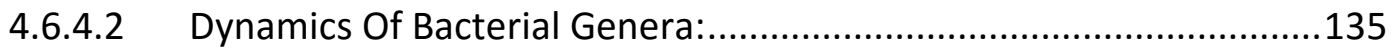

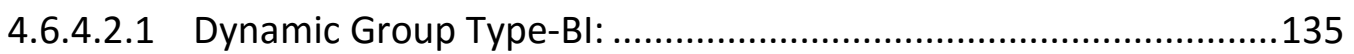

4.6.4.2.2 Dynamic Group Type-BII: .......................................................137

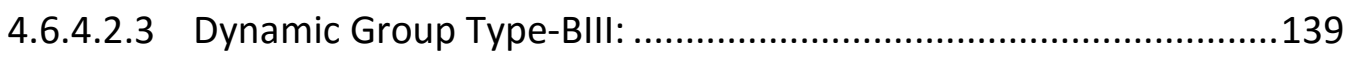

4.6.4.2.4 Dynamic Group Type-BIV: .....................................................140

4.6.4.3 Microenvironmental $\mathrm{pH}$ Homeostasis As A Function Of Growth ......142

5 Conclusion And Future Direction. 145 
Supplement-A: Authorization for sampling .......................................................... ii

Supplement-B: The total and the active archaeal diversity table ................................ iv

Supplement-C: The total and the active bacterial diversity table .............................. iv

Supplement-D: Additional total diversity of Archaea and Bacteria ............................. iv

Supplement-E: Changing Relative Abundance of Archaea and Bacteria in Suboptimal

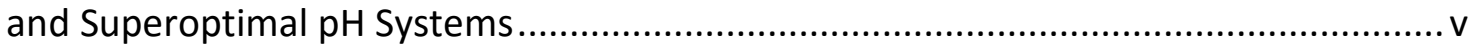

Supplement-F: Diversity of Functional genes observed by direct metagenome analysis . v

Supplement-G: Details of the sequence submitted to NCBI .................................... Supplement-H: Results from Construction and screening of Metagenomic Libraries... vi

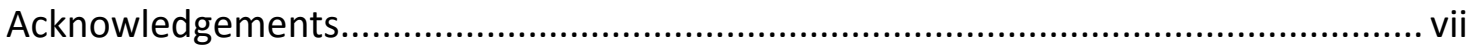




\section{AbBREVIATIONS}

\begin{tabular}{|c|c|}
\hline Abbreviation & Description \\
\hline${ }^{\circ} \mathrm{C}$ & Degree Celsius \\
\hline$\mu \mathbf{F}$ & Microfarad \\
\hline$\mu l$ & Microliter \\
\hline 16S rDNA & $16 \mathrm{~S}$ ribosomal DNA \\
\hline A & Adenine \\
\hline bp & Base Pairs \\
\hline BSA & Bovine Serum Albumin \\
\hline C & cytosine \\
\hline CTAB & Cetrimonium Bromide \\
\hline dATP & Deoxyadenosine triphosphate \\
\hline dATPaS & a-thiotriphosphate \\
\hline $\mathrm{dH} 2 \mathrm{O}$ & Deionized water \\
\hline DMSO & Dimethyl sulfoxide \\
\hline DNA & Deoxyribonucleic acid \\
\hline dNTP & Deoxynucleoside Triphosphate \\
\hline E. coli & Escherichia coli \\
\hline EcoRI & E. coli restriction enzyme I \\
\hline EDTA & Ethylenediaminetetraacetic Acid \\
\hline EtBr & Ethidium Bromide \\
\hline $\mathbf{F}$ & Forward \\
\hline g & Gram \\
\hline G & Guanine \\
\hline GITC & Guanidinium Thiocyanate \\
\hline gm & Gram \\
\hline h & Hour \\
\hline hrs & Hours \\
\hline kb & Kilobase Pairs \\
\hline kV & Kilovolt \\
\hline LB Medium & Luria - Bertani Medium \\
\hline LMP & Low Melting Point \\
\hline MID & Multiplex Identifier \\
\hline
\end{tabular}




\begin{tabular}{|c|c|}
\hline Abbreviation & Description \\
\hline $\min$ & Minute \\
\hline ml & Milliliter \\
\hline $\mathrm{mM}$ & Millimolar \\
\hline ng & Nanogram \\
\hline $\mathrm{nm}$ & Nanometer \\
\hline No. & Number \\
\hline OTU & Operational Taxonomic Units \\
\hline PCR & Polymerase Chain Reaction \\
\hline PPi & Pyrophosphate \\
\hline $\mathbf{R}$ & Reverse \\
\hline $\mathbf{R}$ & Purines (adenine or guanine) \\
\hline RNA & Ribonucleic Acid \\
\hline RNase & Ribonuclease \\
\hline rpm & Revolutions per Minute \\
\hline RT & Room Temperature \\
\hline S.O.C. & Super Optimal Broth with Catabolite Repression \\
\hline SDS & Sodium Dodecyl Sulfate \\
\hline Sec & Second \\
\hline StMQ & Sterile MilliQ \\
\hline $\mathbf{T}$ & Thymine (5-methyluracil) \\
\hline TAE & Tris-Acetate-EDTA-Buffer \\
\hline Taq & Thermus aquaticus \\
\hline Tris & Tris (hydroxymethyl) -aminomethane \\
\hline $\mathbf{U}$ & Unit \\
\hline UV & Ultraviolet radiation \\
\hline $\mathbf{v}$ & Volt \\
\hline $\mathbf{x g}$ & 9.8 meter/second ${ }^{2}$ (acceleration caused by gravity) \\
\hline $\mathbf{Y}$ & Pyrimidines (cytosine, thymine or uracil) \\
\hline
\end{tabular}




\section{LIST OF FIGURES}

FIGURE 1: A COMPARISON OF INVESTIGATION EFFORT ON LONAR AND OTHER SODA LAKES.

FIGURE 2: VIEW OF THE LONAR CRATER LAKE FROM THE TOP OF THE IMPACT EJECTA. PHOTOGRAPH BY SOUMYA BISWAS.

FIGURE 3: OVERVIEW OF THE OBJECTIVES AND WORKFLOW. THE FIGURE SHOWS THE WORKFLOW FROM SAMPLES TO OBJECTIVES.

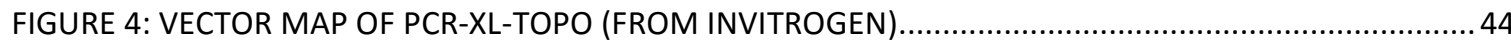

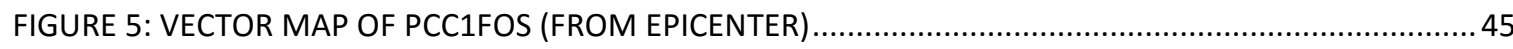

FIGURE 6: RAREFACTION CURVES INDICATING THE OBSERVED NUMBER OF OPERATIONAL TAXONOMIC UNITS (OTUS) IN THE TOTAL AND THE ACTIVE COMMUNITY STUDY. THREE DIFFERENT SAMPLES ARE INDICATED IN RED, GREEN AND BLACK RESPECTIVELY FOR LONAR 1, LONAR 2 AND LONAR 3. THE CURVES INDICATE GRADUAL SATURATION IN THE NUMBER OF OTUS WITH AN INCREASE IN THE NUMBER OF SEQUENCES EXAMINED. ON THE LEFT RAREFACTION CURVES FOR ARCHAEA AND ON THE RIGHT FOR BACTERIA, ALL THE CURVES ARE AT $3 \%$ GENETIC DISTANCES.

FIGURE 7: BOXPLOT DIAGRAM OF THE NUMBER OF TAXONOMIC UNITS (OTUS) AT THE SPECIES LEVEL IN DIFFERENT SAMPLING EFFORTS. ON THE LEFT IS THE BOXPLOT DIAGRAM FOR ARCHAEA AND ON THE RIGHT IS FOR BACTERIA.

FIGURE 8: RELATIVE DISTRIBUTION OF UNCULTURED AND CULTURED UNIQUE OTUS. ON THE LEFT DISTRIBUTION OF UNCULTURED AND CULTURED UNIQUE OTUS AMONG ARCHAEA IS SHOWN. ON THE RIGHT DISTRIBUTION OF UNCULTURED AND CULTURED UNIQUE OTUS AMONG BACTERIA IS SHOWN.

FIGURE 9: RELATIVE ABUNDANCES OF ARCHAEAL ORDERS IN LONAR SEDIMENTS. SAMPLE NUMBERS INDICATING THE DIFFERENT SEDIMENT SAMPLES ARE GIVEN BELOW THE RESPECTIVE BARS. ORDERS ARE ACCOUNTING FOR <1 \% OF ALL CLASSIFIED SEQUENCES ARE SUMMARIZED IN THE ARTIFICIAL GROUP 'OTHERS.'

FIGURE 10: RELATIVE ABUNDANCES OF THE RARE ARCHAEAL ORDER IN LONAR SEDIMENTS. SAMPLE NUMBERS INDICATING THE DIFFERENT SEDIMENT SAMPLES ARE GIVEN BELOW THE RESPECTIVE BARS. ONLY THE PHYLOGENETIC GROUPS ARE ACCOUNTING FOR <1 \% OF ALL CLASSIFIED SEQUENCES ARE SHOWN.

FIGURE 11: RELATIVE ABUNDANCES OF THE MOST ABUNDANT ARCHAEAL GENERA IN LONAR SEDIMENTS. SAMPLE NUMBERS INDICATING THE DIFFERENT SEDIMENT SAMPLES ARE GIVEN BELOW THE RESPECTIVE BARS. ONLY THE PHYLOGENETIC GROUPS ACCOUNTING FOR >1\% OF ALL CLASSIFIED SEQUENCES ARE SHOWN.

FIGURE 12: RELATIVE ABUNDANCES OF THE RARE ARCHAEAL GENERA IN LONAR SEDIMENTS. SAMPLE NUMBERS INDICATING THE DIFFERENT SEDIMENT SAMPLES ARE GIVEN BELOW THE RESPECTIVE 
BARS. ONLY THE PHYLOGENETIC GROUPS, ACCOUNTING FOR <1 \% OF ALL CLASSIFIED SEQUENCES ARE SHOWN.

FIGURE 13: RELATIVE ABUNDANCES OF DOMINANT BACTERIAL PHYLUM GROUPS IN LONAR SEDIMENTS. SAMPLE NUMBERS INDICATING THE DIFFERENT SEDIMENT SAMPLES ARE GIVEN BELOW THE RESPECTIVE BARS. PHYLOGENETIC GROUPS ACCOUNTING FOR <1\% OF ALL CLASSIFIED SEQUENCES ARE SUMMARIZED IN THE ARTIFICIAL GROUP 'OTHERS.' ....

FIGURE 14: RELATIVE ABUNDANCES OF THE RARE BACTERIAL PHYLUM IN LONAR SEDIMENTS. SAMPLE NUMBERS INDICATING THE DIFFERENT SEDIMENT SAMPLES ARE GIVEN BELOW THE RESPECTIVE BARS. ONLY THE PHYLOGENETIC GROUPS, ACCOUNTING FOR <1 \% OF ALL CLASSIFIED SEQUENCES ARE SHOWN.

FIGURE 15: RELATIVE ABUNDANCES OF THE MOST ABUNDANT BACTERIAL GENERA IN LONAR SEDIMENTS. SAMPLE NUMBERS INDICATING THE DIFFERENT SEDIMENT SAMPLES ARE GIVEN BELOW THE RESPECTIVE BARS. ONLY THE PHYLOGENETIC GROUPS ACCOUNTING FOR >1\% OF ALL CLASSIFIED SEQUENCES ARE SHOWN.

FIGURE 16: RELATIVE ABUNDANCES OF THE RARE BACTERIAL GENERA IN LONAR SEDIMENTS. SAMPLE NUMBERS INDICATING THE DIFFERENT SEDIMENT SAMPLES ARE GIVEN BELOW THE RESPECTIVE BARS. ONLY THE PHYLOGENETIC GROUPS ACCOUNTING FOR $<1 \%$ OF ALL CLASSIFIED SEQUENCES ARE SHOWN. .

FIGURE 17: VENN DIAGRAM OF RELATIVE COVERAGE BETWEEN DIFFERENT SURVEYING EFFORTS. UPPER LEFT- ORDER LEVEL, ARCHAEA, LOWER LEFT- GENUS LEVEL, ARCHAEA, UPPER RIGHT- PHYLUM LEVEL, BACTERIA, LOWER RIGHT- GENUS LEVEL, BACTERIA.

FIGURE 18: RAREFACTION CURVES INDICATING THE OBSERVED NUMBER OF OPERATIONAL TAXONOMIC UNITS (OTUS) IN ADDITIONAL ASSESSMENT OF THE TOTAL DIVERSITY. THREE DIFFERENT SAMPLES ARE INDICATED IN RED, GREEN AND BLACK RESPECTIVELY FOR LONAR 1, LONAR 2 AND LONAR 3. THE CURVES INDICATE GRADUAL SATURATION IN THE NUMBER OF OTUS WITH AN INCREASE IN THE NUMBER OF SEQUENCES EXAMINED. ON THE LEFT RAREFACTION CURVES FOR ARCHAEA AND ON THE RIGHT FOR BACTERIA AT $3 \%$ GENETIC DISTANCES ARE SHOWN.

FIGURE 19: COMPARISON OF CURRENT AND PREVIOUS INVESTIGATIONS IN DETECTION GENERA. THE FIGURE SHOWS MUTUAL COVERAGE OF DETECTED GENERA IN ALL PREVIOUS INVESTIGATIONS (OTHERS) AND CURRENT INVESTIGATION (PRESENT). THE RED CIRCLE REPRESENTS THIS STUDY AND BLUE REPRESENTS ALL OTHER STUDIES.

FIGURE 20: TAXONOMIC COMPOSITION OF THE METAGENOME. THE FIGURE SHOWS RELATIVE ABUNDANCE OF THE TAXONOMIC GROUPS IN THE LONAR METAGENOME.

FIGURE 21: RELATIVE ABUNDANCE OF FUNCTIONAL CATEGORIES IN THE LONAR SEDIMENT. THE PIE DIAGRAM SHOWS THE RELATIVE ABUNDANCE OF DETECTED AND ANNOTATED ORFS IN THE LONAR SEDIMENT WITH RESPECT TO ITS FUNCTIONAL CATEGORY.

FIGURE 22: METHANE METABOLISM (A). THE FIGURE SHOWS EXPERIMENTAL DATA (RED) MAPPED ON THE REFERENCE PATHWAY. 
FIGURE 23: METHANE METABOLISM (B). THE FIGURE SHOWS EXPERIMENTAL DATA (RED) MAPPED ON

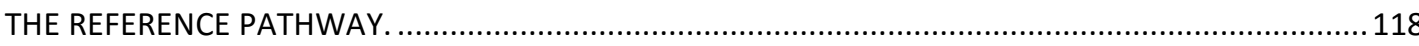

FIGURE 24: NITROGEN METABOLISM (A). THE FIGURE SHOWS EXPERIMENTAL DATA (RED) MAPPED ON THE REFERENCE PATHWAY.

FIGURE 25: NITROGEN METABOLISM (B). THE FIGURE SHOWS EXPERIMENTAL DATA (RED) MAPPED ON THE REFERENCE PATHWAY.

FIGURE 26: SULFUR METABOLISM (A). THE FIGURE SHOWS EXPERIMENTAL DATA (RED) MAPPED ON THE REFERENCE PATHWAY.

FIGURE 27: SULFUR METABOLISM (B). THE FIGURE SHOWS EXPERIMENTAL DATA (RED) MAPPED ON THE REFERENCE PATHWAY.

FIGURE 28: CHANGE OF EXTRACELLULAR PH. THE FIGURE SHOWS CHANGES IN MICROENVIRONMENTAL PH WITH TIME. THE BLUE LINE DEPICTS THE CHANGES OF PH IN THE SUPEROPTIMAL PH SYSTEM AND RED LINE DEPICTS THE CHANGES IN THE SUBOPTIMAL PH SYSTEM.

FIGURE 29: CHANGES IN THE MICROENVIRONMENT IN RESPONSE TO SUBOPTIMAL OR SUPEROPTIMAL PH. AMINO ACIDS ARE GIVEN ABOVE THE RESPECTIVE BARS. PH 9 IS CONSIDERED AS SUBOPTIMAL, AND PH IS CONSIDERED AS SUPEROPTIMAL

FIGURE 30: CHANGES IN THE NUMBER OF OTUS WITH TIME. THE FIGURE SHOWS AN OVERALL INITIAL DROP OF THE TOTAL NUMBER OF OTUS AND INCREASE AT THE END IN BOTH SUPEROPTIMAL AND SUBOPTIMAL PH SYSTEMS.

FIGURE 31: CHANGES IN THE PROKARYOTIC DIVERSITY WITH TIME. THE FIGURE SHOWS CHANGES IN RELATIVE ABUNDANCE OF ARCHAEAL PHYLUM AND BACTERIAL ORDER IN SUBOPTIMAL AND SUPEROPTIMAL PH IN RELATION TO TIME.

FIGURE 32: DYNAMIC GROUP TYPE-AI. THE FIGURES SHOW CHANGES IN RELATIVE ABUNDANCE IN SUBOPTIMAL AND SUPEROPTIMAL PH IN RELATION TO TIME.

FIGURE 33: DYNAMIC GROUP TYPE-AII. THE FIGURES SHOW CHANGES IN RELATIVE ABUNDANCE IN SUBOPTIMAL AND SUPEROPTIMAL PH IN RELATION TO TIME.

FIGURE 34: DYNAMIC GROUP TYPE-BI. THE FIGURES SHOW CHANGES IN RELATIVE ABUNDANCE IN SUBOPTIMAL AND SUPEROPTIMAL PH IN RELATION TO TIME.

FIGURE 35: DYNAMIC GROUP TYPE-BII. THE FIGURES SHOW CHANGES IN RELATIVE ABUNDANCE IN SUBOPTIMAL AND SUPEROPTIMAL PH IN RELATION TO TIME.

FIGURE 36: DYNAMIC GROUP TYPE-BIII. THE FIGURES SHOW CHANGES IN RELATIVE ABUNDANCE IN SUBOPTIMAL AND SUPEROPTIMAL PH IN RELATION TO TIME.

FIGURE 37: DYNAMIC GROUP TYPE-BIV. THE FIGURES SHOW CHANGES IN RELATIVE ABUNDANCE IN SUBOPTIMAL AND SUPEROPTIMAL PH IN RELATION TO TIME.

FIGURE 38: PARTIAL-RESIDUAL PLOT SHOWING MICROENVIRONMENTAL PH WITH TIME, OTUS AND NONOPTIMAL INITIAL PH.

FIGURE 39: FIGURE SHOWS THE GLOBAL DISTRIBUTION OF SODA LAKES AND THEIR LOCATION. 146

FIGURE 40: MUTUAL AND EXCLUSIVE COVERAGE OF GENERA BY GROUPS OF SODA LAKES. 149 


\section{LIST OF TABLES}

TABLE 1: COMPREHENSIVE REVIEW OF AVAILABLE PUBLICATIONS ON SODA LAKES. THE COLUMN ON THE LEFT DEPICTS THE CRUCIAL AREAS OF INVESTIGATIONS AND COLUMN ON THE RIGHT DEPICTS THE RELEVANT STUDIES. .13

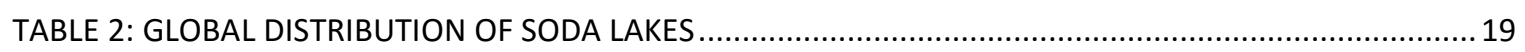

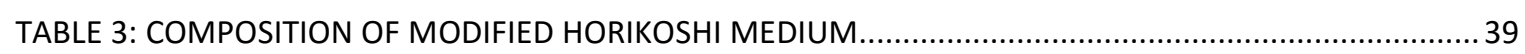

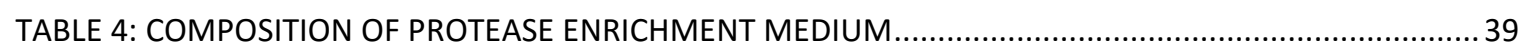

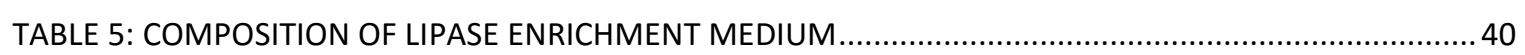

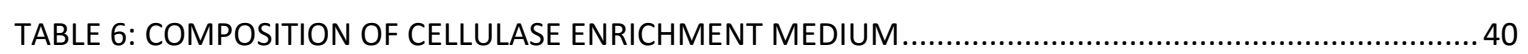

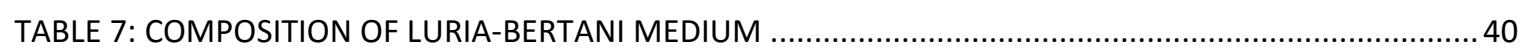

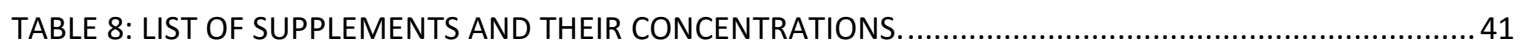

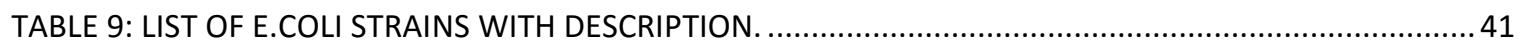

TABLE 10: LIST OF 16S RRNA PRIMERS FOR ROCHE PLATFORM SEQUENCING ........................................42

TABLE 11: LIST OF 16S RRNA PRIMERS FOR ILLUMINA PLATFORM SEQUENCING...................................43

TABLE 12: LIST OF VECTORS USED FOR CONSTRUCTION OF METAGENOMIC LIBRARIES ............................43

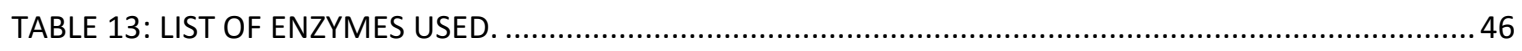

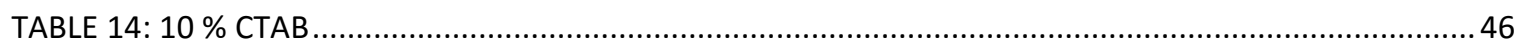

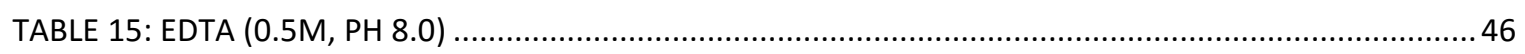

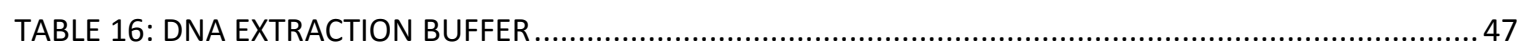

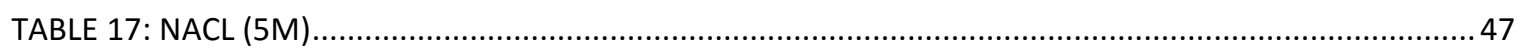

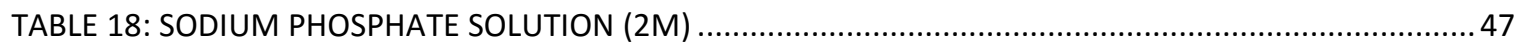

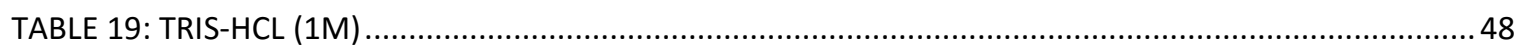

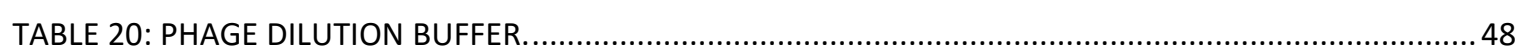

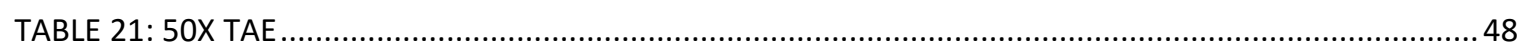

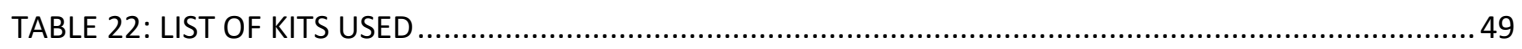

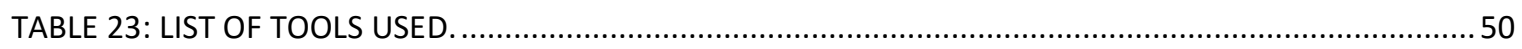

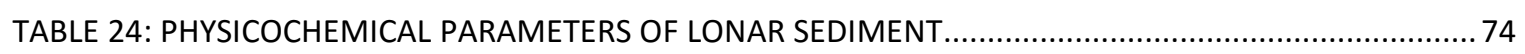

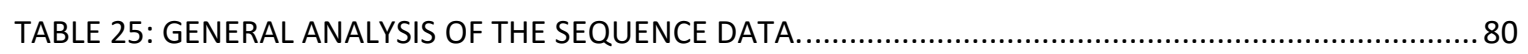

TABLE 26: GENERAL ANALYSIS OF THE ADDITIONAL TOTAL DIVERSITY SEQUENCING DATA...................... 104

TABLE 27: GENERA INVOLVED IN VARIOUS BIOGEOCHEMICAL CYCLE .............................................. 109

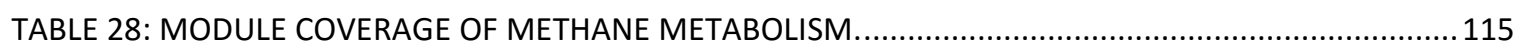

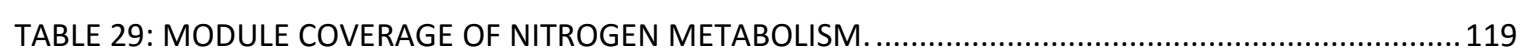

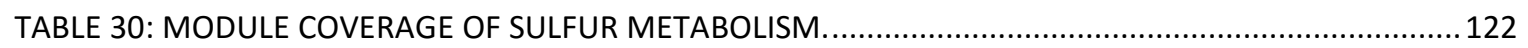

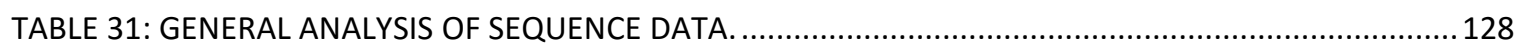

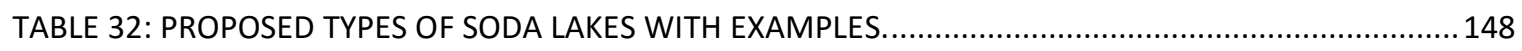


TABLE 33: RELATIVE ABUNDANCE OF THE TOTAL AND THE ACTIVE ARCHAEAL ORDER. LONAR 1, LONAR 2 AND LONAR 3 REPRESENT 3 DIFFERENT SAMPLES, AND THE VALUES ARE AVERAGE OF 3 SEPARATE EXPERIMENTS.

TABLE 34: RELATIVE ABUNDANCE OF THE TOTAL AND THE ACTIVE ARCHAEAL GENERA. LONAR 1, LONAR 2 AND LONAR 3 REPRESENT 3 DIFFERENT SAMPLES, AND THE VALUES ARE AVERAGE OF 3 SEPARATE EXPERIMENTS.

TABLE 35: RELATIVE ABUNDANCE OF THE TOTAL AND THE ACTIVE BACTERIAL PHYLUM. LONAR 1, LONAR 2 AND LONAR 3 REPRESENT 3 DIFFERENT SAMPLES, AND THE VALUES ARE AVERAGE OF 3 SEPARATE EXPERIMENTS

TABLE 36: RELATIVE ABUNDANCE OF THE TOTAL AND THE ACTIVE BACTERIAL GENERA. LONAR 1, LONAR 2 AND LONAR 3 REPRESENT 3 DIFFERENT SAMPLES, AND THE VALUES ARE AVERAGE OF 3 SEPARATE EXPERIMENTS

TABLE 37: RELATIVE ABUNDANCE OF ARCHAEA AND BACTERIA FROM ADDITIONAL ASSESSMENT. LONAR 1, LONAR 2 AND LONAR 3 REPRESENT 3 DIFFERENT SAMPLES, AND THE VALUES ARE AVERAGE OF 3 SEPARATE EXPERIMENTS.

TABLE 38: RELATIVE ABUNDANCE OF PROKARYOTES. TO TO T5 REPRESENTS TIME POINTS FROM DAY ZERO TO DAY 25. ALL THE VALUES ARE AVERAGE OF 3 SEPARATE EXPERIMENT AND ONLY UP TO 5

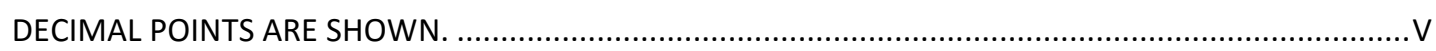

TABLE 39: RELATIVE ABUNDANCE OF ORF IN FUNCTIONAL CATEGORIES .................................................

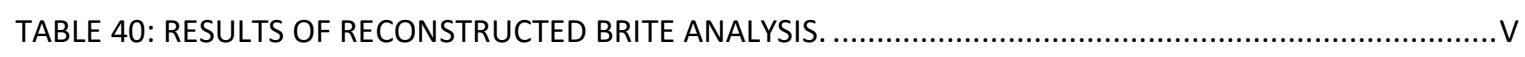

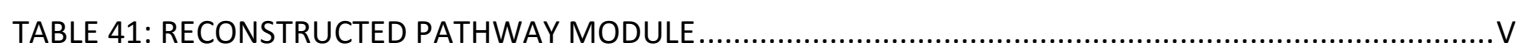

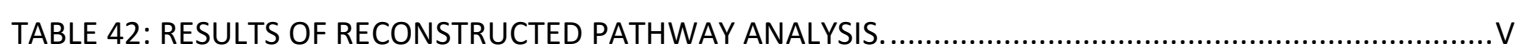

TABLE 43: CHARACTERIZATION OF CONSTRUCTED METAGENOMIC LIBRARIES (SMALL INSERT LIBRARY) AND SCREENING FOR FUNCTIONAL GENES . VI 


\section{SUMMARY}

This thesis is on the Archaea and Bacteria from a hypersaline hyperalkaline lake sediment of a meteorite impact crater named Lonar. We have surveyed the active and the total biodiversity of the sediment from Lonar. We have detected biogeochemically related important taxa and functional genes from the sediment. We have constructed and screened metagenomic libraries for industrially relevant enzymes. We have also investigated this communities' ability to engineer its microenvironment in terms of $\mathrm{pH}$.

The study site, Lonar crater lake represents a unique environment. As per its origin, Lonar is a meteorite impact crater and as per physicochemical parameters, it is hypersaline and hyperalkaline. This meteorite crater soda lake is located in the southern peninsula of Indian subcontinent known as Lonar lake. Main objectives were to investigate the total (DNA-based) and the active (RNA-based) biodiversity of Archaea and Bacteria, the presence of different taxa and genes (metagenome-based) with their role in biogeochemical cycles, and the ability of the microbial community to engineer their microenvironmental $\mathrm{pH}$.

A total of 85,668 high-quality partial 165 rRNA gene sequences of archaeal and 182,137 sequences of bacterial origin were recovered and analyzed. In Archaea, the total and the active community diversity, a coverage of $74.21 \%$ and $84.07 \%$ was observed. The total and the active community diversity of Bacteria showed a coverage of $59.78 \%$ and $88.98 \%$ respectively. Among the Archaea at the order level, most dominant taxa was Halobacteriales. Halobacteriales is mostly represented by Natronococcus, which was also the most dominant genera both in the total and the active community diversity. In the case of Bacteria most dominant phyla was Firmicutes and the genera were Alkaliphilus and Bacillus. Both of these genera represents Firmicutes. Upon comparison of all the previous studies on Lonar lake and this investigation, more than $67 \%$ of all bacterial and archaeal genera are unique to this study and were not observed in previous investigations. In our study, we have observed 24 genera, for example, Methanosaeta and Methylobacterium, which may have been involved in methane cycle. In Archaea, they contribute to an average of $39.24 \%$ relative abundance in the active community. In the case of Bacteria, they contribute to an average of $0.50 \%$ relative abundance in the active 
community. A total of 16 genera, for example, Ammonifex and Nitratireductor, were found which may have been involved in the nitrogen cycle. Among Archaea, they contribute to an average of $1.37 \%$ relative abundance in the active community. In the case of Bacteria, they contribute to an average of $2.87 \%$ relative abundance in the active community. A significantly high diversity of bacterial genera, totaling 36 , involved in the sulfur cycle were recorded, for example, Desulfococcus and Thioalkalivibrio. They represent an average relative abundance of $0.93 \%$ relative abundance in the active community.

A total of 32 million paired-end reads were obtained from direct metagenome sequencing. Analysis of the metagenome resulted in 588,668 contigs, with a total number of base of $371 \mathrm{Mb}(371,120,372$ bases). Several ORFs involved in these biogeochemical cycles were detected. The predicted relative abundance of ORFs in relation to methane metabolism, nitrogen metabolism, and sulfur metabolism pathways were found to be $1.49 \%, 0.50 \%$, and $0.68 \%$. Experimental data mapped on the reference pathways provides a comprehensive overall view of methane, nitrogen and sulfur metabolism in the sediments of Lonar crater lake.

A total of 235,943 archaeal and 1,657,168 bacterial partial 16S rRNA gene sequences were recovered from the different time point of the nonoptimal $\mathrm{pH}$ exposure of the sediments. The microbial community, from the Lonar meteorite crater soda lake sediments, was exposed to suboptimal and superoptimal $\mathrm{pH}$ conditions. The change of $\mathrm{pH}$ of the culture filtrate was monitored. Community dynamics was also measured at a resolution of 5 days for a total of 25 days using high-throughput $16 \mathrm{~S}$ rRNA gene analysis. We observed an average coverage of $71.04 \%$ in Archaea and $85.56 \%$ in Bacteria. We have seen a 10-fold change in the initial hydrogen ion concentration difference to a point between suboptimal and superoptimal pH. Several archaeal and bacterial taxa at phylum (Bacteria) or order (Archaea) level and genus (both Archaea and Bacteria) level have been identified to modulate significantly upon exposure to nonoptimal $\mathrm{pH}$. Several of them regained their original or extremely close to their original relative abundance with the progression of time. Also, from HPLC analysis, it is evident that metabolism of ammonia and hydroxyproline have a function in this community dynamics and eventual microenvironmental $\mathrm{pH}$ homeostasis. However, we were not able to confirm if this 
observation is due to correlation or causality. It was also observed, that the dynamics of several archaeal and bacterial genera can be grouped in to different types of dynamic groups based on their changing relative abundances. We found two types of dynamic groups in Archaea and four types of dynamic groups in Bacteria. Considering, all these observations, it might be safe to speculate that this microbial community can change their microenvironment to a more favorable (hypothetical optimal) one in terms of $\mathrm{pH}$ at the same time resisting permanent change in its community structure. 


\section{$\underline{\text { Introduction }}$}




\section{INTRODUCTION}

\subsection{State Of The Research On Prokaryotes Inhabiting SOdA LAKES}

This study on the Lonar meteorite crater soda lake at prima facia deals with soda lakes as subject and metagenomics as the approach to investigate this soda lake for getting answers to some fundamental questions. The questions like, what is the microbial community structure, what are the ecologically important functional genes and if this community can engineer their own environment. A survey was conducted to understand the attention of researchers on soda lakes in general and Lonar lake specifically. It was found that although the soda lakes have been subjected to scrutiny from as early as the beginning of the 1990s, the Lonar Crater Lake has been studied thoroughly only since 2006. In 2015, a total of 28 publications were found from all other soda lakes whereas 13 were found on Lonar. Considering the number of available literature from the previous years both are gaining contemporary relevance in recent past (Figure 1).

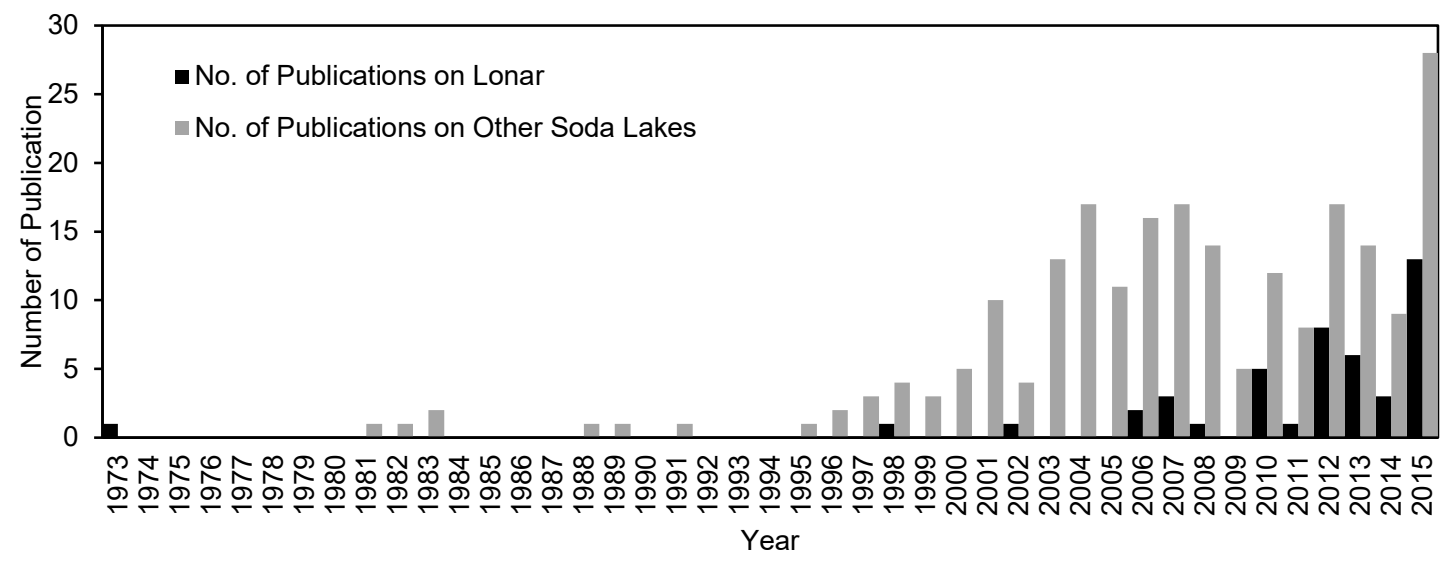

Figure 1: A Comparison of Investigation EfFort on Lonar and Other Soda Lakes.

A comprehensive review also revealed the crucial areas of investigations that have been subjected to examination by various researchers; it is tabulated in Table 1 and discussed later in this chapter. Most of the detailed biological analyses have been limnological rather than microbiological. The most vividly studied soda lakes are of the East African Rift Valley where detailed limnological and microbiological investigations have been carried out 
since as early as the 1930s. Microbiological studies of Central Asian soda lakes have also been thoroughly documented.

Table 1: Comprehensive Review of Available Publications on Soda Lakes. The column on the left depicts the crucial areas of investigations and column on the right depicts the relevant studies.

\begin{tabular}{ll}
\hline Area of Contribution & Reference \\
\hline Cultivation and isolation & (Duckworth, Grant et al. 1996, Ochsenreiter, Pfeifer et al. \\
of Bacteria & 2002, Surakasi, Wani et al. 2007, Dimitriu, Pinkart et al. \\
& 2008, Joshi, Kanekar et al. 2008, Mwirichia, Muigai et al. \\
& 2010) \\
Biodiversity of Soda & (Duckworth, Grant et al. 1996, Jones, Grant et al. 1998, \\
Lakes & Ochsenreiter, Pfeifer et al. 2002, Humayoun, Bano et al. \\
& 2003, Ma, Zhang et al. 2004, Rees, Grant et al. 2004, Tiago, \\
& Chung et al. 2004, Wani, Surakasi et al. 2006, Mesbah, \\
& Abou-El-Ela et al. 2007, Surakasi, Wani et al. 2007, Dimitriu, \\
& Pinkart et al. 2008, Joshi, Kanekar et al. 2008, Mwirichia, \\
& Cousin et al. 2010, Surakasi, Antony et al. 2010, Deshmukh, \\
& Pathak et al. 2011, Xiong, Liu et al. 2012)
\end{tabular}

Carbon cycle/utilization (Oremland, Marsh et al. 1982, Sorokin, Jones et al. 2000, in Soda Lakes Kaluzhnaya, Khmelenina et al. 2001, Lin, Radajewski et al. 2004, Antony, Kumaresan et al. 2010, Antony, Doronina et al. 2012, Antony, Murrell et al. 2012, Nolla-Ardevol, Strous et al. 2012, Shetty, Marathe et al. 2013)

Nitrogen cycle/utilization (Milford, Achenbach et al. 2000, Sorokin, Gijs Kuenen et al. in Soda Lakes 2001, Boltianskaia lu, Kevbrin et al. 2007, Shapovalova, Khijniak et al. 2008, Sorokin, van Pelt et al. 2009, Shao, Zhang et al. 2010) 


\begin{tabular}{ll}
\hline Area of Contribution & Reference \\
\hline Sulfur cycle/utilization in & (Sorokin and Kuenen 2005, Zhilina, Zavarzina et al. 2005, \\
Sodakes & Foti, Ma et al. 2006, Asao, Takaichi et al. 2007, Foti, Sorokin \\
& et al. 2007, Sorokin, Foti et al. 2007, Banciu, Sorokin et al. \\
& 2008, Sorokin, Tourova et al. 2008, Sorokin, van den Bosch \\
& et al. 2008, Gorlenko, Bryantseva et al. 2009, Sorokin and \\
& Muyzer 2010, Sorokin and Muyzer 2010, Sorokin, Rusanov \\
& et al. 2010, Asao, Pinkart et al. 2011, Sorokin, Detkova et \\
& al. 2011, Sorokin, Kuenen et al. 2011, Sorokin, Muntyan et \\
& al. 2012, Sorokin, Tourova et al. 2012, Sorokin, Tourova et \\
& al. 2012, Tourova, Slobodova et al. 2013) \\
(Ciulla, Diaz et al. 1997, Hollibaugh, Budinoff et al. 2006, & Kulp, Hoeft et al. 2006, Sorokin, Zhilina et al. 2006, Hoeft, \\
Lakes & Blum et al. 2007, Kulp, Han et al. 2007, Sorokin, Tourova et \\
al. 2012)
\end{tabular}

\subsubsection{PROKARYOTES ISOLATEd FROM SOdA LAKES}

Prokaryotes have been isolated from various soda lakes as early as the end 1970's. In the year 1979, William D. Grant isolated an alkaliphilic species of Ectothiorhodospira from a Kenyan soda lake named Lake Hannington. It resembled Ectothiorhodospira shaposhnikovii in some aspects but contrasted in demonstrating more extreme alkaliphily, the $\mathrm{pH}$ optimum of $\mathrm{pH} 9.0$ to $\mathrm{pH}$ 9.5, and in being obligatory phototrophic (Grant, Mills et al. 1979). Since then numerous prokaryotes have been isolated, and many novel genera and species of Archaea and Bacteria have also been reported from various soda lakes from around the world. 


\subsubsection{Prokaryotic Biodiversity And Biogeochemical CyCles In SOdA LAKeS}

Regardless of the seemingly hostile circumstances enforced by high alkalinity and occasionally high salinity, soda lakes harbour alkaliphilic prokaryotes. These prokaryotes living and flourishing in the soda lakes are representatives of most of the major evolutionary and trophic groups of Archaea and Bacteria (Duckworth, Grant et al. 1996, Jones, Grant et al. 1998, Grant, Gerday et al. 2006). They are also associated with the active carbon, nitrogen, and sulfur cycling under the aerobic and anaerobic environment (Grant and Sorokin 2011, Sorokin, Berben et al. 2014). Conventionally, investigations on microbial communities were limited to only a few cultured isolates. A species of Halobacterium has been isolated from solar evaporation ponds and sodium sesquicarbonate deposits at Lake Magadi, Kenya. It differs from known species of Halobacterium in being obligate alkaliphilic with a $\mathrm{pH}$ optimum between $\mathrm{pH} 9.0$ and $\mathrm{pH}$ 10.0 (Tindall, Mills et al. 1980). A new phototrophic bacterium, new species Ectothiorhodospira vacuolata, have been isolated from Jordanian and Kenyan alkaline salt lakes. They use sulfide and thiosulfate as photosynthetic electron donors. During the oxidation of sulfide to sulfate, this new species forms elemental sulfur which accumulates outside the cells. This species is strictly anaerobic, moderately halophilic and alkaliphilic (Imhoff, Tindall et al. 1981). An alpha-amylase-producing haloalkaliphilic archaeon Natronococcus amylolyticus sp. nov., has been isolated from Kenyan soda lakes (Kanal, Kobayashi et al. 1995). An extremely haloalkaliphilic, chemoorganotrophic, homoacetogenic bacteria, Natroniella acetigena gen. nov., sp. nov., has been isolated from Lake Magadi, Kenya. It is an obligate anaerobic Bacteria with optimal growth $\mathrm{pH}$ in the range of $\mathrm{pH} 9.7$ to $\mathrm{pH}$ 10.0(Zhilina, Zavarzin et al. 1996). An alkaliphilic, halotolerant microaerophilic bacteria, Bogoriella caseilytica gen. nov., sp. nov., with optimal growth $\mathrm{pH}$ values between $\mathrm{pH} 9$ and $\mathrm{pH} 10$ has been isolated from Lake Bogoria, Kenya (Groth, Schumann et al. 1997). A new alkaliphilic, sulfate-reducing bacterium, Desulfonatronovibrio hydrogenovorans gen. nov., sp. nov., has been isolated from Lake Magadi in Kenya with optimum growth pH between pH 9.5 to pH 9.7(Zhilina, Zavarzin et al. 1997). An alkaliphilic anaerobic ammonifier, Tindallia magadii gen. nov., sp. nov., has been isolated from Lake Magadi, Kenya with optimum growth $\mathrm{pH}$ of 8.5(Kevbrin, Zhilina 
et al. 1998). An alkaliphilic acetogenic anaerobe, Natronoincola histidinovorans gen. nov., sp. nov., has been isolated from Lake Magadi, Kenya with a pH optimum of pH 9.4(Zhilina, Detkova et al. 1998). A new strictly anaerobic purple sulfur bacterium, Thiorhodospira sibirica gen. nov., sp. nov., has been isolated from Lake Malyi Kasytui, southeast Siberia with $\mathrm{pH}$ optima of $\mathrm{pH}$ 9.0. This new bacterium under anoxic conditions uses hydrogen sulfide and elemental sulfur as photosynthetic electron donors (Bryantseva, Gorlenko et al. 1999). Two haloalkaliphilic strictly aerobic archaea, Natronorubrum bangense gen. nov., sp. nov. and Natronorubrum tibetense gen. nov., sp. nov, has been isolated from a soda lake in Tibet in 1999 with optimum growth $\mathrm{pH}$ between $\mathrm{pH} 9.0$ and $\mathrm{pH}$ 9.5(Xu, Zhou et al. 1999). An alkaliphilic obligatory phototrophic strictly anaerobic purple sulfur bacterium, Thioalkalicoccus limnaeus gen. nov., sp. nov., has been isolated from soda lakes in the steppe of southeast Siberia, Russia with optimal growth $\mathrm{pH}$ of $\mathrm{pH}$ 9(Bryantseva, Gorlenko et al. 2000). An alkaliphilic purple nonsulfur bacterium, Rhodobaca bogoriensis gen. nov., sp. nov., has been isolated from African Rift Valley soda lakes Lake Bogoria and Crater Lake with the $\mathrm{pH}$ optimum for growth at $\mathrm{pH}$ 9(Milford, Achenbach et al. 2000). Two new genera, Thioalkalimicrobium and Thioalkalivibrio, with two and three new species respectively, Thioalkalimicrobium aerophilum gen. nov., sp. nov., T. sibericum sp. nov., and Thioalkalivibrio versutus gen. nov., sp. nov., T. nitratis sp. nov., $T$. denitrificancs sp. nov., has been isolated from soda lakes in south-east Siberia, Russia and Kenya. They are all obligate alkaliphilic and obligate chemolithoautotrophic sulfur-oxidizing Bacteria (Sorokin, Lysenko et al. 2001). A novel lithoautotrophic sulfuroxidizing alkaliphilic moderately halophilic bacterium, Thioalkalispira microaerophila gen. nov., sp. nov., has been isolated from Lake Fazda, Wadi Natrun, Egypt with optimum growth $\mathrm{pH}$ of $\mathrm{pH}$ 10(Sorokin, Tourova et al. 2002). New alkaliphilic anaerobic fermentative bacteria, Anoxynatronum sibiricum gen. nov., sp. nov., has been isolated from the soda lake Nizhnee Beloye, Baikal with pH optima of pH 9.1(Garnova, Zhilina et al. 2003). A new anaerobic alkaliphilic saccharolytic bacteria, Alkaliflexus imshenetskii gen. nov., sp. nov., have been isolated from the alkaline lake, Verkhneye Beloye of Central Asia with an optimum growth $\mathrm{pH}$ around $\mathrm{pH}$ 8.5(Zhilina, Appel et al. 2004). Novel aerobic haloalkaliphilic archaea, Natronolimnobius baerhuensis gen. nov., sp. nov., and $N$. innermongolicus sp. nov., has been isolated from soda lakes in Inner Mongolia, China growing optimally between pH 9.0 and pH 9.5(Itoh, Yamaguchi et al. 2005). A novel 
alkaliphilic anaerobe, Anaerovirgula multivorans gen. nov., sp. nov., has been isolated from Owens Lake, California, USA with optimal growth $\mathrm{pH}$ of $\mathrm{pH}$ 8.5(Pikuta, Itoh et al. 2006). An alkalitolerant moderately halophilic bacterium, Salsuginibacillus kocurii gen. nov., sp. nov., has been isolated from the Lake Chagannor in the Inner Mongolia Autonomous Region, China with pH optima of pH 8.5(Carrasco, Marquez et al. 2007). Two novel alkaliphilic moderately halotolerant obligate anaerobes, Dethiobacter alkaliphilus gen. nov., sp. nov., and Desulfurivibrio alkaliphilus gen. nov., sp. nov., has been isolated from north-eastern Mongolian soda lakes and Wadi al Natrun lakes in Egypt able to grow between pH 8.5 and pH 10.3(Sorokin, Tourova et al. 2008). One new genus and one new species of anaerobic halophilic alkaliphilic thermophilic bacteria, Natronovirga wadinatrunensis gen. nov., sp. nov., and Natranaerobius trueperi sp. nov., has been isolated from lakes of the Wadi An Natrun, Egypt (Mesbah and Wiegel 2009). An obligate haloalkaliphilic obligate anaerobic dissimilatory sulfur-reducing bacterium, Desulfurispira natronophila gen. nov., sp. nov., has been isolated from soda lakes of Kulunda Steppe, Altai, Russia with a pH growth optimum from pH 10 to pH 10.2(Sorokin and Muyzer 2010). One new haloalkaliphilic heterotrophic sulfate reducing bacterial genera and one species of Desulfobulbus, Desulfonatronobacter acidivorans gen. nov., sp. nov., and Desulfobulbus alkaliphilus sp. nov., have been isolated from hypersaline soda lakes in Kulunda Steppe Altai, Russia (Sorokin, Tourova et al. 2012). An obligate alkaliphilic halotolerant anaerobic bacterium, Natranaerobaculum magadiense gen. nov., sp. nov., has been isolated from Lake Magadi, Kenya with pH optima between pH 9.25 and pH 9.5(Zavarzina, Zhilina et al. 2013). An extremely haloalkaliphilic archaeon, Halostagnicola bangensis sp. nov., has been isolated from Lake Bange in the region of Tibet, China (Corral, Corcelli et al. 2015). With the advent of modern high-throughput sequencing techniques, the study of microbial community composition as a whole become more and more feasible. A significant number of cultured isolates has already been found from soda lakes, as described in the previous section. Culture-independent approaches are also uncovering a much more detailed and diverse microbial community from soda lakes. The complete range of soda lake prokaryotic community structure and the roles played by individual members of the community has not been entirely discovered. It is speculated that yet unrepresented phylogenetic groups will eventually prove to have soda lake members and 
perhaps the elusive, exclusively soda lake group will emerge in the future (Sorokin, Berben et al. 2014).

\subsection{SODA LAKE ENVIRONMENT}

One of the most remarkable features of alkaline soda lakes is that irrespective of their apparent adverse conditions conferred by its extreme alkaline $\mathrm{pH}$ and often high salinity, they are one of the most productive aquatic ecosystems on Earth(Melack and Kilham 1974). Soda lakes are naturally occurring alkaline environments. They characterize the most alkaline, natural environments on earth, mostly between $\mathrm{pH} 8.5$ to $\mathrm{pH} 10$, occasionally reaching as high as pH 12(Grant and Jones 1992). The existence of large amounts of sodium carbonate or complexes of it distinguishes soda lakes. With the progression of evaporative concentration alkalinity develops as the concentration of $\mathrm{CO}_{3}{ }^{2-}$ exceeds the concentration of $\mathrm{Mg}^{2+}$ and $\mathrm{Ca}^{2+}$. As a consequence of this process, a shift in the $\mathrm{CO}_{2} / \mathrm{HCO}_{3}{ }^{-} / \mathrm{CO}_{3}{ }^{-} / \mathrm{OH}^{-}$equilibrium is observed (Grant, Gerday et al. 2006). Soda lakes occur throughout the geological record. At Green River formation in Wyoming and Utah, one of the largest and between 36 and 55 million years old fossil soda lakes are reported. Geological formations at Ventersdorf formation of South Africa advocate up to 2.3 billionyear-old fossil soda lakes (Grant and Jones 1992). Distribution of soda lakes spread throughout the world. Some of them are listed in Table 2.

Several soda lakes have been studied extensively, but they still represent only a small fraction of all the soda lakes distributed on different continents. Among the best studied soda lakes are the soda lakes of East African rift valley (Grant, Mwatha et al. 1990, Duckworth, Grant et al. 1996, Jones, Grant et al. 1998), Mono Lake in California (Ward, Martino et al. 2000, Humayoun, Bano et al. 2003), hyper alkaline spring waters in Maquqrin, Jordan(Pedersen, Nilsson et al. 2004, Tiago, Chung et al. 2004), Inner Mongolian Baer soda lake(Ma, Zhang et al. 2004, Dadheech, Glockner et al. 2013) and Kenyan soda lakes(Rees, Grant et al. 2004, Mwirichia, Cousin et al. 2010). 
TABle 2: Global Distribution of Soda Lakes

\begin{tabular}{|c|c|c|c|}
\hline Continent & Country & Name & pH \\
\hline \multirow[t]{19}{*}{ Africa } & Egypt & Wadi El Natrun lakes & $8.5-9.5$ \\
\hline & Sudan & Malha Crater Lake & $9.5-10.3$ \\
\hline & Ethiopia & Lake Arenguadi & $9.5-9.9$ \\
\hline & Ethiopia & Lake Basaka & 9.6 \\
\hline & Ethiopia & Lake Shala & 9.8 \\
\hline & Ethiopia & Lake Chitu & 10.3 \\
\hline & Ethiopia & Lake Abijatta & 9.9 \\
\hline & Kenya & Lake Magadi & 10 \\
\hline & Kenya & Lake Bogoria & 10.5 \\
\hline & Kenya & Lake Turkana & $8.5-9.2$ \\
\hline & Kenya & Lake Nakuru & 10.5 \\
\hline & Kenya & Lake Logipi & $9.5-10.5$ \\
\hline & Kenya & Lake Sonachi & 10.4 \\
\hline & Tanzania & Lake Manyara & $9.5-10$ \\
\hline & Tanzania & Lake Natron & $9-10.5$ \\
\hline & Tanzania & Lake Rukwa & $8.0-9.0$ \\
\hline & Tanzania & Lake Eyasi & 9.3 \\
\hline & Botswana & Lake Ngami & 9 \\
\hline & Chad & Rombou Lake & 10.2 \\
\hline \multirow[t]{12}{*}{ Asia } & Russia & Kulunda Steppe Lakes & $9.95-11.05$ \\
\hline & Russia & Lake Khatyn & 10 \\
\hline & Turkey & Lake Van & $9.7-9.8$ \\
\hline & Turkey & Lake Salda & 9 \\
\hline & Iran & Lake Urmia & $7.35-8.45$ \\
\hline & India & Lonar Lake & 9.5-10.5 \\
\hline & India & Sambhar Salt Lake & 9.5 \\
\hline & India & Khyagar Lake & 9.5 \\
\hline & India & Tso Moriri Salt Lake & 9 \\
\hline & India & Tso Kar Salt Lake & 8.8 \\
\hline & Aksai Chin & Lake Surigh Yilganing Kol & NA \\
\hline & Aksai Chin & Tso Tang Lake & NA \\
\hline
\end{tabular}




\begin{tabular}{|c|c|c|c|}
\hline Continent & Country & Name & pH \\
\hline & Aksai Chin & Aksayqin Hu Lake & NA \\
\hline & Aksai Chin & Lake Hongshan Hu & NA \\
\hline & Aksai Chin & Tianshuihai lake & NA \\
\hline & Aksai Chin & Guozha lake & NA \\
\hline & Aksai Chin & North Tianshuihai lake & NA \\
\hline & India \& China & Pangong Salt Lake & 9.4 \\
\hline & India \& China & Spanggur Tso & NA \\
\hline & China & Qinghai Lake & 9.3 \\
\hline & China & Namucuo Lake & 9.4 \\
\hline & China & Lake Zabuye & 10 \\
\hline & Mongolia & Taboos-nor & NA \\
\hline Australia & Australia & Lake Werowrap & 9.8 \\
\hline \multirow[t]{5}{*}{ Europe } & Hungary & Lake Fehér & NA \\
\hline & Hungary & Böddi-szék & $8.8-9.8$ \\
\hline & Austria, Hungary & Lake Neusiedl & $9-9.3$ \\
\hline & Serbia & Rusanda & 9.3 \\
\hline & Hungary & Kelemen-szék & $9-9.7$ \\
\hline \multirow[t]{11}{*}{ North America } & USA & Mono Lake & 9.8 \\
\hline & USA & Big Soda Lake & 9.7 \\
\hline & USA & Soap Lake & 9.7 \\
\hline & USA & Alkali Lake & 11 \\
\hline & USA & Summer Lake & NA \\
\hline & USA & Owens Lake & $9.1-9.7$ \\
\hline & USA & Borax Lake & NA \\
\hline & Canada & Manitou Lake & NA \\
\hline & Canada & Goodenough Lake & 10.2 \\
\hline & Mexico & Lake Texcoco & $8.8-11.5$ \\
\hline & Mexico & Lake Alchichica & 8.9 \\
\hline South America & Chile & Antofagasta Lake & NA \\
\hline
\end{tabular}




\subsubsection{ORIGIN OF SODA LAKES}

The soda lakes are a class of lakes with waters showing an excess of the total alkalinity, $\mathrm{TA}=\mathrm{HCO}_{3}{ }^{-}+2 \mathrm{CO}_{3}{ }^{2-}$, (the total of the charges of the bicarbonate ion and carbonate ion) over the charges of the alkaline earth metal ions magnesium and calcium; $\mathrm{HCO}_{3}{ }^{-}+2 \mathrm{CO}_{3}{ }^{2-}$ $>2 \mathrm{Mg}^{2+}+2 \mathrm{Ca}^{2+}$. When the water of this property evaporates the high concentration of $\mathrm{CO}_{3}{ }^{2-}$ will cause a rise in $\mathrm{pH}$ making the water alkaline. The perfect condition for the establishment of a soda lake has a lot in common with those for the creation of a thalassohaline salt lake. However, in soda lakes; carbonate or complexes of it becomes the major anion in the solution. The most significant contributing feature for creation of a soda lake is the lack of alkaline earth metal ions, (cations, $\mathrm{Ca}^{2+}$ and $\mathrm{Mg}^{2+}$ ) in the nearby topography, which basically means a lack of rocks of sedimentary origin. Additional conditions require a formation of a closed drainage basin of shallow depression with a high marginal relief, also with sufficient rainfall to sustain the source of water entering the basin to construct a standing body of water. In arid zones through higher rates of evaporation than the rate of inflow, salts accumulate by evaporative concentration. For example, in the Rift Valley of Kenya-Tanzania, the graben is composed of Pleistocene alkaline trachyte lavas which are high in $\mathrm{Na}^{+}$, low in $\mathrm{Ca}^{2+}$ and low in $\mathrm{Mg}^{2+}$. Under these conditions in the groundwater of meteoric origin (water derived from precipitation), saturated with $\mathrm{CO}_{2}$, the molar concentration of $\mathrm{HCO}_{3}{ }^{-} / \mathrm{CO}_{3}{ }^{2-}$ greatly exceeds that of $\mathrm{Ca}^{2+}$ $/ \mathrm{Mg}^{2+}$. Saturation of the alkaline earth metal cations is rapidly achieved as a result of evaporation in this arid tropical zone, and they precipitate out of solution in the form of insoluble carbonates leaving $\mathrm{Na}^{+}, \mathrm{Cl}^{-}$, and $\mathrm{HCO}_{3}{ }^{-} / \mathrm{CO}_{3}{ }^{2-}$ as the major ions in solution.

\subsubsection{PH AS A MAJOR ENVIRONMENTAL VARIABLE}

There has been a detailed investigation of how $\mathrm{pH}$ affects bacterial growth. One particular problem with $\mathrm{pH}$-growth models is that they are not 1:1. Two different values of $\mathrm{pH}$ can give the same growth rate. Considering the definition of $\mathrm{pH}$, at face value, both a high and low concentration of hydrogen ions influence the growth rate similarly (Lambert 2011). 
Initially, the $\mathrm{pH}$-growth models were exponential or square root models later they have been moved to cardinal polynomial models. Most widely used standard model for the effect of $\mathrm{pH}$ is known as the CPM (Cardinal pH Model) or based on CPM. Cardinal pH Model was introduced by Rosso et al. in 1995 (Rosso, Lobry et al. 1995). In later year other models were also proposed, in 1997 by Presser et al. (Presser, Ratkowsky et al. 1997), in 2000 by Tienungoon et al. (Tienungoon and Ratkowsky 2000) and another one by Lambert and Pearson (Lambert and Pearson 2000), then in 2003 by Lambert et al. known as extended Lambert-Pearson model (Tienungoon and Ratkowsky 2000, Lambert and Lambert 2003). However, none of them explain the effect of $\mathrm{pH}$ at the community level, or they prove to fit accurately at high alkaline $\mathrm{pH}$. Most of these studies were conducted keeping issues of food quality and pathogens in mind.

The $\mathrm{pH}$ of naturally existing environments can contrast extensively from approximately pH 0.6 to almost pH 12.6 (Becking, Kaplan et al. 1960). pH value can drive or shape prokaryotic communities. In research of lake sediments of Tibetan Plateau, no correlation between the relative abundance of Acidobacteria and Bacteriodetes and $\mathrm{pH}$ was found (Xiong, Liu et al. 2012). In another study of sediments and other samples from springs in Western Canada (Boström, Pettersson et al. 1989) and the Taupo Volcanic Zone, New Zealand (Giggenbach 1995) by C. E. Sharp et al. found that pH can only explain variability from $13 \%$ to $20 \%$ (Sharp, Brady et al. 2014). These are the reasons; the significance of pH cannot be seen as the lone limiting environmental influence on bacterial communities.

\subsection{ELEMENT CyCLING IN THE SOdA LAKE ENVIRONMENT}

\subsubsection{CARBON CYCLE}

Photosynthetic primary production seems to have an imperative part in the soda lakes in supporting all other microbial community. Oxygenic and anoxygenic haloalkaliphilic phototrophs and chemolithoautotrophs, autotrophic primary producers, living in the soda lakes are capable of fixing inorganic $\mathrm{CO}_{2}$ into organic polymers. The primary production in most soda lakes is high due to a dense population of haloalkaliphilic Cyanobacteria. They 
are primitive taxa of photosynthetic prokaryotic microorganisms (Wood, Rueckert et al. 2008). Cyanobacteria have existed on this planet for around 2.8 billion years (Olson 2006). Dense blooms of Cyanobacteria usually dominate the less alkaline lakes. Hypersaline soda lakes support both Cyanobacteria and alkaliphilic anoxygenic phototrophs belonging to the genera Ectothiorhodospira and Halorhodospira (Grant, Mwatha et al. 1990, Jones, Grant et al. 1998). Several cyanobacteria from the orders Nostocales and Chroococcales have also been reported from the highly alkaline lake, Santa Olalla, southwest of Spain (Lopez-Archilla, Moreira et al. 2004). The cyanobacterial members mostly, Oscillatoriales, Nostocales and Chroococcales, which are dominant in tropical soda lakes in Kenya and Ethiopia, include the genera Arthrospira, Microcoleus, Lyngbya, Oscillatoria, Trichodesmium, Anabaenopsis, Cyanospira and Synechococcus (Ballot, Kotut et al. 2009, Krienitz, Dadheech et al. 2012, Dadheech, Glockner et al. 2013, Schagerl, Burian et al. 2015). Cyanobacterial genera Leptolyngbya was also reported from Lake Arenguadi of Ethiopia (Lanzen, Simachew et al. 2013). Anoxygenic phototrophic purple bacteria, other than Cyanobacteria, also produce organic matter (Kompantseva, Sorokin et al. 2005, Kompantseva 2007, Nuianzina-Boldareva and Gorlenko 2014). The most thoroughly studied alkaliphilic purple Bacteria are from Lake Wadi-el-Natrun, Egypt (Imhoff, Sahl et al. 2009), the lakes of the Kenyan Rift Valley (Tindall, Mills et al. 1980) and the lakes of the southeastern Transbaikal region (Kompantseva, Sorokin et al. 2005). Also two new strictly anaerobic obligate phototrophic purple sulfur bacteria, Thiorhodospira sibirica and Thioalkalicoccus limnaeus, were isolated from low saline soda lakes in the steppe of southeast Siberia (Bryantseva, Gorlenko et al. 1999, Bryantseva, Gorlenko et al. 2000). Under anoxic conditions, these Bacteria use hydrogen sulfide and elemental sulfur as photosynthetic electron donors. The haloalkaliphilic members of Chromatiales like Thiorhodospira at moderate salinity and Ectothiorhodospiracea like Ectothiorhodospira and Halorhodospira at high salinity, also represent anoxygenic phototrophs which contribute to the primary production in soda lakes (Bryantseva, Gorlenko et al. 1999, Gorlenko, Briantseva et al. 2004, Kovaleva, Tourova et al. 2011). Also, aerobic chemolithoautotrophic Bacteria contribute to inorganic carbon fixation in soda lakes (Sorokin, Berben et al. 2014). Very few purple nonsulfur Bacteria also have been reported from soda lakes with low mineralization. The Rhodobaca bogoriensis, is capable of both, phototrophic and chemotrophic growth have been isolated from Lake Bogoria, Kenya, 
(Milford, Achenbach et al. 2000). Also, two more alkaliphilic heliobacteria, Heliorestis daurensis and $H$. baculata have been isolated from Siberian soda lakes able to grow photoheterotrophically(Bryantseva, Gorlenko et al. 1999, Bryantseva, Gorlenko et al. 2000). Also, Roseinatronobacter thiooxidans, another alkaliphilic Bacteriochlorophyll-a containing Bacteria, has been isolated from Siberian low-salt soda lakes (Sorokin, Turova et al. 2000).

The primary degradation of organic matter, which is formed by the autotrophic Bacteria, is performed by the heterotrophic Bacteria. These heterotrophic Bacteria comprise of aerobes and fermentative anaerobes. These fermentative anaerobes, in turn, are composed of two subgroups, hydrolytics, and secondary heterotrophs. The hydrolytics accomplish degradation of polymers, and the resulting monomers are utilized by the secondary heterotrophs (Sorokin, Berben et al. 2014). Several known isolates, performing aerobic hydrolytics, were recovered from soda lakes. They mostly include aerobic Firmicutes, such as Bacillus, Amphibacillus, Clostridium, Natronoincola and several Actinobacteria, such as Cellulomonas, Dietzia, Rathayibacter, Microbacterium and Proteobacteria, such as Alkalimonas, Alcalilimnicola (Martins, Davids et al. 2001, Yakimov, Giuliano et al. 2001, Sorokin, Tourova et al. 2002, Humayoun, Bano et al. 2003, Grant, Sorokin et al. 2004, Carrasco, Marquez et al. 2007, Wu, Zheng et al. 2010, Grant and Sorokin 2011, Wang, Huang et al. 2014). The occurrence of haloalkaliphilic chitinolytic microbial community in hypersaline soda lakes has been described like, Marinimicrobium from hypersaline soda lakes of Kulunda Steppe, Altai, Russia (Sorokin, Tourova et al. 2012). An anaerobic low salt-tolerant cellulolytic Clostridium has also been reported from soda lakes (Zhilina, Kevbrin et al. 2005, Zvereva, Fedorova et al. 2006). Pectin utilizing anaerobic haloalkaliphiles Natronoflexus, and Natronovirga have been isolated from soda lakes of the Kulunda Steppe, Altai, Russia (Sorokin, Panteleeva et al. 2011, Sorokin, Tourova et al. 2012). A fermentative haloalkaliphilic bacteria, Chitinivibrio alkaliphilus, specialized in exclusive chitin utilization have been isolated from soda lakes (Sorokin, Gumerov et al. 2014). The most detailed studied groups of aerobic haloalkaliphiles are secondary heterotrophs isolated from soda lakes. They are capable of utilizing monomeric organic compounds, sugars, amino acids, organic acids and alcohols. The genus Halomonas from the Proteobacteria, Bacillus from the Firmicutes, and Actinobacteria are 
the most abundant haloalkaliphilic aerobes (Duckworth, Grant et al. 1996, Grant and Sorokin 2011). Most dominated anaerobic haloalkaliphilic heterotrophic genera found in soda lakes are Anaerobacillus, Alkaliphilus, Anoxynatronum, Anaerovirgula, Anaerobranca, Natranaerobius, Natranaerobaculum and Spirochaeta (Zavarzin, Zhilina et al. 1999, Zavarzin and Zhilina 2000, Bowers, Mesbah et al. 2009, Grant and Sorokin 2011, Mesbah and Wiegel 2012). The homoacetogens and methanogens are the less exhaustively studied functional groups of secondary anaerobes performing the last stage of organic carbon degradation in soda lake microbial communities (Sorokin, Berben et al. 2014). They mostly include Tindallia, Natronincola, and Natroniella represent heterotrophic fermentative haloalkaliphilic acetogens, utilizing amino acids and alcohols as substrates (Zhilina, Zavarzin et al. 1996, Kevbrin, Zhilina et al. 1998, Zhilina, Detkova et al. 1998, Pikuta, Hoover et al. 2003, Alazard, Badillo et al. 2007). The only culturable haloalkaliphilic obligately anaerobic hydrogenotrophic homoacetogen from soda lake, Fuchsiella alkaliacetigena of the order Halanaerobiales, have been reported in 2012 from soda lake Tanatar III, Altay, Russia (Zhilina, Zavarzina et al. 2012).

There is sufficient evidence for biogenic methane production in soda lakes. The methane cycle has been studied in soda lakes as a significant part of the microbial carbon cycle. Among the most detailed studied ones are North American and Central Asian soda lakes (Oremland, Marsh et al. 1982, Oremland, Cloern et al. 1988, Khmelenina, Eshinimaev et al. 2000, Lin, Radajewski et al. 2004, Nolla-Ardevol, Strous et al. 2012, Sorokin, Abbas et al. 2015). One carbon compounds are most probably abundant in soda lakes due to anaerobic degradation of cyanobacterial mats. The strains of haloalkaliphilic methanogens have been isolated, as early as the 1980s, from Lake Wadi-el-Natrun, Egypt (Boone, Worakit et al. 1986). Most of the prokaryotes, involved in methane cycle, isolated from various soda lakes are related to members of the family Methanosarcinaceae within the phylum Euryarchaeota. Most of the methanogenic Archaea isolated so far are mainly methylotrophic. They use a variety of one-carbon (C1) compounds like methanol and methylamine. These particular methanogens are mostly represented by the genus Methanocalculus, Methanosalsum, and Methanolobus (Antony, Murrell et al. 2012, Sorokin, Abbas et al. 2015, Sorokin, Abbas et al. 2015). Hydrogen-utilizing methanogens, Methanobacterium spp, has also been reported from soda lakes (Nolla-Ardevol, Strous et 
al. 2012). The bacterial genera like Methylobacter and Methylomicrobium are methaneoxidizing prokaryotes (Sorokin, Jones et al. 2000, Kaluzhnaya, Khmelenina et al. 2001). They utilize methane in soda lakes under aerobic or microaerophilic conditions and return carbon of methane to the soda lakes organic matter by methanotrophy.

\subsubsection{NitRogen CYCLE}

The contribution of Cyanobacteria in soda lake is not only limited to primary production but also they are well-known nitrogen fixers. Undoubtedly heterocystous Cyanobacteria such as Anabaenopsis, Cyanospira and Nodularia as observed in soda lakes of the African Rift Valley are active in atmospheric nitrogen fixation (Florenzano, Sili et al. 1985, Krienitz, Dadheech et al. 2012, Sorokin, Berben et al. 2014). Nonheterocystous Cyanobacteria, like Oscillatoria, have also been recorded from soda lakes to fix nitrogen as members of diazotrophic microbial communities in alkaline hypersaline Mono Lake, California (Oremland 1990). Heterotrophic anaerobic fermentative haloalkaliphiles, Bacillus alkalidiazotrophicus and Natronobacillus azotifigans, are known to fix nitrogen actively in soda lakes of the Kulunda Steppe, Altai, Russia and north-eastern Mongolia (Sorokin, Kravchenko et al. 2008, Sorokin, Kravchenko et al. 2008, Sorokin, Zadorina et al. 2008). In some other soda lakes anaerobes show the presence of the nifH gene, for example, Geoalkalibacter ferrihydriticus and Clostridium alkalicellulosi(Zhilina, Kevbrin et al. 2005, Zavarzina, Kolganova et al. 2006). Anoxygenic phototrophs may also contribute to nitrogen fixation in soda lakes as the nifH gene has been detected in several cases (Tourova, Spiridonova et al. 2007). Several heterotrophs are known for denitrification in soda lakes. They are represented by extremely halotolerant alkaliphiles of the genus Halomonas, facultative anaerobic lithotrophs of the genus Thioalkalivibrio and the Alkalilimnicola-Alkalispirillum group belonging to the class Gammaproteobacteria (Sorokin, Zhilina et al. 2006, Shapovalova, Khijniak et al. 2008, Shapovalova, Khijniak et al. 2009, Berben, Sorokin et al. 2015). In soda lakes, for example, Mongolian soda lakes, ammonium produced during nitrogen fixation is oxidized to nitrite by prokaryotes like a subpopulation of Nitrosomonas halophila and this nitrite is further oxidized to nitrate by 
Nitrobacter alkalicus (Sorokin, Muyzer et al. 1998, Sorokin, Tourova et al. 2001, Sorokin and Kuenen 2005).

\subsubsection{SULFUR CYCLE}

The sulfur cycle has been studied with significant details in soda lakes (Foti, Sorokin et al. 2007, Sorokin, Kuenen et al. 2011, Sorokin, Berben et al. 2014). Sulfidogenesis is a typical and important biogeochemical processes in soda lakes (Sorokin, Rusanov et al. 2010). Oxidized sulfur compounds for example sulfate, sulfite, thiosulfate, and sulfur are converted into sulfide during dissimilatory reduction. Dissimilatory reduction of oxidized sulfur is performed by several obligatory anaerobic and obligatory haloalkaliphilic Bacteria. Most investigated ones are represented by the members of the Deltaproteobacteria such as genera Desulfonatronum, Desulfonatronovibrio, and Desulfonatronospira represent lithotrophic sulfate-reducing Bacteria in soda lakes(Zhilina, Zavarzin et al. 1997, Pikuta, Hoover et al. 2003, Zhilina, Zavarzina et al. 2005, Sorokin, Tourova et al. 2008, Sorokin, Tourova et al. 2011, Sorokin, Tourova et al. 2012, Zakharyuk, Kozyreva et al. 2015). Hydrogen, formate or short chain organic compounds are used as electron donor and sulfate, thiosulfate or sulfite as an electron acceptor by the sulfate-reducing Bacteria (SRB) of soda lakes to obtain energy by oxidation. Disproportionation of thiosulfate or sulfite is also used by SRB to obtain energy (Sorokin, Tourova et al. 2008, Sorokin, Kuenen et al. 2011). Incompletely oxidizing heterotrophic SRB utilizes either propionate as in the case of Desulfobulbus alkaliphilus or butyrate as in the case of Desulfobotulus alkaliphilus as electron donor or carbon source and sulfate or thiosulfate as electron acceptor, in the process they form acetate as the end product (Sorokin, Detkova et al. 2010, Sorokin, Tourova et al. 2012). Completely oxidizing SRB is also reported from soda lakes, for example, Desulfonatronobacter acidivorans. It can oxidize several volatile fatty acids completely to $\mathrm{CO}_{2}$ with sulfate or thiosulfate as an electron acceptor (Sorokin, Tourova et al. 2012). Reduction of elemental sulfur in soda lakes is accomplished by diverse obligatory anaerobic haloalkaliphiles. They can use polysulfide formed abiotically at high $\mathrm{pH}$ as an electron acceptor. They include Desulfurispira natronophila of the phylum Chrysiogenetes, Desulfuribacillus 
alkaliarsenatis and Natroniella sulfidigena of the phylum Firmicutes (Sorokin and Muyzer 2010, Sorokin, Detkova et al. 2011, Sorokin, Tourova et al. 2012).

Alkaliphilic anaerobes from soda lakes have been reported to be able to grow chemolithoautotrophically by sulfur or polysulfide disproportionation, for example Dethiobacter alkaliphilus and Desulfurivibrio alkaliphilus (Sorokin, Tourova et al. 2008, Poser, Lohmayer et al. 2013).

Phototrophic sulfur oxidizing Bacteria (SOB) oxidize sulfide, produced by sulfidogens, to elemental sulfur or sulfate (Sorokin and Kuenen 2005). They are dominated by anoxygenic purple sulfur Bacteria mostly represented by members of the genera Ectothiorhodospira, Halorhodospira, Thiorhodospira, Thioalkalicoccus, and Ectothiorhodosinus (Imhoff, Tindall et al. 1981, Bryantseva, Gorlenko et al. 1999, Bryantseva, Gorlenko et al. 2000, Gorlenko, Briantseva et al. 2004, Gorlenko, Bryantseva et al. 2009, Sorokin, Kuenen et al. 2011). Other than the phototrophic SOB in soda lakes chemotrophic SOB are also dominant. They can use reduced sulfur compounds such as sulfide, polysulfide, thiosulfate, polythionates, and elemental sulfur as the electron donor (Sorokin, Kuenen et al. 2001, Sorokin, Tourova et al. 2002, Banciu, Sorokin et al. 2004). Several chemotrophic SOB has been reported to be haloalkaliphilic Gammaproteobacteria such as Thioalkalimicrobium, Thioalkalispira, Thioalkalivibrio and Thioalkalibacter (Sorokin, Lysenko et al. 2001, Sorokin, Tourova et al. 2002, Banciu, Sorokin et al. 2004, Foti, Ma et al. 2006, Banciu, Sorokin et al. 2008, Sorokin, Banciu et al. 2013).

\subsection{UNIQUE NATURE OF LONAR}

The Lonar crater lake is a 50,000 year (Approximately) old impact structure it is situated in the Buldhana district of Maharashtra, India (Nayak 1972, Fredriksson, Dube et al. 1973). This lake is a roughly circular depression in the basalt flows of the Deccan Traps. It is 1830 $\mathrm{m}$ across and is almost $150 \mathrm{~m}$ deep; a shallow alkaline saline lake occupies the majority of the floor. In the region of most of the circumference, the rim is raised about $30 \mathrm{~m}$ above the nearby plain (Fudali, Milton et al. 1980). A view of the Lonar Crater Lake is provided in Figure 2. 


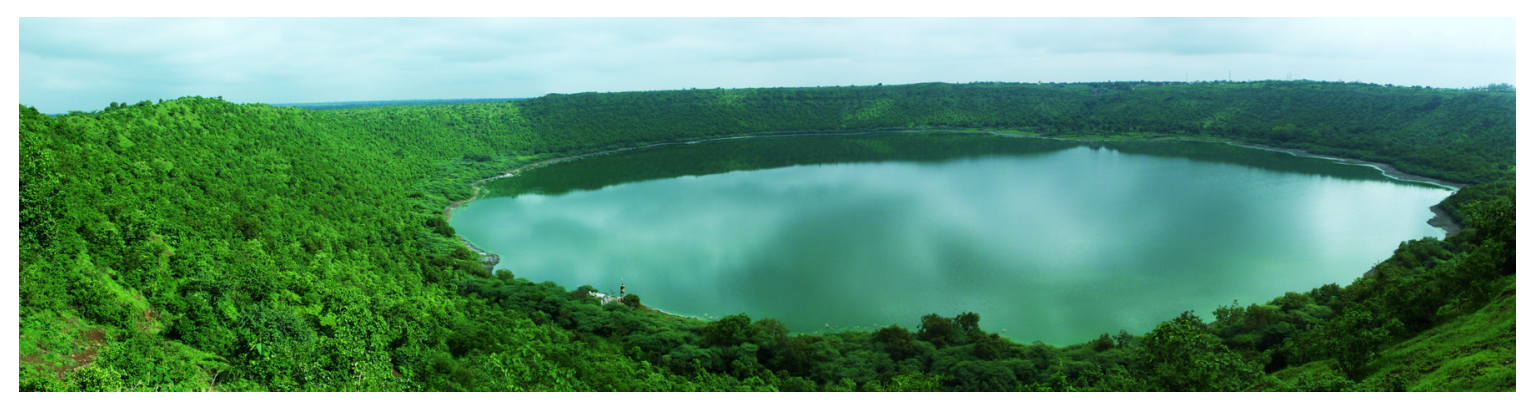

Figure 2: View of the Lonar Crater lake from the top of the Impact Ejecta. Photograph by Soumya Biswas.

This comparatively small crater is one of only two acknowledged (so far) terrestrial craters to be created in basaltic target rock surface by a meteorite impact; the other one is the Logancha crater in Russia(Feldman, Sazonova et al. 1983). The target rocks are mostly classified as quartz-normative tholeiites that contain a moderate level of iron enrichment. These tholeiitic basalts comprise higher total iron, lower $\mathrm{MgO}$, lower $\mathrm{Al}_{2} \mathrm{O}_{3}$, and higher $\mathrm{CaO}$ content than do other terrestrial tholeiitic provinces (Roy and Chatterjee 1998). The unusual compositional characteristics of the Lonar crater strongly match the composition of Martian basalts, which also have higher Fe and lower Al abundances than most terrestrial basalts (Mcsween 1994, McSween 2002). Another fascinating characteristic of the Lonar crater was documented in 1996 by Nayak, who suggested that the groundwater underlying the Lonar crater was heated by remnant impact energy, thus resulting in the establishment of post-impact hydrothermal activity. The validity of this hydrothermal hypothesis is supported by evidence of impact-induced hydrothermal systems in other terrestrial craters (Newsom 1980, Allen, Gooding et al. 1982, Crossey and McCarville 1993).

As per our observation on available literature regarding Lonar, we found some general trend. There is a paucity of available literature on ecologically important taxa and ecologically important functional genes present in Lonar. A lack of using metagenomics in general or high throughput sequencing specifically to survey the microbial diversity is prominent. Therefore, it is reasonable to consider this study a timely endeavor to investigate Lonar Meteorite Crater Soda Lake using metagenomics. 


\subsection{BIODIVERSITY AND RIBOSOMAL RNA GENES}

The most exclusive quality of the planet Earth is the existence of life, and the most amazing characteristic of life is its diversity. Approximately two decades ago, at the first Earth Summit (The United Nations Conference on Environment and Development held in Rio de Janeiro on 3rd June to 14th June 1992) the vast majority of the world's nations acknowledged that human actions were dismantling the Earth's ecosystems, eliminating species, biological traits and genes at a shocking rate (Cardinale, Duffy et al. 2012). To be able to study diversity or the number and variety of organisms found within a specified geographic region it is of utmost importance to identify, classify and catalog these variations and this is the sole objective of biosystematics.

The principal purpose of bacterial systematic is the founding of a classification that spans the hole of the prokaryote kingdom. However, classification by conventional techniques has been proved to be difficult for prokaryotes, due to the relative morphological simplicity. Diverse molecules have been discussed, for a long time, in relation to their suitability for providing the ground for a molecular phylogeny. rRNA genes had been used widely to identify and classify prokaryotes. The ribosome is undoubtedly of a very ancient origin and is essentially everywhere. The primary structures of these rRNA molecules are satisfactorily constrained that on the whole, they have not altered rapidly over time (Fox, Pechman et al. 1977). They include regions of both extremely conserved regions (Woese, Fox et al. 1975) and hypervariable regions (Sogin, Sogin et al. 1971) so that both distant and close relationships can be investigated using rRNA genes. Earlier alignments of bacterial 16S rRNA gene sequences have discovered nine separate hypervariable regions, which was termed as V1 to V9 in relation to previous nomenclature (Van de Peer, Chapelle et al. 1996). 


\subsection{COMMUNITY DYNAMICS AND MICROENVIRONMENTAL PH HOMEOSTASIS}

Microorganisms can endure and rapidly adapt to non-optimal and fluctuating environmental situations. They are small in size, ubiquitous in distribution, versatile in metabolism, flexible in adaptation and demonstrates genetic plasticity. Prokaryotes sense their environment and react to specific environmental challenges individually as well as cooperatively, demonstrating communal activities. In most of the microbial ecosystems, the functionally the active unit is not a solitary species but a consortium of many species sharing a common microenvironment (Guerrero and Berlanga 2006). Rich biodiversity stabilizes microbial ecosystems. Richness stabilizes communities mainly by increasing community biomass and reducing the strength of demographic stochasticity and also with asynchrony in the responses of the community dwellers to environmental fluctuations (de Mazancourt, Isbell et al. 2013). Various environmental variables largely shape community structure and community dynamics. However, one issue concerning this question is apparently under investigated; that is, if and to what extent microbial community can affect its environment or microenvironment in the context of microbial ecology. The microenvironment is a comparatively small, often noticeably specialized and effectively isolated biophysical environment surrounding a living organism. $\mathrm{pH}$ is one of the most significant of these environmental variables.

\subsection{METAGENOMICS}

A revolution took place in the field of microbiology during the last 30 years, which has changed microbiologist's view of microorganisms and how to study them. Accepting the fact that most microorganisms cannot be grown willingly in pure culture (till date) and the credible demonstration that the uncultured microbial world is greater than the cultured world along with evidence that these uncultivable microorganisms can be studied was at the heart of this revolution (Olsen, Pace et al. 1985, Pace, Stahl et al. 1985, Pace 1995). In the following years of this essential addition to the revolutionary approach to studying microbial life forms, microbiologists devoted earnest attempt to describe the 
phylogenetic diversity of exotic and usual environments like sea surfaces, deep sea hydrothermal vents, hot springs, soils, animal rumens and guts, human oral cavity and intestine. Several new lineages were classified exclusively based on their molecular signatures. The next development that followed was to reveal the functions of these new phylotypes and conclude whether they epitomized new species, genera, or phyla of prokaryotic life. These questions triggered the development of diverse techniques, including metagenomics itself.

During the last ten years, the science of metagenomics has been transformed by the use of whole genome shotgun sequencing technology that a decade or so earlier revolutionized the field of the single organism genomics (Fleischmann, Adams et al. 1995). More current advances in the next generation sequencing technologies, causing a remarkable drop in the price of DNA sequencing, resulted in efforts on the scale considerably surpassing the scale permissible by the conventional technologies in DNA (genome, genes, cDNA and whole transcriptome) sequencing. Previously unfeasible questions in microbiology, turn out to be possible to address, due to these developments. They have also been demonstrated to be useful to accelerate considerably genome-based detection for medical and biotechnological applications of microbial, previously untapped, resources by delivering a comprehensive and high-resolution blueprint of a variety of biochemical transformations that has been evolved and fine-tuned by nature since the emergence of life itself. In the last few years, the study of uncultured microorganisms had expanded from just the study of diversity to their function and application. 


\section{Objective and Importance}




\section{OBJeCTIVE AND IMPORTANCE}

The overview of the workflow from sediment sample to objectives is provided in a simple flow chart below (Figure 3).

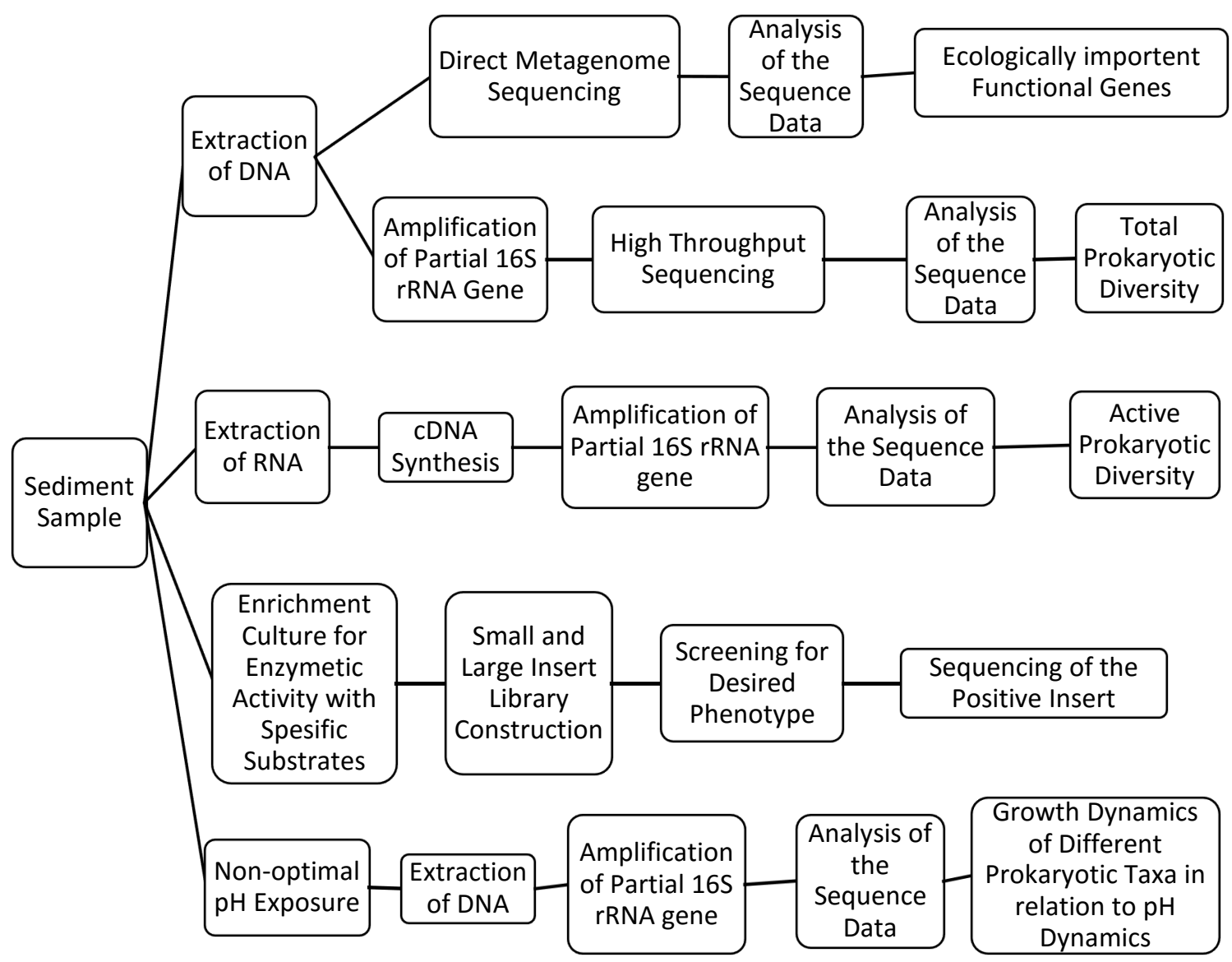

Figure 3: Overview of the Objectives and Workflow. The figure shows the workflow from samples to objectives.

\subsection{OBJECTIVES Of THE INVESTIGATION}

Our primary objectives of the current investigation were-

1. To assess the total prokaryotic biodiversity and the active prokaryotic biodiversity using high-throughput sequencing-based techniques,

2. To assess the relative abundance and presence of different ecologically important functional genes using high-throughput sequencing based direct metagenome analysis, 
3. To study the community dynamics during microenvironmental $\mathrm{pH}$ homeostasis of the prokaryotic community from the hyperalkaline and saline Lonar meteorite crater lake in India.

4. To investigate any possibilities of exploiting the polyextremophilic adaptations of the microbial community for industrial use.

\subsection{IMPORTANCE OF THIS INVESTIGATION}

Sediment microbial communities play important roles in ecosystem functioning and processes such as biogeochemical cycles and nutrient transformation (Nissenbaum 1975, Whitby, Saunders et al. 2001, Foti, Sorokin et al. 2007, Emmerich, Bhansali et al. 2012, Melton, Schmidt et al. 2012, Zeng, Zhao et al. 2012, Li, Jin et al. 2013, Vissers, Anselmetti et al. 2013, Eyice, Namura et al. 2015). Microorganisms have indispensable roles in influencing and regulating nearly all ecosystems. Archaea and Bacteria exist in different metabolic states in these ecosystems. They could be actively growing, dormant and recently deceased. These various metabolic states can have a differential influence on their environment. Consequently, it is of substantial importance to truly associate microbial taxa with its metabolic state. So that it is possible to have any inference of the relationships between ecosystem functions and microbial community structure (Blazewicz, Barnard et al. 2013). However, most of the metagenomic exploration used DNA-based approaches. As a result, they concentrate only on the total bacterial community, which contains dormant microorganisms, dead cells and extracellular DNA (Lennon and Jones 2011). There is no known literature about overall diversity on the potentially metabolically active archaeal and bacterial communities in Lonar sediment. Although there are very few reports on the active community study in sediments of other types; from the sea (Sorensen and Teske 2006, Edlund, Hardeman et al. 2008, Mills, Reese et al. 2012, Kormas, Pachiadaki et al. 2015), lakes (Nercessian, Noyes et al. 2005) and estuary (Li, Wang et al. 2012, Chen, Wang et al. 2013). These populations can be evaluated by analysis of 16S rRNA transcripts (Pace, Stahl et al. 1985). The abundance of rRNA serves as an index of activity but not as a direct measure of activity (Blazewicz, Barnard et al. 
2013). Thus, variations in the relative abundance essentially do not mirror variations in the activity of the studied microbial group.

Studying microbial diversity of hyperalkaline hypersaline meteorite impact crater lake ecosystems is valuable for several reasons. Research on the microbial community of soda lakes may provide clues to the evolution of life on earth; as some of the earliest microbial life on Earth might have been haloalkaliphiles (Kunte, Trüper et al. 2002). Due to the presence of hypersaline conditions on Mars, terrestrial saline environments can be used as an appropriate analog for investigation (Mancinelli, Fahlen et al. 2004). Lonar, specifically, is preferable over other soda lakes as Mars analog due to its strong resemblance with martian basalts. The origin of Lonar lake, the impact event itself, makes Lonar even more unique to all other soda lakes. The post impact crater and hydrothermal activity could mimic the prebiotic chemistry (Cockell 2006) in relation to the origin of life itself. Impact structures are a scarce ecosystem on earth, but wherever they are present, they can potentially have a significant influence on the local ecology. Impact events are one of the processes that can cause localized obliteration to ecosystems, understanding the behavior of recolonization of these impact structures is of ecological interest. Impact craters are a universal phenomenon on solid planetary surfaces, and so they are of possible biological importance on other planetary habitats(Cockell, Osinski et al. 2003). 
Materials and Methods 


\section{Materials And Methods}

\subsection{SeDIMENT SAMPLES}

The sediment samples used in this study were collected on $14^{\text {th }}$ of September 2014 from three different places of Lonar Lake, Buldhana district, Maharashtra, India. A total of 3 sediment samples were collected from various locations in triplicate. These triplicates were mixed in equal weight to obtain the working samples which will be referred as Lonar 1, Lonar 2 and Lonar 3 in the rest of the article.

\subsection{HANDLING OF EQUIPMENT AND REAGENTS}

All glassware, culture media, buffers and other solutions were autoclaved $\left(20 \mathrm{~min}, 121^{\circ} \mathrm{C}\right.$ ) to sterilize except for the heat labile substances. Non-autoclavable or heat labile substances (e. g. lysozyme, glucose) were dissolved in sterile buffers or water and filtersterilized. Tools that were not autoclavable were first rinsed with $70 \%(w / v)$ ethanol and subsequently with sterile dd $\mathrm{H} 2 \mathrm{O}$.

\subsection{Media, Media Supplements And Antibiotics}

All the reagents and recipes of preparation are provided bellow.

Modified Horikoshi

Glucose

Component (A)

Soluble Starch

Peptone
Amount

$6.75 \mathrm{~g}$

$6.25 \mathrm{~g}$

$6.25 \mathrm{~g}$ 


\begin{tabular}{lc}
\hline Modified Horikoshi & Amount \\
\hline Yeast Extract & $6.25 \mathrm{~g}$ \\
KH2PO4 (Potassium dihydrogen phosphate) & $1.25 \mathrm{~g}$ \\
MgSO4 7 H2O (Magnesium sulfate) & $0.25 \mathrm{~g}$ \\
NaCl (Sodium chloride) & $12.50 \mathrm{~g}$ \\
Component (B) & \\
\hline Na2CO3 (Sodium carbonate) & $12.50 \mathrm{~g}$ \\
\hline
\end{tabular}

Table 3: Composition of Modified Horikoshi Medium.

\begin{tabular}{lc}
\hline Enrichment Medium for Protease & Amount \\
\hline Casin & $10.00 \mathrm{~g}$ \\
$\mathrm{NaCl}$ & $20.00 \mathrm{~g}$ \\
$\mathrm{NaCO}_{3}$ & $10.00 \mathrm{~g}$ \\
$\mathrm{~K}_{2} \mathrm{HPO}_{4}$ & $0.50 \mathrm{~g}$ \\
$\mathrm{CaCl}_{2}$ & $0.025 \mathrm{~g}$ \\
$\mathrm{MgSO}_{4}$ & $0.005 \mathrm{~g}$ \\
Deionized H2O & $1000 \mathrm{ml}$ \\
\hline
\end{tabular}

Table 4: Composition of Protease Enrichment Medium

\begin{tabular}{lc}
\hline Enrichment Medium for Lipase & Amount \\
\hline Olive oil & $3.5 \mathrm{ml}$ \\
$\mathrm{NaCl}$ & $20.00 \mathrm{~g}$ \\
$\mathrm{NaCO}_{3}$ & $10.00 \mathrm{~g}$ \\
$\mathrm{~K}_{2} \mathrm{HPO}_{4}$ & $0.50 \mathrm{~g}$
\end{tabular}




\begin{tabular}{lc}
\hline Enrichment Medium for Lipase & Amount \\
\hline $\mathrm{CaCl}_{2}$ & $0.025 \mathrm{~g}$ \\
$\mathrm{MgSO}_{4}$ & $0.005 \mathrm{~g}$ \\
Deionized H2O & $1000 \mathrm{ml}$ \\
\hline
\end{tabular}

TAble 5: Composition of Lipase Enrichment Medium

\begin{tabular}{lc}
\hline Enrichment Medium for Cellulase & Amount \\
\hline Cellulose & $10.00 \mathrm{~g}$ \\
$\mathrm{NaCl}$ & $20.00 \mathrm{~g}$ \\
$\mathrm{NaCO}_{3}$ & $10.00 \mathrm{~g}$ \\
$\mathrm{~K}_{2} \mathrm{HPO}_{4}$ & $0.50 \mathrm{~g}$ \\
$\mathrm{CaCl}_{2}$ & $0.025 \mathrm{~g}$ \\
$\mathrm{MgSO}_{4}$ & $0.005 \mathrm{~g}$ \\
\hline Deionized H2O & $1000 \mathrm{ml}$ \\
\hline
\end{tabular}

Table 6: Composition of Cellulase Enrichment Medium

\begin{tabular}{lc}
\hline Luria-Bertani (LB) medium (Sambrook, 1989) & Amount \\
\hline Tryptone & $10 \mathrm{~g}$ \\
Yeast extract & $5 \mathrm{~g}$ \\
$\mathrm{NaCl}$ & $10 \mathrm{~g}$ \\
Deionized H2O & $1000 \mathrm{ml}$ \\
\hline
\end{tabular}

TABLE 7: Composition of LURIA-Bertani Medium 


\begin{tabular}{lll}
\hline Supplement & Stock solution & Working concentration \\
\hline Ampicillin & $50 \mathrm{mg} / \mathrm{ml} 50 \%$ Ethanol & $050-100 \mathrm{mg} / \mathrm{ml}$ \\
Kanamycin & $25 \mathrm{mg} / \mathrm{ml} \mathrm{dd} \mathrm{H2O}$ & $50 \mathrm{mg} / \mathrm{ml}$ \\
IPTG & $25 \mathrm{mg} / \mathrm{ml} \mathrm{dd} \mathrm{H2O}$ & $50 \mathrm{mg} / \mathrm{ml}$ \\
X-Gal & $20 \mathrm{mg} / \mathrm{ml}$ Dimethylformamide & $40 \mathrm{mg} / \mathrm{ml}$
\end{tabular}

TABle 8: LIST Of SUPPLEMENTS AND their Concentrations.

3.4 ORganisms, OLIGONUCLEOTIDES, ENZYMES, AND BUfFERS

\subsubsection{STRAIN DESCRIPTION}

\begin{tabular}{|c|c|c|}
\hline $\begin{array}{l}\text { E. coli } \\
\text { strain }\end{array}$ & Genotype & Source \\
\hline DH5 $\alpha$ & $\begin{array}{l}\text { F- } \phi 80 \text { lacZ } \Delta M 15 \Delta \text { (lacZYA-argF) U169 endA1 recA1 hsdR17 } \\
\text { (rk-, mk+) supE44 thi -1 gyrA96 relA1 phoA }\end{array}$ & Invitrogen \\
\hline TOP10 & $\begin{array}{l}\text { F- mcrA } \Delta \text { (mrr-hsdRMS-mcrBC) } \phi 80 \text { lacZ } \Delta \text { M15 } \Delta \text { lacX74 } \\
\text { recA1 araD139 } \Delta \text { (ara-leu) } 7697 \text { galU galK rpsL (StrR) end A1 } \\
\text { nupG }\end{array}$ & Invitrogen \\
\hline EPI300-T1 & $\begin{array}{l}\text { F- mcrA } \Delta \text { (mrr-hsdRMS-mcrBC) (StrR) } \phi 80 \text { dlacZ } \Delta \text { M15 } \\
\Delta \text { lacX74 recA1 endA1 araD139 } \Delta \text { (ara, leu) } 7697 \text { galU galK } \lambda- \\
\text { rpsL nupG trfA tonA dhfr }\end{array}$ & Epicentre \\
\hline
\end{tabular}

TABLE 9: LIST OF E.COLI STRAINS WITH DESCRIPTION. 


\subsubsection{DESCRIPTION OF PRIMERS}

\subsubsection{Primers For Roche Platform Sequencing}

The V3-V5 region was amplified with the following set of primers containing the Roche 454 pyrosequencing adaptors (blue), key (red) and MID or multiplex identifier (10 bp long) in the case of forward primer only. Modified bacterial primers were S-D-Bact-0343-a-S-15 (Bac343F) (Nossa, Oberdorf et al. 2010) and S-D-Bact-0907-a-A-20 (Bac907R) (Muyzer, Teske et al. 1995). Modified archaeal primers were S-D-Arch-0340-a-S-18 (Arch340F) (Ovreås, Forney et al. 1997) and S-D-Arch-0911-a-A-20 (Arch915R) (Stahl and Amann 1991).

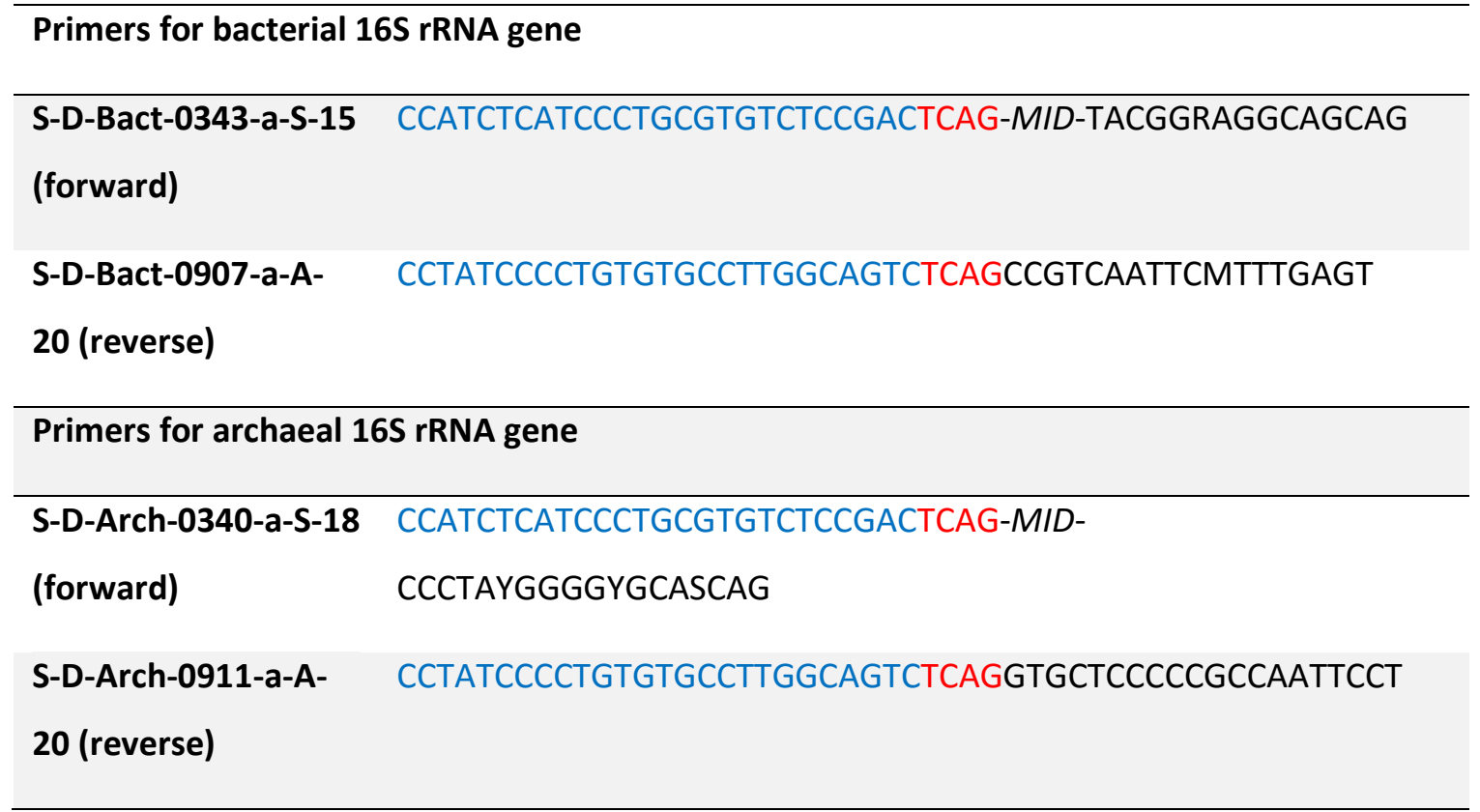

TABLE 10: LIST OF 16S RRNA PRIMERS FOR ROCHE PLATFORM SEQUENCING

\subsubsection{Primers For Illumina Platform Sequencing}

The V3-V4 region was amplified with the following set of primers containing the Illumina overhang adapter (blue). Primer set used for amplification of bacterial V3-V4 was S-D- 
Bact-0341-b-S-17 (forward) and S-D-Bact-0785-a-A-21 (reverse) (Klindworth, Pruesse et al. 2013) with modifications. For Archaea 514Fa (Reed, Fujita et al. 2002) and In-house were used.

Primers for bacterial 16S rRNA gene

S-D-Bact-0341-b- TCGTCGGCAGCGTCAGATGTGTATAAGAGACAGCCTACGGGNGGCWGCAG

S-17 (forward)

S-D-Bact-0785-a- $\quad$ GTCTCGTGGGCTCGGAGATGTGTATAAGAGACAGGACTACHVGGGTATCTAATCC A-21 (reverse)

Primers for archaeal 16S rRNA gene

514Fa (forward) TCGTCGGCAGCGTCAGATGTGTATAAGAGACAGGGTGBCAGCCGCCGCGGTAA

In-house GTCTCGTGGGCTCGGAGATGTGTATAAGAGACAGCCCGCCAATTYCTTTAAG

TABLE 11: LIST OF 16S RRNA PRIMERS FOR ILLUMINA PLATFORM SEQUENCING.

\subsubsection{VECTORS}

\begin{tabular}{lll}
\hline Vector Name & Purpose & Source \\
\hline pCR-XL-TOPO & Small insert Library (Plasmid Library) & Invitrogen \\
pCC1FOS & Large insert Library (Fosmid library) & Epicentre \\
\hline
\end{tabular}

TABLE 12: LIST OF VECTORS USED FOR CONSTRUCTION OF METAGENOMIC LIBRARIES 
201 CACACAGGAA ACAGCTATGA COATGATTAC GCCAAGCTAT TTAGGTGACG CGTTAGAATA GTGFTCCTT TGTCGATACT GGTACTAATG CGGTTCGATA AATCCACTGC GCAATCTTAT

NsiI Hind III Kon I Ecil36 II Sacl BamH I Spe I

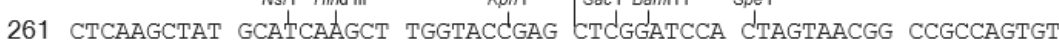
GAGTTCGATA CGTAGTTCGA ACCATGGCTC GAGCCTAGGT GATCATTGCC GGCGGTCACA

ECORI

EcoR I

PstI ECORV

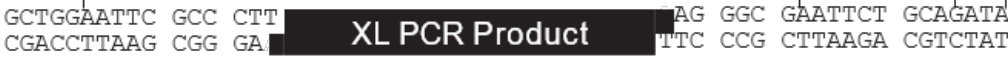

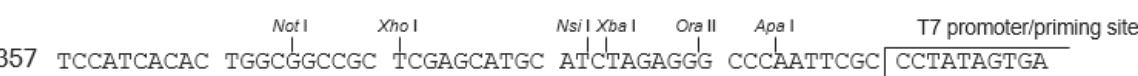
AGGTAGTGTG ACCGCCGGCG AGCTCGTACG TAGATCTCCC GGGTTAAGCG GGATATCACT

M13 Forward (-20) priming site

417 GTCGTATTAC AATTCAFTGG CCGTCGTTTT ACAACGTCGT GACTGGGAAA ACCCTGGCGT 470 CAgCATAATG TTAAGTEACC GGCAGCAAAA TGTTGCAGCA CTGACCCTTT TGGGACCGCA

Comments for PCR-XL-TOPO ${ }^{\circledR}$ 3519 nucleotides

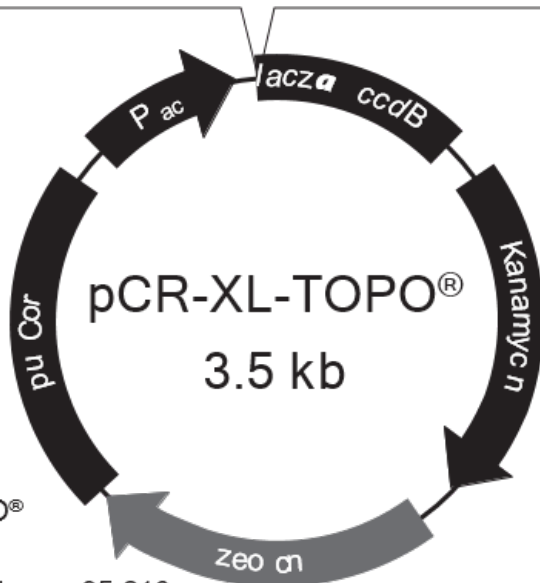

Lac promoter/operator region: bases 95-216

M13 Reverse priming site: bases 205-221

Lac Za ORF: bases 217-576

Multiple Cloning Site: bases 248-399

TOPO ${ }^{\circledR}$ Cloning site: bases $336-337$

T7 promoter priming site: bases $406-425$

M13 Forward (-20) priming site: bases 433-448

Fusion joint: bases 577-585

ccdB lethal gene ORF: bases $586-888$

Kanamycin resistance ORF: bases 1237-2031

Zeocin resistance ORF: bases 2238-2612 pUC

origin: bases $2680-3393$

FIGURE 4: Vector MAP OF PCR-XL-TOPO (FROM INVITROGEN) 


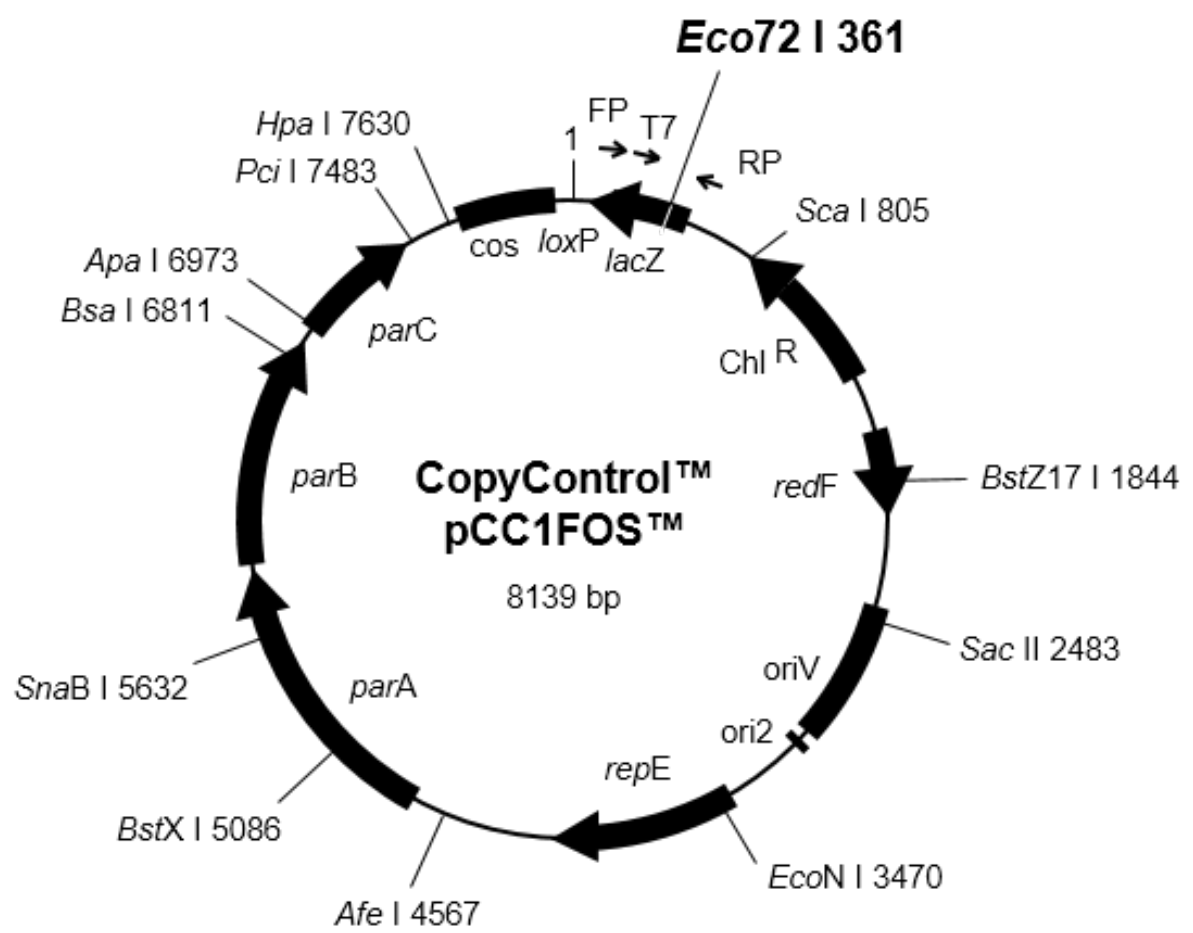

Note: Not all restriction enzymes that cut only once are indicated above. See Appendix E for complete restriction information.

Primers are not drawn to scale.

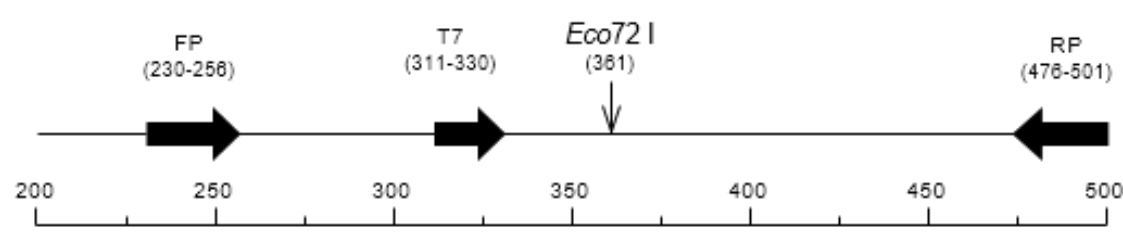

$\mathrm{FP}=\mathrm{pCC}^{\mathrm{TM}} / \mathrm{pEpiFOS}^{\mathrm{TM}}$ Foward Sequencing Primer 5' GGATGTGCTGCAAGGCGATTAAGTTGG 3' $\mathrm{RP}=\mathrm{pCC}^{\mathrm{TM}} / \mathrm{pE} \mathrm{EiFOS}^{\mathrm{TM}}$ Reverse Sequencing Primer 5' CTCGTATGTTGTGTGGAATTGTGAGC 3' T7 = T7 Promoter Primer 5' TAATACGACTCACTATAGGG 3'

FIGURE 5: VeCtOR MAP OF PCC1FOS (From EPICENTER) 


\subsubsection{DetAILS Of The ENZYMES}

\begin{tabular}{ll}
\hline Enzymes & Usage \\
\hline Antarctic Phosphatase (5U) & Dephosphorylation of DNA ends \\
EcoRI Restriction enzyme & Plasmid Digestion \\
Lysozyme & Cell lysis during DNA extraction \\
Phusion DNA Polymerase (2U) & PCR for cloning \\
T4 Polymerase (5U) & Generation of blunt-end DNA \\
Taq Polymerase (5U) & Temperature gradient PCR \\
\hline
\end{tabular}

TABLE 13: LIST OF ENZYMES USED.

\subsubsection{COMPOSITION Of BUfFERS AND STOCK SOLUTIONS}

\begin{tabular}{lc}
\hline Reagent & Amount \\
\hline CTAB & $10 \mathrm{~g}$ \\
StMQ $\mathrm{H}_{2} \mathrm{O}$ & $100 \mathrm{ml}$ \\
\hline
\end{tabular}

TABLE 14: $10 \%$ CTAB

\begin{tabular}{lc}
\hline Reagent & Amount \\
\hline $\mathrm{Na}_{2} \mathrm{EDTA} .2 \mathrm{H}_{2} \mathrm{O}$ & $186.1 \mathrm{~g}$ \\
$\mathrm{NaOH}$ & $20 \mathrm{~g}$ \\
Adjust $\mathrm{pH}$ to 8.0 & \\
StMQ $\mathrm{H}_{2} \mathrm{O}$ & $1000 \mathrm{ml}$ \\
\hline TABLE 15: EDTA (0.5M, PH 8.0)
\end{tabular}




\begin{tabular}{lc}
\hline Reagent & Amount \\
\hline Tris HCl (100mM; pH 8.0) ) & $100 \mathrm{ml}$ \\
Sodium Phosphate Buffer (2M) & $50 \mathrm{ml}$ \\
Sodium EDTA (100mM; pH 8.0) & $200 \mathrm{ml}$ \\
NaCL (1.5 M) & $300 \mathrm{ml}$ \\
CTAB 1 \% & $100 \mathrm{ml}$ \\
\hline
\end{tabular}

TABLE 16: DNA Extraction BUffer

\begin{tabular}{lc}
\hline Reagent & Amount \\
\hline $\mathrm{NaCl}$ & $292 \mathrm{~g}$ \\
StMQ $\mathrm{H}_{2} \mathrm{O}$ & $1000 \mathrm{ml}$ \\
\hline TABLE 17: NACL (5M) &
\end{tabular}

\begin{tabular}{lc}
\hline Reagent & Amount \\
\hline $\mathrm{Na}_{2} \mathrm{HPO}_{4}$ & $141.95 \mathrm{~g}$ \\
\hline $\mathrm{NaH}_{2} \mathrm{PO}_{4}$ & $119.97 \mathrm{~g}$ \\
$\mathrm{StMQ} \mathrm{H}$ & $\mathrm{O}$ \\
\hline TABLE 18: SODIUM PHOSPHATE SOLUTION (2M) & $1000 \mathrm{ml}$
\end{tabular}




\begin{tabular}{lc}
\hline Reagent & Amount \\
\hline Tris & $121 \mathrm{~g}$ \\
\hline Adjust $p H$ with con. $\mathrm{HCl}$ to 8.0 & $1000 \mathrm{ml}$ \\
StMQ $\mathrm{H}_{2} \mathrm{O}$ & \\
\hline TABLE 19: TRIS-HCL (1M) & \\
& \\
\hline Reagent & Amount \\
\hline Tris- $\mathrm{HCl}^{-}$ & $0.157 \mathrm{mg}$ \\
$\mathrm{NaCl}$ & $0.584 \mathrm{~g}$ \\
$\mathrm{MgCl} 2.6 \mathrm{H}_{2} \mathrm{O}$ & $0.203 \mathrm{~g}$ \\
StMQ $\mathrm{H}_{2} \mathrm{O}$ & $100 \mathrm{ml}$ \\
\hline
\end{tabular}

Table 20: Phage Dilution Buffer.

\begin{tabular}{lc}
\hline Reagent & Amount \\
\hline Tris & $242 \mathrm{~g}$ \\
Acetate & $57 \mathrm{ml}$ \\
EDTA (0.5 M) & $100 \mathrm{ml}$ \\
StMQ $\mathrm{H}_{2} \mathrm{O}$ & Add $1000 \mathrm{ml}$ \\
\hline TABLE 21: 50X TAE &
\end{tabular}




\subsection{COMMERCIAL KITS}

\begin{tabular}{ll}
\hline Kit & Provider \\
\hline GeneRead Size Selection Kit & Qiagen GbH, Germany \\
peqGOLD Gel Extraction Kit (Safety-Line) & Peqlab Biotechnologie GbH, Germany \\
peqGOLD Plasmid Miniprep Kit I & Peqlab Biotechnologie GbH, Germany \\
PowerClean DNA cleanup kit & MoBio Laboratories, Inc., USA \\
Quant-iT dsDNA BR assay kit & Invitrogen GbH, Germany \\
RNA PowerSoil DNA elution accessory kit & Mo Bio Laboratories, Inc., USA \\
RNA PowerSoil total RNA isolation kit & Mo Bio Laboratories, Inc., USA \\
RNeasy MinElute Cleanup kit & Qiagen GbH, Germany \\
SureClean Kit & Bioline GbH, Germany \\
TOPO XL PCR Cloning Kit & Invitrogen GbH, Germany \\
\hline TURBO DNA-free kit & Ambion Applied Biosystems, Germany \\
\hline
\end{tabular}

TABLE 22: LIST OF KITS USED 


\subsection{COMPUTATIONAL ANd StATISTICAL ANALYSIS TOOLS}

\begin{tabular}{|c|c|}
\hline Software/Services & Source \\
\hline NanoDrop 1000, version 3.8.0 & ThermoFisher Scientific \\
\hline USEARCH version 8.1 & http://drive5.com/usearch/ \\
\hline \multirow[t]{2}{*}{ UPARSE } & http://drive5.com/uparse/ \\
\hline & Reff. (Edgar 2013) \\
\hline \multirow[t]{2}{*}{ UCHIME } & http://drive5.com/usearch/manual/uchime_algo.html \\
\hline & Reff. (Edgar, Haas et al. 2011) \\
\hline $\begin{array}{l}\text { QIIME, Version } 1.9 \\
\text { (Quantitative Insights into } \\
\text { Microbial Ecology) }\end{array}$ & $\begin{array}{l}\text { http://qiime.org/ Reff. (Caporaso, Kuczynski et al. } \\
\text { 2010) }\end{array}$ \\
\hline $\mathrm{R}$ version $\mathbf{3 . 2 . 3}$ & https://www.r-project.org Reff. (R Core Team 2015) \\
\hline $\begin{array}{l}\text { SigmaPlot, Exact Graphs and } \\
\text { Data Analysis }\end{array}$ & $\begin{array}{l}\text { Systat Software, Inc., San Jose California USA, } \\
\text { www.sigaplot.com }\end{array}$ \\
\hline Trimmomatic v.0.30 & $\begin{array}{l}\text { http://www.usadellab.org/cms/?page=trimmomatic } \\
\text { Reff. (Bolger, Lohse et al. 2014) }\end{array}$ \\
\hline SPAdes version 3.7.1 & $\begin{array}{l}\text { http://bioinf.spbau.ru/en/spades Reff. (Bankevich, } \\
\text { Nurk et al. 2012) }\end{array}$ \\
\hline Prodigal version $\quad 2.6 .0$ & http://prodigal.ornl.gov/ \\
\hline $\begin{array}{l}\text { (Prokaryotic } \quad \text { Dynamic } \\
\text { Programming } \quad \text { Genefinding } \\
\text { Algorithm) }\end{array}$ & Reff. (Hyatt, Chen et al. 2010) \\
\hline GhostKOALA version 2.0 & http://www.kegg.jp/ghostkoala/ \\
\hline & Reff. (Kanehisa, Sato et al. 2016) \\
\hline
\end{tabular}

TABLE 23: LIST OF TOOLS USED. 


\subsection{DNA AND RNA EXTRACTION METHODS}

Extraction of DNA was carried out by two general methods with minor modifications. The first method is Phenol-chloroform extraction. It is a liquid-liquid extraction method in biochemistry. It is broadly used in molecular biology for isolating DNA, RNA, and protein. Equal volumes of phenol : chloroform mixture and an aqueous sample are mixed, forming a biphasic mixture. This method can take longer than a column-based system, such as the silica-based purification, but has the benefit of high recovery of DNA. It was formerly used by Piotr Chomczynski and Nicoletta Sacchi (referred to as guanidinium thiocyanatephenol-chloroform extraction) and published in 1987 (Chomczynski and Sacchi 1987). In 1998, this basic Phenol-Chloroform extraction was adapted by Yeats (Yeates, Gillings et al. 1998). In this thesis, we have used the method revised by Yeates et al. with some more modifications. It is described in next two chapters. The second method is column based. The key to these systems is the binding matrix/column that avidly, but reversibly, binds under certain optimal conditions allowing proteins and other contaminants to be removed. Then the nucleic acids can be easily eluted with deionized water.

\subsubsection{Extraction Of DNA And RNA For The Total ANd The Active Prokaryotic Biodiversity AsSessment By ILlumina PLATFORM}

Co-extraction of total environmental RNA and DNA were performed from $0.5 \mathrm{~g}$ of sediment of each of the Lonar 1, Lonar 2 and Lonar 3. The RNA PowerSoil total RNA isolation kit and the RNA PowerSoil DNA elution accessory kit were used respectively, as per the recommendation of the manufacturer (MoBio Laboratories, USA). The extracted RNA was purified from residual DNA with the TURBO DNA-free kit (Ambion Applied Biosystems, Germany). The success of purification was confirmed by PCR to determine the absence of DNA as described by Wemheuer et al. (Wemheuer, Wemheuer et al. 2012). Purification and concentration of the DNA-free RNA were achieved with the RNeasy MinElute Cleanup kit (Qiagen GbH, Hilden, Germany). Isolated DNA was cleaned with the PowerClean DNA cleanup kit (MoBio Laboratories). Concentrations of DNA and RNA were 
determined using a NanoDrop ND-1000 spectrophotometer (Peqlab Biotechnologie GbH, Erlangen, Germany). cDNA synthesis was performed, from approximately $500 \mathrm{ng}$ of purified RNA, with the SuperScriptTM III reverse transcriptase as recommended by the manufacturer (Invitrogen, Karlsruhe, Germany) and the reverse primer S-D-Bact-0785-aA-21 (reverse) (Klindworth, Pruesse et al. 2013) and in-house (reverse) of the next PCR reaction separately. These DNA and cDNA will be used to assess the biodiversity of the total and the active bacterial and archaeal community.

\subsubsection{EXTRACTION Of DNA FOR AdDITIONAL BIODIVERSITY ASSESSMENT BY} ROCHE PLATFORM

DNA extraction protocol for lake sediments in use was modified after Yeates (Yeates, Gillings et al. 1998). $10 \mathrm{~g}$ of sediment was suspended in $20 \mathrm{ml}$ of wash buffer (50mM Tris$\mathrm{HCl}, 50 \mathrm{mM}$ EDTA, and $25 \%$ sucrose), it was vortexed briefly to disperse the soil particles and centrifuged at 10,000g for 3 minutes. The supernatant was discarded. This helps eliminate the salts and exopolysaccharides. The sediment was resuspended in $15 \mathrm{ml}$ of DNA extraction buffer [100 mM Tris- $\mathrm{HCl}(\mathrm{pH} 8.0), 100 \mathrm{mM}$ sodium EDTA ( $\mathrm{pH}$ 8.0) , $1.5 \mathrm{M}$ $\mathrm{NaCl}, \mathrm{CTAB} 1 \% \mathrm{w} / \mathrm{v}$ ]. $75 \mu \mathrm{l}$ of lysozyme (from a $100 \mathrm{mg} / \mathrm{ml}$ stock solution) and $75 \mu \mathrm{l}$ of RNAseA (from a $100 \mathrm{mg} / \mathrm{ml}$ stock solution) were added and incubated at $37{ }^{\circ} \mathrm{C}$ for $1 \mathrm{~h}$. It was frozen using liquid nitrogen and then thawed in a water bath at $65^{\circ} \mathrm{C}$ for 30 minutes. This freeze-thaw cycle was repeated one more time. $1.6 \mathrm{ml}$ of $20 \%(\mathrm{w} / \mathrm{v})$ SDS and $0.7 \mathrm{ml}$ of 6M GITC was added, mixed gently by inversion and incubated for $2 \mathrm{hrs}$ at $65^{\circ} \mathrm{C}$ with occasional gentle mixing. After $2 \mathrm{hrs}$, the mixture was centrifuged at 15,000 rpm for 20 $\min$ at $10^{\circ} \mathrm{C}$ to remove soil residue, and the supernatant was transferred, which contains the crude DNA, into a clean tube. An equal volume of chloroform: isoamyl alcohol (24:1) was added and mixed gently on a slow shaker for 10 minutes. The mixture was centrifuged at $15,000 \mathrm{rpm}$ for $20 \mathrm{~min}$ at $10^{\circ} \mathrm{C}$ and the supernatant was transferred to a clean tube. The $0.7 x$ volume of isopropanol was added and allowed to mix on a slow shaker for 10 minutes. The mixture was centrifuged at $15,000 \mathrm{rpm}$ for $40 \mathrm{~min}$ at $10^{\circ} \mathrm{C}$ to pellet the DNA, and all traces of the supernatant were removed. The DNA pellet was resuspended in a 
minimum amount ( $2 \mathrm{ml}$ ) of St.MQ and aliquoted into Eppendorf tubes using a wide bore pipette tip. The DNA was purified by using an equal volume of phenol/chloroform/isoamyl alcohol (25:24:1). One was extracted with Chloroform: isoamyl alcohol (24:1) to remove traces of phenol. The mixture was centrifuged at $15,000 \mathrm{rpm}$ for $20 \mathrm{~min}$ at $10^{\circ} \mathrm{C}$ and the supernatant was transferred to a clean tube. The $0.7 x$ volume of isopropanol was added and allowed to mix on a slow shaker for 10 minutes. The mixture was centrifuged at 15,000 rpm for $20 \mathrm{~min}$ at $10^{\circ} \mathrm{C}$ to pellet the DNA and remove all traces of the supernatant. The pellet was washed twice with $80 \%(\mathrm{v} / \mathrm{v})$ ethanol, air-dry and dissolves in $2 \mathrm{ml} \mathrm{St.MQ}$. The quality and quantity were checked by $0.8 \%$ agarose gel electrophoresis and Nanodrop (NanoDrop ND-1000, Thermo Scientific). This DNA will be used for additional surveying of the total diversity to confirm the coverage.

\subsubsection{EXtraction Of DNA From Agarose Gel}

Gel extraction of DNA with peqGOLD Gel Extraction Kit (Safety-Line, Cat. No.12-2500-01). The sonicated sample was mixed with Loading Dye and loaded on a $0.8 \%$ agarose gel. The electrophoresis was performed for $90 \mathrm{~min}$ at $90 \mathrm{~V}$. Afterward, the sides with the marker were cut out and stained in Ethidium Bromide (EtBR). The gel with DNA from 6 to $10 \mathrm{~kb}$ was excised out under UV to mark the region of interest. The rest of the unstained gel was added in between the marked stained gel pieces and was cut as well (it was not stained with EtBR or exposed to UV). For DNA Extraction from the gel, the peqGOLD Gel Extraction Kit provided by Peqlab Biotechnology was used along with the provided protocol described in the next paragraph.

The approximate volume of the gel slice was determined (by weighing) to add an equal volume of the provided Binding Buffer. The mixture was incubated for $7 \mathrm{~min}$. at $65^{\circ} \mathrm{C}$. During this time, it was inverted from time to time to mix thoroughly until the gel was completely dissolved. A PerfectBindDNA Column was placed in a $2 \mathrm{ml}$ Collection Tube (both provided with the kit) and loaded with the DNA/agarose solution. The column/tube was centrifuged for $1 \mathrm{~min}$. at $10.000 \times \mathrm{g}$. The flow-through was discarded, and the column was loaded again until there was no solution left. Afterward, the Binding Buffer was added 
to the column, and another centrifugation step (same conditions) was performed. Then, the column was washed with CG Wash Buffer (diluted with ethanol). Again, the column/tube was centrifuged for $1 \mathrm{~min}$ at $10.000 \times \mathrm{g}$. The centrifugation step was repeated to dry the column and remove ethanol. The column was placed in a fresh tube, and prewarmed Elution Buffer was added directly to the filter. The column/tube was centrifuged for $1 \mathrm{~min}$. at $5.000 \times \mathrm{g}$ to elute the DNA. The success of the DNA gel extraction was verified by gel electrophoresis.

\subsubsection{Extraction Of DNA For Direct MetagenOMe ANALYSIS}

The DNA extraction protocol is same as described in the chapter 3.7.2. The only difference was, before storing the extracted DNAs were further cleaned using SureClean Kit (Bioline, Germany).

\subsubsection{EXTRACTION Of DNA FOR THE STUdY Of COMMUNITY DYNAMICS DURING MICROENVIRONMENTAL PH HOMEOSTASIS}

Cultures from non-optimum $\mathrm{pH}$ exposures were subjected to centrifugation as $15 \mathrm{ml}$ aliquots. The cell pellet was resuspended in $15 \mathrm{ml}$ of DNA extraction Buffer and $75 \mu \mathrm{l}$ of lysozyme were added. The mixture was incubated at $37^{\circ} \mathrm{C}$ for $1 \mathrm{~h}$. Afterward, $1.6 \mathrm{ml}$ of 20 $\%$ SDS and $0.7 \mathrm{ml}$ of $6 \mathrm{M} \mathrm{GITC}$ were added. The sample incubated for $2 \mathrm{hrs}$ and $65^{\circ} \mathrm{C}$. It was inverted from time to time. An equal volume of phenol/chloroform/isoamyl alcohol $(25: 24: 1)$ was added and mixed on a slow shaker for $10 \mathrm{~min}$. Followed by a centrifugation step for $20 \mathrm{~min}$. at $15,000 \mathrm{rpm}$ and $10^{\circ} \mathrm{C}$. The supernatant was transferred to a clean tube. To remove traces of Phenol; Chloroform/Isoamylalcohol (24:1) was added. The mixture was centrifuged at $15.000 \mathrm{rpm}$ for $20 \mathrm{~min}$ at $10^{\circ} \mathrm{C}$ and the supernatant was placed in a clean tube. The $1 \mathrm{X}$ volume of Isopropanol was added, and the solution was mixed gently and kept overnight at $-20^{\circ} \mathrm{C}$. On the next day, the mixture was centrifuged at $15.000 \mathrm{rpm}$ for $40 \mathrm{~min}$ at $10^{\circ} \mathrm{C}$ to precipitate the DNA as a pellet. All traces of supernatant were 
removed. The pellet was washed twice with $80 \%$ ethanol, air-dried and dissolved in $1 \mathrm{ml}$ StMQ water.

\subsubsection{EXTRACTION Of DNA FOR CONSTRUCTION OF METAGENOMIC LIBRARIES}

Enrichment cultures (as described in 3.9.1) were subjected to centrifugation as $15 \mathrm{ml}$ aliquots. Rest of the protocol is as described above (3.7.2).

\subsubsection{EXTRACTION OF PLASMID DNA}

\subsubsection{Isolation Of Plasmid Using Peqgold Plasmid Miniprep Kit}

For plasmid isolation the peqGOLD Plasmid Miniprep Kit I was used, offered by Peqlab Biotechnology. The cultures were transferred to $2 \mathrm{ml}$ tubes and centrifuged 2 times for 10 min at $5.000 \times \mathrm{g}$. The bacterial pellet was resuspended in Solution I (with RNase A) to lyse the Bacteria. Solution II was added and the mixture was mixed by inverting. The lysate was neutralized by adding Solution III and inverting. A white flocculent precipitate was observed. The solution was centrifuged at $10.000 \times \mathrm{g}$ for $10 \mathrm{~min}$ at room temperature. The supernatant was transferred to a column collection tube. The column and the tube were centrifuged $1 \mathrm{~min}$ at $10.00 \mathrm{xg}$ at room temperature, and the flow through was discarded. Then, three washing steps followed: HB Buffer was added, and the Solution was centrifuged for $1 \mathrm{~min}$ at $10.000 \mathrm{xg}$. Then, Wash Buffer completed with ethanol was added two times to the column. The Centrifugation was repeated. For drying, the column was centrifuged one more time with same conditions. Afterward, DNA was eluted by placing the column to a fresh tube adding Elution Buffer and centrifuging at $5.000 \times \mathrm{g}$ for $1 \mathrm{~min}$. An analytical gel electrophoresis was performed to check the extraction success. 


\subsubsection{IsOlation Of Plasmid Using QIAGEN Plasmid Plus Midi KIT}

Pelleted cell mass was resuspended in $2 \mathrm{ml}$ Buffer P1 (with RNase A). The pellet was resuspended completely by vortexing. $2 \mathrm{ml}$ of Buffer P2 was added and gently mixed by inverting. The mixture was incubated at $25^{\circ} \mathrm{C}$ for $3 \mathrm{~min} .2 \mathrm{ml}$ of Buffer $\mathrm{S} 3$ was added to the lysate and mixed immediately by inverting several times. The lysate was transferred immediately to the QIAfilter Cartridge and incubate at room temperature for $10 \mathrm{~min}$. During incubation, the vacuum manifold, and the QIAGEN Plasmid Plus Midi spin columns were prepared. The plunger was inserted gently into the QIAfilter Cartridge and filter the cell lysate into a new tube, allowing space for the addition of Buffer BB. Filtration was performed until all of the lysates has passed through the QIAfilter Cartridge. $2 \mathrm{ml} \mathrm{Buffer}$ BB was added to the cleared lysate and mix by inverting several times. The lysate was transferred to a QIAGEN Plasmid Plus Midi spin column with a tube extender attached on the vacuum set. The solution was drawn through the QIAGEN Plasmid Plus Midi spin column using -300 mbar pressure. $0.7 \mathrm{ml}$ of Buffer ETR was added to the DNA to wash. The tube extenders were discarded and the QIAGEN Plasmid Plus Midi Spin Column was placed into the $2 \mathrm{ml}$ collection tube, provided with the kit. The column was washed by centrifuging for $1 \mathrm{~min}$ at 10,000 x g. The flow-through was discarded. $0.7 \mathrm{ml}$ of Buffer PE was added. The column was washed again by centrifuging for $1 \mathrm{~min}$ at 10,000 $\mathrm{x} \mathrm{g}$. The flow-through was discarded. The column was again centrifuged for $1 \mathrm{~min}$ at $10,000 \mathrm{xg}$ in a microcentrifuge to remove the residual wash buffer completely. The QIAGEN Plasmid Plus Midi spin column was placed into a clean $1.5 \mathrm{ml}$ microcentrifuge tube. The DNA or Plasmid was eluted by adding $200 \mu$ l of stMQ Water to the center of the QIAGEN Plasmid Plus Midi spin column. The setup was allowed to stand for $1 \mathrm{~min}$ and then centrifuged for $1 \mathrm{~min}$ at $10,000 \times \mathrm{g}$. The plasmid was stored at $-20^{\circ} \mathrm{C}$. 


\subsection{QUANTIFICATION OF DNA}

Nucleic acids absorb ultraviolet light in a precise pattern. In a spectrophotometer, a sample is exposed to ultraviolet light at $260 \mathrm{~nm}$ and a photodetector measures the light that travels through the sample. The more light absorbed by the sample, the higher the nucleic acid concentration in the sample. Using the Beer-Lambert Law, it is achievable to correlate the quantity of light absorbed to the concentration of the absorbing molecule.

In this thesis the DNA concentration was measured with two instruments one is with Nano-Drop Spectrophotometer (Cat No. ND-1000) by Thermo Fisher Scientific and the other is Qubit 2.0 Fluorometer (Cat No. Q32866) by Life Technologies. Qubit 2.0 Fluorometer unlike Nano-Drop Spectrophotometer uses fluorescence rather than absorbance.

\subsubsection{DETERMINATION OF DNA CONCENTRATION BY NANO-DROP SPECTROPHOTOMETER}

Before every measurement, the sample plate was cleaned with $5 \mu$ of StMQ water and dried with a tissue. Afterward, a blank was measured using $2 \mu \mathrm{l}$ of the solution in which the DNA was dissolved (StMQ water or any other DNA Elution Buffer). The sample plate was cleaned again, and $2 \mu \mathrm{l}$ of the sample were placed on the plate. The concentrations were determined using the computer program NanoDrop 1000 (version 3.8.0) provided by ThermoFisher Scientific. The concentration was stated in $\mathrm{ng} / \mu \mathrm{l}$. In addition, other values were available, which contains calculations of absorbance ratios and allows drawing conclusions about the quality or purity of the examined DNA. One of the most important values was the A260/A280 ratio (1.8 can be considered as pure or clean). 


\subsubsection{DeterminATION Of DNA CONCENTRATION BY QUBIT FLUOROMETER}

The principle of measurement of DNA concentration by Qubit is based on fluorescent dyes that bind specifically to DNA, RNA or protein. The dye releases a detectable fluorescent signal when it is bind to its target (DNA, RNA or Protein). Therefore, the Qubit measurement is more accurate than the NanoDrop measurement. NanoDrop is based on absorbance, where it is possible that other molecules can exist in the DNA solution, which is measured along with the DNA and provide inaccurate measurement compared to Qubit. Before starting the measurement, a Working Solution has to be prepared. $199 \mu \mathrm{l}$ of provided buffer is mixed with $1 \mu$ of dye for every sample. The solution is mixed by vortexing. $190 \mu \mathrm{l}$ of it were aliquoted for standards. They were completed with $10 \mu \mathrm{l}$ of standard solution ( 2 per measurement). The other working solution was used for the samples. Depending on the amount of sample which is used for measurement, $198 \mu \mathrm{l}-199$ $\mu \mathrm{l}$ Working Solution were aliquoted in assay tubes. In the end, the total volume should be $200 \mu \mathrm{l}$. So, $1 \mu \mathrm{l}-2 \mu \mathrm{l}$ of the sample were added. The solution was mixed by vortexing and incubated for $2 \mathrm{~min}$ at room temperature. Then the measurement starts by choosing the kind of the sample and blanking the Qubit with Standard Solution 1 and 2 by putting the assay tubes in the designated place. Afterward, the samples are measured using the provided computer program.

\subsection{Construction And SCREening Of Metagenomic LibRARIES}

\subsubsection{ENRICHMENT CULTURES}

An enrichment culture is a medium with definite and known character that positively discriminates the growth of a specific microorganism above others. The microbiologist (and botanist) Martinus Willem Beijerinck (March 16, 1851 - January 1, 1931) is credited with developing the first enrichment cultures (King-Thom and Hunter 1996). We established three different enrichment cultures to get the population of protease, lipase 
and cellulase producing microorganism vastly obtainable. The recipe as described in Chapter 3.3 (Table 4, Table 5, Table 6).

\subsubsection{CONSTRUCTION OF SMALL INSERT LIBRARY}

For the construction of small insert library TOPO XL PCR Cloning Kit provided by Invitrogen was used in this experiment.

\subsubsection{Preparation Of Electrocompetent Cells}

For the preparation of electrocompetent cells, a $5 \mathrm{ml}$ overnight culture was added to 250 $\mathrm{ml}$ growth medium. LB supplemented with kanamycin was used for $E$. coli $\mathrm{DH} 5 \alpha$. The cells were incubated at $30^{\circ} \mathrm{C}$ until an optical density (OD600) of $0.5-1$. The OD was measured with an Ultraspec 3300 pro photometer (Amersham Pharmacia Biotech Europe GbH). The E. coli culture was then incubated $20 \mathrm{~min}$ on ice before being centrifuged for $10 \mathrm{~min}$ (5000 $x \mathrm{~g}, 4{ }^{\circ} \mathrm{C}$ ). The pellet was washed two times with equal volume of sterile $\mathrm{H}_{2} \mathrm{O}$ and subsequently washed one time with $10 \mathrm{ml}$ glycerol (10\%). Resuspension was done with $0.5 \mathrm{ml}$ of glycerol (10\%) and for further use aliquots of $40 \mu \mathrm{l}$ were prepared and frozen using liquid nitrogen before storage at $-70^{\circ} \mathrm{C}$.

\subsubsection{SMALL INSERT LIBRARY}

Small-insert libraries were constructed using the TOPO XL PCR Cloning Kit (Invitrogen GbH, Karlsruhe, Germany) with plasmid PCR-XL-TOPO as a vector. For each enrichment culture, approximately, $10 \mu \mathrm{g}$ extracted DNA was separated by agarose gel electrophoresis. DNA fragments of more than $6 \mathrm{~kb}$ in size were selected and purified from the gels using the peqGold Gel Extraction Kit (Peqlab Biotechnologie GbH, Germany). The purified DNA fragments were subjected to sticky end repairing using T4 DNA polymerase (MBI 
Fermentas, Germany) as suggested by the manufacturer. Afterward, the DNA was purified using SureClean Kit (Bioline GbH, Germany) and the resulting DNA pellet was suspended in $35 \mu \mathrm{l} \mathrm{H}{ }_{2} \mathrm{O}$. Then, a deoxyadenosine was added to the $3^{\prime}$ end of the DNA to facilitate the TA cloning method. For this purpose, $1 \mu \mathrm{ldATP}$ solution $(100 \mathrm{mM}), 6 \mu \mathrm{l} \mathrm{MgCl} 2$ solution (25 mM) , $7 \mu$ of 10X Taq DNA polymerase buffer containing $\left(\mathrm{NH}_{4}\right)_{2} \mathrm{SO}_{4-}$ (Fermentas) , 1 $\mu \mathrm{l}$ of Taq DNA polymerase ( $5 \mathrm{U}$ ), and $20 \mu \mathrm{l}$ of $\mathrm{H} 2 \mathrm{O}$ were mixed with the DNA solution, incubated at $72{ }^{\circ} \mathrm{C}$ for $30 \mathrm{~min}$, and purified using SureClean solution (Bioline $\mathrm{GbH}$ ). The resulting DNA pellet was suspended in $15 \mu \mathrm{H} 2 \mathrm{O}$ and dephosphorylated using $5 \mathrm{U}$ Antarctic Phosphatase (NEB, Ipswich, MA). The blunt-end-DNA with 3' A-overhang was mixed with $1.5 \mu$ l of Antarctic Phosphatase Buffer (10x) and $1 \mu$ l of Antarctic Phosphatase (5U). The sample was incubated for $15 \mathrm{~min}$. at $37^{\circ} \mathrm{C}$ and inactivated by another incubation step at $65^{\circ} \mathrm{C}$ for $15 \mathrm{~min}$.

Finally, the recovered DNA fragments were inserted into pCR-XL-TOPO using the TOPO XL PCR cloning kit (Invitrogen) by adding $1 \mu$ l of the PCR-XL-TOPO vector to $4 \mu$ l of prepared enrichment culture DNA (protease and lipase separately). The mixture was incubated for $5 \mathrm{~min}$ at room temperature. Then, $1 \mu \mathrm{l}$ Stop solution (provided with the kit) was added, and the ligation mixture was kept on the ice.

\subsection{Transformation Of E. Coli TOP1O And E. Coli DH5a Cells By Electroporation}

Electroporation is a quick transformation method (Dower, Miller et al. 1988). It is based on the permeability of the cell membrane. The rapid breakdown of the membrane potential allows the absorption of DNA, mostly plasmids.

The TOPO-Cloning reactions were used to transform Escherichia coli TOP10 cells with the electroporation method. $2 \mu \mathrm{l}$ of the TOPO-Cloning reaction was added to one vial of OneShot electrocompetent $E$. coli cells and mixed gently. The cells with the DNA were transferred to a chilled $0.1 \mathrm{~cm}$ electroporation cuvette. Electroporation occurred at $25 \mu \mathrm{F}$, $200 \Omega$ and $2.5 \mathrm{kV}$ with the pulse controller II and the gene controller II manufactured by BioRad. Immediately after electroporation $450 \mu$ l of S.O.C. medium (room temperature) was added and mixed well. The solution was transferred to a $2 \mathrm{ml}$ tube and incubated for 
one hour at $37^{\circ} \mathrm{C}$ to allow expression of the antibiotic resistance genes. During incubation, the solution was inverted from time to time. Afterward, the cells were spread on four plates, one of $50 \mu \mathrm{l}$, two of $100 \mu \mathrm{l}$ and one of $150 \mu \mathrm{l}$. The plates were incubated overnight at $37^{\circ} \mathrm{C}$.

The metagenomic libraries were used to transform E. coli DH5 $\alpha$ cells in the same way as described above. Instead of the TOPO-Cloning reaction the library itself is used.

\subsection{Detection Of Recombinant Cells By Blue-White Screening}

Kanamycin provided the selection for successful transformation in addition of X-Gal and IPTG. The presence of X-Gal (bromo-chloro-indolyl-galactopyranoside) allows a selection of insert-carrying plasmids. Galactoside is linked to indole. Galactose and 5-bromo-4chloro-3-hydroxyindole emerge from cleavage by $\beta$-galactosidase. Oxidation of 5-bromo4-chloro-3-hydroxyindole results in a blue product. Since the aminoterminal region of the lacZ gene is situated in the multiple cloning site, an insert-carrying clone is not able to produce a functional $\beta$-galactosidase, assumed that the host cells carry an inactive lacZ gene or lack the aminoterminal region. IPTG (Isopropyl $\beta$-D-1-thiogalactopyranoside) served as an inducer to ensure the activity of possible presence of $\beta$-galactosidases.

\subsection{Library Preparation}

The white and blue E. coli TOP10 clones resulting from TOPO-XL-cloning were counted and removed from plates, followed by a QIAGEN Plasmid Plus Midi preparation as described in 3.7.7.2. The plasmids were then collected in one tube, stored at $-20^{\circ} \mathrm{C}$, and referred to as a metagenomic library.

All the procedures were performed three times with three enrichment culture DNA resulting into three small insert libraries. 


\subsubsection{SCREENING OF SMALL INSERT LIBRARIES}

\subsection{Protease Activity Screening}

LB agar plates containing skimmed milk were used for detection of proteolytic activity. Skimmed milk can be degraded by proteolytic enzymes leading to the formation of a halo around a positive clone. After transforming the protease enrichment library into $E$. coli $\mathrm{DH} 5 \alpha$, recombinant cells were plated and incubated at $37^{\circ} \mathrm{C}$ for 3 to 14 days.

\subsection{Lipase Activity Screening}

LB agar plates containing glycerol tributyrate were used for detection of lipolytic activity. Recombinant cells expressing lipolytic enzymes can be detected by halo formation caused by the degradation of short-chain triglycerides. After transforming the lipase enrichment library into $E$. coli $\mathrm{DH} 5 \alpha$, recombinant cells were plated and incubated at $37^{\circ} \mathrm{C}$ for 3 to 14 days.

\subsubsection{LARGE INSERT LIBRARY}

For the construction of large insert library, Copy Control Fosmid Library Production Kit provided by Epicentre was used in this experiment.

\subsubsection{Preparation Of Infection Cells}

Infection cells were prepared before packaging. $1 \mu$ of E. coli EPI300 cells were inoculated into $50 \mathrm{ml}$ of LB (+ $10 \mathrm{mM} \mathrm{MgSO}$ ). The flask was incubated at $37^{\circ} \mathrm{C}$ for overnight on a shaker. $5 \mathrm{ml}$ of overnight grown culture was transferred into $50 \mathrm{ml}$ of LB (+ $10 \mathrm{mM}$ 
MgSO4). The flask was incubated at $37^{\circ} \mathrm{C}$ with shaking until OD600 reaches $0.8-1.0$. The culture was stored at $4{ }^{\circ} \mathrm{C}$ for later use (maximum of 5 days).

\subsubsection{SHEARING THE INSERT DNA}

DNA extracted from enrichment culture (for cellulase) was sufficiently sheared as a result of the purification process, and additional shearing was not necessary.

\subsubsection{End-Repair Of The Sheared DNA}

For each reaction, $60 \mu \mathrm{l}$ of sheared DNA (up to $20 \mu \mathrm{g}$ ), $8 \mu \mathrm{l}$ of 10x End-Repair Buffer, $8 \mu \mathrm{l}$ of $2.5 \mathrm{mM}$ dNTPs, $8 \mu \mathrm{l}$ of 10mM ATP and $4 \mu \mathrm{l}$ of End-Repair Enzyme Mix were mixed gently and incubated for $2 \mathrm{~h}$. After incubation, the insert DNA was purified with Bioline SureClean and eluted with $12 \mu \mathrm{l}$ of sterile water.

\subsubsection{LIGATION REACTION}

For each reaction $2 \mu \mathrm{l}$ of $10 \mathrm{X}$ Ligation Buffer, $2 \mu \mathrm{l}$ of $10 \mathrm{mM}$ ATP, $2 \mu \mathrm{l}$ of Copy Control pCC1FOS Vector $(0.5 \mu \mathrm{g} / \mu \mathrm{l}), 12 \mu \mathrm{l}$ of insert DNA and $2.0 \mu \mathrm{l}$ of DNA Ligase were mixed and incubated at $16{ }^{\circ} \mathrm{C}$ for overnight. Following overnight ligation additional $1 \mu$ l of DNA ligase was added to the ligation mix and incubate at room temperature for $2 \mathrm{hrs}$. The reaction was inactivated by heating at $70^{\circ} \mathrm{C}$ for 10 minutes. The reaction mix was cooled on ice for $10 \mathrm{~min}$.

\subsubsection{PACKAgIng Of FoSMID CLONES}

The entire ligation mix was used in this step. $25 \mu$ of thawed Max Plax packaging extract was added to the ligation mix (the remaining $25 \mu$ of the Max Plax Packaging Extract was 
kept at $-70^{\circ} \mathrm{C}$ ). The mix was incubated at $30^{\circ} \mathrm{C}$ for $120 \mathrm{~min}$. After incubation additional 25 $\mu l$ of the phage packaging extract was added to the sample and incubated again for 120 min at $30{ }^{\circ} \mathrm{C}$. Phage dilution buffer was added to a final volume of $1 \mathrm{ml}$, and $25 \mu \mathrm{l}$ of chloroform was added to the sample. The sample was stored at $4{ }^{\circ} \mathrm{C}$ until further use.

\subsubsection{INFECTION}

During infection, different volumes (e.g. $10 \mu \mathrm{l} / 30 \mu \mathrm{l} / 50 \mu \mathrm{l}$ ) of the packaged sample were added to $100 \mu$ l of infection cells. The cells were incubated at $37^{\circ} \mathrm{C}$ for $90 \mathrm{~min}$ in a heating block. The library was plated onto LB (+ $12.5 \mu \mathrm{g} / \mathrm{ml}$ Chloramphenicol) plates. The plates were incubated at $37^{\circ} \mathrm{C}$ overnight.

\subsection{PCR AMPLIFICATION OF PARTIAL 16S RRNA GENE}

The polymerase chain reaction (PCR) is the fundamental laboratory technique of molecular biology. It is one of the most influential laboratory techniques that have been discovered ever; PCR combines the distinctive properties of being very sensitive and specific with an immense degree of flexibility. With the PCR, it is achievable to address a specific DNA sequence and to amplify this sequence to an extremely high number of copy. Since its initial development in the early 1980's, several variations on the fundamental idea of PCR have successfully been carried out.

\subsubsection{Amplification Of PARTIAL 16S RRNA Gene For The TOtAL AND THE ACTIVE COMMUNITY DIVERSITY ASSESSMENT}

The V3-V4 region of the 16S rRNA gene was amplified by PCR (polymerase chain reaction). Every sample was amplified in triplicates. Every sample was amplified 3 times in replica along with negative controls (no template) resulting in a total of 40 reactions; $50 \mu l$ each 
(36 samples, 4 controls). 3 sediment samples (Lonar 1, Lonar 2 and Lonar 3) , two type of template (DNA and cDNA), two set of primers (Archaeal and Bacterial) and 3 replicas for

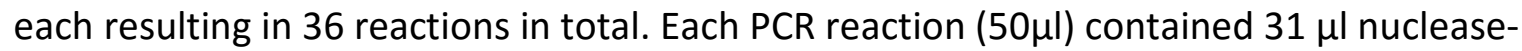
free demineralized sterile $\mathrm{H}_{2} \mathrm{O}, 10 \mu \mathrm{l}$ X reaction buffer (Phusion GC Buffer for Archaea and Phusion HF buffer for Bacteria, ThermoFisher Scientific), $1 \mu \mathrm{l}$ of $10 \mathrm{mM}$ of deoxynucleoside triphosphates (all four) , $2.5 \mu \mathrm{l}$ DMSO, $2 \mu \mathrm{l}$ of BSA [20 mg ml-1 in $10 \mathrm{mM}$ Tris- $\mathrm{HCl}$ (pH 7.4 at 25o C) , $100 \mathrm{mM} \mathrm{KCl,} 1 \mathrm{mM}$ EDTA and $50 \%$ (v/v) glycerol] (ThermoFisher Scientific) , $1 \mu \mathrm{l}$ of $10 \mu \mathrm{M}$ primer each (forward and reverse) , $0.5 \mu \mathrm{l}$ of $2 \mathrm{U} / \mu \mathrm{l}$ Phusion highfidelity DNA Polymerase (ThermoFisher Scientific) , $1 \mu$ l of isolated DNA diluted to $50 \mathrm{ng} / \mu \mathrm{l}$ concentration as template. The V3-V4 hypervariable region was selected as the parameter for identification of Bacteria (Vasileiadis, Puglisi et al. 2012, Vilo and Dong 2012). Primer set used for amplification of V3-V4 region was S-D-Bact-0341-b-S-17 (forward) and S-DBact-0785-a-A-21 (reverse) (Klindworth, Pruesse et al. 2013) with modifications(3.4.2.2). The V3-V4 hypervariable region was also selected as the parameter for identification of Archaea. Primer set used for amplification of V3-V4 region was 514Fa (forward) and Inhouse (reverse) with modifications(3.4.2.2). The scheme of thermal cycling was- initial denaturation at $98{ }^{\circ} \mathrm{C}$ for $5 \mathrm{~min}, 25$ cycles of denaturation at $95{ }^{\circ} \mathrm{C}$ for $45 \mathrm{~s}$, annealing at $57{ }^{\circ} \mathrm{C}$ for $45 \mathrm{~s}$, and extension at $72{ }^{\circ} \mathrm{C}$ for $90 \mathrm{~s}$ followed by a final extension for $10 \mathrm{~min}$ at $72{ }^{\circ} \mathrm{C}$. The PCR products were visualized on $0.8 \%$ agarose gel and cleaned using GeneRead Size Selection Kit (QIAGEN) following the protocol as suggested by the manufacturer. Quantification of the cleaned PCR products was performed using the Quant-iT dsDNA BR assay kit and a Qubit fluorometer (Invitrogen) as suggested by the manufacturer. PCR products were pooled in an equal amount of DNA as per sediment sample, primer and type of template resulting in 6 samples for Archaea ( 3 each for DNA and cDNA) and 6 for Bacteria (3 each for DNA and cDNA). The Goettingen Genomics Laboratory determined the sequences of the partial 16S rRNA genes by using a MiSeq System (Illumina) and the instructions of the manufacturer for amplicon sequencing. 


\subsubsection{AMPLIFICATION Of PARTIAL 16S RRNA GENE For AdDITIONAL TOTAL DIVERSITY ASSESSMENT}

The V3-V5 region of the $16 \mathrm{~S}$ rRNA gene was amplified by PCR (polymerase chain reaction). Every sample was amplified 3 times in replica along with negative controls (no template) resulting in a total of 20 reactions; $50 \mu$ l each (18 samples, 2 controls). 3 sediment samples (Lonar 1, Lonar 2 and Lonar 3), one type of template (DNA), two set of primers (archaeal and bacterial) and 3 replicas for each resulting in 18 reactions in total. Each PCR reaction $(50 \mu \mathrm{l})$ contained $31 \mu \mathrm{l}$ nuclease-free demineralized sterile $\mathrm{H}_{2} \mathrm{O}, 10 \mu \mathrm{l} 5$ fold reaction buffer (Phusion GC Buffer, Thermo Scientific), $1 \mu \mathrm{l}$ of $10 \mathrm{mM}$ of deoxynucleoside triphosphates (all four), $2.5 \mu \mathrm{I}$ DMSO, $2 \mu \mathrm{l}$ of BSA, $1 \mu \mathrm{l}$ of $10 \mu \mathrm{M}$ primer each (forward and reverse) , $0.5 \mu \mathrm{l}$ of $2 \mathrm{U} / \mu \mathrm{l}$ Phusion high-fidelity DNA Polymerase (Thermo Scientific) , $1 \mu$ l isolated DNA of $50 \mathrm{ng} / \mu \mathrm{l}$ as template. The V3-V5 region was amplified with the following set of primers containing the Roche 454 pyrosequencing adaptors, key and MID or multiplex identifier in the case of forward primer only. For Bacteria, the primer sequences were modified Bac343F(Nossa, Oberdorf et al. 2010) primer and modified Bac907R(Muyzer, Teske et al. 1995); for Archaea modified Arch340F(Ovreås, Forney et al. 1997) primer and modified Arch915R(Stahl and Amann 1991). Details of the primers are provided in 3.4.2.1. The scheme of thermal cycling was- initial denaturation at $98{ }^{\circ} \mathrm{C}$ for $5 \mathrm{~min}, 25$ cycles of denaturation at $95{ }^{\circ} \mathrm{C}$ for $45 \mathrm{~s}$, annealing at $64^{\circ} \mathrm{C}$ for $45 \mathrm{~s}$, and extension at $72{ }^{\circ} \mathrm{C}$ for $90 \mathrm{~s}$ followed by a final extension for $10 \mathrm{~min}$ at $72{ }^{\circ} \mathrm{C}$.

All amplified triplicate samples were pooled in equal amounts resulting in 6 samples ( 3 for Bacteria and 3 for Archaea, and purified using the peqGold gel extraction kit as recommended by the manufacturer (Peqlab Biotechnology). Quantification of the PCR products was performed using the Quant-iT dsDNA BR assay kit and a Qubit fluorometer (Invitrogen) as suggested by the manufacturer. PCR products were pooled in an equal amount of DNA as per sediment sample and primer resulting in 3 samples for Archaea and 3 for Bacteria. The Goettingen Genomics Laboratory determined the sequences of the partial 16S rRNA genes by using a Roche GS-FLX 454 pyrosequencer (Roche) and the instructions of the manufacturer for amplicon sequencing. 


\subsubsection{AMPLIFICATION Of PARTIAL 16S RRNA GENE For COMMUNITY DYNAMICS STUDY DURING MICROENVIRONMENTAL PH HOMEOSTASIS}

The V3-V4 region of the $16 \mathrm{~S}$ rRNA gene was amplified by PCR (polymerase chain reaction). Every sample was amplified 3 times in replica along with negative controls (no template) resulting in a total of 208 reactions; $50 \mu$ l each (186 samples, 22 controls). Each PCR reaction $(50 \mu \mathrm{l})$ contained $31 \mu \mathrm{l}$ nuclease-free demineralized sterile $\mathrm{H}_{2} \mathrm{O}, 10 \mu \mathrm{l} 5 \mathrm{X}$ reaction buffer (Phusion GC Buffer for Archaea and Phusion HF buffer for Bacteria, ThermoFisher Scientific), $1 \mu \mathrm{l}$ of $10 \mathrm{mM}$ of deoxynucleoside triphosphates (all four), $2.5 \mu \mathrm{l}$ DMSO, $2 \mu \mathrm{l}$ of BSA [20 mg ml-1 in $10 \mathrm{mM}$ Tris- $\mathrm{HCl}$ (pH 7.4 at 25o C), $100 \mathrm{mM} \mathrm{KCl,} 1$ mM EDTA and $50 \%$ (v/v) glycerol] (ThermoFisher Scientific), $1 \mu$ of $10 \mu \mathrm{M}$ primer each (forward and reverse), $0.5 \mu \mathrm{l}$ of $2 \mathrm{U} / \mu \mathrm{l}$ Phusion high-fidelity DNA Polymerase (ThermoFisher Scientific), $1 \mu \mathrm{l}$ of isolated DNA diluted to $50 \mathrm{ng} / \mu \mathrm{l}$ concentration as template.

The V3-V4 hypervariable region was selected as the parameter for identification of Bacteria (Vasileiadis, Puglisi et al. 2012, Vilo and Dong 2012). Primer set used for amplification of V3-V4 region was S-D-Bact-0341-b-S-17 (forward) and S-D-Bact-0785-aA-21 (reverse) (Klindworth, Pruesse et al. 2013) with modifications (3.4.2.2). The V3-V4 hypervariable region was also selected as the parameter for identification of Archaea. Primer set used for amplification of V3-V4 region was 514Fa (forward) and In-house (reverse) with modifications (3.4.2.2).

The scheme of thermal cycling was- initial denaturation at $98{ }^{\circ} \mathrm{C}$ for $5 \mathrm{~min}, 25$ cycles of denaturation at $95{ }^{\circ} \mathrm{C}$ for $45 \mathrm{~s}$, annealing at $57^{\circ} \mathrm{C}$ for $45 \mathrm{~s}$, and extension at $72{ }^{\circ} \mathrm{C}$ for $90 \mathrm{~s}$ followed by a final extension for $10 \mathrm{~min}$ at $72{ }^{\circ} \mathrm{C}$. The PCR products were visualized on 0.8 \% agarose gel and cleaned using GeneRead Size Selection Kit (QIAGEN) following the protocol as suggested by the manufacturer. Quantification of the cleaned PCR products was performed using the Quant-iT dsDNA BR assay kit and a Qubit fluorometer (Invitrogen) as suggested by the manufacturer. The Goettingen Genomics Laboratory determined the sequences of the partial 16S rRNA genes by using a MiSeq System (Illumina) and the instructions of the manufacturer for amplicon sequencing. 


\subsection{NONOPTIMAL MICROENVIRONMENTAL PH EXPOSURE}

To investigate how this microbial community responds to nonoptimal microenvironmental $\mathrm{pH}$. We used Horikoshi media (with modification) which is the most commonly used culture medium for isolating alkaliphiles designed by Koki Horikoshi (Horikoshi 1999). The prokaryotic cultures were set up using modified Horikoshi media, which is essentially a $50 \%$ v/v Horikoshi-I and Horikoshi-II. This modified Horikoshi media contains glucose $5 \mathrm{~g}$, soluble starch $5 \mathrm{~g}$, peptone $5 \mathrm{~g}$, yeast extract $5 \mathrm{~g}, \mathrm{KH}_{2} \mathrm{PO}_{4} 1 \mathrm{~g}, \mathrm{MgSO}_{4}$. $7 \mathrm{H}_{2} \mathrm{O} 0.2 \mathrm{~g}, \mathrm{Na}_{2} \mathrm{CO}_{3} 10 \mathrm{~g}$ and $\mathrm{NaCl} 40 \mathrm{~g}$ for every $1000 \mathrm{ml}$ of media. The $\mathrm{pH}$ was adjusted to pH 9 (suboptimal) and pH 10 (superoptimal) with sterile $\mathrm{NaOH}$, respectively. A total of 8 cultures of $300 \mathrm{ml}$ modified Horikoshi were set up 4 for each initial pH; 3 samples and 1 control. The modified Horikoshi medium was inoculated with $3 \mathrm{~g}$ of the sediment mix. Controls were used to see the extent of the effect of aeration due to shaking and the impact of the sediment itself. Two controls, one for each $\mathrm{pH}$, were inoculated with $3 \mathrm{~g}$ of double autoclaved sediment. The cultures were incubated at $30^{\circ} \mathrm{C}$ on a shaker at $100 \mathrm{rpm}$. $50 \mathrm{ml}$ of culture from each flask was taken every 5 days until 25 days. The samples were centrifuged for $15 \mathrm{~min}$ at $10,000 \mathrm{rpm}$ and $10{ }^{\circ} \mathrm{C}$ (Sorvall RC 6 Centrifuge, Thermo Scientific). The supernatants were used for $\mathrm{pH}$ measurement and HPLC analysis. The resulting cell pellets were used for DNA extraction.

\subsection{HPLC ANALYSIS Of CULTURE FILTRATE FROM NONOPTIMAL PH EXPOSURE BY VARIAN STAR PLATFORM}

Culture filtrates were collected and centrifuged at low rpm resulting supernatants were filter sterilized and lyophilize, stored in the freezer until required. HPLC was performed on a Varian Star instrument where channel was $A=$ Fluores $1 \mathrm{~V}$, detector type was ADCB (1 Volt), bus address 16 , sample rate $5.00 \mathrm{~Hz}$ and run time was $50.003 \mathrm{~min}$. Run mode was analysis, peak measurement was peak area and calculation type was percent. 


\subsection{SEQUeNCING}

In this study, we have used high-throughput next generation sequencing (NGS) techniques to explore the total and the active prokaryotic biodiversity of sediment from Lonar crater lake. High-throughput sequencing is also deployed to follow the community dynamics of prokaryotes during microenvironmental $\mathrm{pH}$ homeostasis and direct metagenome analysis. With the advance in high-throughput sequencing techniques, it is possible to produce an enormous volume of data cheaply (Metzker 2010). In this study, we have used two different high-throughput sequencing platform, both based on 'sequencing by synthesis' principle of Melamade(Melamade 1985, Hyman 1988). One is Roche GS-FLX 454 pyrosequencer, and the other is Illumina MiSeq.

\subsubsection{SEQUENCING BY ILLUMINA MISEQ}

In the case of Illumina, solid-phase amplification PCR is used for clonal amplification of templates to yield arbitrarily distributed clusters on a glass slide. Forward and reverse primers are covalently attached to the slide. The primer-template ratio delimits density of the amplified clusters. This process results in hundreds of millions spatially distinct template clusters. Illumina uses a four-color cyclic reversible terminator (CRT) chemistry that includes four different fluorescently labeled nucleotide incorporation, fluorescence imaging, and cleavage repeatedly (Metzker 2005). A DNA polymerase, attached to the primed template, adds only one fluorescently modified nucleotide, which represents the complement of the template base. The DNA synthesis is termination after the addition of a single nucleotide. The remaining unincorporated nucleotides are discarded. After that imaging is performed to identify the incorporated nucleotide. Then a cleavage step removes the terminating or inhibiting group along with the fluorescent dye. After washing, next cycle is performed. In this way, one nucleotide per cycle, the sequence is determined. Four colors are detected by total internal reflection fluorescence imaging using two lasers (Metzker 2010). 


\subsubsection{SEQUENCING By ROCHE GS-FLX 454 PyROSEQUENCER}

In the case of Roche, emulsion PCR (emPCR) is used to amplify the templates clonally. Universal priming sites of adaptors are ligated to the target ends; the DNA strands are separated and arrested onto beads as one DNA molecule per bead. After emPCR beads are amplified and enriched, they are deposited on individual picotiter plate (PTP) wells (Leamon, Lee et al. 2003, Metzker 2010). The NGS chemistry is performed in these wells. Smaller beads with attached sulfurylase and luciferase are loaded into wells surrounding the larger template beads. Different dNTPs are then flowed through the wells and dispensed in a predetermined chronological order. The sequencing chemistry of Roche is a non-electrophoretic, bioluminescence scheme that measures the release of inorganic pyrophosphate, that is pyrosequencing, by proportionately translating it into a visible light signal using a series of enzymatic reactions (Ronaghi, Karamohamed et al. 1996, Ronaghi, Uhlen et al. 1998). This bioluminescence is imaged with a charge-coupled device camera.

\subsection{AnAlysis Of SEQUENCING DATA}

\subsubsection{Analysis Of Sequencing Of PARTIAL 16S RRNA Gene Data FROM ILLUMINA PLATFORM}

Raw sequence data from samples of the total and the active community diversity was extracted from Illumina MiSeq. Datasets, generated from MiSeq sequencing, of partial 16S rRNA gene, were processed with Usearch version 8.0.1623 (Edgar 2010, Edgar and Flyvbjerg 2015). Paired-end reads were merged and quality filtered. Filtering included the removal of reads shorter than $400 \mathrm{bp}$. Processed sequences of all samples were joined and clustered into operational taxonomic units (OTUs) at $3 \%$ genetic dissimilarity using the UPARSE algorithm (Edgar 2013) implemented in USEARCH. A denovo chimera removal was included in the clustering step. Afterward, putative chimeric sequences were removed using UCHIME (Edgar, Haas et al. 2011) in reference mode. It was done with the 
SILVA database (Silva SSURef 123 NR) (Quast, Pruesse et al. 2013, Yilmaz, Parfrey et al. 2014) as reference dataset (Camacho, Coulouris et al. 2009). Subsequently, processed sequences were mapped to OTU sequences to obtain an OTU table. Taxonomy was determined by the representative sequence of each OTU classified by BLAST alignment against the most recent SILVA database (see above). All non-Bacterial or non-Archaeal OTUs were removed. Alpha diversity indices and rarefaction curves were calculated with QIIME version 1.9 (Caporaso, Kuczynski et al. 2010) as described by Wemheuer et al. (Wemheuer, Taube et al. 2013).

\subsubsection{Analysis Of Sequencing Of Partial 16S rRNA Gene Data FROM ROCHE PLATFORM}

Raw sequence data from samples of additional total diversity survey was extracted from Roche GS-FLX 454 pyrosequencer. Sequences with shorter read than 300bp, with an average quality value below 25 , sequences with number of ambiguous base exceeding 6 , possessing long homopolymer stretches (>8bp) and primer mismatches $(>3)$ were removed. These sequences were denoised using Acacia denoiser (Bragg, Stone et al. 2012). Remaining primer sequences were truncated from the obtained reads with Cutadapt (Martin 2011). Chimeric sequences were also removed using UCHIME and the current greengenes core set as reference dataset (DeSantis, Hugenholtz et al. 2006, Edgar, Haas et al. 2011). Processed sequences of all samples were joined, sorted by decreasing the length, and clustered employing the UCLUST algorithm (Edgar 2010). Sequences were clustered into operational taxonomic units (OTUs) at $3 \%$ genetic divergence according to Simon et al. (Simon, Wiezer et al. 2009). OTUs at 3 \% divergences represent species level (Schloss and Handelsman 2005). The phylogenetic composition was determined using the QIIME (Version 1.9) assign_taxonmy.py script (Caporaso, Kuczynski et al. 2010). A BLAST alignment against the Silva SSURef 123 NR database (Pruesse, Quast et al. 2007) was thereby performed. Sequences were classified as per the Silva taxonomy of their best hit. Rarefaction curves, Shannon indices (Shannon 2001) and Chao1 indices (Chao and Bunge 2002) were calculated. 


\subsubsection{Analysis Of Direct Metagenome Sequencing Data From ILLUMINA PLATFORM}

Reads were obtained from the direct sequencing of the Lonar metagenome and filtered with Trimmomatic v.0.30(Bolger, Lohse et al. 2014). Assembling of this metagenomic data was performed with SPAdes, v 3.7.0, (Bankevich, Nurk et al. 2012, Nurk, Bankevich et al. 2013) using its metaSPAdes function and default settings. Resulting contigs were analyzed for predicted ORFs (Open Reading Frame) with Prodigal (Prokaryotic Dynamic Programming Gene Finding Algorithm), v 2.6.0 (Hyatt, Chen et al. 2010) using recommended mode for metagenome, Anonymous mode. All the protein translation results of these ORFs from Prodigal are annotated and analyzed using GhostKOALA, v 2.0 (Kanehisa, Sato et al. 2016), a KEGG (Kyoto Encyclopedia of Genes and Genomes) tool for functional characterization of the genome and metagenome sequences. Reconstruction of Genes or proteins (KEGG GENES), KO groups (KEGG ORTHOLOGY), KEGG modules, functional hierarchy (KEGG BRITE) and pathway maps (KEGG PATHWAY) were also obtained from the GhostKOALA service by KEGG. 
$\underline{\text { Results and Discussion }}$ 


\section{RESULTS AND DISCUSSION}

\subsection{Description Of Sediment SAMPLES From Lonar Crater LAKE}

The coordinates of Lonar 1, Lonar 2 and Lonar 3 (as described in 3.1) were 19.58'20.65"N $76^{\circ} 30^{\prime} 22.74^{\prime \prime} \mathrm{E}, 19^{\circ} 58^{\prime} 36.70^{\prime \prime} \mathrm{N} 76^{\circ} 30^{\prime} 45.19^{\prime \prime} \mathrm{E}$ and $19^{\circ} 58^{\prime} 47.82^{\prime \prime} \mathrm{N} 76^{\circ} 30^{\prime} 17.50^{\prime \prime} \mathrm{E}$. Their respective $\mathrm{pH}$ and temperature were found to be $\mathrm{pH} 9.7, \mathrm{pH} 10.2, \mathrm{pH} 10.3$ and $27.2{ }^{\circ} \mathrm{C}$, $28.5^{\circ} \mathrm{C}, 28.3^{\circ} \mathrm{C}$. Lonar 1 , Lonar 2 and Lonar 3 were mixed thoroughly $\mathrm{w} / \mathrm{w}$ and analyzed to determine an overview of physicochemical parameters of Lonar lake sediment (Table 24). All samples were stored at $-80^{\circ} \mathrm{C}$ until further processing.

Table 24: Physicochemical Parameters of Lonar Sediment

\begin{tabular}{|c|c|c|c|}
\hline Parameter & Unit & Measuring Value & Detection Limit \\
\hline Ash $815^{\circ} \mathrm{C}$ (FG) & $\%$ of Wet Weight & 57.9 & \\
\hline Ash $815^{\circ} \mathrm{C}$ (FG) & $\%$ of Dry Weight & 97.3 & \\
\hline Carbon & $\%$ of Wet Weight & 0.8 & \\
\hline Carbon & $\%$ of Dry Weight & 1.3 & \\
\hline Hydrogen & $\%$ of Wet Weight & 0.1 & \\
\hline Hydrogen & $\%$ of Dry Weight & 0.1 & \\
\hline Nitrogen & $\%$ of Wet Weight & 0.2 & \\
\hline Nitrogen & $\%$ of Dry Weight & 0.3 & \\
\hline Oxygen & $\%$ of Wet Weight & 0.6 & \\
\hline Oxygen & $\%$ of Dry Weight & 1 & \\
\hline Sulphur & $\%$ of Wet Weight & 0 & \\
\hline Sulphur & $\%$ of Dry Weight & 0 & \\
\hline Aluminium & $\mathrm{mg} / \mathrm{L}$ & 0.18 & 0.02 \\
\hline Antimony & $\mathrm{mg} / \mathrm{L}$ & $<0.010$ & 0.01 \\
\hline Arsenic & $\mathrm{mg} / \mathrm{L}$ & $<0.010$ & 0.01 \\
\hline
\end{tabular}




\begin{tabular}{|c|c|c|c|}
\hline Parameter & Unit & Measuring Value & Detection Limit \\
\hline Barium & $\mathrm{mg} / \mathrm{L}$ & $<0.0050$ & 0.005 \\
\hline Beryllium & $\mathrm{mg} / \mathrm{L}$ & $<0.001$ & 0.001 \\
\hline Boron & $\mathrm{mg} / \mathrm{L}$ & 0.89 & 0.02 \\
\hline Cadmium & $\mathrm{mg} / \mathrm{L}$ & $<0.001$ & 0.001 \\
\hline Calcium & $\mathrm{mg} / \mathrm{L}$ & 6 & 0.1 \\
\hline Chromium & $\mathrm{mg} / \mathrm{L}$ & $<0.005$ & 0.005 \\
\hline Copper & $\mathrm{mg} / \mathrm{L}$ & 0.089 & 0.005 \\
\hline Iron & $\mathrm{mg} / \mathrm{L}$ & $<0.005$ & 0.005 \\
\hline Lead & $\mathrm{mg} / \mathrm{L}$ & $<0.01$ & 0.01 \\
\hline Lithium & $\mathrm{mg} / \mathrm{L}$ & $<0.02$ & 0.02 \\
\hline Magnesium & $\mathrm{mg} / \mathrm{L}$ & 0.56 & 0.1 \\
\hline Manganese & $\mathrm{mg} / \mathrm{L}$ & $<0.005$ & 0.005 \\
\hline molybdenum & $\mathrm{mg} / \mathrm{L}$ & 0.029 & 0.005 \\
\hline Nickel & $\mathrm{mg} / \mathrm{L}$ & $<0.005$ & 0.005 \\
\hline Phosphorus & $\mathrm{mg} / \mathrm{L}$ & 1.57 & 0.05 \\
\hline Potassium & $\mathrm{mg} / \mathrm{L}$ & 4.3 & 0.1 \\
\hline Selenium & $\mathrm{mg} / \mathrm{L}$ & $<0.01$ & 0.01 \\
\hline Sodium & $\mathrm{mg} / \mathrm{L}$ & 374 & 0.1 \\
\hline Strontium & $\mathrm{mg} / \mathrm{L}$ & 0.0289 & 0.005 \\
\hline Thallium & $\mathrm{mg} / \mathrm{L}$ & $<0.005$ & 0.005 \\
\hline Tin & $\mathrm{mg} / \mathrm{L}$ & $<0.0$ & 0.005 \\
\hline Titanium & $\mathrm{mg} / \mathrm{L}$ & $<0.02$ & 0.02 \\
\hline Vanadium & $\mathrm{mg} / \mathrm{L}$ & 0.98 & 0.005 \\
\hline Zinc & $\mathrm{mg} / \mathrm{L}$ & 0.039 & 0.01 \\
\hline
\end{tabular}


The physicochemical parameters of the sediments samples that we collected differ from some of the other studies in certain aspects, particularly Sulphur, Iron and Nickel. In our analysis, we failed to detect these elements whereas in the studies from 2006 (Wani, Surakasi et al. 2006) and 2015 (Paul, Kumbhare et al. 2015) these elements have been detected. Sulfates as high as $53.84 \mathrm{mg} / \mathrm{L}$, Iron as high as $7.9 \mathrm{~g} / \mathrm{L}$ and Nickel as high as 8.25 $\mathrm{mg} / \mathrm{L}$ has been reported from these studies from 2006 and 2015.

\subsection{The Total And The Active Prokaryotic Diversity Of LonAR CRATER LAKE}

\subsubsection{General Analyses Of The Total And The Active Community SEQUENCING DATA}

The significant benefit of illumine sequencing technique is the assembly of paired-end reads. This assembly prominently decreases the number of erroneous sequences included in downstream analyses (Bartram, Lynch et al. 2011). Significantly low total error rates, between 0.0030 and 0.0049, has been reported for Illumina MiSeq (Ross, Russ et al. 2013). As described in 3.10 .1 and 3.13.1, V3-V4 region of the 16S rRNA gene was amplified and sequenced. Reads shorter than 400bp was removed. Processed sequences of all samples were joined and clustered into operational taxonomic units (OTUs) at $3 \%$ genetic dissimilarity using the UPARSE algorithm (Edgar 2013) implemented in USEARCH. The analysis method is provided in 3.14.1. A total of 12 samples ( 3 sediments $X 2$ types of target domains $X 2$ types of template DNA) as described in 3.10.1 and 3.10.2. In 6 samples of the total diversity assessment, a total of 31,650 and 59,079 of archaeal and bacterial sequences were found. It ranges from 11,664 to 5,567 with an average of 10,550 in Archaea and in Bacteria it varies from 26,430 to 13,979 with an average of 19,693. In the case of 6 samples of the active community diversity, a total of 20,724 and 71,205 of archaeal and bacterial sequences were found. It ranges from 9,691 to 4,907 with an average of 6,908 for Archaea and for Bacteria it is 28,270 to 16,079 with an average of 23,735 . 


\subsubsection{PRokaryotic Diversity AND RICHNESS}

All the OTUs were identified at genetic distances of $3 \%$ by using 4,907 randomly selected and denoised sequences per sample for Archaea and 13,979 sequences per sample for Bacteria were used. These OTUs were used to determine rarefaction curves, richness, and diversity. At $3 \%$ genetic distance all rarefaction curves attain a significant level of saturation, indicating that the surveying effort covered a substantial range of taxonomic diversity present in the samples at this genetic distance (Figure 6).

Rarefaction Curves for Archaea

(Genetic Distance 3\%) - Lonar 1 - Lonar 2 - Lonar 3
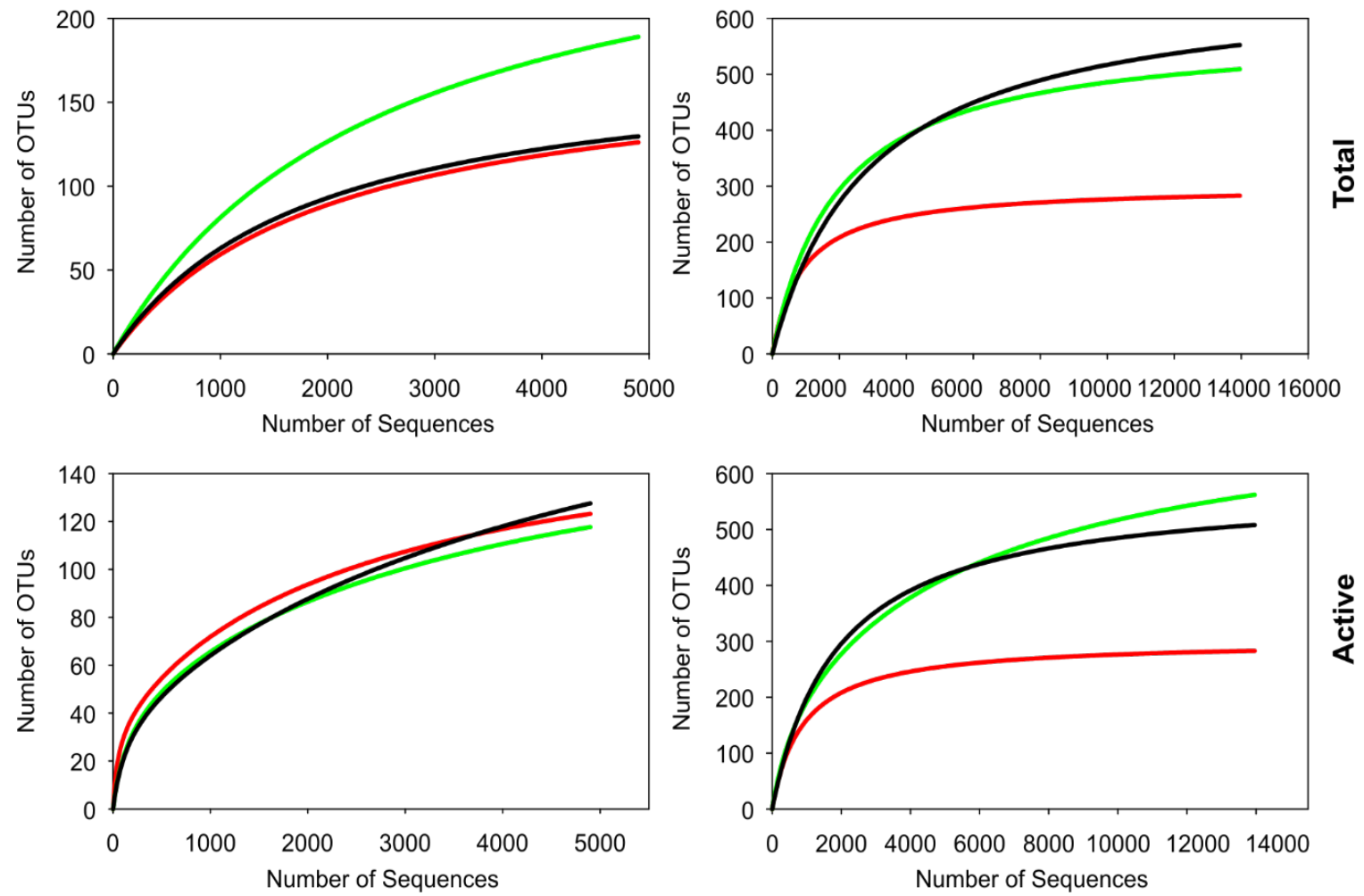

Figure 6: Rarefaction Curves indicating The Observed number of Operational TAXonomic Units (OTUS) In the Total AND the Active Community StUdy. Three different samples are indicated in red, green and black respectively for Lonar 1, Lonar 2 and Lonar 3. The curves indicate gradual saturation in the number of OTUs with an increase in the number of sequences examined. On the left rarefaction curves for Archaea and on the right for Bacteria, all the curves are at $3 \%$ genetic distances. 
Evaluation of the rarefaction analyses with the number of OTUs determined by Max. clusters $\left(n_{\max }\right)$ revealed that among Archaea, the total and the active community diversity covered $74.21 \%( \pm 1.83)$ and $84.07 \%( \pm 3.52)$ of the estimated complete diversity. In the case of Bacteria the total and the active community diversity covered $59.78 \%( \pm 2.24)$ and $88.98 \%$ ( \pm 3.96$)$. Highest coverage in Bacteria among all samples was observed in the active community of Lonar 1, $93.95 \%$. Lowest coverage was found in the total diversity of Lonar 2 for Bacteria, $56.61 \%$. Thus, we did not survey the full extent of taxonomic diversity at these genetic distances, but the surveying efforts assessed a substantial fraction of the prokaryotic diversity within individual sediment samples. In samples of the total and the active community diversity, variation in the number of OTUs is observed (Figure 7).
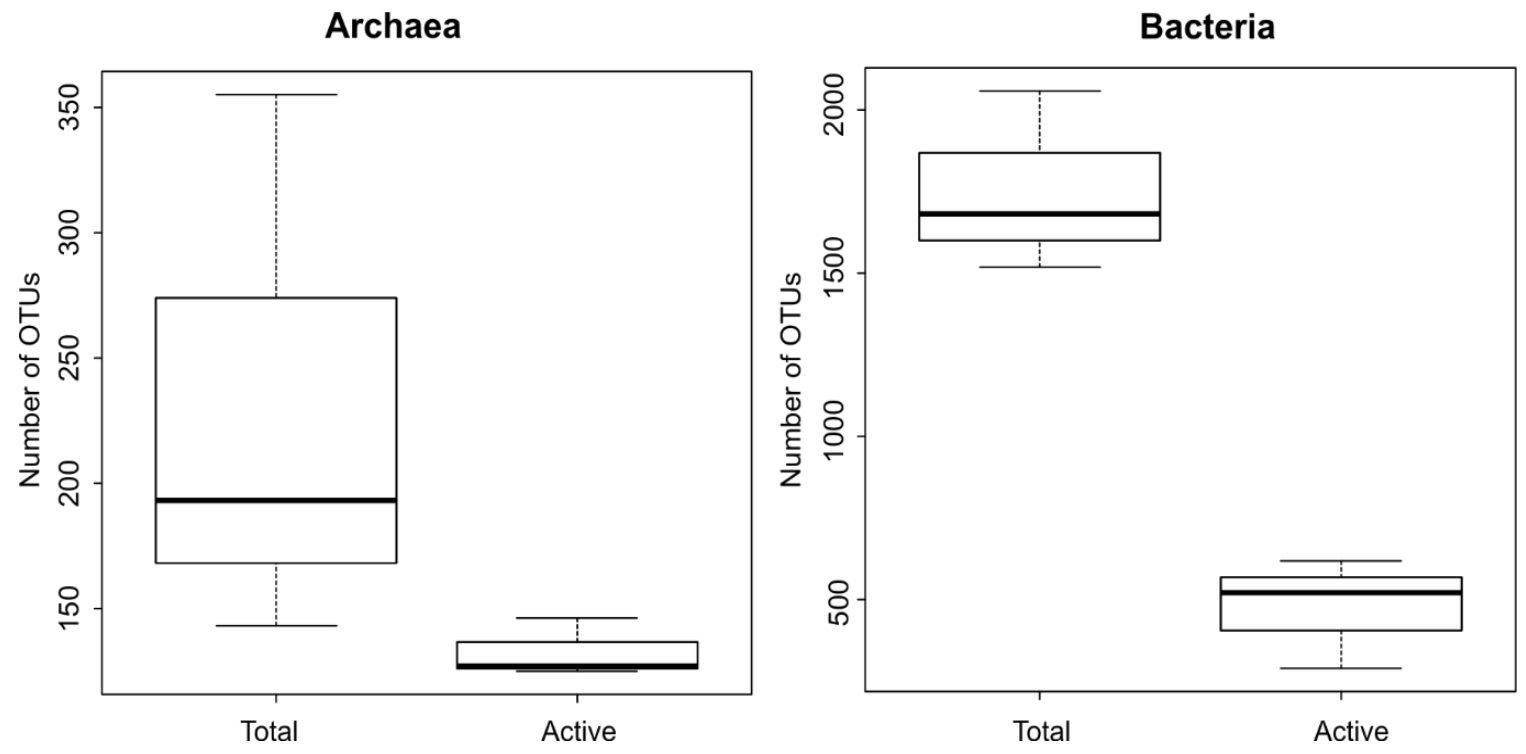

FigURE 7: BOXPLOT DIAGRAM OF THE NUMBER OF TAXONOMIC UNITS (OTUS) AT THE SPECIES LEVEL IN DIFFERENT SAMPLING EFFORTS. On the left is the boxplot diagram for Archaea and on the right is for Bacteria.

In the survey of the total diversity, the highest number of unique OTUs in Archaea and Bacteria were found from Lonar 2 and Lonar 1 of 355 OTUs and 2,057 OTUs respectively. Among the active community, the highest number of OTUs in Archaea and Bacteria were observed in Lonar 1 and Lonar 3 of 146 OTUs and 618 OTUs respectively. Most of the OTUs derived from all the samples shows that majority of them are not cultured (Figure 8). One noteworthy observation in this regard is that the total archaeal diversity has more cultured representatives than the active archaeal diversity. However, in the case of Bacteria, the active community diversity is better represented in terms of closely related 
cultured members than in the total diversity. In archaeal samples, the average percentage of cultured OTUs in the total and the active community diversity was found to be $32.11 \%$ $( \pm 13.21)$ and $17.6 \%( \pm 4.56)$. In the case of Bacteria, we observed, the average percentage of cultured OTUs in the total and the active community diversity of $26.25 \%( \pm 8.14)$ and $48.75 \%$ ( \pm 8.04$)$. Among all the observations highest percentage of cultured prokaryotes, $59.95 \%$, was found in the active bacterial community of Lonar 3 sediment. Lowest percentage of cultured prokaryotes were observed in the active archaeal community of Lonar 3 sediment. These observations indicate that bacterial community of soda lakes are better investigated than archaeal community. Also, the majority of the prokaryotes do not have a cultured representative.

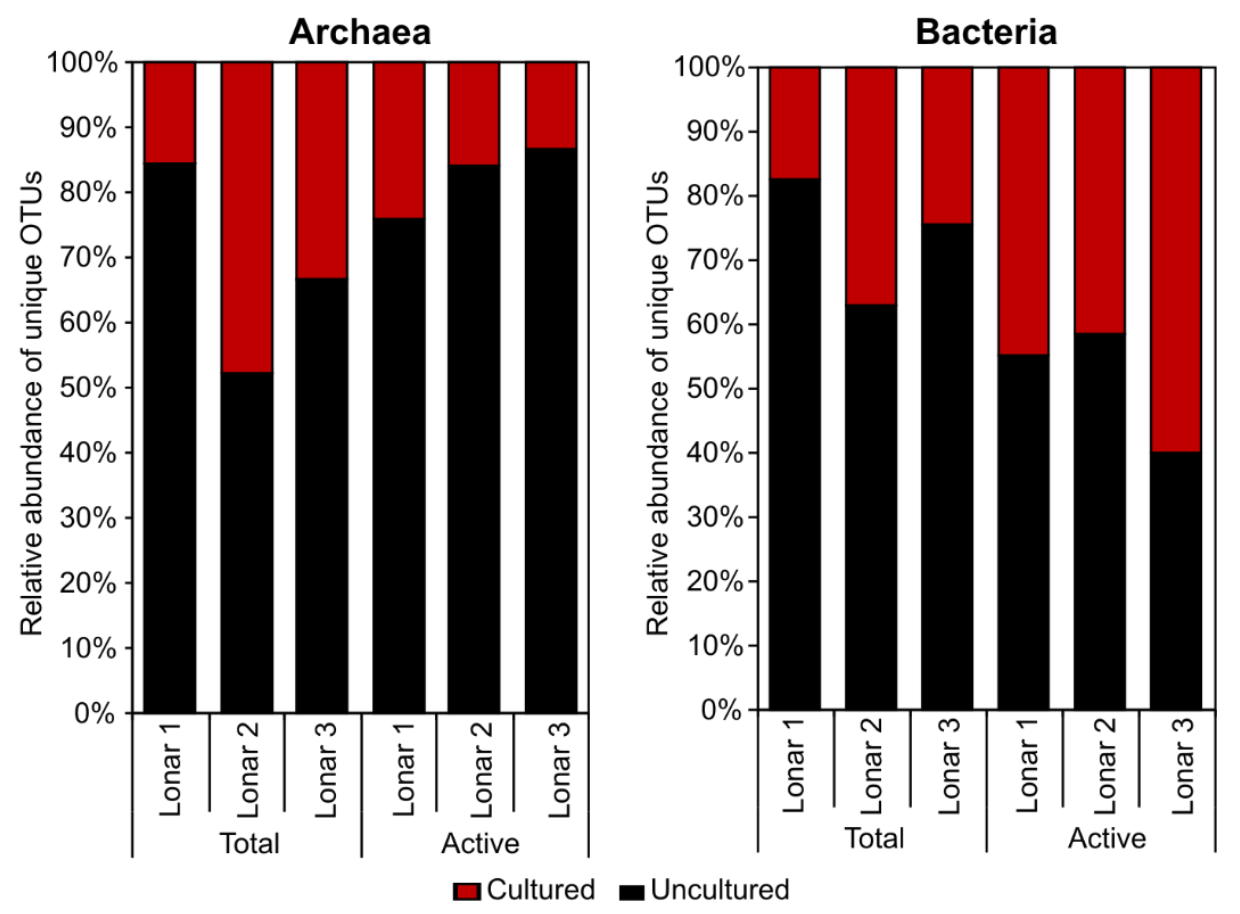

Figure 8: Relative distribution of UNCULtURED AND CULTUREd unique OTUs. On the left distribution of uncultured and cultured unique OTUs among Archaea is shown. On the right distribution of uncultured and cultured unique OTUs among Bacteria is shown.

Details of all 12 individual observations with their Observed clusters, Max. clusters ( $\mathrm{n}_{\max }$ ), Coverage (\%), Shannon index $\left(\mathrm{H}^{\prime}\right)$ and Chao1 are given in Table 25. The comparison of coverage of all the 12 observations highest 5 covered samples shows that all 5 are from the active community. It indicates that, in our survey, the active community is more widely covered than the total diversity. Also, this observation signifies that the 
total diversity is more diverse than the active community, and all the prokaryotes of the sediment may not be active at the time of collection. Out of these 5 observations, only 2 are from Archaea and 3 from Bacteria. In our assessment Bacteria is better covered than Archaea. It may be a result of recovering more bacterial sequences than Archaeal. The coverage of these samples ranged from $93.96 \%$ to $84.27 \%$. The comparison of Shannon index from all 12 observations revealed that out of highest indexed 5 samples 3 of them were from the total diversity and 2 of them were from the active community. It indicates that the total diversity is more diverse than the active community. Also, we noticed that all of these 5 observations were from Bacteria, which signifies that bacterial diversity is more than archaeal in this habitat. Highest Shannon index was observed to be 7.762 in the total diversity of Lonar 3 Bacteria. In the case of Chao 1 among the 5 with highest values are all from Bacteria. 3 of which are from the total diversity and other 2 are from the active community diversity. In these 5 samples, Chao 1 values are between 3,755.51 to 545.27. From all the Observed clusters, Max. clusters (nmax), Shannon index $\left(H^{\prime}\right)$ and Chao1, sediments of Lonar 3 and Lonar 2 tends to be more diverse than Lonar 1 sediments.

Table 25: General Analysis of the Sequence Data.

\begin{tabular}{|c|c|c|c|c|c|c|}
\hline Sample & & $\begin{array}{l}\text { Observed } \\
\text { clusters }\end{array}$ & $\begin{array}{l}\text { Max. } \\
\text { clusters } \\
\left(n_{\max }\right)\end{array}$ & $\begin{array}{l}\text { Coverage } \\
(\%)\end{array}$ & $\begin{array}{l}\text { Shannon } \\
\text { index } \\
\left(H^{\prime}\right)\end{array}$ & Chao1 \\
\hline \multirow[t]{8}{*}{ Total } & $\begin{array}{l}\text { Lonar } 1 \\
\text { (Archaea) }\end{array}$ & 131.6 & 177.49 & 74.14 & 3.01 & 225.52 \\
\hline & $\begin{array}{l}\text { Lonar } 2 \\
\text { (Archaea) }\end{array}$ & 191.9 & 266.52 & 71.99 & 3.75 & 453.88 \\
\hline & $\begin{array}{l}\text { Lonar } 3 \\
\text { (Archaea) }\end{array}$ & 135 & 176.47 & 76.49 & 3.67 & 226.82 \\
\hline & Mean & 152.83 & 206.83 & 74.21 & 3.48 & 302.08 \\
\hline & SD & 27.65 & 42.21 & 1.83 & 0.33 & 107.34 \\
\hline & $\mathrm{CV}$ & 0.18 & 0.20 & 0.02 & 0.09 & 0.35 \\
\hline & $\begin{array}{l}\text { Lonar } 1 \\
\text { (Bacteria) }\end{array}$ & 1405 & 2292.51 & 61.28 & 7.50 & 3491.55 \\
\hline & $\begin{array}{l}\text { Lonar } 2 \\
\text { (Bacteria) }\end{array}$ & 1405.3 & 2482.00 & 56.61 & 6.75 & 3557.27 \\
\hline
\end{tabular}




\begin{tabular}{|c|c|c|c|c|c|c|}
\hline Sample & & $\begin{array}{l}\text { Observed } \\
\text { clusters }\end{array}$ & $\begin{array}{l}\text { Max. } \\
\text { clusters } \\
\left(n_{\max }\right)\end{array}$ & $\begin{array}{l}\text { Coverage } \\
(\%)\end{array}$ & $\begin{array}{l}\text { Shannon } \\
\text { index } \\
\left(H^{\prime}\right)\end{array}$ & Chao1 \\
\hline \multirow[t]{3}{*}{ Total } & $\begin{array}{l}\text { Lonar } 3 \\
\text { (Bacteria) }\end{array}$ & 1518 & 2469.82 & 61.46 & 7.76 & 3755.51 \\
\hline & Mean & 1442.76 & 2414.77 & 59.78 & 7.33 & 3601.44 \\
\hline & SD & 53.19 & 86.59 & 2.24 & 0.42 & 112.19 \\
\hline \multirow[t]{2}{*}{ Sample } & & $\begin{array}{l}\text { Observed } \\
\text { clusters }\end{array}$ & $\begin{array}{l}\text { Max. } \\
\text { clusters } \\
\left(n_{\max }\right)\end{array}$ & $\begin{array}{l}\text { Coverage } \\
(\%)\end{array}$ & $\begin{array}{l}\text { Shannon } \\
\text { index } \\
\left(H^{\prime}\right)\end{array}$ & Chao1 \\
\hline & $\mathrm{CV}$ & 0.03 & 0.03 & 0.03 & 0.05 & 0.03 \\
\hline \multirow[t]{12}{*}{ Active } & $\begin{array}{l}\text { Lonar } 1 \\
\text { (Archaea) }\end{array}$ & 123.3 & 140.31 & 87.87 & 4.41 & 145.78 \\
\hline & $\begin{array}{l}\text { Lonar } 2 \\
\text { (Archaea) }\end{array}$ & 118.2 & 139.13 & 84.95 & 3.79 & 157.32 \\
\hline & $\begin{array}{l}\text { Lonar } 3 \\
\text { (Archaea) }\end{array}$ & 127 & 159.98 & 79.38 & 3.71 & 157.51 \\
\hline & Mean & 122.83 & 146.47 & 84.07 & 3.97 & 153.54 \\
\hline & SD & 3.60 & 9.56 & 3.52 & 0.31 & 5.48 \\
\hline & CV & 0.02 & 0.06 & 0.04 & 0.07 & 0.03 \\
\hline & $\begin{array}{l}\text { Lonar } 1 \\
\text { (Bacteria) }\end{array}$ & 283.7 & 301.93 & 93.95 & 5.69 & 291.22 \\
\hline & $\begin{array}{l}\text { Lonar } 2 \\
\text { (Bacteria) }\end{array}$ & 512.4 & 577.52 & 88.72 & 6.23 & 545.27 \\
\hline & $\begin{array}{l}\text { Lonar } 3 \\
\text { (Bacteria) }\end{array}$ & 559 & 663.35 & 84.26 & 5.74 & 628.31 \\
\hline & Mean & 451.7 & 514.27 & 88.98 & 5.89 & 488.27 \\
\hline & SD & 120.30 & 154.17 & 3.96 & 0.24 & 143.36 \\
\hline & $\mathrm{CV}$ & 0.26 & 0.29 & 0.04 & 0.04 & 0.29 \\
\hline
\end{tabular}




\subsubsection{Distribution Of TAXa ANd PhyLOtYPes}

\subsubsection{The Total And The Active Community Diversity Of ArchaeA}

Among Archaea, we were able to classify $99.91 \%$ and $98.94 \%$ of all the sequences above domain level in the total and the active community diversity respectively. All the archaeal OTUs were distributed to 10 Order or order-level taxa and 47 Genera. In the total and the active community 45 and 27 genera were observed. Relative abundances of archaeal orders are presented in Figure 9 and Figure 10. The genera are presented in Figure 11 and Figure 12. Details of the relative abundances of the orders and genera are provided in Table 33 and Table 34. Most dominant orders were Halobacteriales, Methanobacteriales, Methanomicrobiales, Thermoplasmatales, Methanosarcinales. 


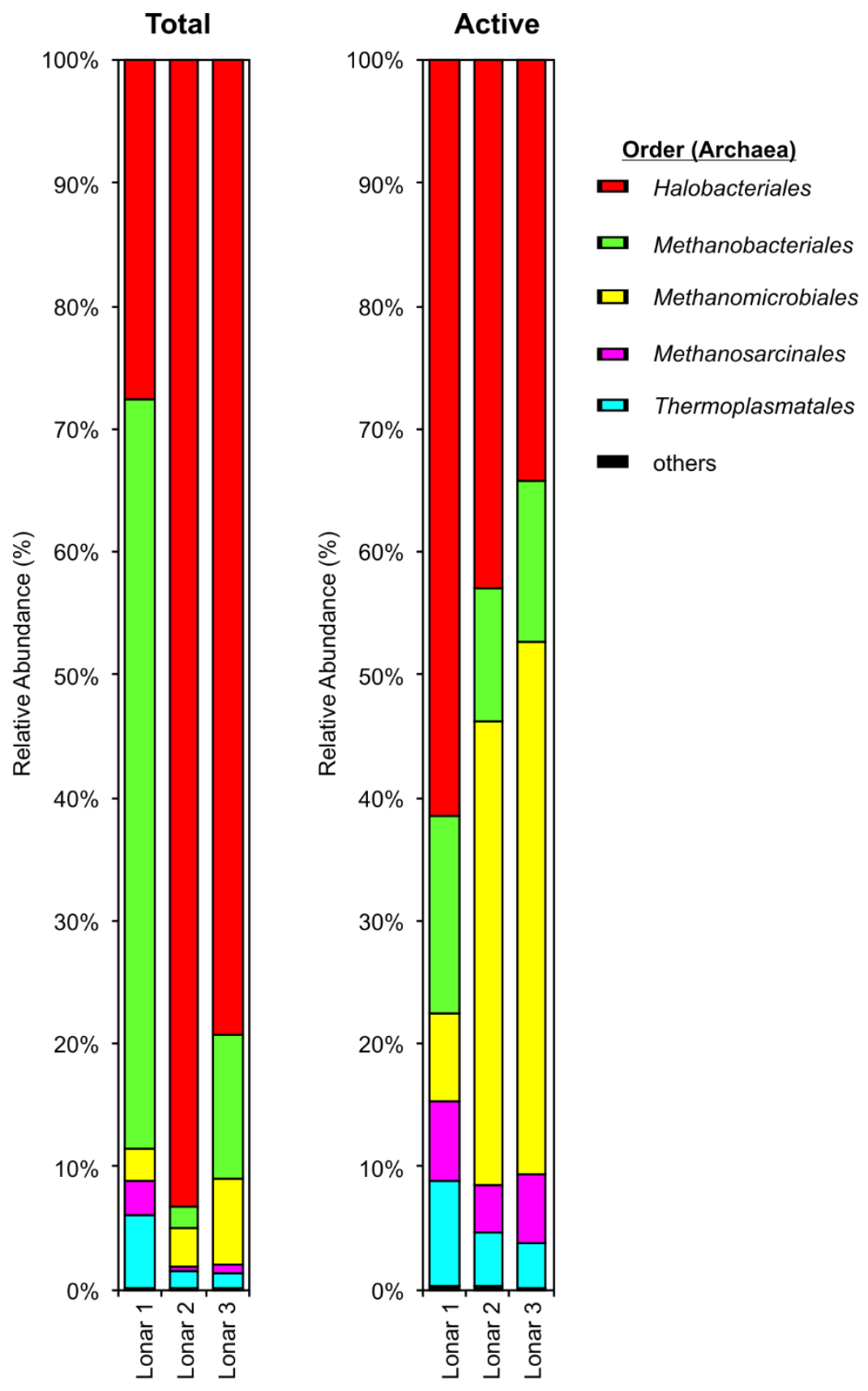

Figure 9: Relative AbUndances of ARChaeal ORders in Lonar SEDiments. Sample numbers indicating the different sediment samples are given below the respective bars. Orders are accounting for $<1 \%$ of all classified sequences are summarized in the artificial group 'others.' 

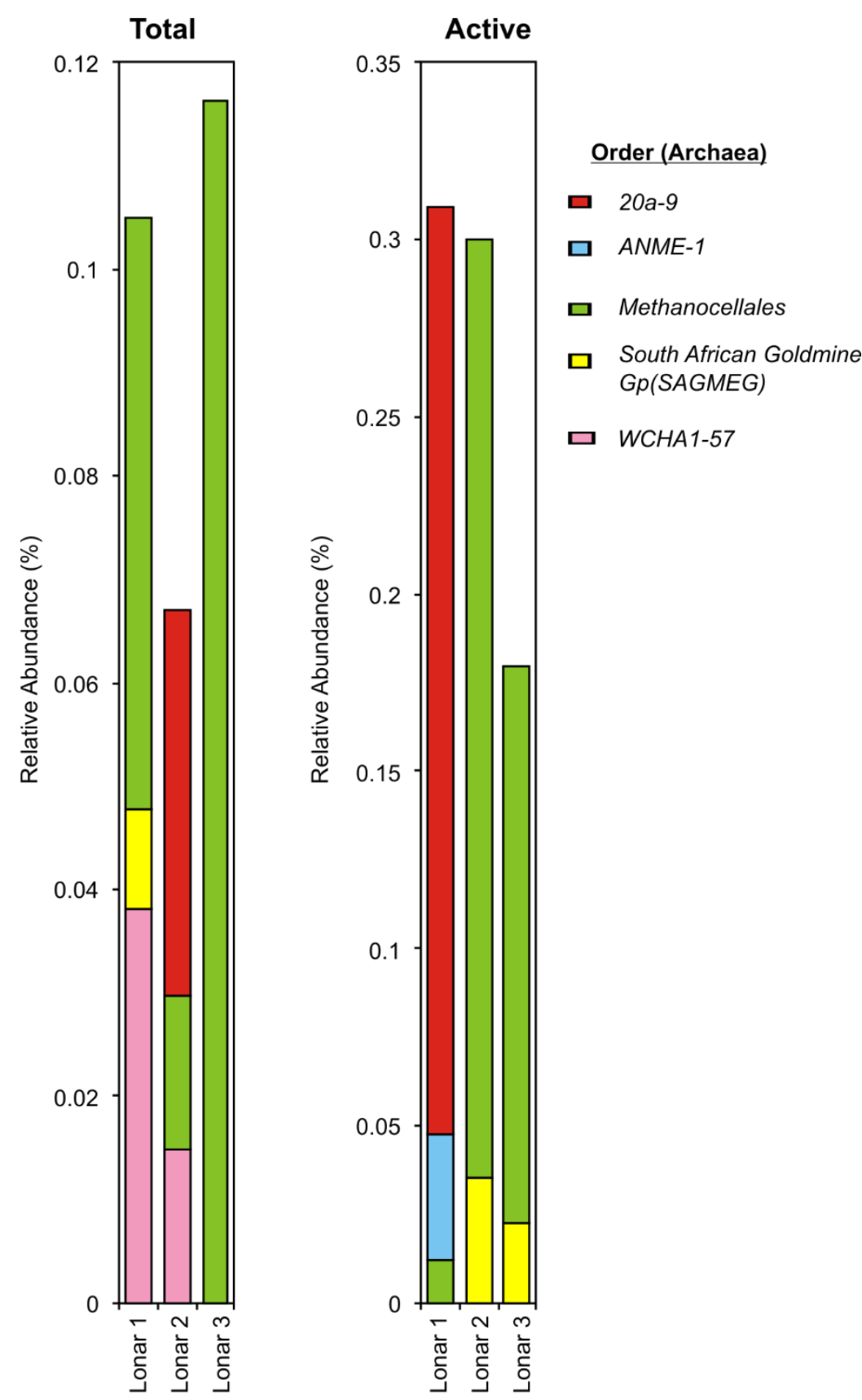

Figure 10: Relative abundances of the RARE ARChAeAL ORDER In LonAR Sediments. Sample numbers indicating the different sediment samples are given below the respective bars. Only the phylogenetic groups are accounting for $<1 \%$ of all classified sequences are shown.

In the total and the active community, Halobacteriales alone contribute to the average relative abundance of $66.73 \%$ and $46.18 \%$. Highest relative abundance, $93.31 \%$, of Halobacteriales was observed in the total diversity of Lonar 3 sediments, and lowest of $27.59 \%$ was found in the sediments of Lonar 1 . In the total diversity, the Halobacteriales were mostly represented by Natronococcus (72.28 \%), Haloterrigena (10.71\%) , Natrialba 
(2.66 \%), Halovivax (1.34 \%), and Natronorubrum (0.59\%). In case of the active community diversity, Natronococcus (50.78 \%) , Haloterrigena (5.87\%) , Halovivax (1.44 \%) , Natrialba (0.82 \%), and Natronorubrum (0.22 \%) represents the order Halobacteriales. Two novel haloalkaliphilic archaeon species of Natronococcus, Natronococcus amylolyticus sp. nov., and Natronococcus roseus sp. nov., has been isolated from Kenyan soda lake, Lake Magadi and sediments of the soda lake Chagannor, Inner Mongolia, China, they are able to grow at ph as high as pH 11 (Kanal, Kobayashi et al. 1995, Corral, Gutierrez et al. 2013). Members of the genus Haloterrigena are mostly halophilic and often alkaliphilic as well. Novel species of this genus has been isolated from soda lakes and are known to grow at $\mathrm{NaCl}$ concentrations as high as $4.5 \mathrm{M}, \mathrm{pH}$ as high as pH 11.(Ventosa, Gutierrez et al. 1999, Selim and Hagagy 2016). The novel genus Halovivax are mostly extremely halophilic and moderately alkaliphilic, they have been isolated from salt lakes of Iran and Inner Mongolia, China, they usually are able to grow at $\mathrm{pH}$ lower than pH 10.(Castillo, Gutierrez et al. 2006, Castillo, Gutierrez et al. 2007, Amoozegar, Makhdoumi-Kakhki et al. 2014, Amoozegar, Makhdoumi-Kakhki et al. 2015). However, Halovivax has also been reported from soda lakes, for example, Lake Elmenteita in Kenya(Mwirichia, Cousin et al. 2010). Novel species of Natrialba, Natrialba hulunbeirensis sp. nov., and Natrialba chahannaoensis sp. nov., has been reported from soda lakes of Inner Mongolia, China(Xu, Wang et al. 2001). Two novel haloalkaliphilic species of novel genus Natronorubrum, Natronorubrum bangense gen. nov., sp. nov., and Natronorubrum tibetense gen. nov., sp. Nov., have been isolated from the soda lakes of Tibet, with the ability to grow at $\mathrm{pH}$ as high as $\mathrm{pH} 11(\mathrm{Xu}$, Zhou et al. 1999).

In the total and the active community diversity the relative abundance of the order Methanobacteriales was found to be $24.75 \%$ and $13.34 \%$ respectively. Sediments of Lonar 1 shows the highest relative abundance of, $60.99 \%$, Methanobacteriales in the total diversity and lowest relative abundance, $1.66 \%$, was found in the sediments of Lonar 2 in the total diversity. The order Methanobacteriales was represented by the genera Methanobacterium (0.68\%), Methanobrevibacter (0.03\%), Methanosphaera $(0.01 \%)$ in the total community and Methanobrevibacter (16.90\%), Methanobacterium (2.01\%), in the active community diversity. We were unable to detect any Methanosphaera in the active community. Several methylotrophic novel species of Methanobacterium has been 
observed from various lake sediments. For example Methanobacterium movens sp. nov., Methanobacterium flexile sp. nov., Methanobacterium lacus sp. nov.,(Zhu, Liu et al. 2011, Borrel, Joblin et al. 2012, Schirmack, Mangelsdorf et al. 2014). Although they are not of significance in terms of alkaliphily, they are well-known methanogens. We found a paucity of available literature about the presence of Methanobrevibacter and Methanosphaera in soda lakes. Which is not surprising as there is a general lack of investigations on Archaea of soda lakes as compared to Bacteria. However, they are both well known for their methanogenic activity(van de Wijngaard, Creemers et al. 1991).

The order Methanomicrobiales was observed to be of $4.30 \%$ and $29.39 \%$ relative abundance in the total and the active community. Sediments of Lonar 3 showed the maximum abundance of Methanomicrobiales; that is $43.21 \%$ in the active community and lowest value of $2.58 \%$ was observed in sediments of Lonar 1 in the total diversity assessment. The order Methanomicrobiales, in the total diversity, was represented by the genera Methanocalculus (2.74 \%), Methanoculleus (0.05 \%) and Methanogenium (0.004 \%). In case of the active diversity, Methanomicrobiales was represented by Methanocalculus (5.87 \%), Methanocorpusculum (0.17\%), Methanospirillum (0.12 \%) and Methanoculleus (0.08 \%). Haloalkaliphilic methanogenic novel species, Methanocalculus alkaliphilus sp. nov., and Methanocalculus natronophilus sp. nov., of the genus Methanocalculus has been isolated from hypersaline soda lakes including Lonar with optimum growth $\mathrm{pH}$ between $\mathrm{pH} 9$ and pH 9.5(Surakasi, Wani et al. 2007, Zhilina, Zavarzina et al. 2013, Sorokin, Abbas et al. 2015). Several novel methanogen species of genus Methanocorpusculum has been isolated from various waterbodies but not from any soda lake(Zellner, Stackebrandt et al. 1989). Novel species of the genus Methanoculleus has been isolated from marine sediment as well as from Lonar before and they are methanogenic(Mikucki, Liu et al. 2003, Dabir, Honkalas et al. 2014, Weng, Chen et al. 2015). New methanogenic species, for example, Methanogenium frigidum sp. nov., Methanogenium marinum sp. nov., Methanogenium boonei sp. Nov., of the genus Methanogenium has been isolated mostly from marine and lake sediments, however, none has been isolated from soda lakes(Franzmann, Liu et al. 1997, Chong, Liu et al. 2002, Kendall, Wardlaw et al. 2007). Novel methanogenic species, Methanospirillum lacunae sp. nov., and Methanospirillum psychrodurum sp. nov., of the genus Methanospirillum has 
been isolated from soils but not from soda lakes mostly able to grow between pH 6.5 and pH 8(lino, Mori et al. 2010, Zhou, Liu et al. 2014).

Relative abundance of the order Thermoplasmatales was observed in the total and the active community to be $2.82 \%$ and $5.48 \%$ respectively. The highest relative abundance of $8.53 \%$ was found in the active community of Lonar 1 sediments, and lowest relative abundance of $1.18 \%$ was found in the sediments of Lonar 3 in the total diversity assessment. The order Thermoplasmatales is represented by the genus Methanomassiliicoccus in both the total and the active community diversity. Higher relative abundance was observed in the active community (0.72\%) than in the total diversity $(0.004 \%)$. Species of the genus Methanomassiliicoccus has been reported from sediments of estuary but not from any soda lake(Zhou, Chen et al. 2014).

In the total and the active community diversity the relative abundance of the order Methanosarcinales was found to be $1.27 \%$ and $5.32 \%$ respectively. Maximum relative abundance was noticed in the active community of Lonar 1 sediments to be $6.49 \%$. The sediments of Lonar 2 in the total diversity showed the lowest relative abundance of 0.32 $\%$. They are mostly represented by Methanosaeta (4.93 \%), Methanosarcina $(0.32 \%)$, Methanolobus (0.01\%), Methanococcoides (0.004 \%) and Methermicoccus $(0.004 \%)$ in the total diversity. In the active community, they are mostly represented by Methanosaeta (14.89\%), Methanosarcina (1.88 \%) and Methanolobus (0.07\%). Methanosaeta has been reported from the soda lakes of Kulunda Steppe, Altai, Russia able to function as methanogenic Archaea between pH 8 and pH 10.5(Sorokin, Abbas et al. 2015). Several methanogenic species of Methanosarcina has been isolated and reported from various lake sediments including Lonar(Cairo, Clarens et al. 1992, Simankova, Parshina et al. 2001, Antony, Kumaresan et al. 2013, Ganzert, Schirmack et al. 2014). Methanogenic species of Methanolobus has been found in soda lakes of Kulunda Steppe, Altai, Russia and also from Lonar(Antony, Murrell et al. 2012, Sorokin, Abbas et al. 2015). Methanogenic species of Methanococcoides has been isolated from marine, lake and estuarine sediments but not from soda lakes(Singh, Kendall et al. 2005, Lyimo, Pol et al. 2009, Ticak, Hariraju et al. 2015). The novel methanogenic genus Methermicoccus with only one species, Methermicoccus shengliensis gen. nov., sp. nov., 
has only been isolated from Shengli oilfield, China. No species of Methermicoccus have been isolated or reported from soda lakes.
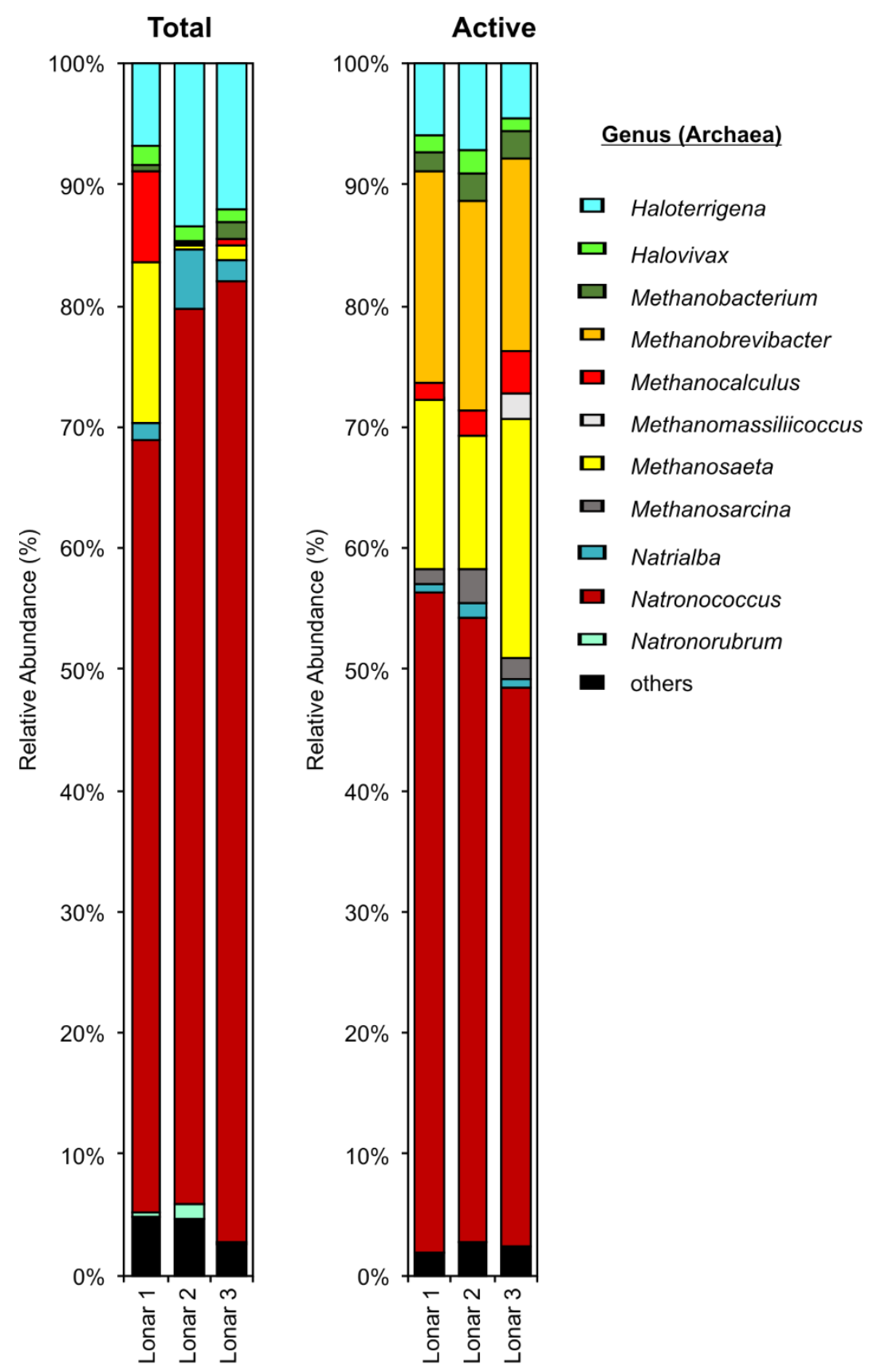

Figure 11: Relative abUndances of the most abUndant aRCHAEAL genera in Lonar SEDIMENTS. Sample numbers indicating the different sediment samples are given below the respective bars. Only the phylogenetic groups accounting for $>1 \%$ of all classified sequences are shown. 


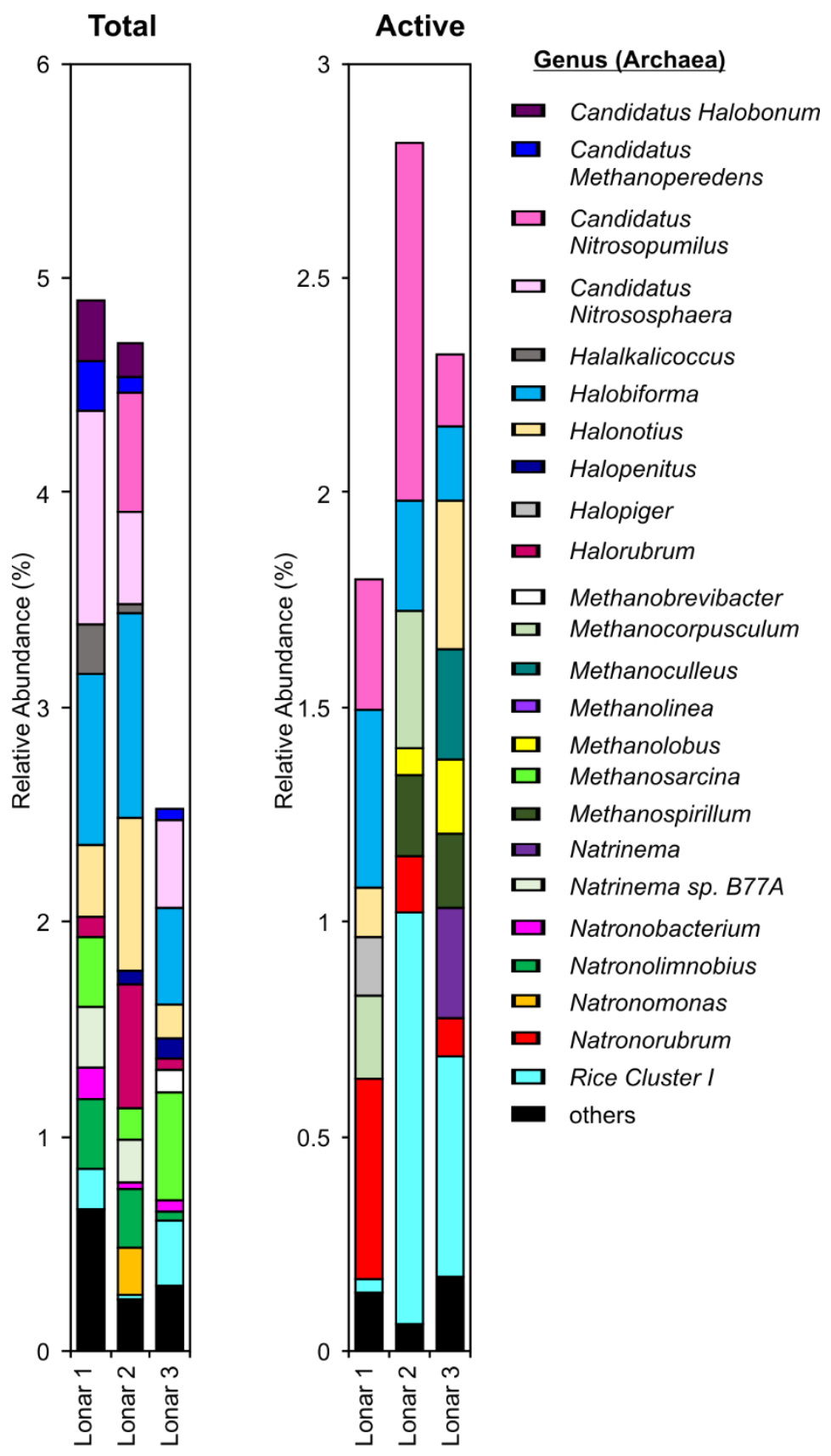

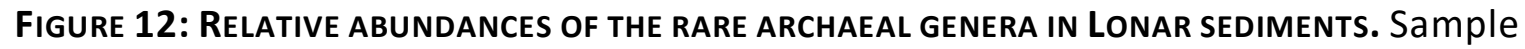
numbers indicating the different sediment samples are given below the respective bars. Only the phylogenetic groups, accounting for $<1 \%$ of all classified sequences are shown. 


\subsubsection{The Total And The Active Community Diversity Of Bacteria}

All the bacterial sequences have been classified above domain level. All the bacterial OTUs were distributed to 47 phylum or phylum-level taxa and 386 genera or genera level taxa in the total diversity. In the case of the active community, all the OTUs were distributed to 40 phylum or phylum-level taxa and 236 genera or genera level taxa. Relative abundances of these phyla and genera are presented in the Figure 13, Figure 14 and Figure 15, Figure 16. Details of the relative abundances of the phyla and genera are provided in Table 35 and Table 36. Most dominant phyla in the total diversity are Firmicutes, Actinobacteria, Chloroflexi, Proteobacteria and Gemmatimonadetes. In the active community, most dominant phyla are Firmicutes, Actinobacteria, Proteobacteria, Chloroflexi and Deinococcus-Thermus. 


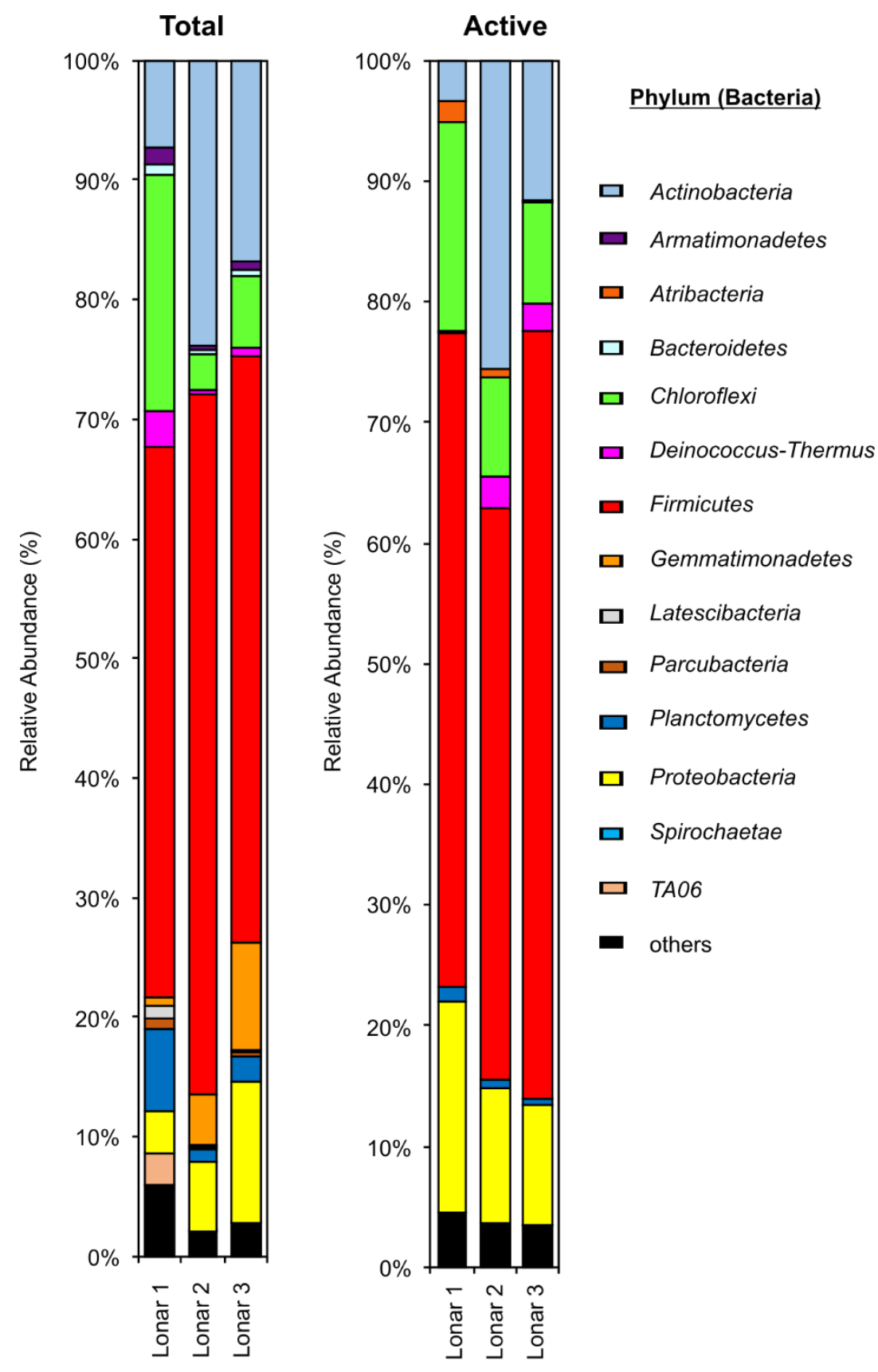

Figure 13: Relative abundances of dominant bacterial phylum groups in LoNAR SEDIMENTS. Sample numbers indicating the different sediment samples are given below the respective bars. Phylogenetic groups accounting for $<1 \%$ of all classified sequences are summarized in the artificial group 'others.' 

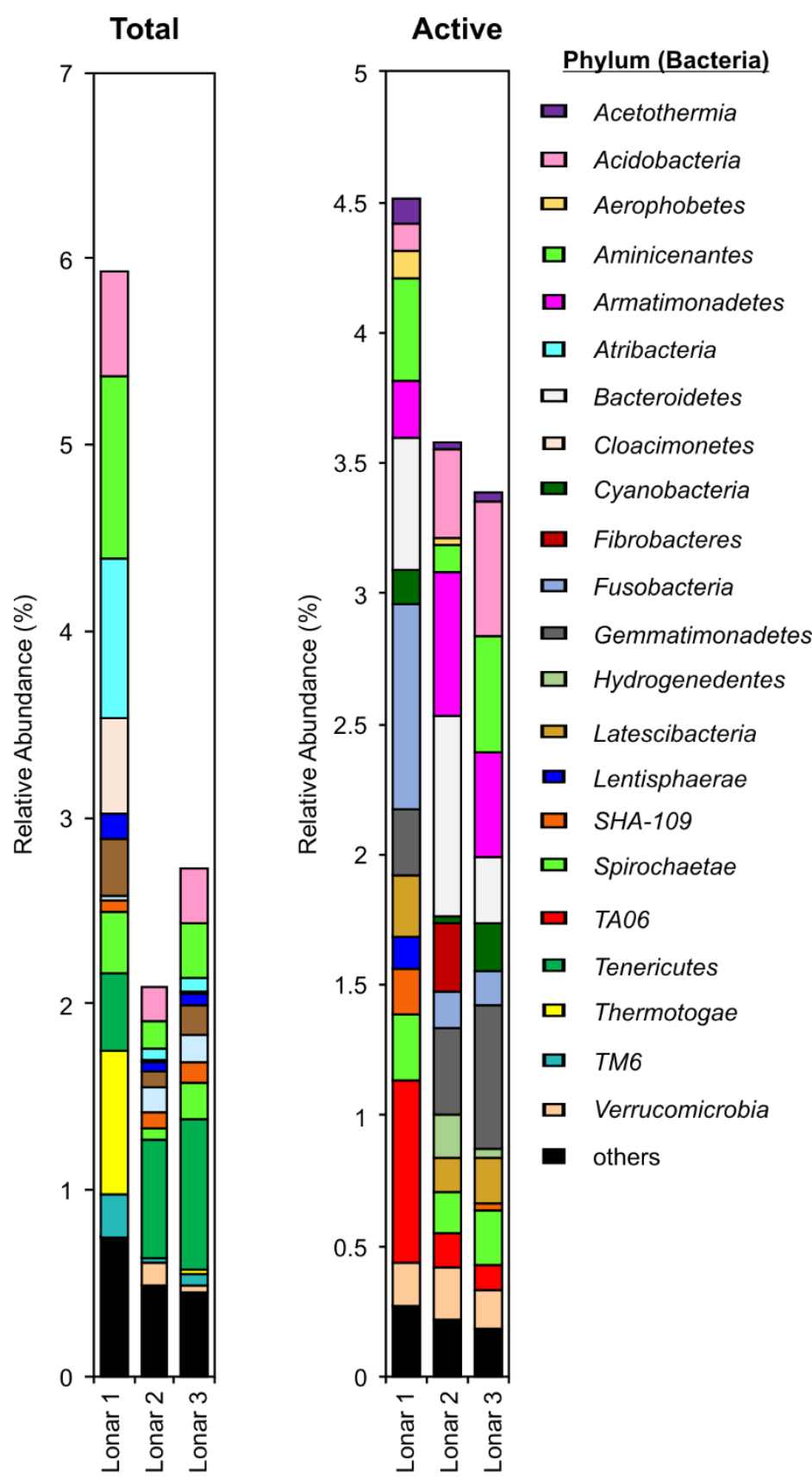

Figure 14: Relative ABUNDANCES OF THE RARE bACTERIAL PHyLUM IN LONAR SEDIMENTS. Sample numbers indicating the different sediment samples are given below the respective bars. Only the phylogenetic groups, accounting for $<1 \%$ of all classified sequences are shown.

In the active and the total community diversity phylum Firmicutes contributes to $51.16 \%$ and $55.03 \%$ relative abundance respectively. The highest relative abundance of $63.55 \%$ was observed in the sediments of Lonar 3 in the active community. Lowest abundance of $45.96 \%$ was found in the sediments of Lonar 1 in the total diversity. Firmicutes, in the total diversity, are mostly represented by Bacillus (34.83\%), Alkaliphilus (10.22 \%), 
Dethiobacter (8.55 \%), Anaerobacillus (7.28 \%) and Natronincola (3.58 \%). In the case of the active community Firmicutes are mostly represented by Alkaliphilus (24.02\%), Anaerobacillus (20.08\%), Bacillus (12.78\%), Natronincola (9.22 \%) and Gelria (0.38\%). Several species including novel species (Bacillus bogoriensis sp. nov., Bacillus chagannorensis sp. nov., Bacillus daliensis sp. nov., Bacillus lonarensis sp. nov., Bacillus caseinilyticus sp. nov.,) of the genus Bacillus has been isolated from various soda lakes around the world including Lonar(Vargas, Delgado et al. 2005, Carrasco, Marquez et al. 2007, Zhai, Liao et al. 2012, Reddy, Thirumala et al. 2015, Vishnuvardhan Reddy, Thirumala et al. 2015). They are mostly alkaliphilic and often halotolerant, some are able to grow at $\mathrm{pH}$ 11. Novel species of the genus Alkaliphilus has been isolated from saline lake (Alkaliphilus halophilus sp. nov.,) and soda lake (Alkaliphilus peptidofermentans sp. nov.,) (Zhilina, Zavarzina et al. 2009, Wu, Shi et al. 2010). They are halophilic and alkaliphilic with $\mathrm{pH}$ optima ranging from $\mathrm{pH} 8$ and $\mathrm{pH}$ 9.1. Novel reductive sulfur cycling genus Dethiobacter (Dethiobacter alkaliphilus gen. nov. sp. nov.,) has been isolated from north-eastern Mongolian soda lakes, with the ability to grow at pH 10.3(Sorokin, Tourova et al. 2008). Novel strictly anaerobic diazotrophic genus Anaerobacillus (Anaerobacillus alkalilacustre gen. nov., sp. nov.) has been isolated from soda lake Khadyn, Russia. They are mesophilic halotolerant obligate alkaliphilic and able to grow between $\mathrm{pH} 8.5$ to $\mathrm{pH}$ 10.7(Zavarzina, Tourova et al. 2009). Two novel obligate alkaliphilic species, Natronincola ferrireducens sp. nov., and Natronincola peptidovorans sp. nov., of the genus Natronincola with $\mathrm{pH}$ optima of $\mathrm{pH} 8.4$ to $\mathrm{pH} 8.8$, have been isolated from soda lakes(Zhilina, Zavarzina et al. 2009). Gelria are obligately anaerobic, obligately syntrophic, in pure culture shows saccharolytic growth and they transfer formed hydrogen to methanogenic partner. However, the novel genus Gelria (Gelria glutamica gen. nov., sp. nov.,) has not been isolated or reported from soda lake and they are able to grow in $\mathrm{pH}$ up to $\mathrm{pH} 8$ (Plugge, Balk et al. 2002).

Phylum Actinobacteria contributes to $15.97 \%$ and $13.49 \%$ in the total and the active community diversity respectively. They show maximum and minimum relative abundance of $25.56 \%$ and $3.37 \%$ in the active community diversity of the sediments of Lonar 2 and Lonar 1 respectively. Phylum Actinobacteria is mostly represented by Longispora (5.51 $\%)$, Luedemannella (0.51\%), Nitriliruptor (0.43\%), Micromonospora (0.23\%) and Euzebya 
$(0.16 \%)$ in the total diversity. In the active community Actinobacteria is mostly represented by Longispora (5.05\%), Euzebya (2.10\%), Nitriliruptor (1.53\%), Micromonospora (0.59\%) and Luedemannella (0.58\%). Two novel species of novel aerobic genus Longispora (Longispora albida gen. nov., sp. nov., and Longispora fulva sp. nov.,) has been isolated from soils but not from soda lakes (Matsumoto, Takahashi et al. 2003, Shiratori-Takano, Yamada et al. 2011). Longispora albida gen. nov., sp. nov., can utilize glucose, inositol, xylose and sucrose as only carbon sources. Longispora fulva sp. nov., can utilize glucose but can not utilize inositol, xylose and sucrose. Two aerobic novel species of novel genus Luedemannella, represented by Luedemannella helvata sp. nov. and Luedemannella flava sp. Nov., have been isolated from soil but not from any soda lakes. They can grow in pH up to 9 (Ara and Kudo 2007). Novel haloalkaliphilic genus, Nitriliruptor alkaliphilus sp. nov., has been isolated from soda lakes of Kulunda Steppe, Altai, Russia, with the ability to grow at pH as high as pH 10.6 (Sorokin, van Pelt et al. 2009). Several species of Micromonospora including some novel species have been isolated from marine and mangrove sediments, but not from any soda lakes (Huang, Lv et al. 2008, Ohlendorf, Schulz et al. 2012, Xie, Qu et al. 2012, Supong, Suriyachadkun et al. 2013, Li and Hong 2015, Phongsopitanun, Kudo et al. 2015). Novel genus Euzebya has been isolated from the ventral epidermis of the Holothuria edulis (sea cucumber) but not from soda lakes. Euzebya tangerina gen. nov, sp. nov., are known to grow at $\mathrm{pH}$ of up to pH 9 (Kurahashi, Fukunaga et al. 2010).

In the total and the active community diversity, the relative abundance of phylum Chloroflexi was found to be $9.57 \%$ and $11.27 \%$ respectively. The highest relative abundance of Chloroflexi was found to be $19.68 \%$ in the sediments of Lonar 1 in the total diversity assessment and lowest, $3.07 \%$, was observed in Lonar 2 sediments of the total diversity. Phylum Chloroflexi is mostly represented by genera Nitrolancea (1.12 \%), Sphaerobacter (0.06 \%), Pelolinea (0.04\%), Dehalococcoides (0.01\%) and Ornatilinea (0.006 \%) in the total diversity and by Nitrolancea (1.10\%), Sphaerobacter $(0.14 \%)$, Dehalococcoides $(0.02 \%)$, Pelolinea $(0.003 \%)$ in the active community. A chemolithoautotrophic nitrite-oxidizing novel genus, Nitrolancea hollandica gen. nov., sp. nov., was isolated from a nitrifying bioreactor with $\mathrm{pH}$ optima between $\mathrm{pH} 6.8$ to $\mathrm{pH} 7.5$ (Sorokin, Vejmelkova et al. 2014). However, they have not been reported from any soda 
lake. Chemoorganotrophic Sphaerobacter thermophilus gen. nov., sp. nov., has been isolated only from sewage sludge (Demharter, Hensel et al. 1989). Obligate anaerobic novel genus Pelolinea submarina gen. nov., sp. nov., has been isolated from marine subsurface sediments near Japan in 2014 , none has been reported from any soda lakes. They can grow in pH up to pH 8.5 (Imachi, Sakai et al. 2014). Dehalococcoides mccartyi gen. nov., sp. nov., are obligate anaerobic hydrogenotrophic, organohalide-respiring Bacteria isolated from digester sludge of a wastewater treatment plant (Loffler, Yan et al. 2013). However, they are not isolated or reported from soda lakes. A new anaerobic organotrophic cellulolytic genus Ornatilinea (Ornatilinea apprima gen. nov., sp. nov.,) able to grow at $\mathrm{pH}$ up to $\mathrm{pH} 9$ has been reported from Russia, but not from any soda lake in 2013 (Podosokorskaya, Bonch-Osmolovskaya et al. 2013).

Phylum Proteobacteria contributes to $7.00 \%$ and $12.93 \%$ in the total and the active community diversity respectively. The highest relative abundance of Proteobacteria, $17.24 \%$, was observed in sediments of Lonar 1 of the active community diversity and lowest, $3.51 \%$, was found in the total diversity of the Lonar 1 sediments. In the total diversity, phylum Proteobacteria is mostly represented by Hyphomicrobium (2.22 \%), Haliangium (1.01\%), Desulfovibrio (0.81\%), Geoalkalibacter (0.79\%) and Vulgatibacter (0.40 \%). Phylum Proteobacteria, in case the active community is mostly represented by Pelomonas (2.35\%), Caulobacter (2.10\%), Acinetobacter (2.09\%), Sphingomonas (0.97 $\%)$ and Brevundimonas (0.81 \%). Methylotrophic species of Hyphomicrobium has been isolated from alkaline soil of coal mine, China and gold mine debris, Portugal, some of them are able to grow at pH as high as pH 12 (Marco, Pacheco et al. 2004, Han, Chen et al. 2009). Two obligate aerobic and moderately halophilic novel species, Haliangium ochraceum sp. nov., and Haliangium tepidum sp. nov., of the novel genus Haliangium gen. nov., has been isolated from coastal seaweed or sea grass of Japan (Fudou, Jojima et al. 2002). Several novel species of sulfate-reducing bacterial genus Desulfovibrio has been isolated from various freshwater, marine, coastal and estuarine sediments of all over the world (Bale, Goodman et al. 1997, Reichenbecher and Schink 1997, Sass, Berchtold et al. 1998, Sun, Cole et al. 2000, Takii, Hanada et al. 2008, Suzuki, Ueki et al. 2009). Members of the novel genus Geoalkalibacter (Geoalkalibacter ferrihydriticus gen. nov. sp. nov.,) has been isolated from soda lakes of Russia. They are obligate alkaliphilic, capable of 
dinitrogen fixation and able to grow at pH as high as pH 10 (Zavarzina, Kolganova et al. 2006). In 2014, an obligate aerobic organotrophic new genus Vulgatibacter (Vulgatibacter incomptus gen. nov., sp. nov.,) has been isolated from a forest soil of Yakushima Island, Japan with the ability to grow at $\mathrm{pH}$ as high as $\mathrm{pH} 9$ (Yamamoto, Muramatsu et al. 2014). However, none has been reported from any soda lake. Two novel species of Pelomonas, Pelomonas aquatica sp. nov., and Pelomonas puraquae sp. nov., with nitrogen fixing ability has been isolated in 2007, but not from soda lakes (Gomila, Bowien et al. 2007). Caulobacter has been reported from a soda lake of Kulunda Steppe, Altai, Russia (Tourova, Grechnikova et al. 2014). Members of the genus Acinetobacter has been reported and isolated from soda lakes of the Kulunda Steppe, Altai, Russia and high-altitude shallow lakes and salterns (Andean lakes) of dry Central Andes region of South America (Foti, Sorokin et al. 2008, Di Capua, Bortolotti et al. 2011, Kurth, Belfiore et al. 2015). They are known for their tolerance to high UV radiation, high salinity, and high heavy metal content. Several members of the genus Sphingomonas has been isolated from freshwater lakes as well as alkaline lake some are associated with environments of high UV irradiation, hypersalinity, drastic temperature changes (Farias, Revale et al. 2011, Chen, Jogler et al. 2013, Salka, Srivastava et al. 2014, Wei, Wang et al. 2015). Some of them can grow at $\mathrm{pH}$ as high as $\mathrm{pH} 10$. Several species of the genus Brevundimonas including few new species, for example, Brevundimonas terrae sp. nov., Brevundimonas kwangchunensis sp. nov., Brevundimonas abyssalis sp. nov., Brevundimonas denitrificans sp. nov., has been isolated from deep subseafloor sediments and alkaline soils, some are able to grow at pH 10 (Yoon, Kang et al. 2006, Yoon, Kang et al. 2006, Tsubouchi, Shimane et al. 2013, Tsubouchi, Koyama et al. 2014).

In the total diversity, the relative abundance of phylum Gemmatimonadetes was found to be $4.69 \%$ and in the case of the active community, it was $0.37 \%$. The maximum relative abundance of the phylum Gemmatimonadetes, of $9.02 \%$ was observed in Lonar 3 of the total diversity and minimum was observed $(0.25 \%)$ in Lonar 1 sediments of the active community assessment. It was represented in the total diversity mostly by Gemmatimonas (only cultured representative) and the genus Gemmatimonas was not detected in the active community diversity. The new aerobe genus Gemmatimonas aurantiaca gen. nov., sp. nov., have been described in 2003 from a laboratory scale 
wastewater treatment process with the ability to grow between $\mathrm{pH} 6.5$ and pH 9.5 (Zhang, Sekiguchi et al. 2003).

In the active community, the relative abundance of the phylum Deinococcus-Thermus was found to be $1.72 \%$ and in the total community, it was $1.3 \%$. Sediments of Lonar 1 in the total diversity shows highest relative abundance of the phylum Deinococcus-Thermus, $3.00 \%$ and lowest of $0.21 \%$, was observed in Lonar 1 sediments in the active community diversity. The phylum Deinococcus-Thermus was mostly represented by Deinococcus $(0.01 \%)$ and Truepera $(2.07 \%)$ in the active community and by Truepera $(2.79 \%)$ in the total community. We were unable to detect any Deinococcus in total diversity. Deinococcus is a well known chemoorganotrophic Bacteria with one of the most radiation resistant cell (vegetative). Few species of the genus Deinococcus (Deinococcus enclensis sp. nov., Deinococcus radiopugnans) have been isolated from soil and marine sediments. However, none has been reported from any soda lake (Masters, Murray et al. 1991, Thorat, Mawlankar et al. 2015). New chemoorganotrophic aerobic alkaliphilic moderately thermophilic and moderately halophilic genus Truepera radiovictrix gen. nov., sp. nov., has been isolated from hot springs with the ability to grow in $\mathrm{pH}$ up to $\mathrm{pH} 11.2$ (Albuquerque, Simoes et al. 2005). They are also radiation resistant. 


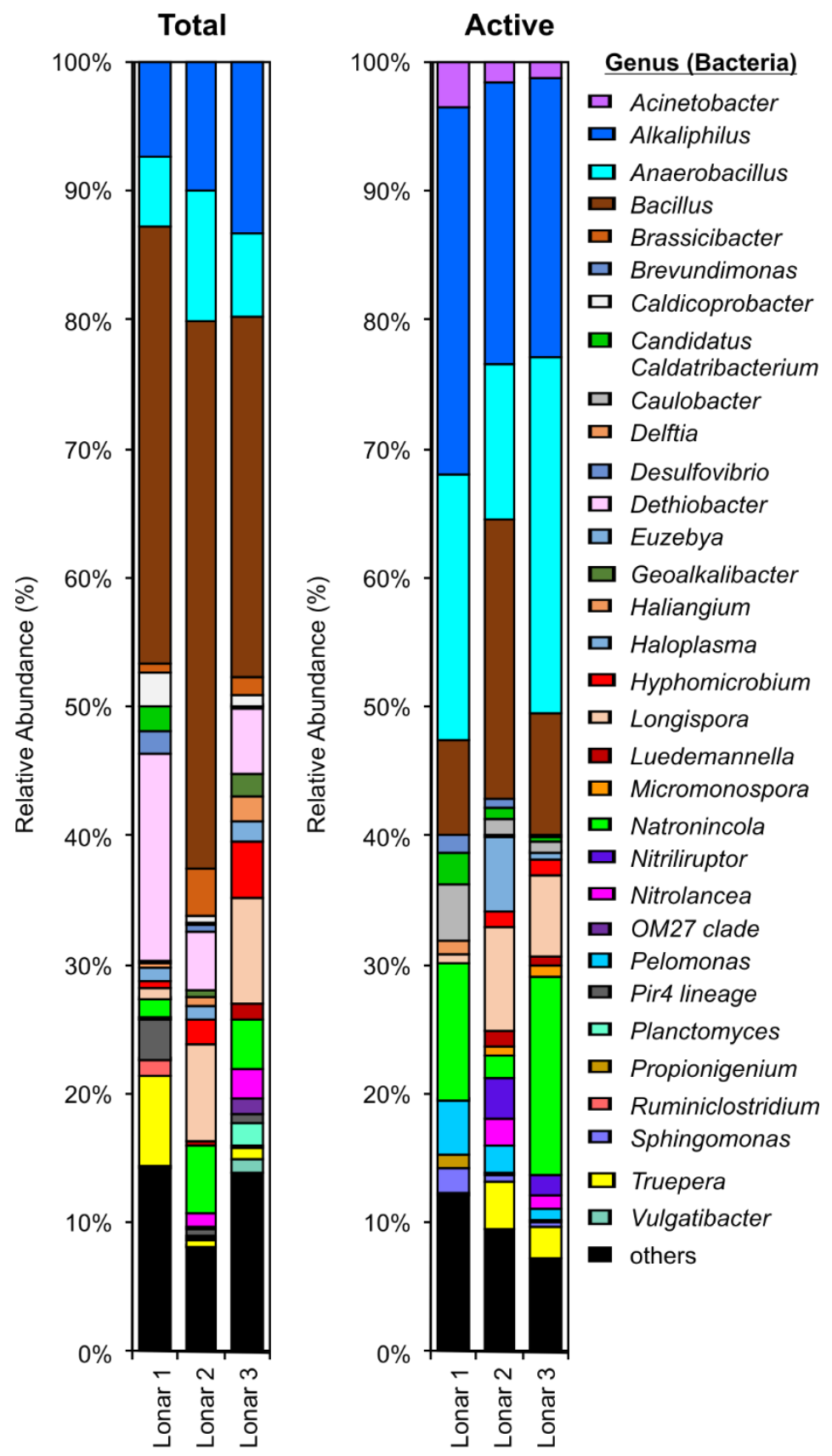

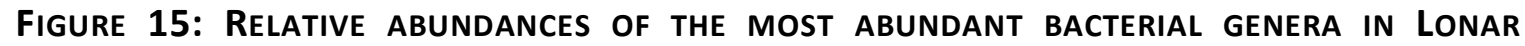
SEDIMENTS. Sample numbers indicating the different sediment samples are given below the respective bars. Only the phylogenetic groups accounting for $>1 \%$ of all classified sequences are shown. 


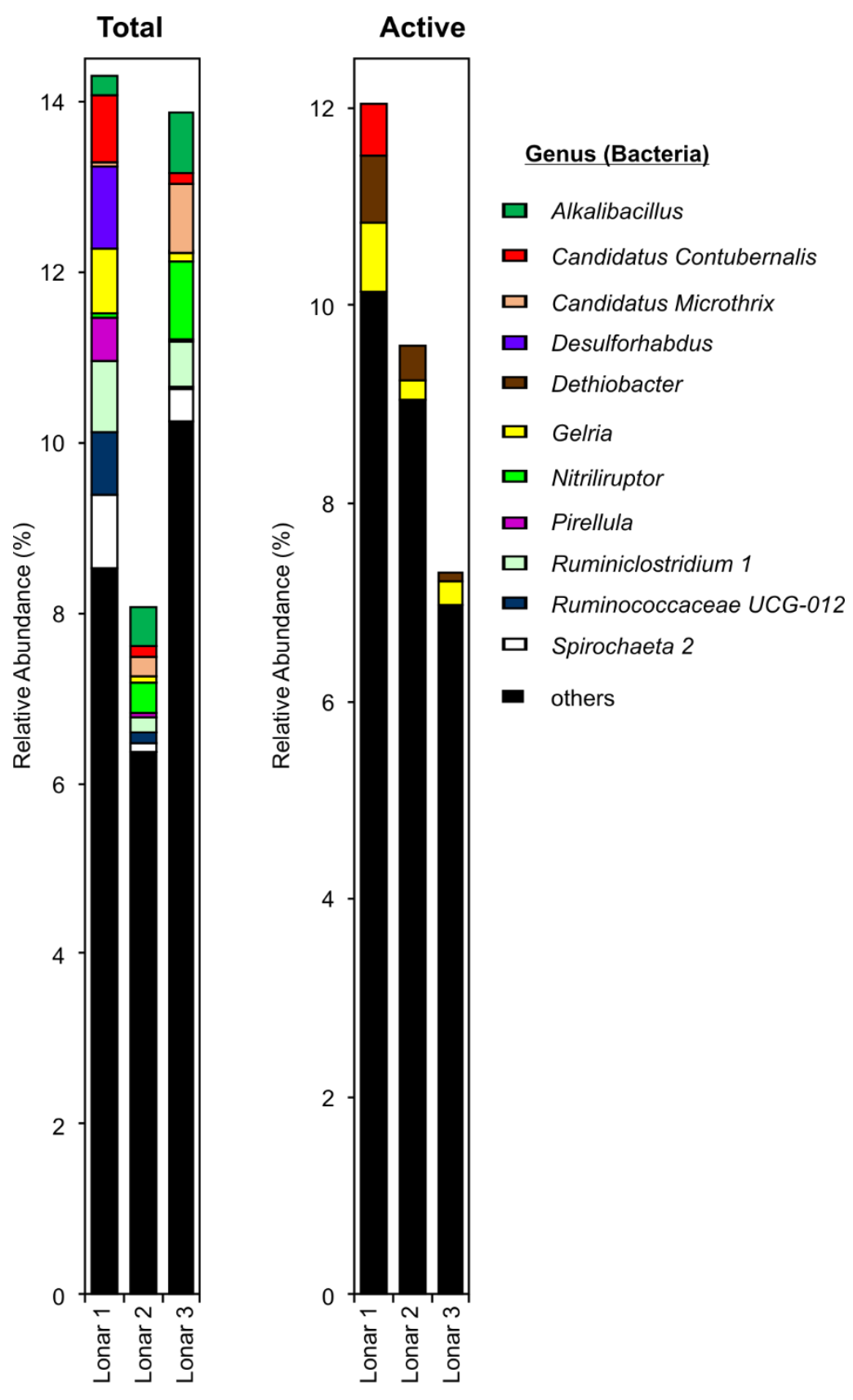

Figure 16: Relative abundances of the RARE bacterial genera in LonAR SEDiments. Sample numbers indicating the different sediment samples are given below the respective bars. Only the phylogenetic groups accounting for $<1 \%$ of all classified sequences are shown. 


\subsubsection{Relative Coverage Of The Total And The Active Community}

Relative coverage of the total and the active community was analyzed using $\mathrm{R}$ version 3.2.3 (R Core Team 2015) and gplots (v 2.17.0) (Gregory R. Warnes 2015), plotrix (v 3.6.1) (Lemon 2006) packages. Among Archaea at order level $80 \%$ are shared between the total and the active community. The total and the active community both shows $10 \%$ unique order or order-level taxa. At the genus level, the ubiquitously shared genera represent $53.2 \%$ in Archaea. The total diversity shows $42.6 \%$ unique genera and in the active community $4.3 \%$ unique genera were observed. Among Bacteria, we observed unique phylum or phylum-level taxa of $16.7 \%$ and $2.1 \%$ in the total and the active community diversity respectively. The total and the active community share $81.2 \%$ phylum. At the genus level, they show $28 \%$ common genera between the total and the active diversity. In the total and the active community diversity, we observed unique genera of $51.4 \%$ and $20.6 \%$ respectively. All the mutual overlap of coverages are shown in Figure 17. It is safe to conclude that individual surveying effort (total or active) does have an effect on detection of taxa. 


\section{Archaea Order}

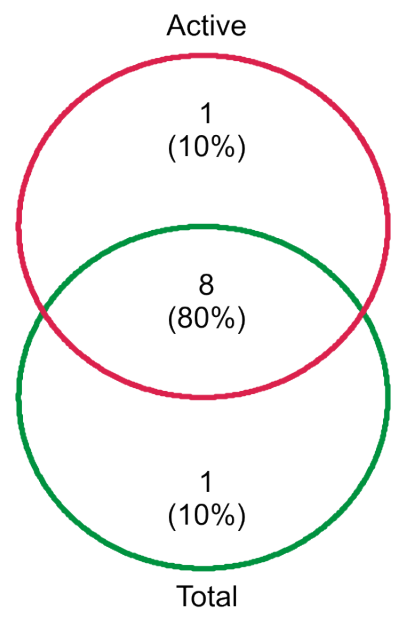

Archaea Genus

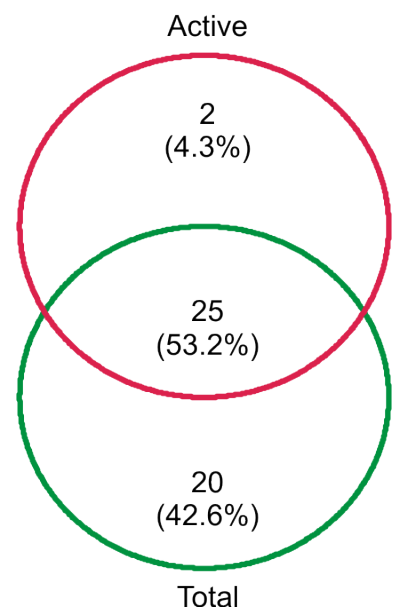

Bacteria Phylum

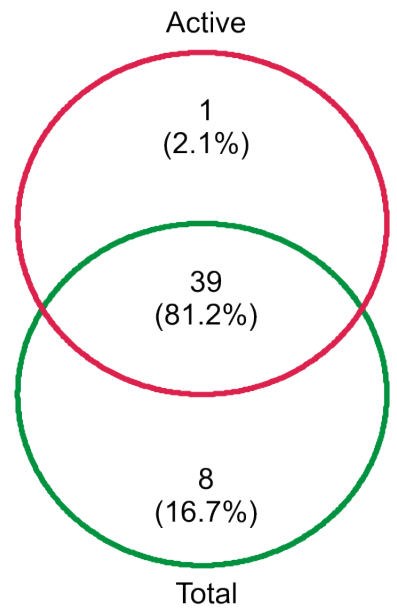

Bacteria Genus

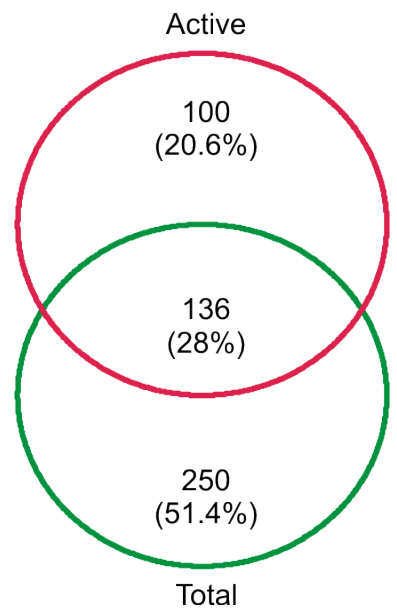

FiguRE 17: VENN DIAGRAM OF RELATIVE COVERAGE BETWEEN DIFFERENT SURVEYING EFFORTS. Upper left- Order level, Archaea, lower left- Genus level, Archaea, upper rightPhylum level, Bacteria, lower right- Genus level, Bacteria. 


\subsection{General Analyses Of The Additional Sequencing Of The TOTAL DIVERSITY DATA FROM LONAR}

High-throughput pyrosequencing of 16S rRNA gene sequences provides more sequence data compared to traditional Sanger sequencing of 16S rRNA gene clone libraries for exploring phylogenetic diversity and community composition (Sogin, Morrison et al. 2006). The error rate in terms of error per base in pyrosequencing of 16S rRNA genes is no greater than that of Sanger sequencing(Huse, Huber et al. 2007). The inherent rate of error of pyrosequencing may cause overestimation of the number of rare phylotypes. To minimize the overestimation of rare phylotypes, quality control filtering of the pyrosequencing-derived dataset was used. For clustering and diversity estimates genetic divergences of $3 \%$ were used (Kunin, Engelbrektson et al. 2010). The analysis method is provided in 3.14.2. The pyrosequencing-based analysis of the V3-V5 region of the $16 \mathrm{~S}$ rRNA genes resulted in the recovery of 61,362 high-quality sequences for Bacteria and 37,968 for Archaea; across all 6 samples, 3 samples each for of Bacteria and Archaea. All the sequences were filtered for sequences with a read length between 300 to $1000 \mathrm{bp}$, the maximum number of allowed ambiguous bases limiting to 6 and a maximum number of allowed mismatches in primer limiting to 3 . The average read length was $469.78 \mathrm{bp}$ for Bacteria and 467.53 for Archaea. The number of sequences per sample for Bacteria ranged from 16,298 to 25,450 with an average of 20,454 and for Archaea, it ranges from 7,754 to 16,084 with an average of 12,656 . Alpha diversity was analyzed at the same level of surveying effort. For Bacteria, it was 13,540 sequences per sample and for Archaea 6,640 sequences per sample. Additionally, denoising of every sequence subset was performed to avoid overestimation of operational taxonomic units (OTUs) and diversity (Bragg, Stone et al. 2012). We were able to assign 51,853 sequences out of 61,362 to the domain Bacteria (84.5\%) and to classify all of these sequences below the domain level (84.5\%). In the case of Archaea, 33,294 sequences out of 37,968 were assigned to the domain Archaea (87.68\%), and we were able to classify 33,266 of these sequences below the domain level (87.61\%).

All the OTUs were identified at genetic distances of $3 \%$ by using 6,640 randomly selected and denoised sequences per sample for Archaea and 13,540 sequences for Bacteria. 
These OTUs were used to determine rarefaction curves, richness, and diversity. At $3 \%$ genetic distance the rarefaction curves attain a significant level of saturation Figure 18.

Rarefaction Curves for Archaea

Rarefaction Curves for Bacteria

(Genetic Distance 3\%) - Lonar $1-$ Lonar 2 Lonar 3
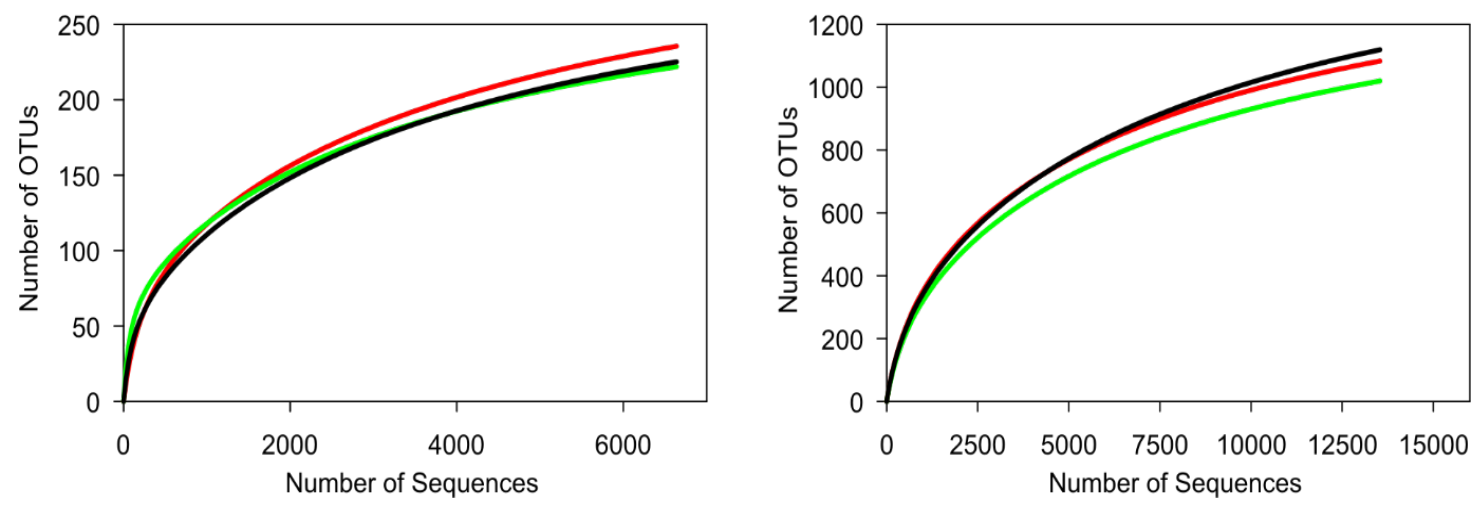

Figure 18: Rarefaction Curves Indicating The Observed Number of Operational Taxonomic Units (OTUS) in Additional Assessment of The Total Diversity. Three different samples are indicated in red, green and black respectively for Lonar 1, Lonar 2 and Lonar 3 . The curves indicate gradual saturation in the number of OTUs with an increase in the number of sequences examined. On the left rarefaction curves for Archaea and on the right for Bacteria at $3 \%$ genetic distances are shown.

As per rarefaction analyses with the number of OTUs determined by Max. clusters ( $\left.n_{\max }\right)$ revealed that Archaea covered $86.48 \%( \pm 1.86)$ of the estimated total diversity. In the case of Bacteria, the coverage was observed to be $81.24 \%$ ( \pm 0.89 ). Thus, we did not survey the full extent of taxonomic diversity at these genetic distances, but the surveying efforts assessed a substantial fraction of the prokaryotic diversity. Details of the Observed clusters, Max. clusters $\left(\mathrm{n}_{\max }\right)$, Coverage $(\%)$, Shannon index $\left(\mathrm{H}^{\prime}\right)$ and Chao1 of individual samples are given in Table 26. The coverage was more than the previous total diversity assessment, where we have surveyed both the total and the active community diversity using Illumina MiSeq. Due to the increased coverage of this additional total diversity assessment furnished several taxa at order or phylum and genus level, which was not detected by our previous total diversity assessment. The proportion of uncultured and cultured OTUs were observed to be $83.24 \%$ and $16.75 \%$ in Archaea. In the case of Bacteria, it was found to be $87.26 \%$ and $12.73 \%$ for uncultured and cultured OTUs respectively. 
Table 26: General Analysis of The Additional Total Diversity Sequencing Data

\begin{tabular}{llllll}
\hline Sample & $\begin{array}{l}\text { Observed } \\
\text { clusters }\end{array}$ & $\begin{array}{l}\text { Max. } \\
\text { clusters } \\
\left(\mathbf{n}_{\max }\right)\end{array}$ & $\begin{array}{l}\text { Coverage } \\
\mathbf{( \% )}\end{array}$ & $\begin{array}{l}\text { Shannon } \\
\text { index } \\
\left(\mathbf{H}^{\prime}\right)\end{array}$ & Chao1 \\
\hline Lonar 1 (Archaea) & 235.6 & 274.33 & 85.88 & 5.34 & 286.06 \\
Lonar 2 (Archaea) & 222 & 249.39 & 89.01 & 5.61 & 260.07 \\
Lonar 3 (Archaea) & 225.7 & 266.91 & 84.55 & 4.91 & 272.35 \\
Mean & 227.76 & 263.54 & 86.48 & 5.29 & 272.82 \\
SD & 5.74 & 10.45 & 1.86 & 0.28 & 10.61 \\
CV & 0.02 & 0.03 & 0.02 & 0.05 & 0.03 \\
Lonar 1 (Bacteria) & 1081.9 & 1314.24 & 82.32 & 8.06 & 1288.14 \\
Lonar 2 (Bacteria) & 1019 & 1253.70 & 81.27 & 7.64 & 1223.63 \\
Lonar 3 (Bacteria) & 1114.9 & 1391.32 & 80.13 & 7.91 & 1357.78 \\
Mean & 1071.93 & 1319.75 & 81.24 & 7.87 & 1289.85 \\
SD & 39.78 & 56.31 & 0.89 & 0.17 & 54.77 \\
CV & 0.03 & 0.04 & 0.01 & 0.02 & 0.04 \\
\hline
\end{tabular}

Due to the increased coverage of this additional total diversity assessment furnished several taxa at order (for Archaea) or phylum (for Bacteria) and genus level, which was not detected by our previous total diversity assessment. Details are provided in Table 37 of supplements.

This additional assessment of the total diversity furnished 2 archaeal order and 5 archaeal genera that has not been detected by our previous surveying effort. One of order is Marine Benthic Group E (0.22 \%), and the other is Archaeoglobales (0.19\%). Also, 1 bacterial phylum-level taxa, LCP-89 (0.01\%) has not been detected by our previous assessment. In the case of Bacteria, 44 genera or genera level taxa has been observed which was not detected by our previous total diversity assessment. 


\subsection{Comparison Of Present And PREVIOUS InVEStigations ON Prokaryotic Diversity Of LonAR Crater LAKE}

The present study contributed 52 archaeal genera and 530 bacterial; out of which 36 (69.23\%) archaeal genera and 407 (76.79\%) bacterial genera has never been reported before from Lonar lake before. Abundances of cultivatable aerobic Bacteria, as described by Joshi in 2008, in Lonar lake water was found to be 102-104 CFU/ml and for sediment samples were found to be 102-106 CFU/g. Previous research on diversity and abundance of heterotrophic Bacteria isolated from the Lonar lake water and sediment showed most dominant phylum to be the Firmicutes, followed by Proteobacteria and Actinobacteria(Wani, Surakasi et al. 2006, Joshi, Kanekar et al. 2008, Antony, Kumaresan et al. 2013); which is also the case for this present study. Study of Lonar lake also resulted in recovery of 4 novel heterotrophs (Nitritalea halakaliphila, Indibacter alkaliphilus, Cecembia lonarensis and Georgenia satyanarayanai) and one new methylotroph (Methylophaga lonarensis) (Anil Kumar, Srinivas et al. 2010, Anil Kumar, Srinivas et al. 2012, Antony, Doronina et al. 2012). DNA stable-isotope probing experiments by Antony in 2010 with Lonar lake sediments showed Methylomicrobium, Methylophaga and Bacillus spp to be the predominant the active methylotrophs utilizing methane, methanol, and methylamine, respectively(Antony, Kumaresan et al. 2010). The previous study of archaeal 16S rRNA genes recovered from Lonar lake sediment showed five crenarchaeotal phylotypes and eight euryarchaeotal phylotypes (Wani, Surakasi et al. 2006). However, we found in this survey that most of the OTUs belong to the phylum Euryarchaeota and Thaumarchaeota some OTUs affiliated to Korarchaeota was also noticed. Methanogenic species associated to Methanosarcina, Methanocalculus and Methanoculleus have been isolated from the Lonar lake sediments(Thakker and Ranade 2002, Surakasi, Wani et al. 2007).

Over the last several years different work, has been undertaken by the various researcher on prokaryotes of Lonar lake resulting in accumulation of hundreds of DNA sequence. We collected all available 16S rRNA gene sequences from NCBI (National Center for Biotechnology Information) Nucleotide database. All sequences with less than $300 \mathrm{bp}$ in size were removed resulting in 1245 number of sequences. These sequences were 
processed with the similar protocol (for details see Chapter 3.14) as the one used to process sequences derived from the present study to make the comparison as valid as possible, mainly to avoid issues regarding phylogeny and taxonomy. A total of 17 archaeal and 197 bacterial genera was found in this analysis in contrast with 530 and 52, respective, genera found in our study. Among these only 139 (23.88\%) genera was found in both of the groups (analyzed NCBI nucleotide database sequences and the present highthroughput sequencing data) and 443 (76.11 \%) genera were found to be unique to our present study. It is worth mentioning here that these 443 genera have never been reported from Lonar before. Relative coverage at genus level of all the previous surveying efforts and the surveying efforts of the present studies are analyzed using R version 3.2.3 (R Core Team 2015) and gplots (v 2.17.0) (Gregory R. Warnes 2015), plotrix (v 3.6.1) (Lemon 2006) packages. Among Archaea both the surveying efforts share $30.2 \%$ genera, and present investigation shows $67.9 \%$ unique genera. In the case of Bacteria, at the genus level, the ubiquitously shared genera represent only $20.4 \%$, and the present investigation reveals $67.4 \%$ unique genera. All the mutual overlaps of coverages are shown in Figure 19. Some of these genera represent a significant relative abundance of the prokaryotic community. 

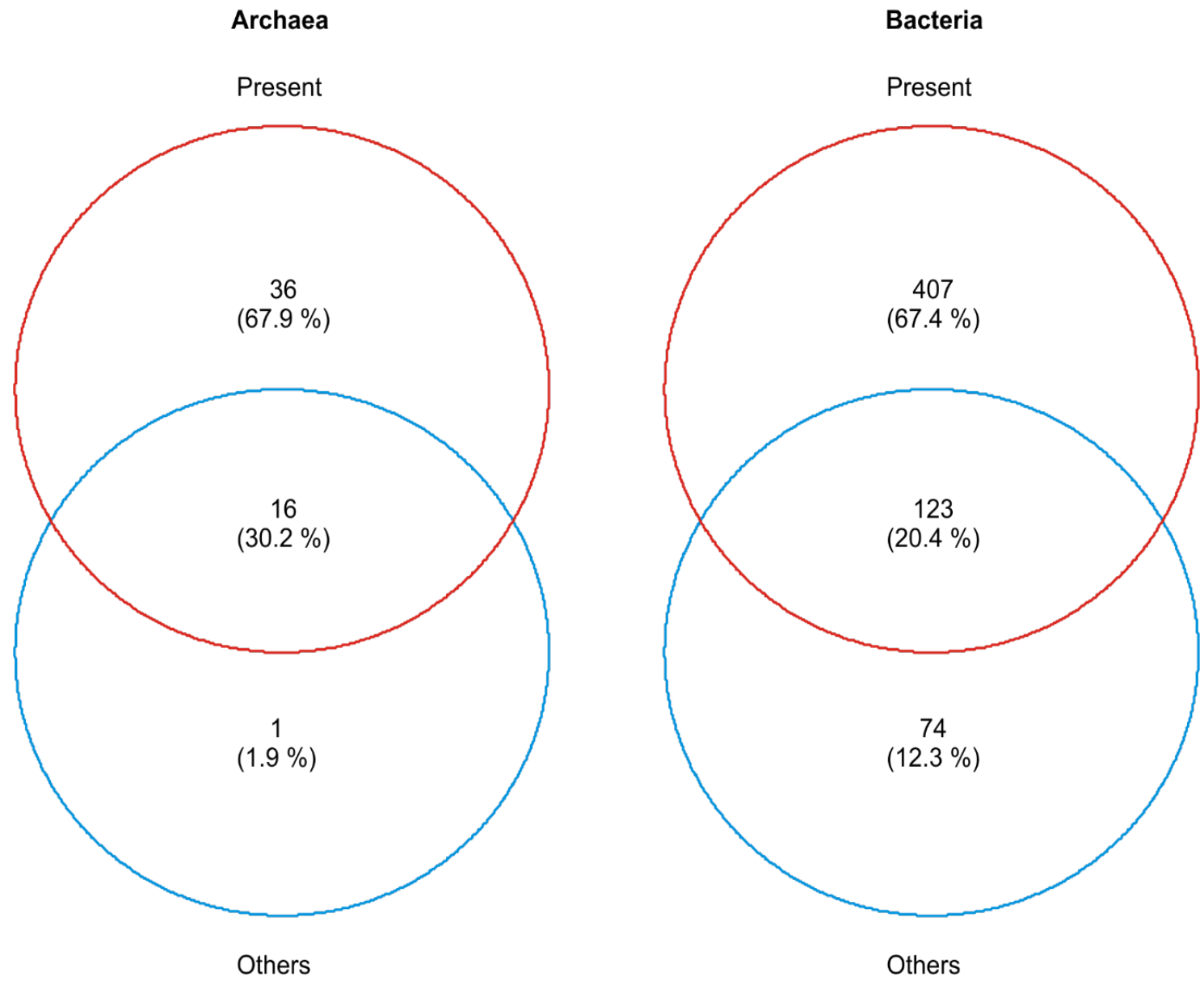

Figure 19: Comparison of current and Previous Investigations in Detection Genera. The figure shows mutual coverage of detected Genera in all previous investigations (Others) and current investigation (Present). The red circle represents this study and blue represents all other studies.

As per this study these unique archaeal genera together represent the average relative abundance of $3.62 \%( \pm 0.51)$ and $21.54 \%( \pm 0.68)$ in the total and the active community respectively. Among these unique archaeal genera, the highest 3 abundant genera in the active community include Methanobrevibacter, Methanobacterium and Methanomassiliicoccus representing relative abundance of as high as $17.54 \%, 2.32 \%$ and $2.15 \%$ respectively. In the total diversity assessment, 3 most abundant of these unique genera are Halobiforma, Methanobacterium and Natronorubrum showing relative abundance as high as $0.96 \%, 1.41 \%$ and $1.24 \%$ respectively. A rarity of available literature about the presence of Methanobrevibacter in soda lakes was noticed. Which is in accordance with the fact that there is a general lack of investigations on Archaea of soda lakes. They obtain energy by reducing $\mathrm{CO}_{2}$ to $\mathrm{CH}_{4}$, using $\mathrm{H}_{2}$ and sometimes formate 
as the electron donor, but not acetate, methanol, methylamines(Leadbetter, Crosby et al. 1998, Tokura, Tajima et al. 1999, Savant, Shouche et al. 2002, Ng, Kittelmann et al. 2015, Zhou, Zeitz et al. 2015). Methanobacterium are also hydrogen-utilizing methanogens, and they have been reported from soda lakes of Central Asia (Nolla-Ardevol, Strous et al. 2012). Methanomassiliicoccus are obligatory anaerobic methanogenic and moderately alkaliphilic (Dridi, Fardeau et al. 2012). The presence of the genus Methanomassiliicoccus has been reported from sediments of the estuary(Zhou, Chen et al. 2014). However, none has been reported from soda lakes. Members of aerobic extremely halophilic novel genus Halobiforma (Halobiforma haloterrestris gen. nov., sp. nov., and Halobiforma lacisalsi sp. nov.,) has been isolated from hypersaline soil, Aswan, Egypt and Salt Lake in Xinjiang, China (Hezayen, Tindall et al. 2002, Xu, Wu et al. 2005). Natronorubrum is strictly aerobic and haloalkaliphilic with optimum growth $\mathrm{pH}$ between 9.0 and 9.5. Two species, Natronorubrum bangense gen. nov., sp. nov., and Natronorubrum tibetense gen. nov., sp. nov, has been isolated from Tibetian soda lake. (Xu, Zhou et al. 1999). Some novel species have also been isolated from salt lakes of Xin-Jiang, China and soils of lake Texcoco, Mexico with most of them able to grow till pH 10 (Cui, Tohty et al. 2006, Cui, Tohty et al. 2007, Ruiz-Romero, Valenzuela-Encinas et al. 2013).

In the case of Bacteria these unique genera cumulatively contribute to $22.21 \%( \pm 4.69)$ and $17.75 \%( \pm 3.22)$ average relative abundance in the total and the active bacterial diversity respectively. Among these unique bacterial genera, highest 3 abundant genera in the total diversity were found to be Longispora, Hyphomicrobium and Brassicibacter representing as high as $8.23 \%, 4.22 \%$, and $3.61 \%$ respectively. In the active community diversity of Bacteria, 3 most abundant of these unique genera were Longispora, Pelomonas and Caulobacter showing relative abundance of $5.05 \%, 2.35 \%$ and $2.10 \%$ respectively. Few members of aerobic genus Longispora has been isolated from soils. They are not reported from soda lakes, but they are known to be able to grow at $\mathrm{pH} 9$ (Matsumoto, Takahashi et al. 2003, Shiratori-Takano, Yamada et al. 2011). Members of Hyphomicrobium are able to grow at $\mathrm{pH}$ as high as $\mathrm{pH}$ 12. They are methylotrophic and has been isolated from alkaline soil of coal mine, China and gold mine debris, Portugal (Marco, Pacheco et al. 2004, Han, Chen et al. 2009). Novel species of obligate anaerobic chemoorganotrophic Brassicibacter (Brassicibacter thermophilus sp. nov.) has been 
isolated from coastal marine sediment. Some members are also known to grow in $\mathrm{pH}$ of up to $\mathrm{pH} 9$ (Fang, Zhang et al. 2012, Wang, Ji et al. 2015). Few nitrogen-fixing members of Pelomonas, Pelomonas aquatica sp. nov., and Pelomonas puraquae sp. nov., has been reported (Gomila, Bowien et al. 2007). However, they are not from soda lakes. Some aerobic chemoorganotrophic species of Caulobacter of are known to grow in $\mathrm{pH}$ up to $\mathrm{pH}$ 9. They have been reported from a hypersaline soda lake of Kulunda Steppe, Altai, Russia (Tourova, Grechnikova et al. 2014).

\subsubsection{Genera Detected In Lonar Crater Soda LaKe With Significance IN BIOGEOCHEMICAL CYCLES}

In this survey of the prokaryotic diversity of the lake sediment from Lonar showed rich biodiversity despite its extreme physicochemical parameters. The presence of different ecologically appealing functional groups was found. Most of these genera had not been reported from Lonar before. A comprehensive list of these genera is provided in Table 27.

TABLE 27: GENERA INVOLVED IN VARIOUS BIOGEOCHEMICAL CYCLE

\begin{tabular}{lll}
\hline Methane cycle & Nitrogen cycle & Sulfur cycle \\
\hline Archaeal genera & Archaeal genera & Bacterial genera \\
$\begin{array}{l}\text { Candidatus } \\
\text { Methanoperedens }\end{array}$ & Candidatus Nitrosopumilus & Candidatus Desulforudis \\
Methanobacterium & Candidatus Nitrososphaera & Desulfatiglans \\
Methanobrevibacter & Bacterial genera & Desulfatitalea \\
Methanocalculus & Ammonifex & Desulfitibacter \\
Methanocella & Ammoniphilus & Desulfitispora \\
Methanococcoides & Azoarcus & Desulfobacca \\
Methanocorpusculum & Azospirillum & Desulfobulbus \\
Methanoculleus & Bradyrhizobium & Desulfococcus \\
Methanogenium & Candidatus & Desulfomonile
\end{tabular}




\begin{tabular}{|c|c|c|}
\hline Methane cycle & Nitrogen cycle & Sulfur cycle \\
\hline Methanolinea & Mesorhizobium & Desulfonatronobacter \\
\hline Methanolobus & Nitratireductor & Desulfonatronospira \\
\hline Methanomassiliicoccus & Nitriliruptor & Desulfonatronum \\
\hline Methanosaeta & Nitrincola & Desulforhabdus \\
\hline Methanosarcina & Nitrolancea & Desulforhopalus \\
\hline Methanosphaera & Nitrosococcus & Desulfosarcina \\
\hline Methanospirillum & Nitrospira & Desulfosporosinus \\
\hline Bacterial genera & Rhizobium & Desulfotomaculum \\
\hline Methylobacterium & & Desulfovibrio \\
\hline Methylobacterium & & Desulfovirga \\
\hline Methylocaldum & & Desulfuribacillus \\
\hline Methyloceanibacter & & Desulfurispora \\
\hline Methylocella & & Desulfurivibrio \\
\hline Methylohalomonas & & Desulfuromonas \\
\hline Methylonatrum & & Desulfuromusa \\
\hline \multirow[t]{12}{*}{ Methylonatrum } & & Dethiobacter \\
\hline & & Sulfitobacter \\
\hline & & Thioalkalispira \\
\hline & & Thioalkalivibrio \\
\hline & & Thiogranum \\
\hline & & Thiohalobacter \\
\hline & & Thiohalocapsa \\
\hline & & Thiohalomonas \\
\hline & & Thiohalophilus \\
\hline & & Thiohalospira \\
\hline & & Thiomicrospira \\
\hline & & Thioprofundum \\
\hline
\end{tabular}

In our study, we have observed 24 genera which may have been involved in methane cycle both from Archaea and Bacteria. In Archaea, they contribute to an average of $39.24 \%$ relative abundance in the active community and an average of $8.97 \%$ in the total community. In the case of Bacteria, they contribute to an average of $0.50 \%$ relative 
abundance in the active community and an average of $0.24 \%$ in the total community. Most dominant genera involved in methane cycle was found to be Methanosaeta (Archaea) exhibiting relative abundance as high as $19.79 \%$ in the active community of Lonar 3 sediments. Several methanogenic species of Methanosaeta has been isolated from rice paddies, natural wetlands, and lake sediments from around the world including marine and estuarine sediments as well as hypersaline soda lakes of Kulunda Steppe, Altai, Siberia (Mizukami, Takeda et al. 2006, Carbonero, Oakley et al. 2010, Mori, lino et al. 2012, Sorokin, Abbas et al. 2015).

A total of 16 genera were found which may have been involved in nitrogen cycle both from Archaea and Bacteria. Among Archaea, they contribute to an average of $0.46 \%$ relative abundance in the active community and an average of $0.79 \%$ in the total community. In the case of Bacteria, they contribute to an average of $2.87 \%$ relative abundance in the active community and an average of $1.95 \%$ in the total community. Most dominant genera involved in nitrogen cycle was found to be Nitriliruptor (Bacteria) with the relative abundance of $2.97 \%$ in Lonar 2 sediments in the active community. Members of obligate aerobic nitrile degrading genus Nitriliruptor are aerobic alkaliphilic and moderately halotolerant. For energy and carbon source they use short-chain organic acids, amides, and aliphatic nitriles. Nitriliruptor alkaliphilus gen. nov., sp. nov., has been isolated from soda lakes which can grow in pH of up to $\mathrm{pH} 10.6$ (Sorokin, van Pelt et al. 2009).

A significantly high diversity of bacterial genera, totaling 36 , involved in the sulfur cycle were recorded. They represent an average relative abundance of $0.93 \%$ relative abundance in the active community and an average of $10.84 \%$ in the total community. The most dominant genus was found to be Dethiobacter representing relative abundance as high as $16.11 \%$ in the total community from Lonar 1 sediments. In the case of the active community, it was found to be also Dethiobacter, from sediments of Lonar 1, with the relative abundance of $0.66 \%$. In reductive sulfur cycling genus Dethiobacter, $\mathrm{H}_{2}$ is used as the electron donor and thiosulfate, elemental sulfur and polysulfide are used as the electron acceptors. Obligate anaerobic chemolithoautotrophic Dethiobacter alkaliphilus gen. nov., sp. nov., has been isolated from soda lakes, northeast Mongolia, able to grow in $\mathrm{pH}$ between $\mathrm{pH} 8.5$ and $\mathrm{pH} 10.3$ (Sorokin, Tourova et al. 2008). 


\subsection{Diversity Of Functional Genes With EMPHASIS ON ECOLOGICAL ROLE}

In the previous chapter several genera potentially involved in the nitrogen cycle, sulfur cycle and methane cycle were detected. This analysis is an attempt to detect functional genes involved in those geobiochemical cycles and also relative abundance of different genes of the different functional category.

\subsubsection{General Analysis Of The Metagenome From The Sediments Of LONAR LAKE}

A total of 32 million paired-end reads were obtained from the sequencing effort. These sequences were analyzed as described in the Chapter 3.14.3. Sequences were assembled with metaSPAdes $v$ 3.7.0 resulting in to 588,668 contigs, total number of base $371 \mathrm{Mb}$ (371,120,372 base). These contigs were analyzed with Prodigal v 2.6.0 for ORF prediction and protein translation resulting in to 790,245 proteins. All the sequences shorter than 150 amino acids were discarded leaving 236,182 deduced protein sequences. These ORFs were annotated and analyzed with GhostKOALA, v 2.0. A total of 104,143 translations (41 \%) were successfully annotated using KEGG database.

The metagenome shows the assignment of the taxonomic composition of the metagenome in accordance with our 16S rRNA gene based assessment of the sediments from Lonar crater lake (Figure 20). Most dominant phyla were Firmicutes, Actinobacteria, Proteobacteria, Chloroflexi and Deinococcus-Thermus in our 16S rRNA gene based assessment as described in 4.2.3. We observed that the metagenome also shows Firmicutes (30.65\%), Proteobacteria (25.87\%), Actinobacteria $(8.78 \%)$, Chloroflexi $(7.24 \%)$ and Deinococcus-Thermus (1.89\%). 


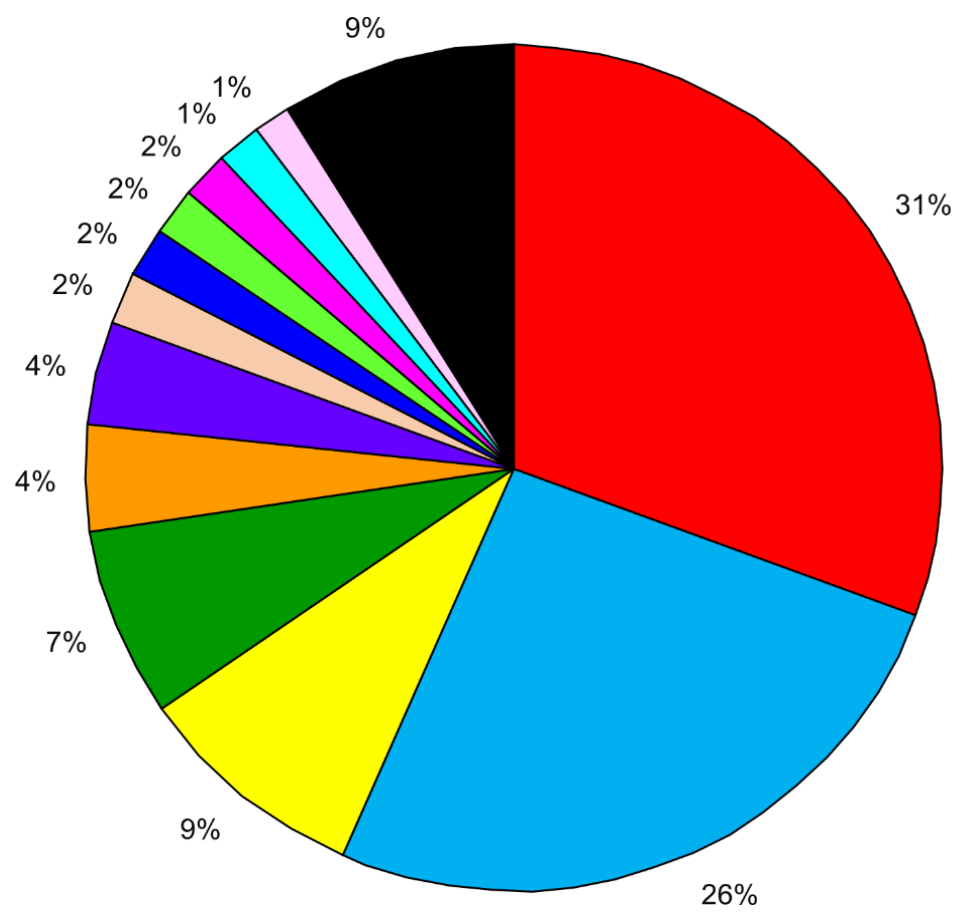

Taxonomic Group

口 Firmicutes

口 Proteobacteria

$\square$ Actinobacteria

- Chloroflexi

$\square$ Bacteroidetes

- Euryarchaeota

Planctomycetes

- Deinococcus-Thermus

$\square$ Gemmatimonadetes

口 Acidobacteria

$\square$ Cyanobacteria

口 Chlorobi

- Others

Figure 20: Taxonomic Composition of the Metagenome. The figure shows relative abundance of the taxonomic groups in the Lonar metagenome.

An overview of reconstruction of Genes or proteins (KEGG GENES), KO groups (KEGG ORTHOLOGY), KEGG modules, functional hierarchy (KEGG BRITE) and pathway maps (KEGG PATHWAY) are provided in Supplement-F: Diversity of Functional genes observed by direct metagenome analysis.

\subsubsection{Relative Abundance Of Functional Category}

The detected ORFs were distributed in 17 (excluding Unclassified) distinct functional categories. Out of these categories most, abundant categories were Genetic Information Processing, Environmental Information Processing and Amino acid metabolism with the relative abundance of $16.72 \%, 13.53 \%$, and $10.33 \%$ respectively. One of the lowest abundant categories was found to be Metabolism of terpenoids and polyketides, Xenobiotics biodegradation \& metabolism and Biosynthesis of other secondary metabolites with an abundance of $1.55 \%, 1.49 \%$, and $1.17 \%$ respectively. Also, it was 
observed that abundance of category Unclassified was significant, $9.58 \%$. Details of the relative abundance of each category are provided in Figure 21.

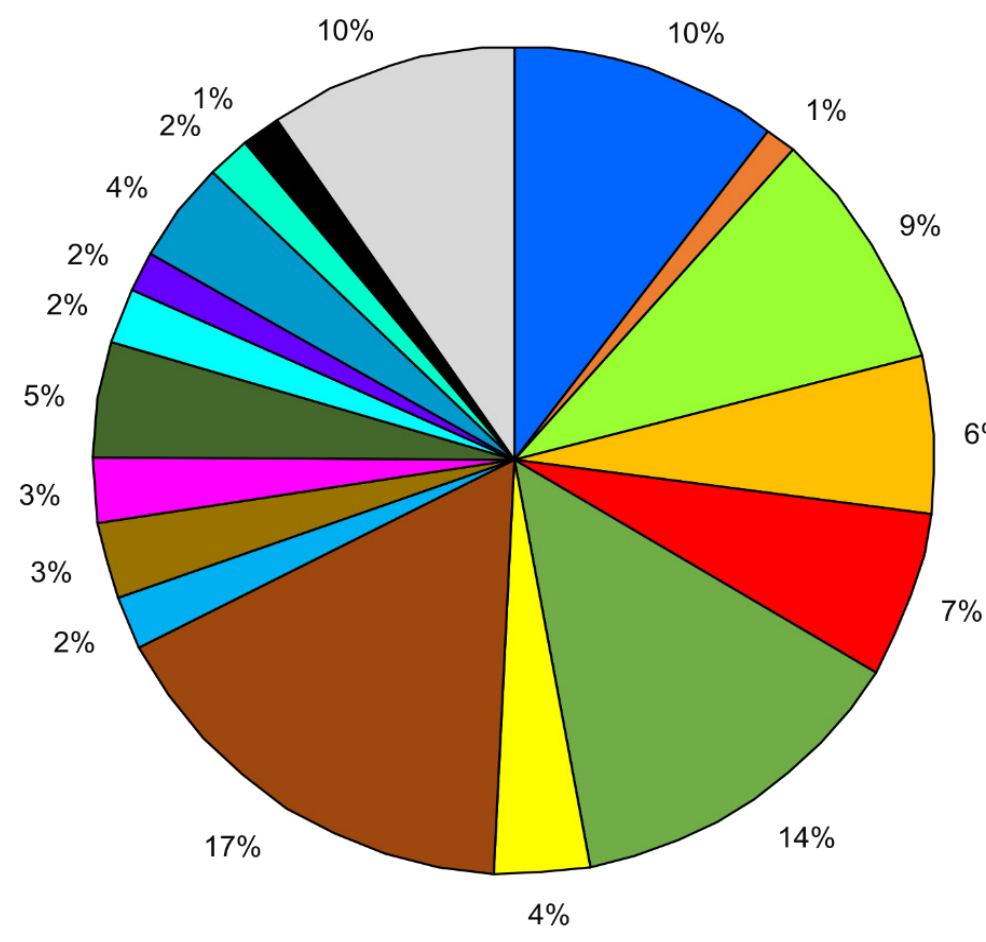

\section{Functional Category}

$\square$ Amino acid metabolism

$\square$ Biosynthesis of other secondary metabolites

$\square$ Carbohydrate metabolism

$\square$ Cellular Processes

$\square$ Energy metabolism

口Environmental Information Processing

$\square$ Enzyme families

$\square$ Genetic Information Processing

$\square$ Glycan biosynthesis and

$6 \%$ metabolism

口Human Diseases

- Lipid metabolism

Metabolism of cofactors and vitamins

$\square$ Metabolism of other amino acids

$\square$ Metabolism of terpenoids and polyketides

口Nucleotide metabolism

口Organismal systems

- Xenobiotics biodegradation and metabolism

口Unclassified

Figure 21: Relative Abundance of Functional Categories in the lonar Sediment. The pie diagram shows the relative abundance of detected and annotated ORFs in the Lonar sediment with respect to its functional category.

\subsubsection{Biogeochemical Cycle And Metabolism Of Methane, Nitrogen, AND SULFUR}

Methane, nitrogen, and sulfur metabolism contribute to $54.73 \%$ of the general functional category Energy metabolism as per the abundance of the KEGG ortholog. This methane, nitrogen, and sulfur metabolism together contribute to $2.69 \%$ of all the detected KEGG ortholog. 


\subsubsection{Methane Metabolism}

In the global carbon cycle methane metabolism is predominantly accomplished by methanotrophs and methanogens. Methane metabolism alone represents $30.52 \%$ of Energy metabolism and $1.49 \%$ of all metabolism in Lonar lake sediment metagenome. 9 pathway modules have been detected in this study. Out of these 9, 3 were complete, and 6 were partial. Details are provided in Table 28. Methane is consumed as the solitary carbon source by methanotrophs and methane is produced as a metabolic by-product by methanogens. Also, there are methylotrophs, able to acquire energy by oxidizing onecarbon compounds, such as methane and methanol.

TABle 28: Module Coverage of Methane Metabolism.

\begin{tabular}{|c|c|c|c|}
\hline Module No. / Description & Path & $\begin{array}{l}\text { No. of } \\
\text { KEGG } \\
\text { Ortholog }\end{array}$ & Coverage \\
\hline M00357 Methanogenesis (acetate $=>$ methane) & $\begin{array}{l}\text { map01200 } \\
\text { map00680 }\end{array}$ & 678 & $\begin{array}{l}2 \text { blocks } \\
\text { missing }\end{array}$ \\
\hline M00356 Methanogenesis (methanol => methane) & $\begin{array}{l}\text { map01200 } \\
\text { map00680 }\end{array}$ & 347 & $\begin{array}{l}2 \text { blocks } \\
\text { missing }\end{array}$ \\
\hline M00358 Coenzyme M biosynthesis & map00680 & 28 & $\begin{array}{l}1 \text { block } \\
\text { missing }\end{array}$ \\
\hline M00608 2-Oxocarboxylic acid chain extension & $\begin{array}{l}\operatorname{map} 01210 \\
\operatorname{map} 00680\end{array}$ & 7 & $\begin{array}{l}1 \text { block } \\
\text { missing }\end{array}$ \\
\hline M00346 Formaldehyde assimilation (serine pathway) & $\begin{array}{l}\text { map01200 } \\
\text { map00680 }\end{array}$ & 351 & $\begin{array}{l}2 \text { blocks } \\
\text { missing }\end{array}$ \\
\hline $\begin{array}{l}\text { M00345 Formaldehyde assimilation (ribulose } \\
\text { monophosphate pathway) }\end{array}$ & $\begin{array}{l}\operatorname{map} 01200 \\
\text { map00680 }\end{array}$ & 227 & complete \\
\hline $\begin{array}{l}\text { M00344 Formaldehyde assimilation (xylulose } \\
\text { monophosphate pathway) }\end{array}$ & $\begin{array}{l}\text { map01200 } \\
\text { map00680 }\end{array}$ & 83 & $\begin{array}{l}1 \text { block } \\
\text { missing }\end{array}$ \\
\hline M00378 F420 biosynthesis & map00680 & 53 & complete \\
\hline M00422 Acetyl-CoA pathway & map00680 & 83 & complete \\
\hline
\end{tabular}

Experimental data mapped on the reference pathway provides a comprehensive overall view of methane metabolism. Figure 22 and Figure 23 shows the pathway and coverage. There are different categories of methanogenic pathways observed in prokaryotes; $\mathrm{CO}_{2}$ to methane, methanol to methane, and acetate to methane. Coenzyme $M$ is used by 
methanogens as the terminal methyl carrier in methanogenesis. Coenzyme $M$ biosynthesis requires 4 enzymes. The presence of 3 out of these 4 enzymes for Coenzyme $\mathrm{M}$ biosynthesis were detected in Lonar sediment metagenome shown in the Figure 23 as enzyme commission (EC) number 4.4.1.19 (phosphosulfolactate synthase), 3.1.3.71 (2phosphosulfolactate phosphatase) and 4.1.1.79 (sulfopyruvate decarboxylase). CoenzymeB-CoenzymeM heterodisulfide reductase $(\mathrm{Hdr})$ is required for the final reaction steps of the methanogenic pathway (Madadi-Kahkesh, Duin et al. 2001, Mander, Duin et al. 2002, Hedderich, Hamann et al. 2005). We were able to detect this Hdr in Lonar sediment metagenome, shown in the Figure 22 as EC number 1.8.98.1. One of the key enzymes of methanogenesis is methyl-coenzyme $M$ reductase, which catalyzes the final step in methanogenesis (Rospert, Breitung et al. 1991, Hallam, Girguis et al. 2003, Dhillon, Lever et al. 2005, Ferry 2011, Zeleke, Lu et al. 2013). We have detected this methylcoenzyme M reductase in Lonar sediments, shown as E.C. 2.8.4.1 in the Figure 22.

Formaldehyde is formed by oxidation of methane by methanotrophs and methylotrophs. This formaldehyde proceeds further by oxidation to $\mathrm{CO}_{2}$ for an energy source or assimilation for biosynthesis of organic matter. Different pathways convert formaldehyde to two-carbon or three-carbon compounds. These pathways are serine pathway and ribulose monophosphate pathway. The enzymes known as methane monooxygenases, oxidize methane to methanol (Nielsen, Gerdes et al. 1996, Hakemian and Rosenzweig 2007, Sirajuddin and Rosenzweig 2015). In our sample, we were unable to detect the presence of methane monooxygenases as shown in Figure 22 as EC number 1.14.13.25 and 1.14.18.3. However, methanol dehydrogenase (EC 1.1.2.7) was observed in Lonar sediment. Methanol dehydrogenase acts on methanol and other primary alcohols (including ethanol, duodecanol, chloroethanol, cinnamyl alcohol) resulting in the formation of formaldehyde (Patel and Felix 1976, Dumont and Murrell 2005). 


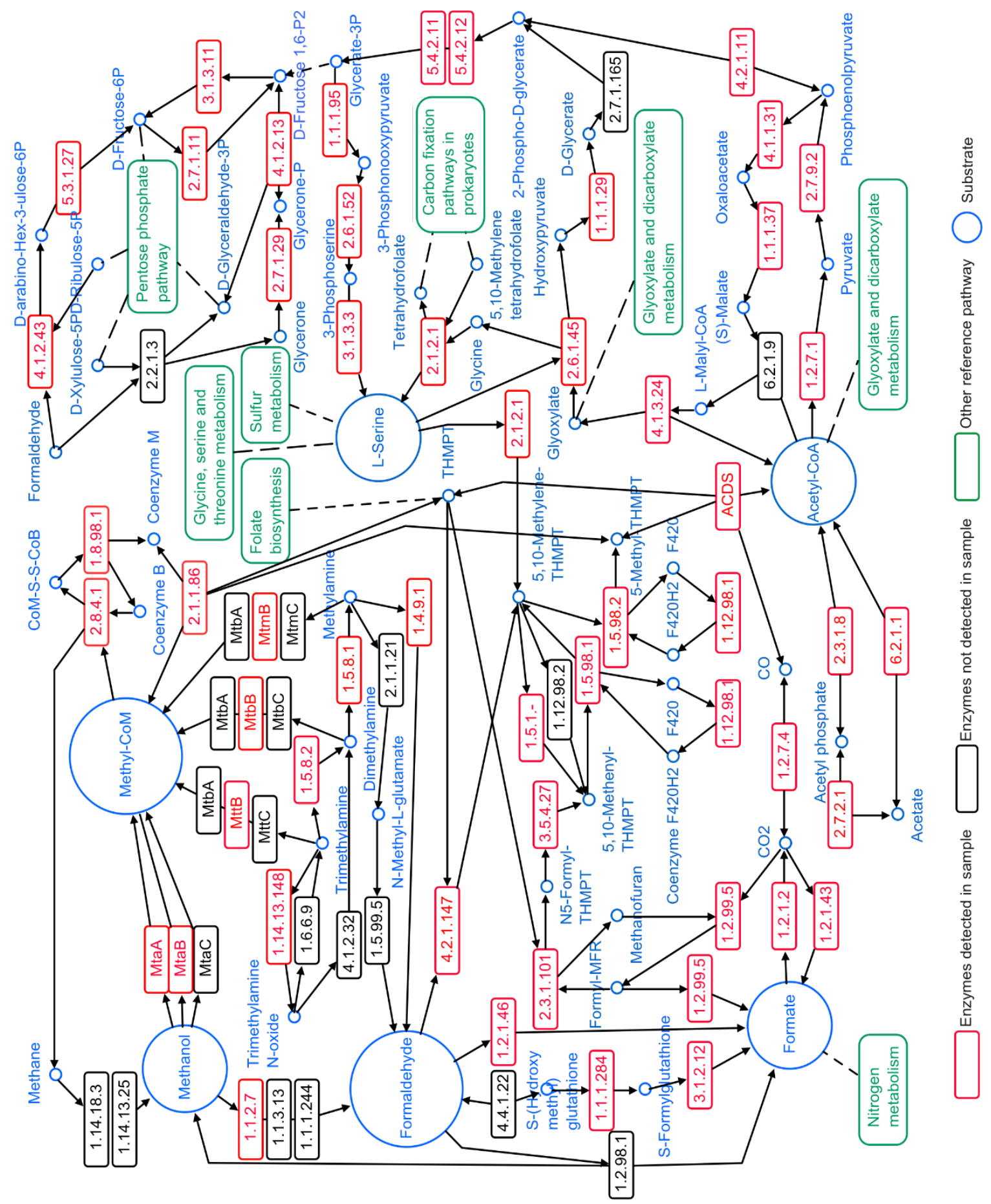

Figure 22: Methane Metabolism (A). The figure shows experimental data (red) mapped on the reference pathway. 
Coenzyme B biosynthesis

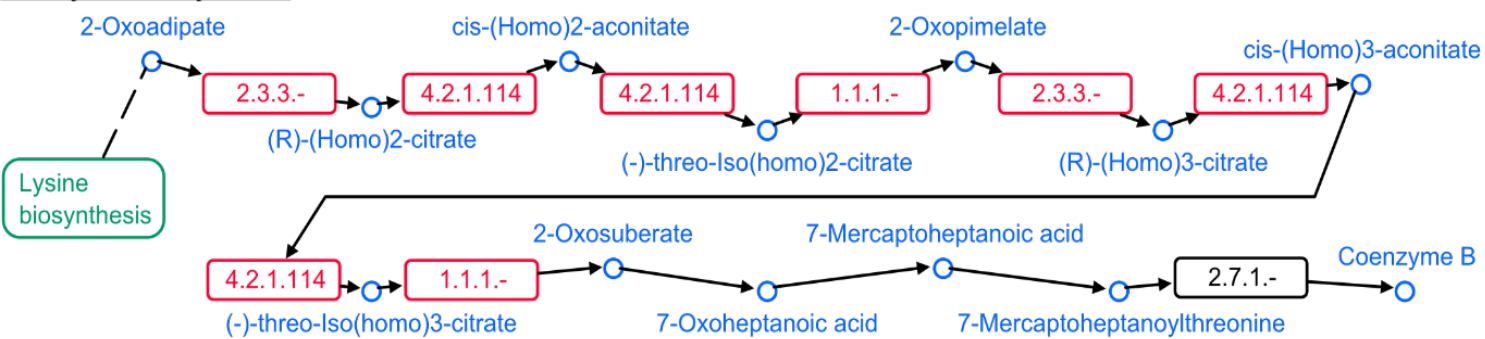

Coenzyme M biosynthesis

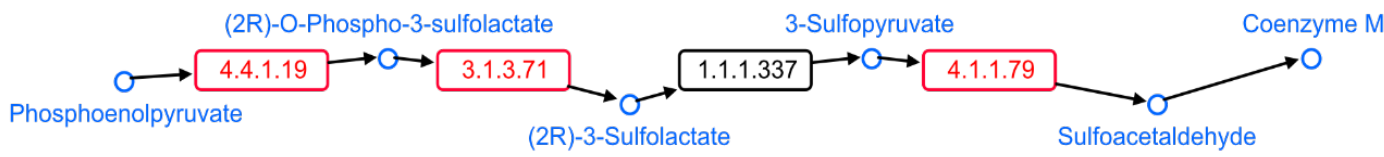

Coenzyme F420 biosynthesis

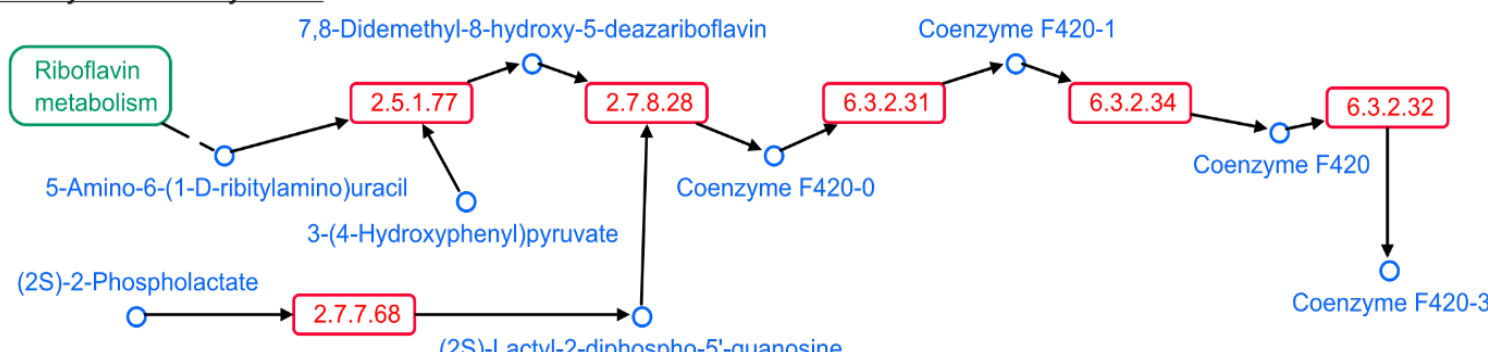

(2S)-Lactyl-2-diphospho-5'-guanosine

Methanofuran biosynthesis

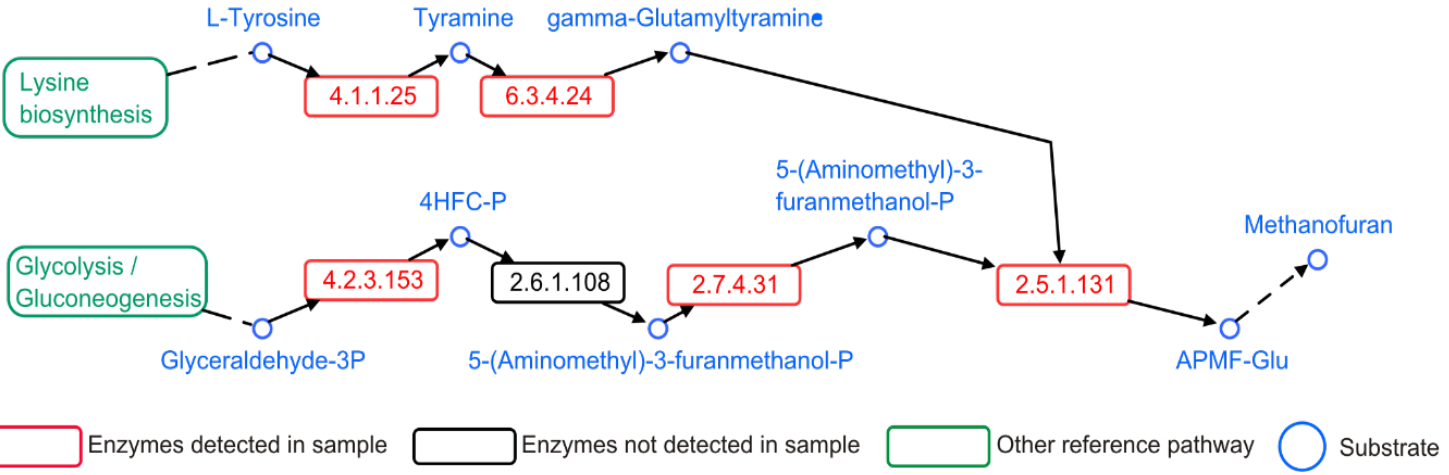

Figure 23: Methane Metabolism (B). The figure shows experimental data (red) mapped on the reference pathway.

\subsubsection{NitRogen MetABOlism}

The multifaceted process of biological nitrogen cycle involves diverse reactions performed by prokaryotes. Nitrogen metabolism alone represents $10.26 \%$ of Energy metabolism and $0.50 \%$ of all metabolism. 5 pathway modules have been detected in this study. Out of these 5, 3 were complete, and 2 were partial. Details are provided in Table 29. During the 
process nitrogen changes its oxidation state varies between +5 in nitrate and -3 in ammonia. There are 4 reductions (Nitrogen fixation, Assimilatory nitrate reduction, Dissimilatory nitrate reduction, Denitrification) and 2 oxidations (Nitrification, Anaerobic ammonium oxidation) pathway involved in the nitrogen cycle.

TAble 29: Module coverage of Nitrogen metabolism.

\begin{tabular}{llrl}
\hline Module No. / Description & Path & $\begin{array}{l}\text { No. of KEGG } \\
\text { Ortholog }\end{array}$ & Coverage \\
\hline M00175 Nitrogen fixation & map00910 & 2 & 1 block missing \\
M00531 Assimilatory nitrate reduction & map00910 & 42 complete \\
M00530 Dissimilatory nitrate reduction & map00910 & 184 complete \\
M00529 Denitrification & map00910 & 177 complete \\
M00804 Complete nitrification & map00910 & 63 2 blocks missing \\
\hline
\end{tabular}

Experimental data mapped on the reference pathway provides a comprehensive overall view of nitrogen metabolism. Figure 24 and Figure 25 shows the pathway and coverage. Atmospheric molecular nitrogen is reduced to ammonia by nitrogen fixation. The reaction is catalyzed by the nitrogenase enzyme system (Kim and Rees 1994, Fani, Gallo et al. 2000, Henson, Watson et al. 2004). In our sample, we detected nitrogenase (genes coding for nitrogenase) as shown in Figure 24 as EC number 1.18.6.1 and in Figure 25 as NifDHK. Assimilatory nitrate reduction and dissimilatory nitrate reduction convert nitrate to ammonia. In the process of assimilatory nitrate reduction, nitrate reductase (EC 1.7.99.4) and ferredoxin nitrite reductase (EC 1.7.7.1) are important enzymes (Pino, Olmo-Mira et al. 2006, Martinez-Espinosa, Lledo et al. 2007, Imamura, Terashita et al. 2010). Both of them have been detected in our assessment as NasAB and NirA as shown in the Figure 25. Also in the Figure 24 , nitrate reductase is shown as EC number 1.7.99.4. The process of dissimilatory nitrate reduction requires nitrate reductase (EC 1.7.5.1 and EC 1.7.99.4,) which converts nitrate to nitrite and nitrite reductase (EC 1.7.1.15 and EC 1.7.2.2) which converts nitrite to ammonia(Bursakov, Carneiro et al. 1997, Smith, Nedwell et al. 2007, Tamegai, Ikeda et al. 2007, Dong, Smith et al. 2009, Kuroki, Igarashi et al. 2014, Mauffrey, Martineau et al. 2015). In the Lonar sediment, we observed all of these enzymes, shown in the Figure 25 as NarGHU, NapAB, NirBD and NrfAH. Denitrification reduces nitrate or nitrite by using them as a terminal electron acceptor and returning $\mathrm{N}_{2}, \mathrm{NO}$ and $\mathrm{N}_{2} \mathrm{O}$ to the atmosphere (Yan, Yang et al. 2005, Barth, Isabella et al. 2009, Torres, Rubia et al. 2011, 
Torres, Rubia et al. 2014). We observed the presence of all the enzymes (genes coding for the enzymes) in sediments of Lonar meteorite crater soda lake shown in the Figure 25 as NarGHU, NapAB, NirK, NirS, NorBC and NosZ. During nitrification ammonia is the oxidized with oxygen into nitrite and nitrite into nitrate. In this process ammonia monooxygenase (EC 1.14.99.39), hydroxylamine dehydrogenase (EC 1.7.2.6) and nitrate reductase (EC 1.7.99.4) catalyzes the reactions converting ammonia to hydroxylamine, hydroxylamine to Nitrite and finally nitrite to nitrate. However, we were able to detect only the nitrate reductase, shown in the Figure 25 as NxrAB. Oxidation of ammonium $\left(\mathrm{NH}_{4}{ }^{+}\right)$to $\mathrm{N}_{2}$ is performed by anaerobic ammonium oxidation (Anammox), where nitrite is used as an electron acceptor. The key enzyme of this process is hydrazine oxidoreductase (EC 1.7.99.8) that converts hydrazine to nitrogen (Jetten, Strous et al. 1998, Schalk, de Vries et al. 2000, Jetten, Sliekers et al. 2003, Smith, Bohlke et al. 2015). In our sample, we were unable to detect the presence of hydrazine oxidoreductase. However, we detected nitrite reductase (EC 1.7.2.1) shown in the Figure 25 as NirK and NirS that converts nitrite to nitric oxide. This nitric oxide combined with ammonia forms hydrazine.

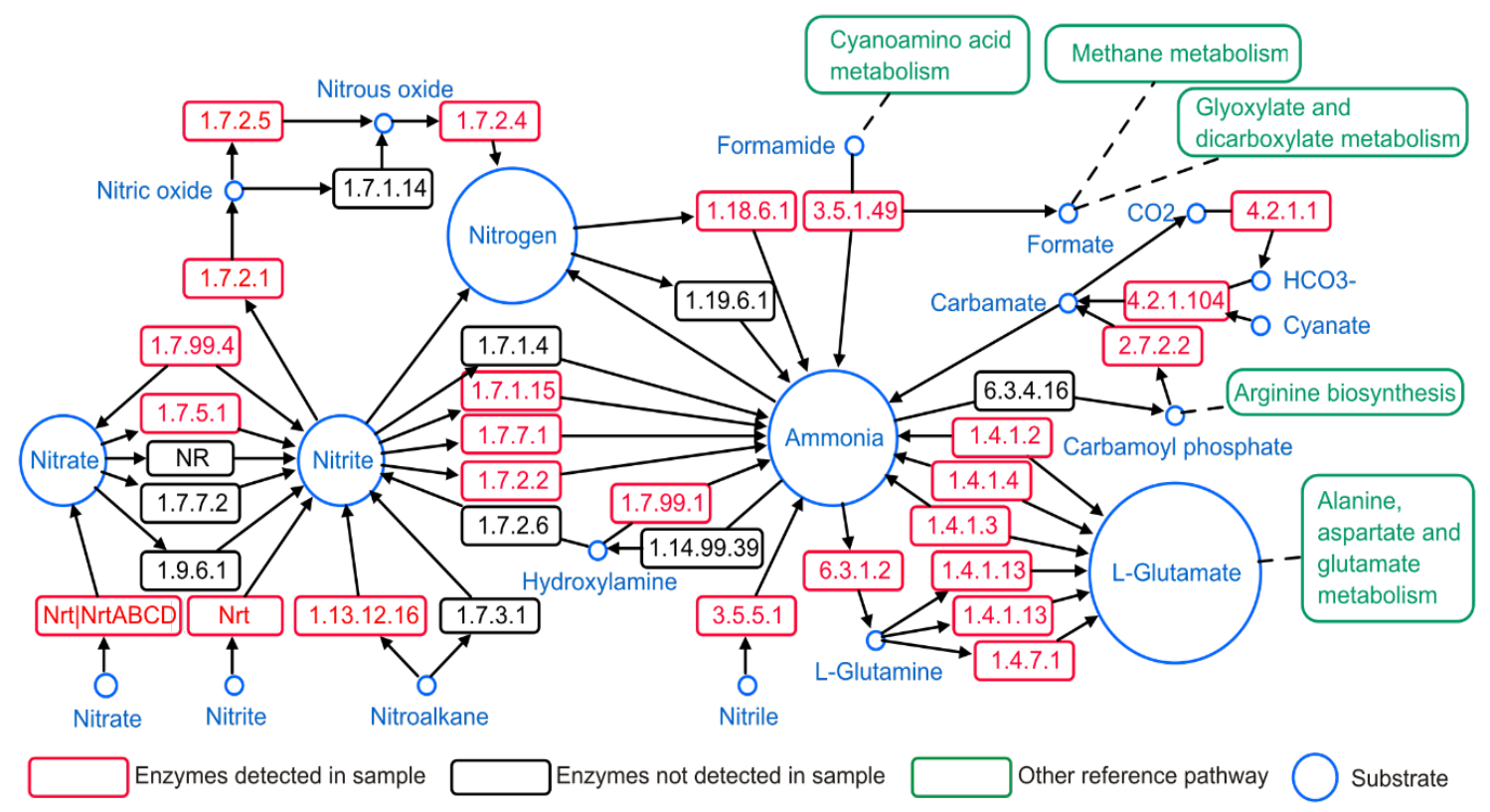

Figure 24: Nitrogen Metabolism (A). The figure shows experimental data (red) mapped on the reference pathway. 

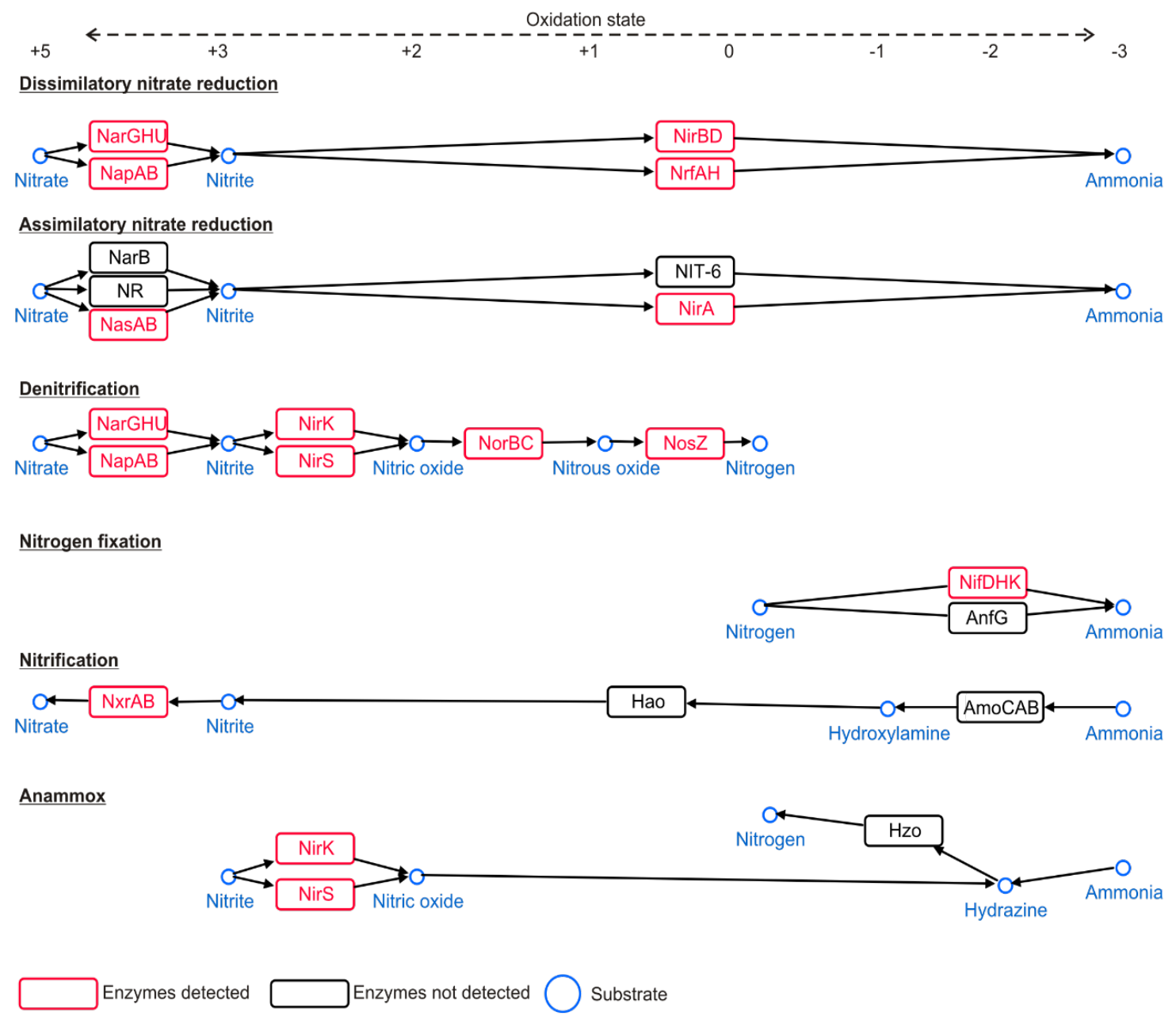

Figure 25: Nitrogen Metabolism (B). The figure shows experimental data (red) mapped on the reference pathway.

\subsubsection{SULFUR METABOLISM}

In the global sulfur cycle, a significant role is played by organic sulfur compound metabolism. Sulfur metabolism alone represents $13.95 \%$ of Energy metabolism and 0.68 $\%$ of all metabolism in Lonar sediments. 3 pathway modules have been detected in this study. Out of these 3, 2 were complete, and 1 was partial. Details are provided in Table 30. Different oxidation states of sulfur are present in the sulfur cycle, between +6 in sulfate and -2 in sulfide. 
Table 30: Module coverage of Sulfur metabolism.

\begin{tabular}{lllll}
\hline Module No. / Description & Path & $\begin{array}{l}\text { No. of } \\
\text { KEGG } \\
\text { Ortholog }\end{array}$ & Coverage \\
\hline M00176 Assimilatory sulfate reduction & map00920 & 197 & complete \\
M00596 Dissimilatory sulfate reduction & map00920 & $79 \quad$ complete \\
M00595 Thiosulfate oxidation by SOX complex & map00920 & 20 & 1 block missing \\
\hline
\end{tabular}

Experimental data mapped on the reference pathway provides a comprehensive overall view of nitrogen metabolism. Figure 26 and Figure 27 shows the pathway and coverage. Sulfate is reduced by assimilatory pathway and dissimilatory pathway (Peck 1961). During biosynthesis of sulfur-containing amino acids, sulfur compounds are reduced by assimilatory pathway (Cuhel, Taylor et al. 1981, Cuhel, Taylor et al. 1982, Daniels, Belay et al. 1986, Liu, Beer et al. 2012). In the case of the dissimilatory pathway, sulfate or sulfur is used as the terminal electron acceptor and inorganic sulfide is produced. The initial step of the assimilatory and dissimilatory pathway is the activation of sulfate that forms adenylyl-sulfate(APS) using ATP (Neumann, Wynen et al. 2000). Sulfate adenylyltransferase (EC 2.7.7.4) is the enzyme that activates sulfate and forms adenylylsulfate(APS) was detected in our sample and shown in Figure 27 as Sat and CysND. This APS, by assimilatory pathway, is transformed to 3'-phospho-adenylyl-sulfate (PAPS) and further reduced to sulfite. This sulfite is again reduced to sulfide. Some of the other enzymes of assimilatory sulfate reduction were also observed. For example, adenylylsulfate kinase (EC 2.7.1.25), phosphoadenylyl-sulfate reductase (EC 1.8.4.8) and assimilatory sulfite reductase (EC 1.8.1.2) were detected and shown in Figure 27 as CysC, CysH, CysJ and Sir. In the case of the dissimilatory pathway, APS is directly reduced to sulfite. This sulfite is again reduced to sulfide (Basen, Kruger et al. 2011, Bradley, Leavitt et al. 2011, Barton, Fardeau et al. 2014). We were able to detect all the enzymes involved in the process such as sulfate adenylyltransferase (EC 2.7.7.4), adenylyl-sulfate reductase (EC 1.8.99.2) and dissimilatory sulfite reductase (EC 1.8.99.5) in the Figure 27 as Sat, AprAB and DsrAB. The sulfur oxidation capacity of the SOX system (sulfur oxidation) is a wellrecognized sulfur oxidation pathway (Wodara, Kostka et al. 1994, Quentmeier, Hellwig et al. 2003, Ghosh and Dam 2009, Grimm, Franz et al. 2011, Yin, Zhang et al. 2014). All the enzymes of SOX system were detected in our sample as shown in the Figure 27. During 
anoxygenic photosynthesis by green and purple sulfur bacteria, reduced sulfur compounds such as sulfide, elemental sulfur, and thiosulfate are used as the electron donor.

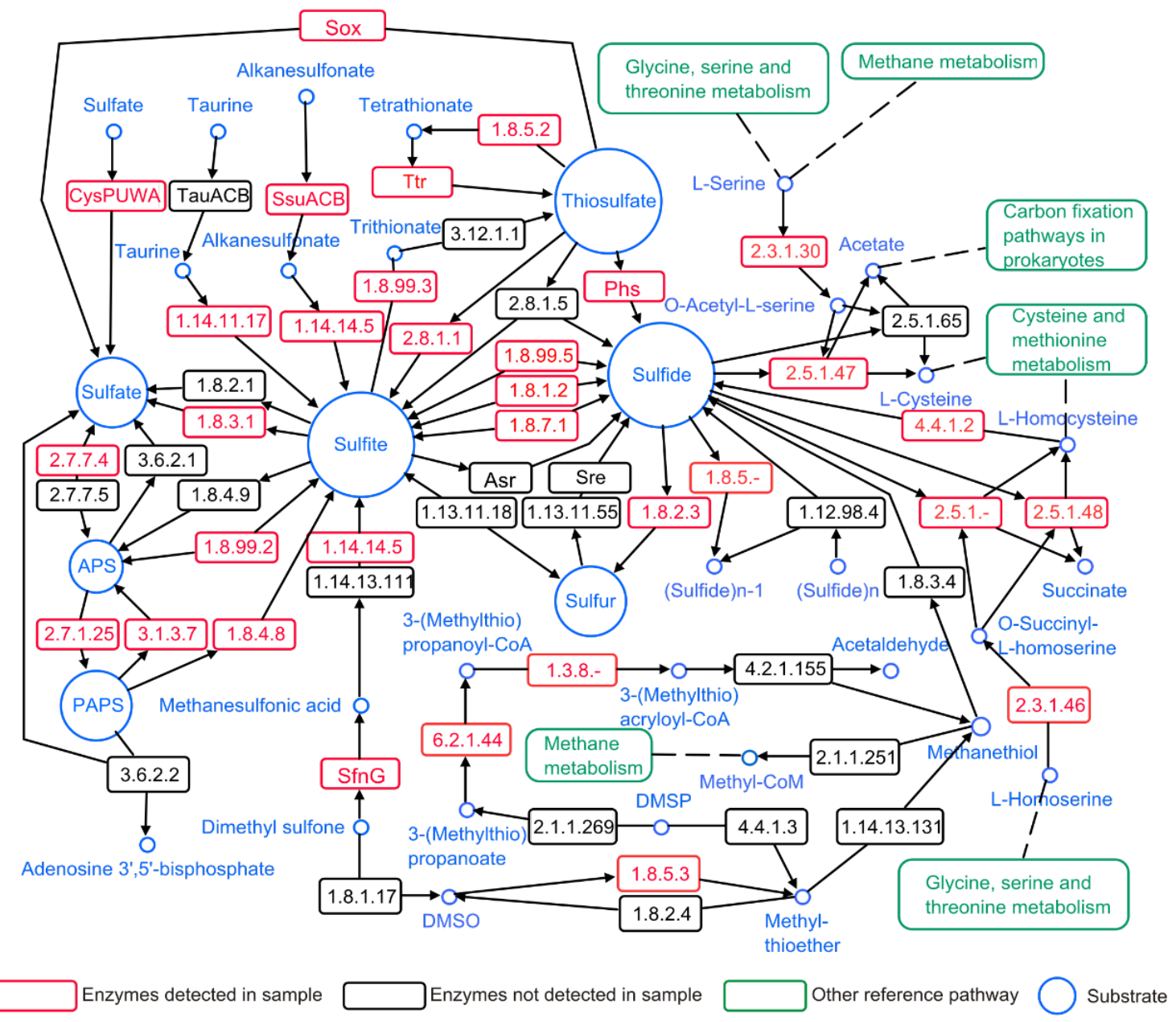

Figure 26: Sulfur Metabolism (A). The figure shows experimental data (red) mapped on the reference pathway. 


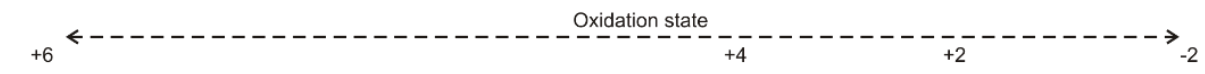

Assimilatory sulfate reduction

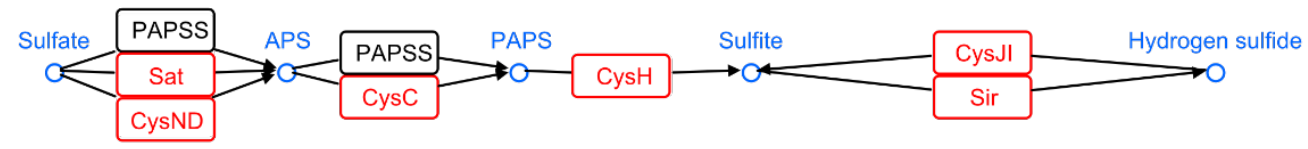

Dissimilatory sulfate reduction and oxidation

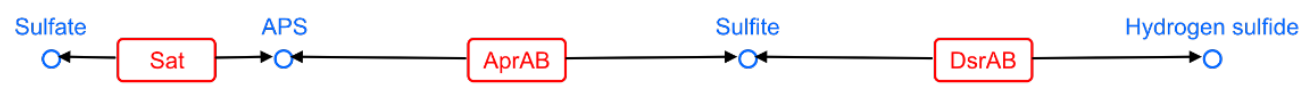

soX system

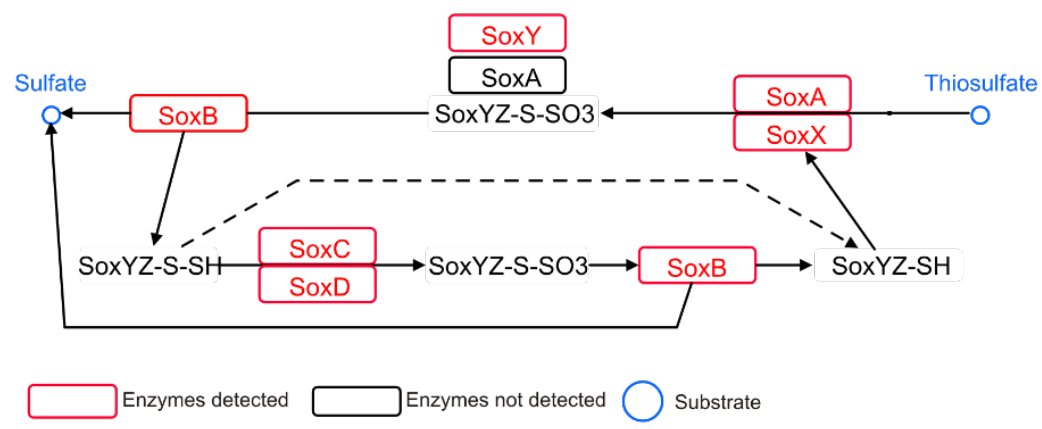

Figure 27: SUlfur METABOLISM (B). The figure shows experimental data (red) mapped on the reference pathway. 


\subsection{COMMUNITY DYNAMICS DURING MICROENVIRONMENTAL PH HOMEOSTASIS}

\subsubsection{SHIFT OF EXTRACELLULAR PH}

The measured $\mathrm{pH}$ of the surface water of Lonar Meteorite Crater Soda Lake ranged between $\mathrm{pH} 9.19$ to $\mathrm{pH}$ 10.5, indicating pronounced seasonality (Badve, Kumaran et al. 1993, Siddiqi 2007). $\mathrm{pH}$ of the sediment itself was recorded at pH 9.65, and in our sample we found it to be $\mathrm{pH} 9.9$, but there is no record of seasonality or maximum and minimum pH variation (Kanekar, Sarnaik et al. 1998). The objective of this experiment was to investigate how this microbial community responds to nonoptimal microenvironmental $\mathrm{pH}$. The prokaryotic cultures were set up using modified Horikoshi media as described in 3.11. The $\mathrm{pH}$ was adjusted to $\mathrm{pH} 9$ (suboptimal) and $\mathrm{pH} 10$ (superoptimal) with sterile $\mathrm{NaOH}$, respectively.

All the measured $\mathrm{pH}$ values from both the superoptimal and suboptimal systems in triplicates at all the time points from t0 to t5 (day 0 to day 25 with a resolution of 5 days) were recorded (Figure 28). The modified Horikoshi medium contains glucose; as a result, we observed a rapid acidification in the beginning (Solé, Lorén et al. 2010). This phenomenon was observed till $\mathrm{t} 1$ in both the suboptimal and superoptimal systems. In superoptimal system pH dropped from pH 10.094 ( \pm 0.049$)$ to $\mathrm{pH} 8.193( \pm 0.075)$ and in suboptimal system $\mathrm{pH}$ dropped from $\mathrm{pH} 9.054( \pm 0.024)$ to $\mathrm{pH} 7.7( \pm 0.087)$. From t2 to t5 in both systems $\mathrm{pH}$ gradually increased to $\mathrm{pH} 9.253( \pm 0.066)$ and $\mathrm{pH} 9.286( \pm 0.053)$ in the superoptimal system and suboptimal system respectively. In this study, we found that the initial $\mathrm{pH}$ difference between both the systems of 1.04 unit of $\mathrm{pH}$ decreased to 0.032 unit of $\mathrm{pH}$. Which in terms of $\mathrm{H}^{+}$ion concentration translates to more than 10 fold. However, the interesting fact is that in both systems, irrespective of initial $\mathrm{pH}$, the final $\mathrm{pH}$ is approximately $\mathrm{pH} 9.3$ (9.253 and 9.286), which is close to the reported $\mathrm{pH}$ of the sediment of $\mathrm{pH} 9.65$. 


\section{Change of Culture Filtrate $\mathrm{pH}$}

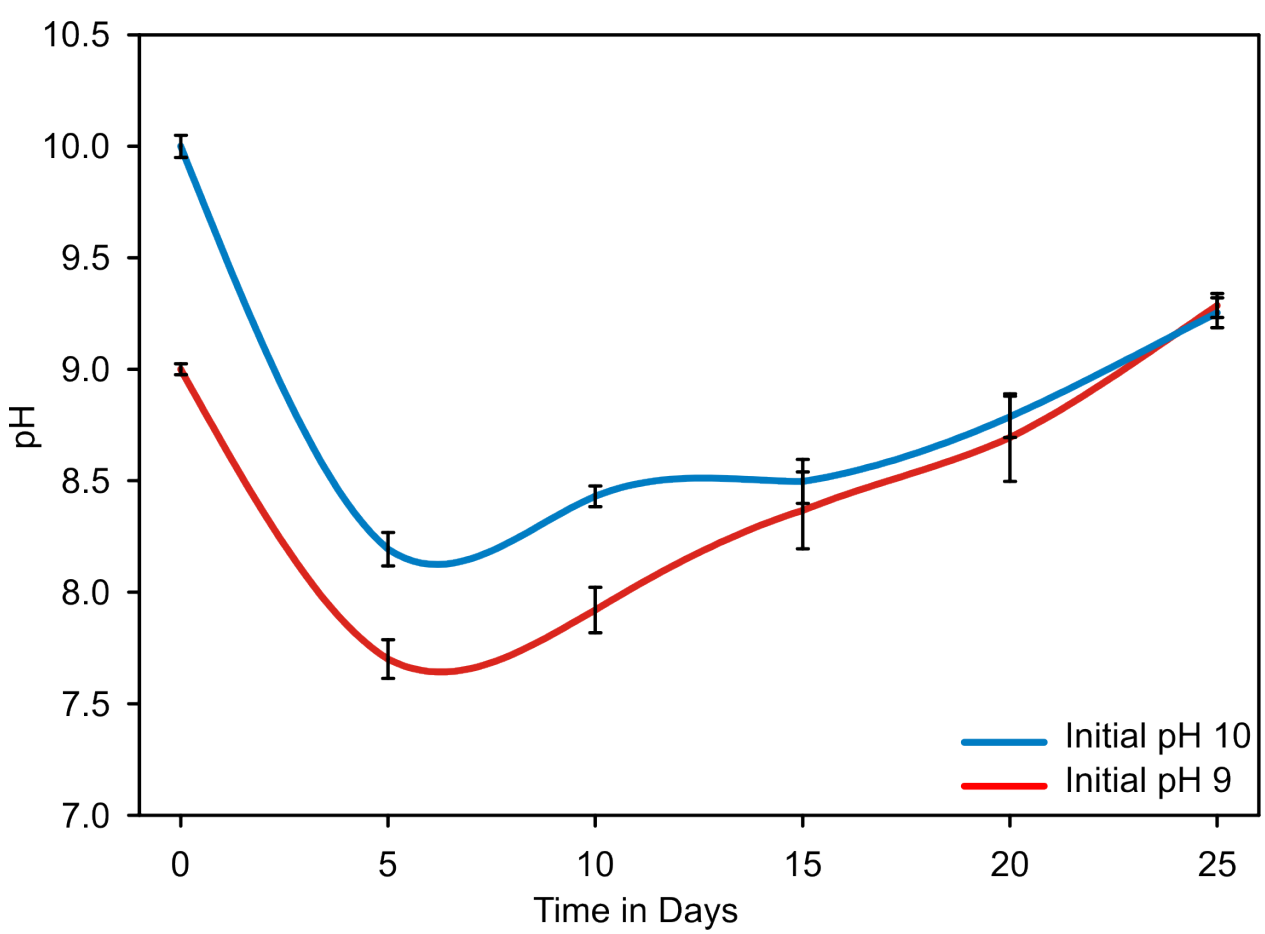

Figure 28: Change of Extracellular PH. The Figure Shows Changes in Microenvironmental $\mathrm{pH}$ with Time. The Blue line depicts the Changes of $\mathrm{pH}$ in the Superoptimal $\mathrm{pH}$ System and Red line depicts the Changes in the Suboptimal $\mathrm{pH}$ System.

\subsubsection{DifFERENTIAL UtILIZATION Of DifFERENT AMINo ACIDS IN SUBOPTIMAL AND SUPEROPTIMAL PH}

Amino acid content of the culture filtrate at to was considered as baseline and culture filtrate at $\mathrm{t} 4$ was compared in both the $\mathrm{pH}$ system to detect any changes. We observed that $\mathrm{NH}_{3}$ and hydroxyproline behave oppositely depending on the $\mathrm{pH}$ system they were exposed to. The amount of $\mathrm{NH}_{3}$ increases in the medium when exposed to suboptimal $\mathrm{pH}$ but decreases when exposed to superoptimal $\mathrm{pH}$. Similarly, hydroxyproline also increases in suboptimal $\mathrm{pH}$ but increases in superoptimal $\mathrm{pH}$. Details are shown in Figure 29. From these observations, it is evident that $\mathrm{NH}_{3}$ and hydroxyproline metabolism does have some effect on the $\mathrm{pH}$ dynamics. 


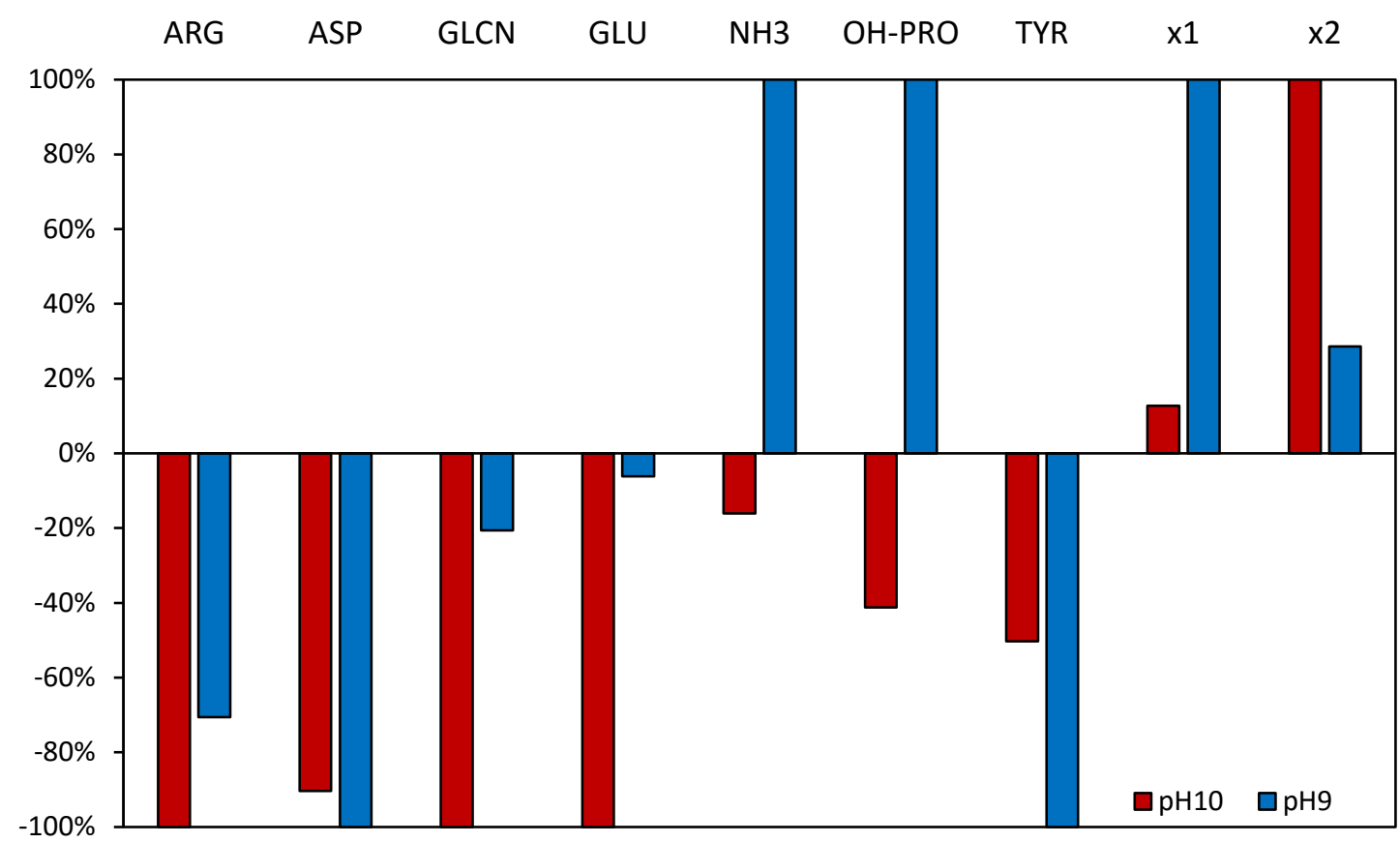

FiguRE 29: CHANGES IN THE MICROENVIRONMENT IN RESPONSE TO SUBOPTIMAL OR SUPEROPTIMAL PH. Amino acids are given above the respective bars. $\mathrm{pH} 9$ is considered as suboptimal, and $\mathrm{pH}$ is considered as superoptimal.

\subsubsection{Prokaryotic Diversity, RICHNess ANd Distribution Of TAXa}

Two $\mathrm{pH}$ system (suboptimal and superoptimal), 5 time points (t1 to t5) in triplicates and t0 (original sediment) resulted in a total of 33 samples. For details see 3.11 . From these 33 samples a total of 235,943 archaeal and 1,657,168 bacterial sequences were found. We observed an average coverage of $71.04 \%( \pm 2.5)$ in Archaea with maximum and minimum coverage as $73.96 \%$ and $65.7 \%$. For Bacteria, the average coverage was 85.56 $\%( \pm 8.3)$, maximum and minimum coverages were $95.13 \%$ and $63.17 \%$ (Table 31 ). 
Table 31: General Analysis of Sequence Data.

\begin{tabular}{|c|c|c|c|c|c|c|}
\hline \multicolumn{7}{|c|}{ Archaea (1,038 Sequences / Sample) } \\
\hline & chao1 & $\begin{array}{l}\text { Michaelis- } \\
\text { Menten } \\
\text { Fit }\end{array}$ & $\begin{array}{l}\text { Observed } \\
\text { OTUs }\end{array}$ & $\begin{array}{l}\text { Shannon } \\
\text { Index }\end{array}$ & $\begin{array}{l}\text { Simpson } \\
\text { Index }\end{array}$ & Coverage \\
\hline Average & $\begin{array}{l}228.61 \\
3\end{array}$ & 155.892 & 110.444 & 4.836 & 0.936 & $71.04 \%$ \\
\hline Maximum & $\begin{array}{l}287.66 \\
7\end{array}$ & 185.696 & 122 & 4.913 & 0.94 & $73.96 \%$ \\
\hline Minimum & $\begin{array}{l}188.07 \\
9\end{array}$ & 138.719 & 102.6 & 4.763 & 0.934 & $65.70 \%$ \\
\hline $\begin{array}{l}\text { Standard } \\
\text { Deviation }\end{array}$ & 34.039 & 14.178 & 6.201 & 0.055 & 0.001 & 2.506 \\
\hline \multicolumn{7}{|c|}{ Bacteria (19,920 Sequences / Sample) } \\
\hline & chao1 & $\begin{array}{l}\text { Michaelis- } \\
\text { Menten } \\
\text { Fit }\end{array}$ & $\begin{array}{l}\text { Observed } \\
\text { OTUs }\end{array}$ & $\begin{array}{l}\text { Shannon } \\
\text { Index }\end{array}$ & $\begin{array}{l}\text { Simpson } \\
\text { Index }\end{array}$ & Coverage \\
\hline Average & $\begin{array}{l}381.25 \\
3\end{array}$ & 262.765 & 206.975 & 3.616 & 0.833 & $85.56 \%$ \\
\hline Maximum & $\begin{array}{l}1584.9 \\
1\end{array}$ & 1058.121 & 668.4 & 4.205 & 0.914 & $95.13 \%$ \\
\hline Minimum & $\begin{array}{l}146.34 \\
1\end{array}$ & 112.489 & 101 & 2.957 & 0.721 & $63.17 \%$ \\
\hline $\begin{array}{l}\text { Standard } \\
\text { Deviation }\end{array}$ & $\begin{array}{l}374.11 \\
5\end{array}$ & 245.141 & 146.073 & 0.359 & 0.054 & 8.3 \\
\hline
\end{tabular}

In the case of Archaea, 1,071 OTUs were unique. The most dominant genus was Methanocalculus representing $11.77 \%$ of all sequences. In the case of Bacteria, in a total of 33 samples, 3,259 OTUs were unique. The most dominant genus was Exiguobacterium representing $20.4 \%$ of all sequences. There is also an overall initial drop of total number of OTUs in both pH systems and increase at the end (Figure 30). 

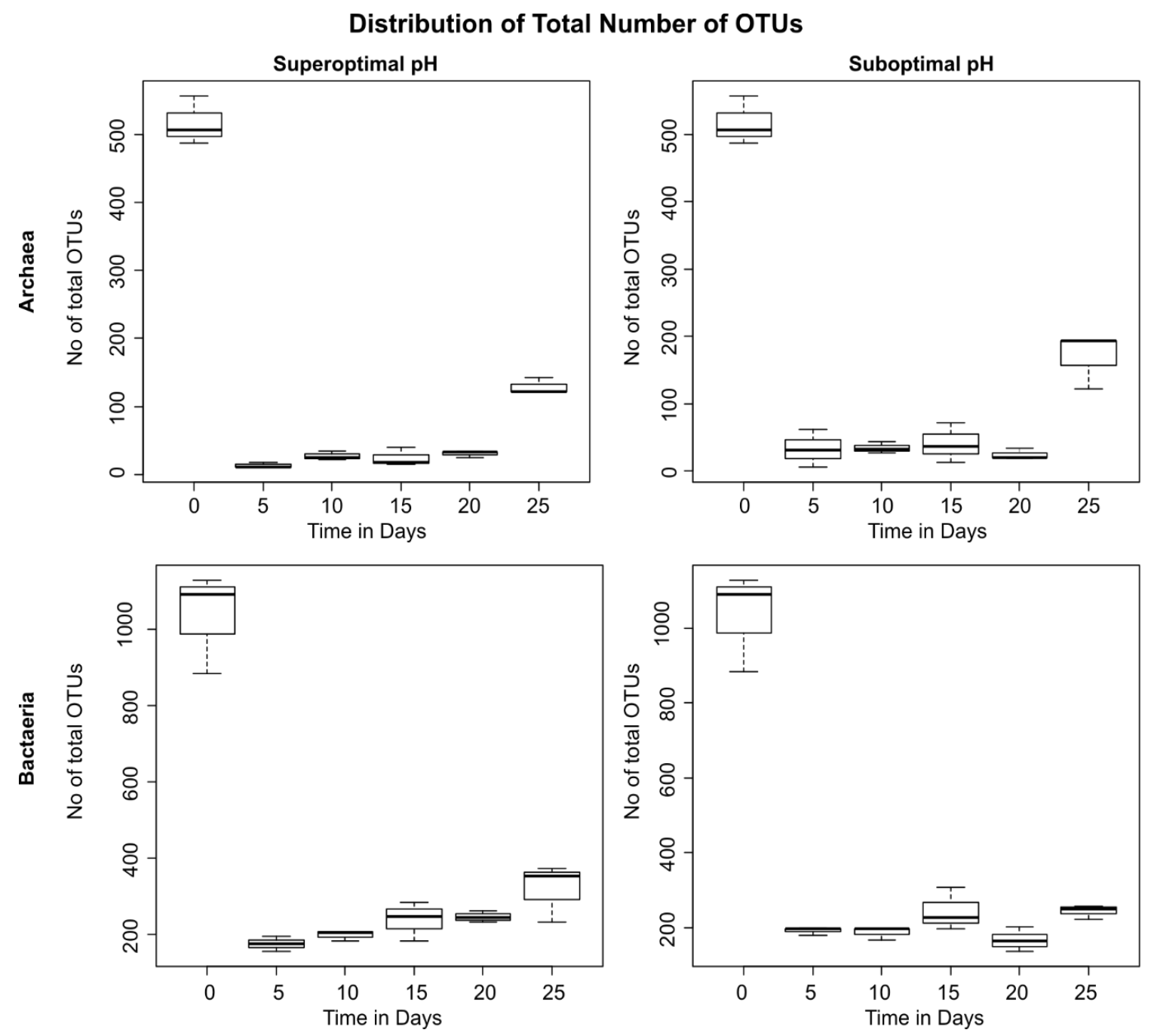

Figure 30: Changes in the Number of OTUs with Time. The Figure shows an overall initial drop of the total number of OTUs and increase at the end in both Superoptimal and Suboptimal pH Systems.

\subsubsection{COMMUNITY DYNAMICS OF PROKARYOTES}

The overarching objective of this experiment was to investigate the community dynamics or changing biodiversity from a temporal perspective as the $\mathrm{pH}$ of the culture changes. Upon reviewing the relative abundance of all the samples at higher level taxa, we can see, there is a fundamental difference in how archaeal and bacterial community responds to exposure to superoptimal or suboptimal pH (Figure 31). 


\section{Overview of Prokaryotic Diversity}
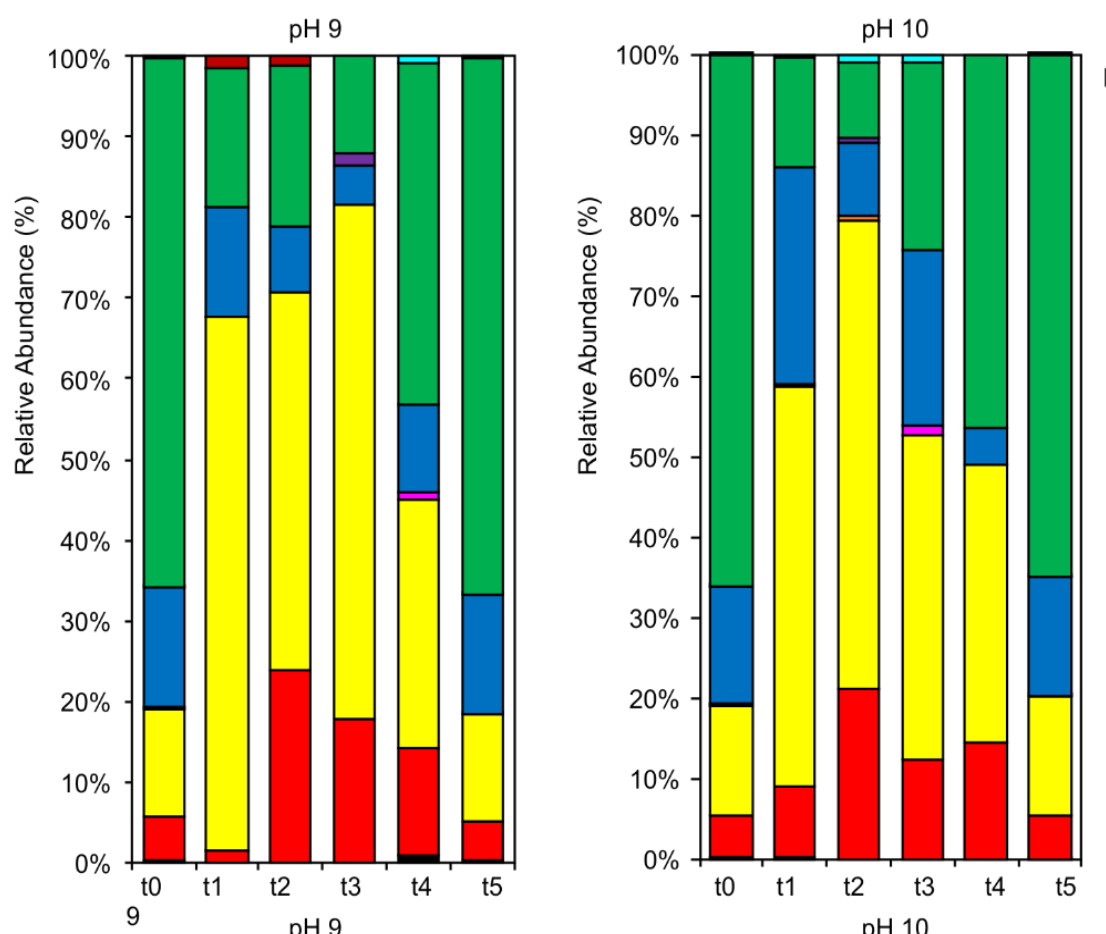

Relative Abundance of Archaea

$$
\text { Phylum }
$$

- Aenigmarchaeota

口 Diapherotrites

- Euryarchaeota

口 Marine Hydrothermal Vent Group(MHVG)

口 Miscellaneous Crenarchaeotic Group

口 Miscellaneous Euryarchaeotic Group(MEG)

口 $S M 1 K 20$

口 Thaumarchaeota

- Woesearchaeota (DHVEG-6)

- others
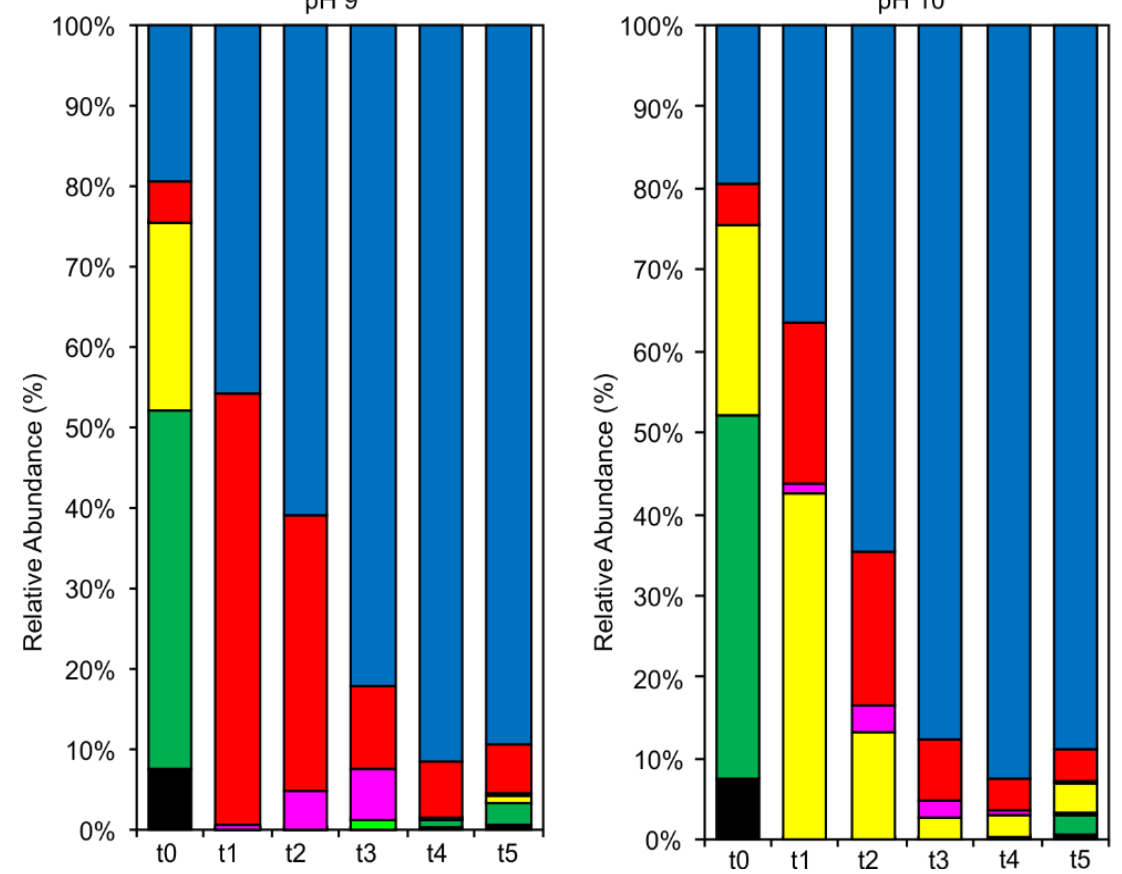

Relative Abundance of Bacteria Order

口 Bacillales

- Clostridiales

口 Haloplasmatales

口 Lactobacillales

口 NB1-n

WN-HWB-116

- Others

Figure 31: Changes in the Prokaryotic Diversity with time. The figure shows changes in relative abundance of archaeal Phylum and bacterial Order in Suboptimal and Superoptimal $\mathrm{pH}$ in relation to time.

Archaeal community changes significantly from to to $\mathrm{t} 1$ but at $\mathrm{t} 5$ in both $\mathrm{pH}$ systems they change gradually and exhibit relative abundance similar to to or original profile. The bacterial community also changes significantly from to to t1 but like the archaeal 
community at $\mathrm{t} 5$ in both $\mathrm{pH}$ systems, they do not show any gradual overall changes in relative abundance to very close relative abundance values of to or original profile. It is noticed that after 25 days of incubation Clostridiales and Haloplasmatales were able to regain its relative abundance closer to its original values in the suboptimal $\mathrm{pH}$ system than in superoptimal pH system.

Looking at the changes in relative abundances of different genera in details, we were able to identify several archaeal and bacterial genera which shows variation. For the purpose of emphasizing on the relative change in population sizes, relative abundance at t0 in the case of both pH systems was considered as 1 or $100 \%$ and variations were plotted as log2 values along the $y$-axis (Figure 32 to Figure 37). Among the Archaea the genera showing significant variations were Candidatus Nitrosopumilus, Natronorubrum, Methanolobus, Halorubrum, Haloterrigena, Halovenus and Halonotius. Among the bacterial genera showing significant variations were Alkalibacterium, Lysinibacillus, Natronincola, Anaerobacillus, Paenibacillus, Anaerovirgula, Desulfitispora, Salimesophilobacter and Clostridium sensu stricto 7.

First of all, we must acknowledge that neither the culture medium nor the culture condition exactly represents the microenvironment of the sediment. Also, the duration of incubation might not be sufficient to let the community work on their microenvironment. However, nonetheless, it can be seen by looking at the dynamics of the above mentioned archaeal and bacterial genera that they can be grouped in to different types of dynamic groups.

\subsubsection{Dynamics Of Archaeal Genera:}

After scrutinizing the growth dynamics of archaeal genera, we were able to identify 7 genera showing significant variation in relative abundance. We were able to group them into 2 groups based on their changing relative abundance pattern. 


\subsection{Dynamic Group Type-Al:}

Five of them namely Natronorubrum, Haloterrigena, Halovenus, Halorubrum and Candidatus Nitrosopumilus show a significant increase in relative abundance in between $\mathrm{t} 2$ and $\mathrm{t} 4 \mathrm{compared}$ to $\mathrm{t} 0$. Then again at $\mathrm{t} 5$, they tend to get closer to the original relative abundance of t0 (Figure 32).

\section{Dynamic Group Type-Al}
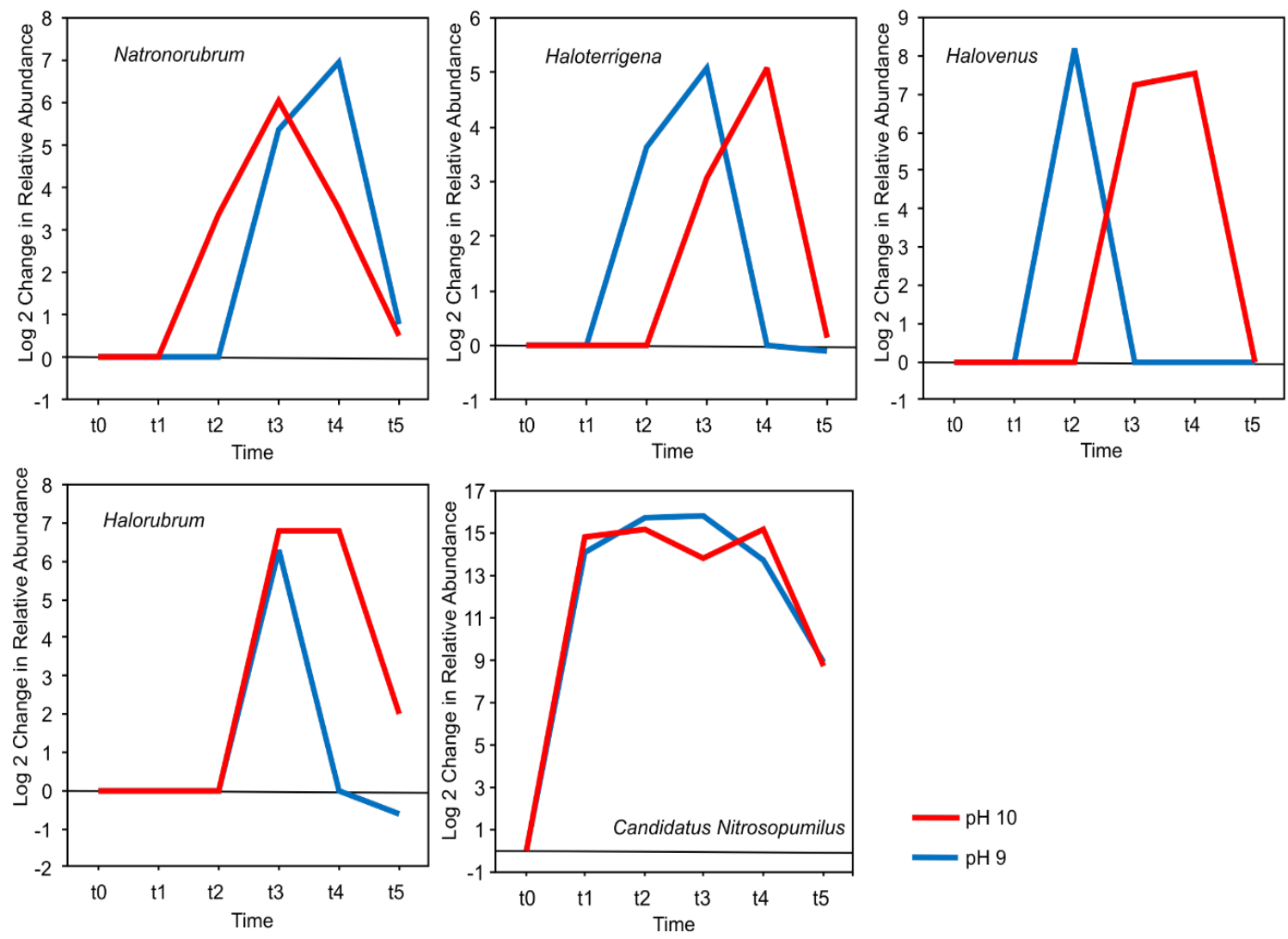

Figure 32: Dynamic Group Type-Al. The figures show changes in relative abundance in Suboptimal and Superoptimal $\mathrm{pH}$ in relation to time.

Natronorubrum reaches its highest relative abundance of $33.333 \%$ in the suboptimal $\mathrm{pH}$ system and $17.777 \%$ in the superoptimal $\mathrm{pH}$ system at $\mathrm{t} 4$ and $\mathrm{t} 3$ respectively. Then decrease to $0.462 \%$ and $0.374 \%$ at t5 which is close to $0.264 \%$ at t0. Natronorubrum have been found and isolated from various habitats like, a soda lake in Tibet, Aibi salt lake in Xin-Jiang (Xu, Zhou et al. 1999), China (Cui, Tohty et al. 2006), Aiding salt lake in XinJiang, China (Cui, Tohty et al. 2007), from sediment of the hypersaline Lake Chagannor in 
Inner Mongolia (Gutierrez, Castillo et al. 2010) and former Lake Texcoco in Mexico (RuizRomero, Valenzuela-Encinas et al. 2013). Most, if not all, of them are known haloalkaliphiles showing growth at $\mathrm{pH}$ as high as 11 with optimal $\mathrm{pH}$ for most of them being between 8.5 to 9.5 and for some of them optimal $\mathrm{NaCl}$ concentration is $3.4 \mathrm{M}$.

Haloterrigena has been reported from different so called extreme habitat, solar salterns of Cabo Rojo, Puerto Rico (Montalvo-Rodriguez, Lopez-Garriga et al. 2000); Aibi salt lake, Xin-Jiang, China (Xu, Liu et al. 2005); Fuente de Piedra salt lake, Spain (Romano, Poli et al. 2007); salt lake Xilinhot in Inner Mongolia, China (Gutierrez, Castillo et al. 2008); salinealkaline soil from Daqing, Heilongjiang Province, China (Wang, Yang et al. 2010). Most of them are extremely halophilic and extremely alkaliphilic, able to grows at a salinity of $5 \mathrm{M}$ $\mathrm{NaCl}$ (Gutierrez, Castillo et al. 2008) and pH 10.5 (Wang, Yang et al. 2010).

Halovenus has been observed in the Aran-Bidgol salt lake, Iran (Makhdoumi-Kakhki, Amoozegar et al. 2012); Isla Bacuta saltern, Huelva, Spain (Infante-Dominguez, Corral et al. 2015). Most of them are extremely halophilic and alkaliphilic, able to grows at a salinity of $5.1 \mathrm{M} \mathrm{NaCl}$ (approximately, actual $30 \%$ w/v) (Infante-Dominguez, Corral et al. 2015) and $\mathrm{pH} 9$.

Halorubrum has been observed in extremely diverse but polyextremophilic habitats, in Lake Tebenquiche, situated in the northern part of the Atacama Saltern, Chile (Lizama, Monteoliva-Sanchez et al. 2002); from Lake Zabuye, on the Tibetan Plateau; China (Fan, Xue et al. 2004); soda lake in Xinjiang, China (Feng, Zhou et al. 2005); Lake Ejinor, a saline lake in Inner Mongolia, China (Castillo, Gutierrez et al. 2006); Aibi salt lake and Aiding salt lake in Xin-Jiang, China (Cui, Tohty et al. 2006); Ayakekum salt lake on the Qinghai-Tibet Plateau (Xu, Wu et al. 2007); Laguna Antofalla in the Argentinian Puna (Burguener, Maldonado et al. 2014); hypersaline lake Aran-Bidgol in Iran (Corral, de la Haba et al. 2016); water and silt sample from Burlinskoye Lake, Altai Krai, Russia (Rozanov, Bryanskaya et al. 2015); subterranean salt mine in Yunnan, China (Chen, Liu et al. 2015). Most of the members of Halorubram genus are extremely halophilic and often alkaliphilic growing at salinity as high as $5 \mathrm{M} \mathrm{NaCl}$ (Gutierrez, Castillo et al. 2011) and pH 10 (Hu, Pan et al. 2008).

Candidatus Nitrosopumilus have been isolated and reported before from varies kind of environment; marine sediment from Svalbard, the Arctic Circle (Park, Kim et al. 2012), 
estuary of San Francisco Bay (Mosier, Allen et al. 2012), pelagic redoxcline in the central Baltic Sea (Labrenz, Sintes et al. 2010) similar sequences has also been reported from underwater cave systems, beneath Australia's vast, dry Nullarbor Plain (Tetu, Breakwell et al. 2013) and the Yellowstone geothermal complex, USA (Kan, Clingenpeel et al. 2011). Candidatus Nitrosopumilus is a known ammonia-oxidizing archaeon.

\subsection{Dynamic Group Type-All:}

In two other genera, Methanolobus and Halonotius similar behavior was observed in the beginning as they show an increase in relative abundance in between $\mathrm{t} 1$ and $\mathrm{t} 4$. Later at t5, although they tend to decrease to the original relative abundance, the similarity is not as close as the first discussed group of archaeal genera. Most logically significant feature to group them apart is that Methanolobus and Halonotius do not behave similarly in suboptimal and superoptimal pH system. Unlike Type-Al, they show these dynamics only in one system (Figure 33).

\section{Dynamic Group Type-All}
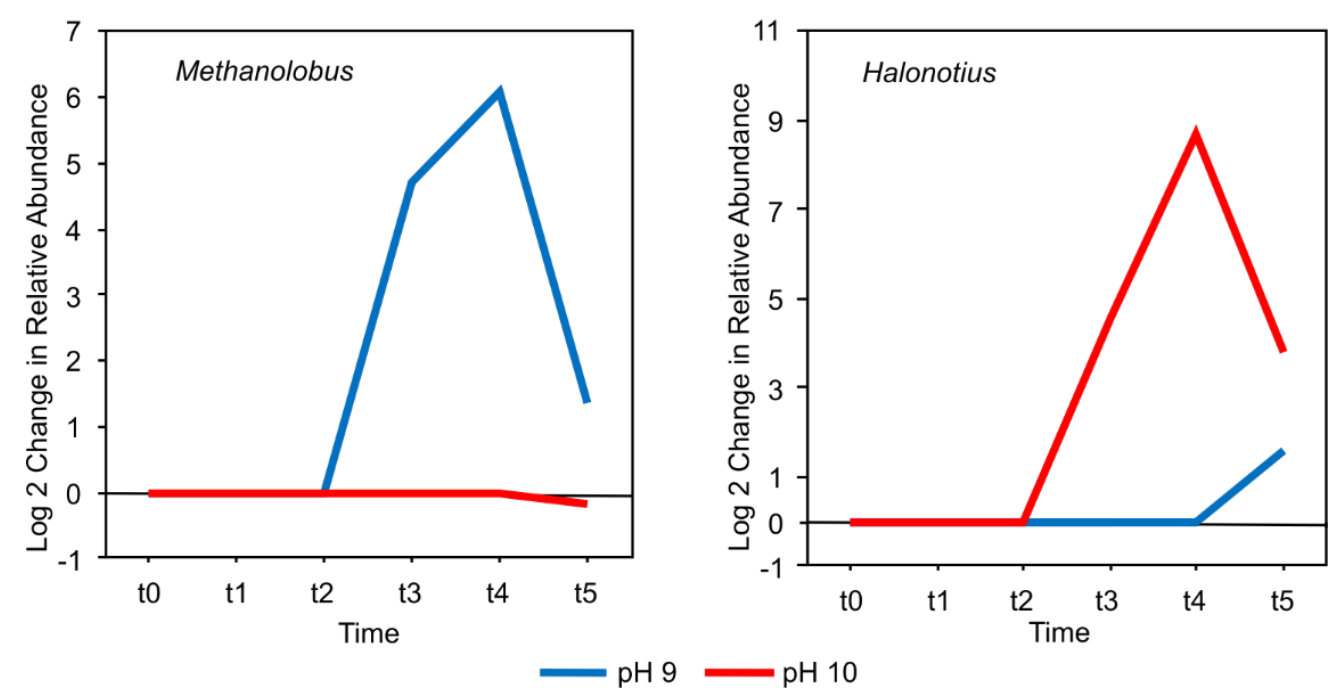

Figure 33: Dynamic Group Type-All. The figures show changes in relative abundance in Suboptimal and Superoptimal $\mathrm{pH}$ in relation to time.

Methanolobus show a highest relative abundance of $19.576 \%$ in the suboptimal pH system at t4; regaining $0.727 \%$ relative abundance at $\mathrm{t} 5$, which is similar to $0.286 \%$ 
relative abundance at to. In the superoptimal $\mathrm{pH}$ system, there is no significant change in the relative abundance of Methanolobus. Methanolobus has been isolated from estuarine sediments (Ticak, Hariraju et al. 2015), Tibetan plateau wetland (Chen, Feng et al. 2015), natural gas field in Japan (Mochimaru, Tamaki et al. 2009), from a coal seam located $926 \mathrm{~m}$ below the surface, Monroe, Louisiana, USA (Doerfert, Reichlen et al. 2009), from the Zoige wetland of the Tibetan plateau (Zhang, Jiang et al. 2008), from gas and oil wells in the Gulf of Mexico (Ni and Boone 1991). Most of them are moderately halophilic and extremely alkaliphilic methanogen, grows over a wide $\mathrm{pH}$ range, from 6.8 to 9.0.

Halonotius has been isolated from a crystallizer pond of Cheetham Salt Works, Geelong, Victoria, Australia (Burns, Janssen et al. 2010); hypersaline Deep Lake, Antarctic (Burns, Camakaris Hm Fau - Janssen et al. 2004). These are extremely halophilic known to grow at near saturation concentration.

\subsubsection{Dynamics Of Bacterial Genera:}

Regarding the complexity of the dynamics, bacterial genera show more variational pattern than in archaeal genera. However, they do not share as high total relative abundance as in archaeal genera. After scrutinizing their dynamics, we identified nine genera that show most variation in relative abundance. Generally speaking, they can be grouped into four groups based on their changing relative abundance pattern.

\subsection{Dynamic Group Type-BI:}

In the first group of genera namely Lysinibacillus and Desulfitispora, it is observed that like Type-Al their relative abundance increases in both suboptimal and superoptimal $\mathrm{pH}$ system at first. Also, at $\mathrm{t} 5$, it tends to decrease but does not successfully reaches the original relative abundance of t0 (Figure 34). 
Dynamic Group Type-BI
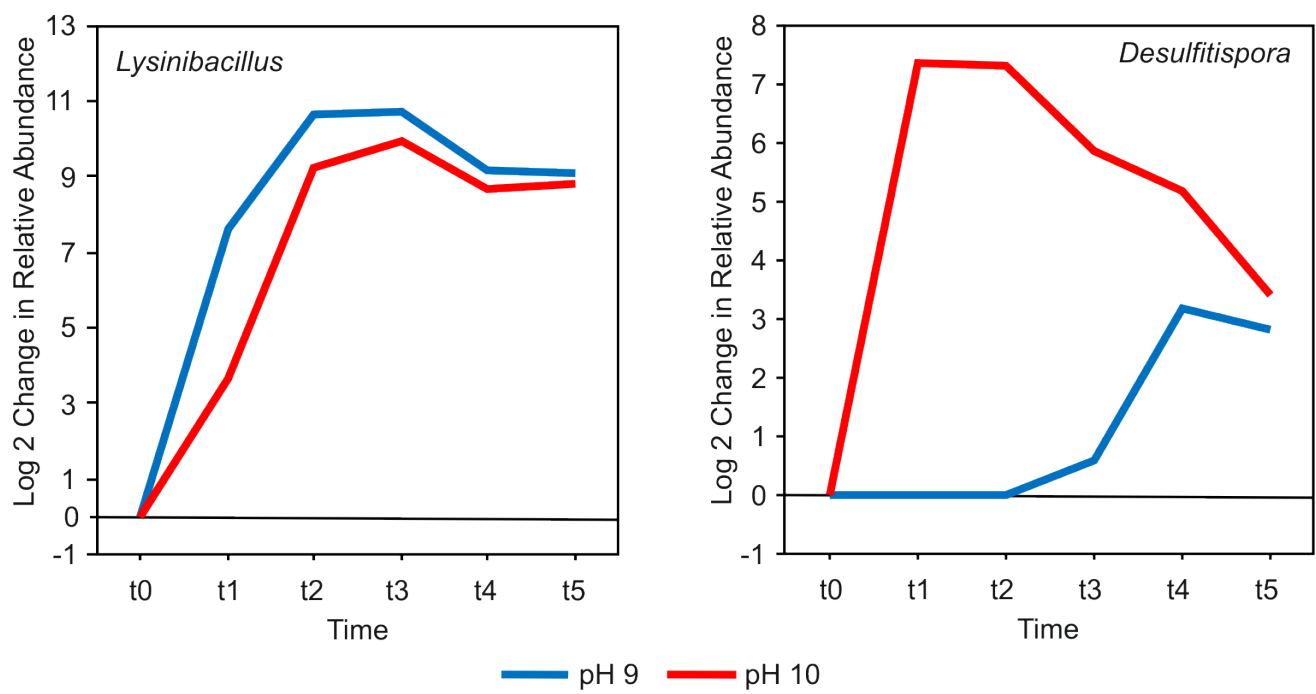

Figure 34: Dynamic Group Type-BI. The figures show changes in relative abundance in Suboptimal and Superoptimal $\mathrm{pH}$ in relation to time.

Lysinibacillus show the highest increase in relative abundance of $8.255 \%$ and $4.829 \%$ in suboptimal and superoptimal pH system respectively at $\mathrm{t} 3$. At $\mathrm{t} 5$, it decreases to $2.598 \%$ $2.153 \%$ in suboptimal and superoptimal pH system respectively but not very close to near zero value at t0. Lysinibacillus has been isolated from both extreme as well as not so extreme habitats. It is reported from saline-alkaline soil samples from Lingxian County, Shandong Province, China (Kong, Wang et al. 2014); agricultural soil (Ahmed, Yokota et al. 2007, Liang, Lu et al. 2009); marine sediments (Zhao, Dong et al. 2016); arsenic contaminated lands (Rahman, Nahar et al. 2015); tropical soil, Malaysia (Chan, Chen et al. 2015). Most of them are not extremophiles. However, some of the members of this genus are known haloalkaliphiles are growing at the alkaline condition as high as pH 10 (Zhao, Feng et al. 2015).

Desulfitispora has been found in soda lakes in south-eastern Kulunda Steppe, Altai, Russia (Sorokin and Muyzer 2010). Only one species has been described so far, Desulfitispora alkaliphila. They are obligately alkaliphilic with a $\mathrm{pH}$ range for growth between 8.5 and 10.3 and an optimum at $\mathrm{pH}$ 9.5. It is also reported to have some effect on the initial $\mathrm{pH}$ of the culture, but it has not been studied in details. 
In another group a general trend in the dynamics of Alkalibacterium, Natronincola, Anaerobacillus and Paenibacillus was observed. They exhibit an increase in one $\mathrm{pH}$ system and a decrease in the other $\mathrm{pH}$ system of relative abundance between $\mathrm{t} 1$ and $\mathrm{t} 4$ with a decrease or increase in relative abundance at $\mathrm{t} 5$ towards its original relative abundance or t0. However, never reaching as close as it was observed in the case of Archaea (Figure 35). For example, Alkalibacterium, the increase of its highest relative abundance is seen in the superoptimal system, at $\mathrm{t} 1$ reaching as high as $42.182 \%$. Then at $\mathrm{t} 5$, they decrease to $3.698 \%$, but although the progression is towards the values observed at $t 0$, it is not as close as we have seen in the case of archaeal genera. In the case of Paenibacillus, the observation is in the suboptimal $\mathrm{pH}$ system instead of the superoptimal $\mathrm{pH}$ system. It shows an increase in relative abundance at $\mathrm{t} 1$ to $0.202 \%$ then a decrease to $0.075 \%$ which is relatively closer to the to relative abundance value of $0.002 \%$. 
Dynamic Group Type-BII
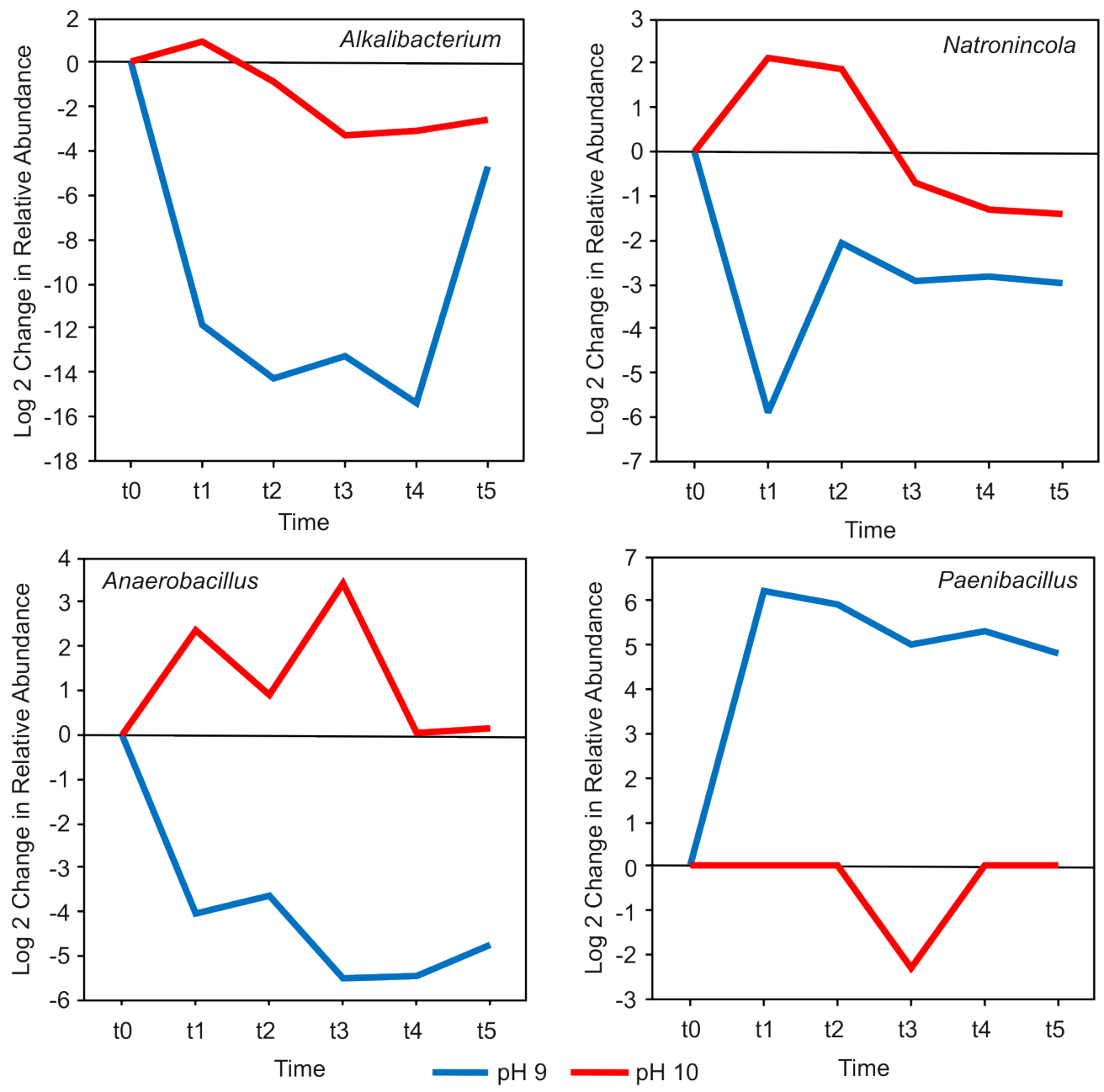

Figure 35: Dynamic Group TyPE-BII. The figures show changes in relative abundance in Suboptimal and Superoptimal $\mathrm{pH}$ in relation to time.

Alkalibacterium has been observed in different habitat, decaying marine algae, decaying seagrass, raw fish, salted fish and salted and fermented shrimp paste, temperate area of Japan and Thailand (Ishikawa, Tanasupawat et al. 2009); from wash-waters during the preparation of edible olives (Ntougias and Russell 2001); They are reported to grow at $\mathrm{pH}$ as high as 12. Paenibacillus has been isolated from various environments, from the alkaline soil, Korea (Yoon, Kang et al. 2005); desert sand sample, Gansu Province, China (Jeon, Lim et al. 2009); soil sample, Assam, India (Rai, Roy et al. 2010). Some of them are extremely haloalkaliphilic able to grow at pH as high as pH 12 (Lee, Lee et al. 2002) and at a salinity of up to $5 \mathrm{M} \mathrm{NaCl}$ (Raddadi, Cherif et al. 2013). 
Natronincola has been reported from bottom sediment of a coastal lagoon of the soda lake Verkhnee Beloe, Buryatia and Lake Khadyn, Tyva (Zhilina, Zavarzina et al. 2009); from soda deposits in Lake Magadi, Kenya (Zhilina, Detkova et al. 1998). Most of them if not all are obligate alkaliphiles growing at $\mathrm{pH}$ as high as 10.5. Anaerobacillus has been observed in various habitats, from soda lake Khadyn, Tuva upper Yenisey region, Russia (Zavarzina, Tourova et al. 2009); the arsenic contaminated environment in Bendigo, Victoria, Australia (Wang, Liu et al. 2015). Most of them are halotolerant or moderately halophilic, obligate or moderately alkaliphilic.

Anaerobacillus has been observed in various habitats, from soda lake Khadyn, Tuva upper Yenisey region, Russia (Zavarzina, Tourova et al. 2009); the arsenic contaminated environment in Bendigo, Victoria, Australia (Wang, Liu et al. 2015). Most of them are halotolerant or moderately halophilic, obligate or moderately alkaliphilic.

Paenibacillus has been isolated from various environments, from the alkaline soil, Korea (Yoon, Kang et al. 2005); desert sand sample, Gansu Province, China (Jeon, Lim et al. 2009); soil sample, Assam, India (Rai, Roy et al. 2010). Some of them are extremely haloalkaliphilic able to grow at pH as high as pH 12 (Lee, Lee et al. 2002) and at a salinity of up to $5 \mathrm{M} \mathrm{NaCl}$ (Raddadi, Cherif et al. 2013).

\subsection{Dynamic Group Type-BIII:}

The third group consists of Clostridium sensu stricto 7, Salimesophilobacter. They increase in their relative abundance in both the $\mathrm{pH}$ system with highest obtained relative abundance at a very early stage of the incubation and not at later stages and at t5 they are farther away from regaining their original relative abundance (Figure 36). For example Clostridium sensu stricto 7 reaches a relative abundance of $23.494 \%$ at $\mathrm{t} 1$ in suboptimal $\mathrm{pH}$ and $0.009 \%$ at $\mathrm{t} 2$ in the superoptimal $\mathrm{pH}$ system from near zero relative abundance at t0. At $\mathrm{t} 5$, they change to $0.688 \%$ in suboptimal and near zero in the superoptimal $\mathrm{pH}$ system. 
Dynamic Group Type-BIII
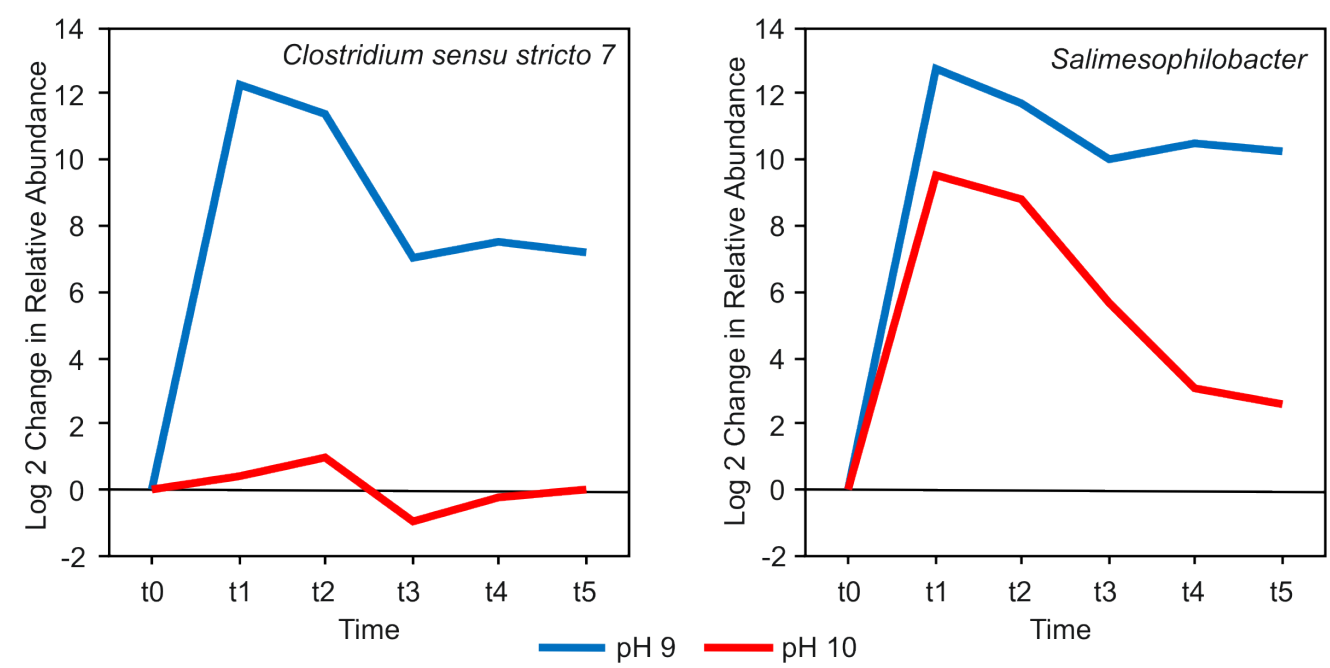

Figure 36: Dynamic Group Type-BIII. The figures show changes in relative abundance in Suboptimal and Superoptimal $\mathrm{pH}$ in relation to time.

Clostridium sensu stricto 7 The species of Clostridium comprise a very heterogeneous assemblage of Bacteria that do not form a phylogenetically coherent group (Gupta and Gao 2009). They are same as the Group-C of Rainey at al. and mostly thermophiles (Rainey, Ward et al. 1993). In our study, we found Clostridium botulinum BKT015925, Clostridium sp. 17cr1, and some uncultured bacterium. Their known role in ecology is not as well studied or understood as its pathology.

Salimesophilobacter has been isolated from the wastewater of a paper mill in Zhejiang, China (Zhang, Fang et al. 2013). So far only one species has been described, Salimesophilobacter vulgaris, they can grow at up to $\mathrm{pH} 9.5$.

\subsection{Dynamic Group Type-BIV:}

Finally, there is Anaerovirgula, where there is an opposite trend at first (t1) in suboptimal and superoptimal pH. After that, it behaves similarly to Type-BI. Anaerovirgula reaches a relative abundance of $0.023 \%$ at $\mathrm{t} 4$ in suboptimal $\mathrm{pH}$ and $0.022 \%$ at $\mathrm{t} 2$ in the 
superoptimal $\mathrm{pH}$ system from near zero, $0.003 \%$ relative abundance at t0 (Figure 37). At t5, it changes to $0.011 \%$ in suboptimal and near zero in the superoptimal pH system.

Dynamic Group Type-BIV

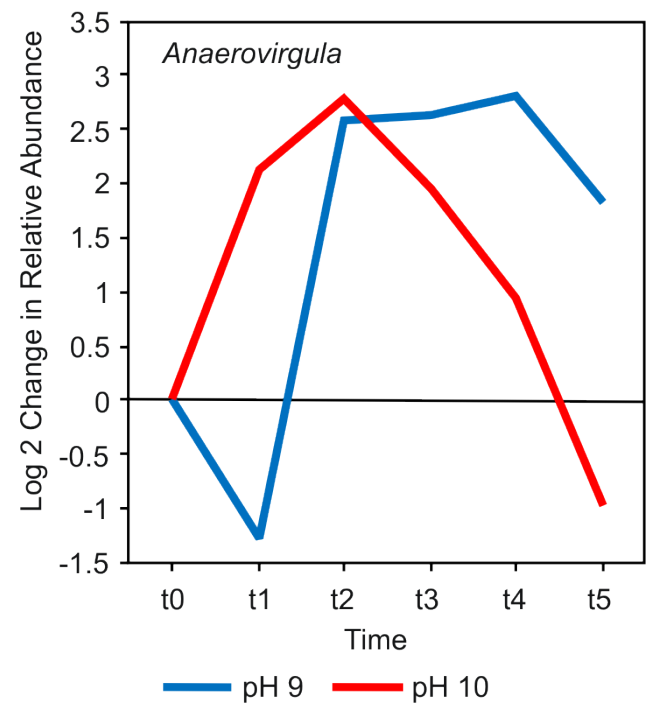

Figure 37: Dynamic Group TyPe-BIV. The figures show changes in relative abundance in Suboptimal and Superoptimal $\mathrm{pH}$ in relation to time.

Anaerovirgula has been reported from mud sediments of a soda lake, California, USA (Pikuta, Itoh et al. 2006). Only one species is described so far, Anaerovirgula multivorans, able to grow at $\mathrm{pH} 10$.

There are many reports and detailed investigations on how the external microenvironmental $\mathrm{pH}$ can change the community dynamics of microbial community as mentioned in the introduction section of this article. Even more, information is available on how single species of numerous genera are affected by its microenvironmental pH(Raevuori and Genigeorgis 1975, Russell and Dombrowski 1980, Chow and Russell 1990, McKay and Peters 1995, Adamberg, Kask et al. 2003, LeBlanc, Garro et al. 2004, Oladipo, Adeleke et al. 2010, Mtimet, Guegan et al. 2016). Also, there is a tremendous amount of literature investigating the response of individual species on their mechanism of sensing and intracellular homeostasis(Krulwich, Guffanti et al. 1982, Nakamura, Kawasaki et al. 1992, Follmann, Becker et al. 2009, Quinn, Resch et al. 2012, Soemphol, Tatsuno et al. 2015). However, there is no significant accumulation of scientific literature on how the microbial community can change their external $\mathrm{pH}$. However very few, although not regarding community but as a single species, literature is available on how 
their growth effect the $\mathrm{pH}$ of their culture media or immediate external microenvironment. It is not bilateral, or acidification and alkalization simultaneously do not happen for one individual species. It is reported that some bacterial species can acidify their microenvironment by producing organic acids(Solé, Lorén et al. 2010). Alkalization of microenvironment is also well known(Anderson 1984, Athmann, Zeng et al. 2000, Shenderov 2013, Cepl, Blahuskova et al. 2014, Yang, Meng et al. 2015). However, irrespective of their initial external $\mathrm{pH}$, a stabilization of $\mathrm{pH}$, which is also as high as $\mathrm{pH}$ 9.3 , is not reported before.

\subsubsection{Microenvironmental pH HOMeOstasis As A Function Of Growth}

We observed that there was a substantial variation in initial $\mathrm{pH}, \mathrm{pH}$ of the culture filtrate, the number of OTUs and incubation duration. All these variables were analyzed with $R$ version 3.2.3. In order to find out which variable predicts best the microenvironmental $\mathrm{pH}$ we performed a linear model fit and plotted as a partial residual plot (Figure 38) with the $\mathrm{R}$ package car version 2.1.0. A partial residual plot is a graphical method that shows the relationship between a given independent variable and the response variable assumed that other independent variables are also in the model. From the Figure 38, we can see that incubation time (Time) have the greatest impact on microenvironmental pH change (Ini.pH) followed by the number of OTUs and lastly exposure to suboptimal or superoptimal $\mathrm{pH}$ with no significant impact. It can be explained as the duration of incubation, and associated community dynamics is the most probable cause of microenvironmental pH homeostasis. 

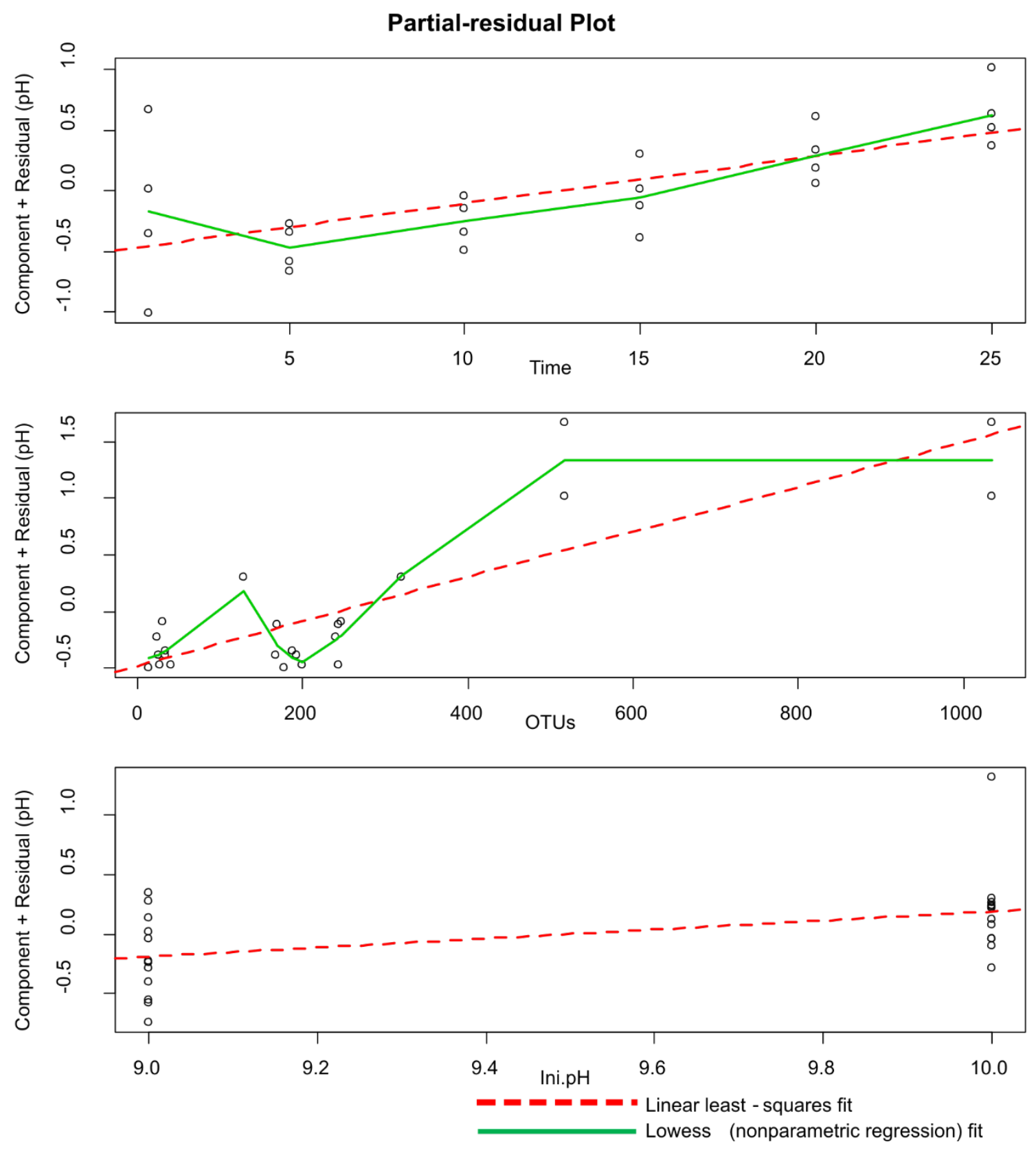

Figure 38: Partial-residual Plot showing Microenvironmental pH With Time, OTUs and NONOPTIMAL INITIAL PH. 


\title{
$\underline{\text { Conclusion }}$
}

\author{
$\&$
}

$\underline{\text { Future Direction }}$ 


\section{Conclusion And Future Direction}

In this thesis, we have found that irrespective of the cataclysmic history of the origin and apparent hostile environmental conditions the prokaryotic community of this meteorite crater soda lake, Lonar, is significantly diverse. We observed Max. clusters $\left(n_{\max }\right)$, Shannon index $\left(\mathrm{H}^{\prime}\right)$ and Chao1 as high as 2482.00, 8.06 and 3755.51 respectively. The hypersaline and hyperalkaline ecosystem flourishes with archaeal and bacterial life. We successfully surveyed the prokaryotic biodiversity at taxa level as low as species (genetic distance of $3 \%)$ and discussed at taxa level as low as genus. We observed coverage (\%) as high as $93.96 \%$ and $89.01 \%$ in Bacteria and Archaea respectively. This investigation contributed 52 archaeal genera and 530 bacterial genera; out of which 36 (69.23\%) archaeal genera and 407 (76.79\%) bacterial genera has never been reported from Lonar lake before. The difference between the total (DNA-based) diversity and the active (RNA-based) diversity is also noticed. In this investigation, we have observed 24, 16 and 36 genera which may have been involved in methane cycle, nitrogen cycle and sulfur cycle respectively. This methane, nitrogen, and sulfur metabolism together contribute to $2.69 \%$ of all the detected KEGG ortholog in the metagenome. The microbial community of Lonar Crater Lake sediment, when exposed to the nonoptimal $\mathrm{pH}$ condition, can change their microenvironment to a more favorable (hypothetical optimal) one in terms of $\mathrm{pH}$, simultaneously resist permanent change in its community structure. 6 different and distinct changing relative abundance patterns of groups of different genera (Dynamic Groups) was also observed. More detailed investigation is needed to confirm their limit and mechanism to modify their microenvironment.

Most of the soda lakes, as described in Table 2, create a kind of clustering at the points where two or more continental plates meet. This distribution pattern has never been reported or observed before. Almost all of them are on or proximity to Rift, Step, Tectonic contact, and Thrust-fault. 


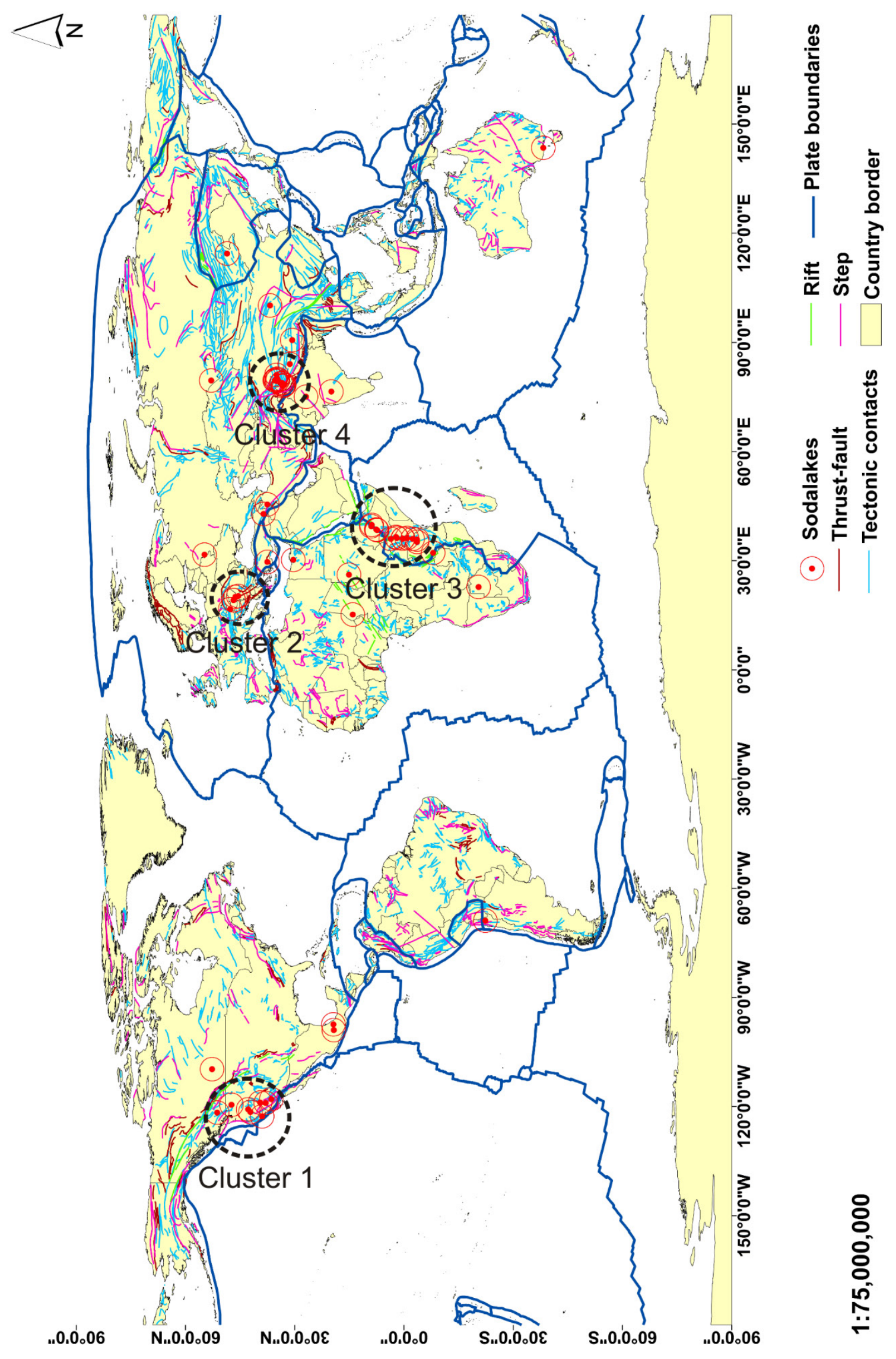

FigURE 39: FIGURE SHOWS THE GLOBAL DISTRIBUTION OF SODA LAKES AND THEIR LOCATION. 
The map was prepared by overlaying the country boundaries and plate boundaries on a GIS platform. The data used is available from https://github.com/fraxen/tectonicplates. It was originally published in the paper titled, An updated digital model of plate boundaries in 2003 (Bird 2003). The map is prepared using UTM projection, and the scale of the map is $1: 75,000,000$.

From the map, it is comprehensible that there are 4 major clusters. One cluster was observed at the meeting point of Juan de Fuca plate, Pacific plate and North American plate. The second cluster is located near the contact of African plate and Eurasian plate. The third cluster is at the junction of Arabian plate and African plate. The fourth cluster is near the meeting point of Indian plate and Eurasian plate. It seems there is a possibility of some correlation of plate tectonic activity and soda lakes. One reasonable question to ask can be if the biodiversity of the soda lakes is also related to its origin in relation to plate tectonic activity.

We at this moment propose a hypothesis that the origin or geological history of the soda lake plays a significant role in shaping the prokaryotic biodiversity of the soda lakes. Thus, these soda lakes can be categorized as follows-

1. Geothermally Active Plate Tectonic Dependent Soda Lake (GAPDSL) - Lakes at the contact points of continental plates with current geothermal activity.

2. Geothermally Inactive Plate Tectonic Dependent Soda Lake (GIPDSL) - Lakes at the contact points of continental plates without current geothermal activity/with past geothermal activity.

3. Plate Tectonic Independent Soda Lake (PISL) - Lakes away from the contact points of continental plates.

For a hypothesis to be valid, it has to be falsifiable. We did a trial analysis from available information to test the hypothesis. We made a comparison, of 10 soda lakes distributed through 4 continents from 40 Short Read Archive (Table 32) and present investigation on Lonar using QIIME in a similar way as described in Chapter 3.14. 
Table 32: Proposed Types of Soda Lakes With examples.

\begin{tabular}{|c|c|c|c|c|}
\hline $\begin{array}{l}\text { Type of } \\
\text { Soda Lake }\end{array}$ & $\begin{array}{l}\text { Geothermally } \\
\text { Tectonic Depe } \\
\text { (GIPDSL) }\end{array}$ & $\begin{array}{l}\text { active Plate } \\
\text { lent Soda Lake }\end{array}$ & $\begin{array}{l}\text { Geothermally the } \\
\text { active Plate } \\
\text { Tectonic } \\
\text { Dependent Soda } \\
\text { Lake } \\
\text { (GAPDSL) }\end{array}$ & $\begin{array}{l}\text { Plate } \\
\text { Tectonic } \\
\text { Independent } \\
\text { Soda Lake } \\
\text { (PISL) }\end{array}$ \\
\hline $\begin{array}{l}\text { Name and } \\
\text { Location }\end{array}$ & $\begin{array}{l}\text { Abhijata, } \\
\text { Arenguadi, } \\
\text { Beseka, Chitu, } \\
\text { Shalla- Africa }\end{array}$ & $\begin{array}{l}\text { Silber, Unterer, } \\
\text { Zicklacke - } \\
\text { Europe }\end{array}$ & $\begin{array}{l}\text { Heart Lake Geyser } \\
\text { Basin - North } \\
\text { America }\end{array}$ & Lonar- Asia \\
\hline \multirow{22}{*}{$\begin{array}{l}\text { Data used } \\
\text { (Short } \\
\text { Read } \\
\text { Archaive, } \\
\text { NCBI) }\end{array}$} & SRR618362 & SRR1519340 & SRR900430 & \multirow{22}{*}{$\begin{array}{l}\text { Present } \\
\text { investigation }\end{array}$} \\
\hline & SRR618380 & SRR1519333 & SRR900451 & \\
\hline & SRR618367 & SRR1519332 & SRR900428 & \\
\hline & SRR618375 & SRR1519335 & SRR900433 & \\
\hline & SRR618366 & SRR1519337 & SRR900431 & \\
\hline & SRR618354 & SRR1519338 & SRR900426 & \\
\hline & SRR618352 & SRR1519334 & SRR900437 & \\
\hline & SRR618356 & SRR1519336 & SRR900457 & \\
\hline & SRR618374 & SRR1519339 & SRR900439 & \\
\hline & SRR618360 & & & \\
\hline & SRR618358 & & & \\
\hline & SRR618370 & & & \\
\hline & SRR618372 & & & \\
\hline & SRR618376 & & & \\
\hline & SRR618373 & & & \\
\hline & SRR618378 & & & \\
\hline & SRR618377 & & & \\
\hline & SRR618353 & & & \\
\hline & SRR618364 & & & \\
\hline & SRR618382 & & & \\
\hline & SRR618368 & & & \\
\hline & SRR618379 & & & \\
\hline
\end{tabular}


QIIME analysis provided a relative abundance of different OTUs with assigned taxonomy. We selected only the genera from the three groups of Soda lakes (GAPDSL, GIPDSL, and PISL) and analyzed in R, as described in Chapter 4.2.3, to find out their mutual coverage in terms of presence or absence of the different genera. The analysis shows that irrespective of the fact that all of these lakes are Soda lakes they share a very small percentage of genera, $0.3 \%$, which is mutually universal. On the other hand, these groups mutually show a higher number of genera to be unique to each group, and the percentage is much greater if considered individually. GAPDSL, GIPDSL, and PISL show $2.1 \%, 47.6 \%$, and $21.6 \%$ genera respectively exclusive when considered mutually. Individually the percentage of exclusive genera for GAPDSL, GIPDSL and PISL shows $60.5 \%, 62.4 \%$, and $43.7 \%$ Figure 40.

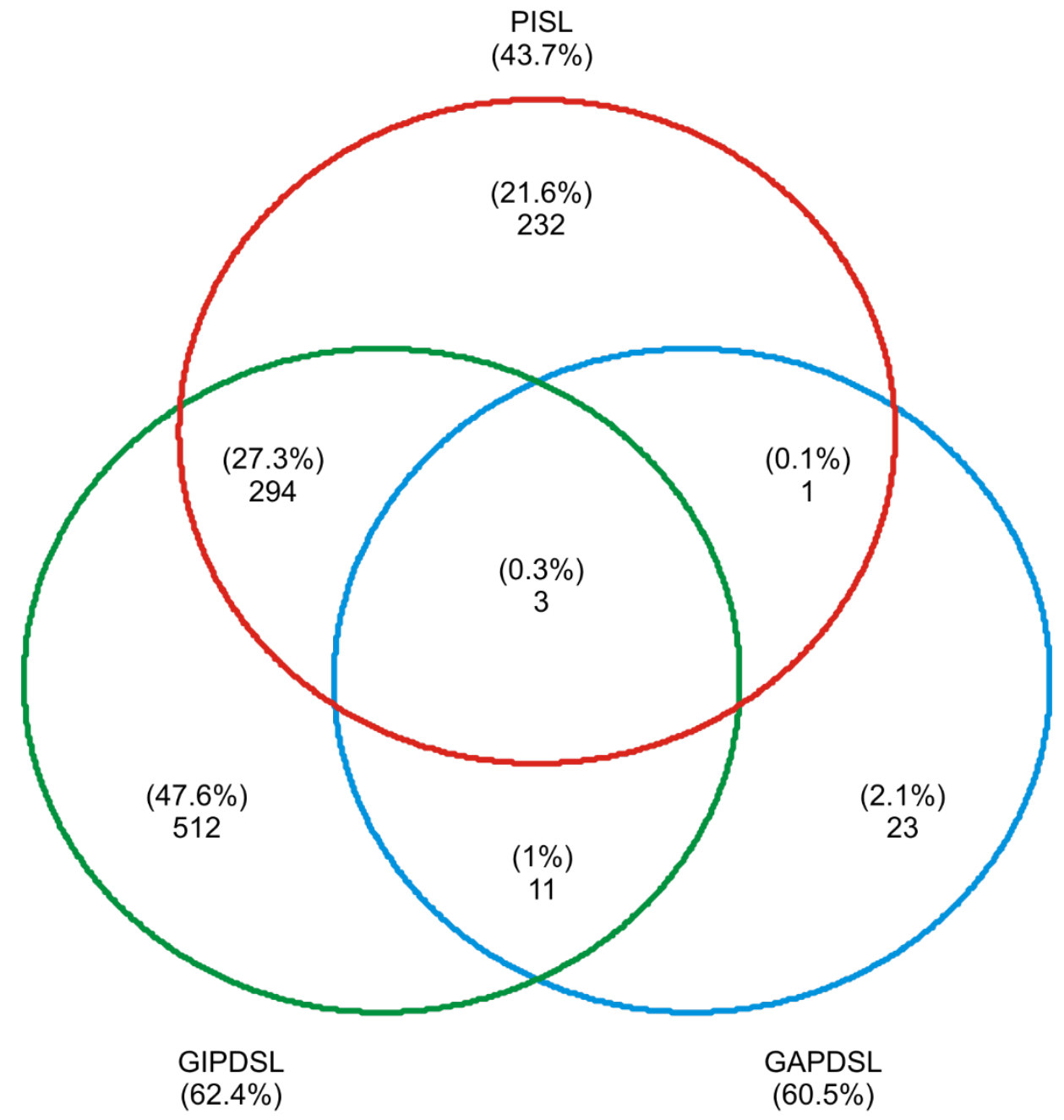

Figure 40: Mutual and Exclusive Coverage of Genera by Groups of Soda Lakes. 
From the above observations, it seems possible that some taxa are exclusive to each soda lake group. If so then the plate tectonics do predict its prokaryotic diversity (to some extent), and the hypothesis on the types of soda lakes is true. Otherwise, there is no effect of the fact that in general most of the soda lakes happen to be near geologically the active zones, and the hypothesis is false. However, to reach any conclusion about it, there has to be more investigation in a uniform approach; as the nature of samples, 16S rRNA gene primers, sequencing platform or chemistry and coverage (surveying effort) were not identical.

To progress our understanding of the alkaliphiles, of Lonar Meteorite Crater Soda Lake specifically and soda lakes in general, we can investigate two broad question.

1. To investigate the mechanisms by which the microbial community of Lonar Crater Lake sediment can modulate their microenvironment to favorable (hypothetical optimal) one in terms of $\mathrm{pH}$, concurrently repelling permanent alteration in its community structure.

2. To investigate if prokaryotic biodiversity of the soda lakes and the proximity of the most of the soda lakes to the geologically the active have any correlation and if the grouping of soda lakes based on its proximity to plate tectonically the active area is reasonable. 


\section{REFERENCE}

Adamberg, K., S. Kask, T. M. Laht and T. Paalme (2003). "The effect of temperature and pH on the growth of lactic acid bacteria: a pH-auxostat study." Int J Food Microbiol 85(1-2): 171-183.

Ahmed, I., A. Yokota, A. Yamazoe and T. Fujiwara (2007). "Proposal of Lysinibacillus boronitolerans gen. nov. sp. nov., and transfer of Bacillus fusiformis to Lysinibacillus fusiformis comb. nov. and Bacillus sphaericus to Lysinibacillus sphaericus comb. nov." Int J Syst Evol Microbiol 57(Pt 5): 1117-1125.

Alazard, D., C. Badillo, M. L. Fardeau, J. L. Cayol, P. Thomas, T. Roldan, J. L. Tholozan and B. Ollivier (2007). "Tindallia texcoconensis sp. nov., a new haloalkaliphilic bacterium isolated from lake Texcoco, Mexico." Extremophiles 11(1): 33-39.

Albuquerque, L., C. Simoes, M. F. Nobre, N. M. Pino, J. R. Battista, M. T. Silva, F. A. Rainey and M. S. da Costa (2005). "Truepera radiovictrix gen. nov., sp. nov., a new radiation resistant species and the proposal of Trueperaceae fam. nov." FEMS Microbiol Lett 247(2): 161169.

Allen, C. C., J. L. Gooding and K. Keil (1982). "Hydrothermally altered impact melt rock and breccia: Contributions to the soil of Mars." Journal of Geophysical Research 87(B12): 10083.

Amoozegar, M. A., A. Makhdoumi-Kakhki, M. Mehrshad, M. Rasooli, S. A. Fazeli, C. Sproer and A. Ventosa (2015). "Halovivax cerinus sp. nov., an extremely halophilic archaeon from a hypersaline lake." Int J Syst Evol Microbiol 65(Pt 1): 65-70.

Amoozegar, M. A., A. Makhdoumi-Kakhki, M. Mehrshad, S. Riazi and A. Ventosa (2014). "Halovivax limisalsi sp. nov., an extremely halophilic archaeon from hypersaline mud." Int J Syst Evol Microbiol 64(Pt 10): 3422-3426.

Anderson, R. E. (1984). "Growth and Corresponding Elevation of Tomato Juice pH by Bacillus coagulans." Journal of Food Science 49(2): 647-647.

Anil Kumar, P., T. N. Srinivas, S. Madhu, R. Sravan, S. Singh, S. W. Naqvi, S. Mayilraj and S. Shivaji (2012). "Cecembia lonarensis gen. nov., sp. nov., a haloalkalitolerant bacterium of the family Cyclobacteriaceae, isolated from a haloalkaline lake and emended descriptions of the genera Indibacter, Nitritalea and Belliella." Int J Syst Evol Microbiol 62(Pt 9): 22522258.

Anil Kumar, P., T. N. Srinivas, P. Pavan Kumar, S. Madhu and S. Shivaji (2010). "Nitritalea halalkaliphila gen. nov., sp. nov., an alkaliphilic bacterium of the family 'Cyclobacteriaceae', phylum Bacteroidetes." Int J Syst Evol Microbiol 60(Pt 10): 23202325.

Antony, C. P., N. V. Doronina, R. Boden, Y. A. Trotsenko, Y. S. Shouche and J. C. Murrell (2012). "Methylophaga lonarensis sp. nov., a moderately haloalkaliphilic methylotroph isolated from the soda lake sediments of a meteorite impact crater." Int J Syst Evol Microbiol 62 (Pt 7): 1613-1618.

Antony, C. P., D. Kumaresan, L. Ferrando, R. Boden, H. Moussard, A. F. Scavino, Y. S. Shouche and J. C. Murrell (2010). "Active methylotrophs in the sediments of Lonar Lake, a saline and alkaline ecosystem formed by meteor impact." The ISME Journal 4(11): 1470-1480.

Antony, C. P., D. Kumaresan, S. Hunger, H. L. Drake, J. C. Murrell and Y. S. Shouche (2013). "Microbiology of Lonar Lake and other soda lakes." ISME J 7(3): 468-476. 
Antony, C. P., J. C. Murrell and Y. S. Shouche (2012). "Molecular diversity of methanogens and identification of Methanolobus sp. as active methylotrophic Archaea in Lonar crater lake sediments." FEMS Microbiol Ecol 81(1): 43-51.

Ara, I. and T. Kudo (2007). "Luedemannella gen. nov., a new member of the family Micromonosporaceae and description of Luedemannella helvata sp. nov. and Luedemannella flava sp. nov." J Gen Appl Microbiol 53(1): 39-51.

Asao, M., H. C. Pinkart and M. T. Madigan (2011). "Diversity of extremophilic purple phototrophic bacteria in Soap Lake, a Central Washington (USA) Soda Lake." Environ Microbiol 13(8): 2146-2157.

Asao, M., S. Takaichi and M. T. Madigan (2007). "Thiocapsa imhoffii, sp. nov., an alkaliphilic purple sulfur bacterium of the family Chromatiaceae from Soap Lake, Washington (USA)." Arch Microbiol 188(6): 665-675.

Athmann, C., N. Zeng, T. Kang, E. A. Marcus, D. R. Scott, M. Rektorschek, A. Buhmann, K. Melchers and G. Sachs (2000). "Local pH elevation mediated by the intrabacterial urease of Helicobacter pylori cocultured with gastric cells." J Clin Invest 106(3): 339-347.

Badve, R. M., K. P. N. Kumaran and C. Rajshekhar (1993). "Eutrophication of Lonar Lake, Maharashtra." Current Sci.

Bale, S. J., K. Goodman, P. A. Rochelle, J. R. Marchesi, J. C. Fry, A. J. Weightman and R. J. Parkes (1997). "Desulfovibrio profundus sp. nov., a novel barophilic sulfate-reducing bacterium from deep sediment layers in the Japan Sea." Int J Syst Bacteriol 47(2): 515-521.

Ballot, A., K. Kotut, E. Novelo and L. Krienitz (2009). "Changes of phytoplankton communities in Lakes Naivasha and Oloidien, examples of degradation and salinization of lakes in the Kenyan Rift Valley." Hydrobiologia 632(1): 359-363.

Banciu, H., D. Y. Sorokin, E. A. Galinski, G. Muyzer, R. Kleerebezem and J. G. Kuenen (2004). "Thialkalivibrio halophilus sp. nov., a novel obligately chemolithoautotrophic, facultatively alkaliphilic, and extremely salt-tolerant, sulfur-oxidizing bacterium from a hypersaline alkaline lake." Extremophiles 8(4): 325-334.

Banciu, H., D. Y. Sorokin, R. Kleerebezem, G. Muyzer, E. A. Galinski and J. G. Kuenen (2004). "Growth kinetics of haloalkaliphilic, sulfur-oxidizing bacterium Thioalkalivibrio versutus strain ALJ 15 in continuous culture." Extremophiles 8(3): 185-192.

Banciu, H. L., D. Y. Sorokin, T. P. Tourova, E. A. Galinski, M. S. Muntyan, J. G. Kuenen and G. Muyzer (2008). "Influence of salts and $\mathrm{pH}$ on growth and activity of a novel facultatively alkaliphilic, extremely salt-tolerant, obligately chemolithoautotrophic sufur-oxidizing Gammaproteobacterium Thioalkalibacter halophilus gen. nov., sp. nov. from SouthWestern Siberian soda lakes." Extremophiles 12(3): 391-404.

Bankevich, A., S. Nurk, D. Antipov, A. A. Gurevich, M. Dvorkin, A. S. Kulikov, V. M. Lesin, S. I. Nikolenko, S. Pham, A. D. Prjibelski, A. V. Pyshkin, A. V. Sirotkin, N. Vyahhi, G. Tesler, M. A. Alekseyev and P. A. Pevzner (2012). "SPAdes: a new genome assembly algorithm and its applications to single-cell sequencing." J Comput Biol 19(5): 455-477.

Barth, K. R., V. M. Isabella and V. L. Clark (2009). "Biochemical and genomic analysis of the denitrification pathway within the genus Neisseria." Microbiology 155(Pt 12): 4093-4103.

Barton, L. L., M. L. Fardeau and G. D. Fauque (2014). "Hydrogen sulfide: a toxic gas produced by dissimilatory sulfate and sulfur reduction and consumed by microbial oxidation." Met lons Life Sci 14: 237-277.

Bartram, A. K., M. D. Lynch, J. C. Stearns, G. Moreno-Hagelsieb and J. D. Neufeld (2011). "Generation of multimillion-sequence 16S rRNA gene libraries from complex microbial 
communities by assembling paired-end illumina reads." Appl Environ Microbiol 77(11): 3846-3852.

Basen, M., M. Kruger, J. Milucka, J. Kuever, J. Kahnt, O. Grundmann, A. Meyerdierks, F. Widdel and S. Shima (2011). "Bacterial enzymes for dissimilatory sulfate reduction in a marine microbial mat (Black Sea) mediating anaerobic oxidation of methane." Environ Microbiol 13(5): 1370-1379.

Becking, L. G. M. B., I. R. Kaplan and D. Moore (1960). "Limits of the Natural Environment in Terms of Ph and Oxidation-Reduction Potentials." Journal of Geology 68(3): 243-284.

Berben, T., D. Y. Sorokin, N. Ivanova, A. Pati, N. Kyrpides, L. A. Goodwin, T. Woyke and G. Muyzer (2015). "Partial genome sequence of Thioalkalivibrio thiocyanodenitrificans ARhD 1(T), a chemolithoautotrophic haloalkaliphilic sulfur-oxidizing bacterium capable of complete denitrification." Stand Genomic Sci 10: 84.

Bird, P. (2003). "An updated digital model of plate boundaries." Geochemistry 4(3): 1-52.

Blazewicz, S. J., R. L. Barnard, R. A. Daly and M. K. Firestone (2013). "Evaluating rRNA as an indicator of microbial activity in environmental communities: limitations and uses." ISME J 7(11): 2061-2068.

Bolger, A. M., M. Lohse and B. Usadel (2014). "Trimmomatic: a flexible trimmer for Illumina sequence data." Bioinformatics 30(15): 2114-2120.

Boltianskaia lu, V., V. V. Kevbrin, A. M. Lysenko, T. V. Kolganova, T. P. Turova, G. A. Osipov and T. N. Zhilina (2007). "[Halomonas mongoliensis sp. nov. and Halomonas kenyensis sp. nov., new haloalkaliphilic denitrifiers capable of reducing N2O, isolated from soda lakes]." Mikrobiologiia 76(6): 834-843.

Boone, D. R., S. Worakit, I. M. Mathrani and R. A. Mah (1986). "Alkaliphilic methanogens from high-pH lake sediments." Systematic and Applied Microbiology 7(2-3): 230-234.

Borrel, G., K. Joblin, A. Guedon, J. Colombet, V. Tardy, A. C. Lehours and G. Fonty (2012). "Methanobacterium lacus sp. nov., isolated from the profundal sediment of a freshwater meromictic lake." Int J Syst Evol Microbiol 62(Pt 7): 1625-1629.

Boström, B., A.-K. Pettersson and I. Ahlgren (1989). "Seasonal dynamics of a cyanobacteriadominated microbial community in surface sediments of a shallow, eutrophic lake." Aquatic Sciences 51(2): 153-178.

Bowers, K. J., N. M. Mesbah and J. Wiegel (2009). "Biodiversity of poly-extremophilic Bacteria: does combining the extremes of high salt, alkaline $\mathrm{pH}$ and elevated temperature approach a physico-chemical boundary for life?" Saline Systems 5(1): 9.

Bradley, A. S., W. D. Leavitt and D. T. Johnston (2011). "Revisiting the dissimilatory sulfate reduction pathway." Geobiology 9(5): 446-457.

Bragg, L., G. Stone, M. Imelfort, P. Hugenholtz and G. W. Tyson (2012). "Fast, accurate errorcorrection of amplicon pyrosequences using Acacia." Nat Methods 9(5): 425-426.

Bryantseva, I., V. M. Gorlenko, E. I. Kompantseva, J. F. Imhoff, J. Suling and L. Mityushina (1999). "Thiorhodospira sibirica gen. nov., sp. nov., a new alkaliphilic purple sulfur bacterium from a Siberian soda lake." Int J Syst Bacteriol 49 Pt 2: 697-703.

Bryantseva, I. A., V. M. Gorlenko, E. I. Kompantseva, L. A. Achenbach and M. T. Madigan (1999). "Heliorestis daurensis, gen. nov. Sp. Nov., An alkaliphilic rod-to-coiled-shaped phototrophic heliobacterium from a siberian soda lake." Arch Microbiol 172(3): 167-174.

Bryantseva, I. A., V. M. Gorlenko, E. I. Kompantseva and J. F. Imhoff (2000). "Thioalkalicoccus limnaeus gen. nov., sp. nov., a new alkaliphilic purple sulfur bacterium with bacteriochlorophyll b." Int J Syst Evol Microbiol 50 Pt 6: 2157-2163. 
Bryantseva, I. A., V. M. Gorlenko, E. I. Kompantseva, T. P. Tourova, B. B. Kuznetsov and G. A. Osipov (2000). "Alkaliphilic heliobacterium Heliorestis baculata sp. nov. and emended description of the genus Heliorestis." Arch Microbiol 174(4): 283-291.

Burguener, G. F., M. J. Maldonado, S. Revale, D. Fernandez Do Porto, N. Rascovan, M. Vazquez, M. E. Farias, M. A. Marti and A. G. Turjanski (2014). "Draft Genome Sequence of the Polyextremophilic Halorubrum sp. Strain AJ67, Isolated from Hyperarsenic Lakes in the Argentinian Puna." Genome Announc 2(1).

Burns, D. G., P. H. Camakaris Hm Fau - Janssen, M. L. Janssen Ph Fau - Dyall-Smith and M. L. DyallSmith (2004). "Combined use of cultivation-dependent and cultivation-independent methods indicates that members of most haloarchaeal groups in an Australian crystallizer pond are cultivable." Applied and Environmental Microbiology 70(9): 5258-5265.

Burns, D. G., P. H. Janssen, T. Itoh, M. Kamekura, A. Echigo and M. L. Dyall-Smith (2010). "Halonotius pteroides gen. nov., sp. nov., an extremely halophilic archaeon recovered from a saltern crystallizer." Int J Syst Evol Microbiol 60(Pt 5): 1196-1199.

Bursakov, S. A., C. Carneiro, M. J. Almendra, R. O. Duarte, J. Caldeira, I. Moura and J. J. Moura (1997). "Enzymatic properties and effect of ionic strength on periplasmic nitrate reductase (NAP) from Desulfovibrio desulfuricans ATCC 27774." Biochem Biophys Res Commun 239(3): 816-822.

Cairo, J. J., M. Clarens, J. P. Touzel, M. Bardulet and J. M. Paris (1992). "Methanosarcina mazei $\mathrm{JC2}$, a new methanogenic strain isolated from lake sediments, that does not use H2/CO2." Microbiologia 8(1): 21-31.

Camacho, C., G. Coulouris, V. Avagyan, N. Ma, J. Papadopoulos, K. Bealer and T. L. Madden (2009). "BLAST+: architecture and applications." BMC Bioinformatics 10: 421.

Caporaso, J. G., J. Kuczynski, J. Stombaugh, K. Bittinger, F. D. Bushman, E. K. Costello, N. Fierer, A. G. Pena, J. K. Goodrich, J. I. Gordon, G. A. Huttley, S. T. Kelley, D. Knights, J. E. Koenig, R. E. Ley, C. A. Lozupone, D. McDonald, B. D. Muegge, M. Pirrung, J. Reeder, J. R. Sevinsky, P. J. Turnbaugh, W. A. Walters, J. Widmann, T. Yatsunenko, J. Zaneveld and R. Knight (2010). "QIIME allows analysis of high-throughput community sequencing data." Nature Methods 7(5): 335-336.

Caporaso, J. G., J. Kuczynski, J. Stombaugh, K. Bittinger, F. D. Bushman, E. K. Costello, N. Fierer, A. G. Pena, J. K. Goodrich, J. I. Gordon, G. A. Huttley, S. T. Kelley, D. Knights, J. E. Koenig, R. E. Ley, C. A. Lozupone, D. McDonald, B. D. Muegge, M. Pirrung, J. Reeder, J. R. Sevinsky, P. J. Turnbaugh, W. A. Walters, J. Widmann, T. Yatsunenko, J. Zaneveld and R. Knight (2010). "QIIME allows analysis of high-throughput community sequencing data." Nat Methods 7(5): 335-336.

Carbonero, F., B. B. Oakley and K. J. Purdy (2010). "Improving the isolation of anaerobes on solid media: the example of the fastidious Methanosaeta." J Microbiol Methods 80(2): 203-205.

Cardinale, B. J., J. E. Duffy, A. Gonzalez, D. U. Hooper, C. Perrings, P. Venail, A. Narwani, G. M. Mace, D. Tilman, D. A. Wardle, A. P. Kinzig, G. C. Daily, M. Loreau, J. B. Grace, A. Larigauderie, D. S. Srivastava and S. Naeem (2012). "Biodiversity loss and its impact on humanity." Nature 486(7401): 59-67.

Carrasco, I. J., M. C. Marquez, Y. Xue, Y. Ma, D. A. Cowan, B. E. Jones, W. D. Grant and A. Ventosa (2007). "Bacillus chagannorensis sp. nov., a moderate halophile from a soda lake in Inner Mongolia, China." Int J Syst Evol Microbiol 57(Pt 9): 2084-2088.

Carrasco, I. J., M. C. Marquez, Y. Xue, Y. Ma, D. A. Cowan, B. E. Jones, W. D. Grant and A. Ventosa (2007). "Salsuginibacillus kocurii gen. nov., sp. nov., a moderately halophilic bacterium from soda-lake sediment." Int J Syst Evol Microbiol 57(Pt 10): 2381-2386. 
Castillo, A. M., M. C. Gutierrez, M. Kamekura, Y. Ma, D. A. Cowan, B. E. Jones, W. D. Grant and A. Ventosa (2006). "Halovivax asiaticus gen. nov., sp. nov., a novel extremely halophilic archaeon isolated from Inner Mongolia, China." Int J Syst Evol Microbiol 56(Pt 4): 765-770.

Castillo, A. M., M. C. Gutierrez, M. Kamekura, Y. Xue, Y. Ma, D. A. Cowan, B. E. Jones, W. D. Grant and A. Ventosa (2006). "Halorubrum orientale sp. nov., a halophilic archaeon isolated from Lake Ejinor, Inner Mongolia, China." Int J Syst Evol Microbiol 56(Pt 11): 2559-2563.

Castillo, A. M., M. C. Gutierrez, M. Kamekura, Y. Xue, Y. Ma, D. A. Cowan, B. E. Jones, W. D. Grant and A. Ventosa (2007). "Halovivax ruber sp. nov., an extremely halophilic archaeon isolated from Lake Xilinhot, Inner Mongolia, China." Int J Syst Evol Microbiol 57(Pt 5): 1024-1027.

Cepl, J., A. Blahuskova, F. Cvrckova and A. Markos (2014). "Ammonia produced by bacterial colonies promotes growth of ampicillin-sensitive Serratia sp. by means of antibiotic inactivation." FEMS Microbiol Lett 354(2): 126-132.

Chan, K. G., J. W. Chen, C. Y. Chang, W. F. Yin and X. Y. Chan (2015). "Draft Genome Sequence of Lysinibacillus sp. Strain A1, Isolated from Malaysian Tropical Soil." Genome Announc 3(2).

Chao, A. and J. Bunge (2002). "Estimating the number of species in a stochastic abundance model." Biometrics 58(3): 531-539.

Chen, H., M. Jogler, B. J. Tindall, H. P. Klenk, M. Rohde, H. J. Busse and J. Overmann (2013). "Sphingomonas starnbergensis sp. nov., isolated from a prealpine freshwater lake." Int J Syst Evol Microbiol 63(Pt 3): 1017-1023.

Chen, J., F. Wang, L. Jiang, X. Yin and X. Xiao (2013). "Stratified communities of active Archaea in shallow sediments of the Pearl River Estuary, Southern China." Curr Microbiol 67(1): 4150.

Chen, S., H. C. Liu, D. Zhao, J. Yang, J. Zhou and H. Xiang (2015). "Halorubrum yunnanense sp. nov., isolated from a subterranean salt mine." Int J Syst Evol Microbiol 65(12): 4526-4532.

Chen, Z., D. Feng, B. Zhang, Q. Wang, Y. Luo and X. Dong (2015). "Proteomic insights into the temperature responses of a cold-adaptive archaeon Methanolobus psychrophilus R15." Extremophiles 19(2): 249-259.

Chomczynski, P. and N. Sacchi (1987). "Single-step method of RNA isolation by acid guanidinium thiocyanate-phenol-chloroform extraction." Anal Biochem 162(1): 156-159.

Chong, S. C., Y. Liu, M. Cummins, D. L. Valentine and D. R. Boone (2002). "Methanogenium marinum sp. nov., a H2-using methanogen from Skan Bay, Alaska, and kinetics of $\mathrm{H} 2$ utilization." Antonie Van Leeuwenhoek 81(1-4): 263-270.

Chow, J. M. and J. B. Russell (1990). "Effect of ionophores and $\mathrm{pH}$ on growth of Streptococcus bovis in batch and continuous culture." Appl Environ Microbiol 56(6): 1588-1593.

Ciulla, R. A., M. R. Diaz, B. F. Taylor and M. F. Roberts (1997). "Organic osmolytes in aerobic bacteria from mono lake, an alkaline, moderately hypersaline environment." Appl Environ Microbiol 63(1): 220-226.

Cockell, C. S. (2006). "The origin and emergence of life under impact bombardment." Philos Trans R Soc Lond B Biol Sci 361(1474): 1845-1855; discussion 1856.

Cockell, C. S., G. R. Osinski and P. Lee (2003). "The impact crater as a habitat: effects of impact processing of target materials." Astrobiology 3(1): 181-191.

Corral, P., A. Corcelli and A. Ventosa (2015). "Halostagnicola bangensis sp. nov., an alkaliphilic haloarchaeon from a soda lake." Int J Syst Evol Microbiol 65(Pt 3): 754-759.

Corral, P., R. R. de la Haba, C. Sanchez-Porro, M. Ali Amoozegar, R. Thane Papke and A. Ventosa (2016). "Halorubrum halodurans sp. nov., an extremely halophilic archaeon isolated from a hypersaline lake." Int J Syst Evol Microbiol 66(1): 435-444. 
Corral, P., M. C. Gutierrez, A. M. Castillo, M. Dominguez, P. Lopalco, A. Corcelli and A. Ventosa (2013). "Natronococcus roseus sp. nov., a haloalkaliphilic archaeon from a hypersaline lake." Int J Syst Evol Microbiol 63(Pt 1): 104-108.

Crossey, L. and P. McCarville (1993). "Post-Impact Alteration of the Manson Impact structure." Twenty-fourth Lunar and Planetary Science Conference XXIV: 351-352.

Cuhel, R. L., C. D. Taylor and H. W. Jannasch (1981). "Assimilatory sulfur metabolism in marine microorganisms: characteristics and regulation of sulfate transport in Pseudomonas halodurans and Alteromonas luteo-violaceus." J Bacteriol 147(2): 340-349.

Cuhel, R. L., C. D. Taylor and H. W. Jannasch (1982). "Assimilatory Sulfur Metabolism in Marine Microorganisms: Sulfur Metabolism, Protein Synthesis, and Growth of Alteromonas luteoviolaceus and Pseudomonas halodurans During Perturbed Batch Growth." Appl Environ Microbiol 43(1): 151-159.

Cui, H. L., D. Tohty, J. Feng, P. J. Zhou and S. J. Liu (2006). "Natronorubrum aibiense sp. nov., an extremely halophilic archaeon isolated from Aibi salt lake in Xin-Jiang, China, and emended description of the genus Natronorubrum." Int J Syst Evol Microbiol 56(Pt 7): 1515-1517.

Cui, H. L., D. Tohty, H. C. Liu, S. J. Liu, A. Oren and P. J. Zhou (2007). "Natronorubrum sulfidifaciens sp. nov., an extremely haloalkaliphilic archaeon isolated from Aiding salt lake in Xin-Jiang, China." Int J Syst Evol Microbiol 57(Pt 4): 738-740.

Cui, H. L., D. Tohty, P. J. Zhou and S. J. Liu (2006). "Halorubrum lipolyticum sp. nov. and Halorubrum aidingense sp. nov., isolated from two salt lakes in Xin-Jiang, China." Int J Syst Evol Microbiol 56(Pt 7): 1631-1634.

Dabir, A., V. Honkalas, P. Arora, S. Pore, D. R. Ranade and P. K. Dhakephalkar (2014). "Draft genome sequence of Methanoculleus sp. MH98A, a novel methanogen isolated from subseafloor methane hydrate deposits in Krishna Godavari basin." Mar Genomics 18PB: 139140.

Dadheech, P. K., G. Glockner, P. Casper, K. Kotut, C. J. Mazzoni, S. Mbedi and L. Krienitz (2013). "Cyanobacterial diversity in the hot spring, pelagic and benthic habitats of a tropical soda lake." FEMS Microbiol Ecol 85(2): 389-401.

Daniels, L., N. Belay and B. S. Rajagopal (1986). "Assimilatory reduction of sulfate and sulfite by methanogenic Bacteria." Appl Environ Microbiol 51(4): 703-709.

de Mazancourt, C., F. Isbell, A. Larocque, F. Berendse, E. De Luca, J. B. Grace, B. Haegeman, H. Wayne Polley, C. Roscher, B. Schmid, D. Tilman, J. van Ruijven, A. Weigelt, B. J. Wilsey and M. Loreau (2013). "Predicting ecosystem stability from community composition and biodiversity." Ecol Lett 16(5): 617-625.

Demharter, W., R. Hensel, J. Smida and E. Stackebrandt (1989). "Sphaerobacter thermophilus gen. nov., sp. nov. A Deeply Rooting Member of the Actinomycetes Subdivision Isolated from Thermophilically Treated Sewage Sludge." Systematic and Applied Microbiology 11(3): 261-266.

DeSantis, T. Z., P. Hugenholtz, N. Larsen, M. Rojas, E. L. Brodie, K. Keller, T. Huber, D. Dalevi, P. Hu and G. L. Andersen (2006). "Greengenes, a chimera-checked $16 \mathrm{~S}$ rRNA gene database and workbench compatible with ARB." Appl Environ Microbiol 72(7): 5069-5072.

Deshmukh, K. B., A. P. Pathak and M. S. Karuppayil (2011). "Bacterial diversity of lonar soda lake of India." Indian J Microbiol 51(1): 107-111.

Dhillon, A., M. Lever, K. G. Lloyd, D. B. Albert, M. L. Sogin and A. Teske (2005). "Methanogen diversity evidenced by molecular characterization of methyl coenzyme $M$ reductase $A$ 
(mcrA) genes in hydrothermal sediments of the Guaymas Basin." Appl Environ Microbiol 71(8): 4592-4601.

Di Capua, C., A. Bortolotti, M. E. Farias and N. Cortez (2011). "UV-resistant Acinetobacter sp. isolates from Andean wetlands display high catalase activity." FEMS Microbiol Lett 317(2): 181-189.

Dimitriu, P. A., H. C. Pinkart, B. M. Peyton and M. R. Mormile (2008). "Spatial and temporal patterns in the microbial diversity of a meromictic soda lake in Washington State." Appl Environ Microbiol 74(15): 4877-4888.

Doerfert, S. N., M. Reichlen, P. Iyer, M. Wang and J. G. Ferry (2009). "Methanolobus zinderi sp. nov., a methylotrophic methanogen isolated from a deep subsurface coal seam." Int J Syst Evol Microbiol 59(Pt 5): 1064-1069.

Dong, L. F., C. J. Smith, S. Papaspyrou, A. Stott, A. M. Osborn and D. B. Nedwell (2009). "Changes in benthic denitrification, nitrate ammonification, and anammox process rates and nitrate and nitrite reductase gene abundances along an estuarine nutrient gradient (the Colne estuary, United Kingdom)." Appl Environ Microbiol 75(10): 3171-3179.

Dower, W. J., J. F. Miller and C. W. Ragsdale (1988). "High efficiency transformation of E. coli by high voltage electroporation." Nucleic Acids Res 16(13): 6127-6145.

Dridi, B., M. L. Fardeau, B. Ollivier, D. Raoult and M. Drancourt (2012). "Methanomassiliicoccus luminyensis gen. nov., sp. nov., a methanogenic archaeon isolated from human faeces." Int J Syst Evol Microbiol 62(Pt 8): 1902-1907.

Duckworth, A. W., W. D. Grant, B. E. Jones and R. Steenbergen (1996). "Phylogenetic diversity of soda lake alkaliphiles." FEMS Microbiology Ecology 19(3): 181-191.

Dumont, M. G. and J. C. Murrell (2005). "Community-level analysis: key genes of aerobic methane oxidation." Methods Enzymol 397: 413-427.

Edgar, R. C. (2010). "Search and clustering orders of magnitude faster than BLAST." Bioinformatics 26(19): 2460-2461.

Edgar, R. C. (2013). "UPARSE: highly accurate OTU sequences from microbial amplicon reads." Nat Methods 10(10): 996-998.

Edgar, R. C. and H. Flyvbjerg (2015). "Error filtering, pair assembly and error correction for nextgeneration sequencing reads." Bioinformatics 31(21): 3476-3482.

Edgar, R. C., B. J. Haas, J. C. Clemente, C. Quince and R. Knight (2011). "UCHIME improves sensitivity and speed of chimera detection." Bioinformatics 27(16): 2194-2200.

Edlund, A., F. Hardeman, J. K. Jansson and S. Sjoling (2008). "Active bacterial community structure along vertical redox gradients in Baltic Sea sediment." Environ Microbiol 10(8): 2051-2063.

Emmerich, M., A. Bhansali, T. Losekann-Behrens, C. Schroder, A. Kappler and S. Behrens (2012). "Abundance, distribution, and activity of $\mathrm{Fe}(\mathrm{II})$-oxidizing and $\mathrm{Fe}$ (III)-reducing microorganisms in hypersaline sediments of Lake Kasin, southern Russia." Appl Environ Microbiol 78(12): 4386-4399.

Eyice, O., M. Namura, Y. Chen, A. Mead, S. Samavedam and H. Schafer (2015). "SIP metagenomics identifies uncultivated Methylophilaceae as dimethylsulphide degrading bacteria in soil and lake sediment." ISME J 9(11): 2336-2348.

Fan, H., Y. Xue, Y. Ma, A. Ventosa and W. D. Grant (2004). "Halorubrum tibetense sp. nov., a novel haloalkaliphilic archaeon from Lake Zabuye in Tibet, China." Int J Syst Evol Microbiol 54(Pt 4): 1213-1216.

Fang, M. X., W. W. Zhang, Y. Z. Zhang, H. Q. Tan, X. Q. Zhang, M. Wu and X. F. Zhu (2012). "Brassicibacter mesophilus gen. nov., sp. nov., a strictly anaerobic bacterium isolated from food industry wastewater." Int J Syst Evol Microbiol 62(Pt 12): 3018-3023. 
Fani, R., R. Gallo and P. Lio (2000). "Molecular evolution of nitrogen fixation: the evolutionary history of the nifD, nifK, nifE, and nifN genes." J Mol Evol 51(1): 1-11.

Farias, M. E., S. Revale, E. Mancini, O. Ordonez, A. Turjanski, N. Cortez and M. P. Vazquez (2011). "Genome sequence of Sphingomonas sp. S17, isolated from an alkaline, hyperarsenic, and hypersaline volcano-associated lake at high altitude in the Argentinean Puna." $\underline{\text { J Bacteriol }}$ 193(14): 3686-3687.

Feldman, V. I., L. V. Sazonova, Y. V. Mironov and I. G. Kapustkina (1983). "Circular structure Logancha as possible meteorite crater in basalts of the Tunguska syneclise." Proceedings, 14 th Lunar and

Planetary Science Conference: 191-192.

Feng, J., P. Zhou, Y. G. Zhou, S. J. Liu and K. Warren-Rhodes (2005). "Halorubrum alkaliphilum sp. nov., a novel haloalkaliphile isolated from a soda lake in Xinjiang, China." Int J Syst Evol Microbiol 55(Pt 1): 149-152.

Ferry, J. G. (2011). "Fundamentals of methanogenic pathways that are key to the biomethanation of complex biomass." Curr Opin Biotechnol 22(3): 351-357.

Fleischmann, R. D., M. D. Adams, O. White, R. A. Clayton, E. F. Kirkness, A. R. Kerlavage, C. J. Bult, J. F. Tomb, B. A. Dougherty, J. M. Merrick and et al. (1995). "Whole-genome random sequencing and assembly of Haemophilus influenzae Rd." Science 269(5223): 496-512.

Florenzano, G., C. Sili, E. Pelosi and M. Vincenzini (1985). "Cyanospira rippkae and Cyanospira capsulata (gen. nov. and spp. nov.): new filamentous heterocystous cyanobacteria from Magadi lake (Kenya)." Archives of Microbiology 140(4): 301-306.

Follmann, M., M. Becker, I. Ochrombel, V. Ott, R. Kramer and K. Marin (2009). "Potassium transport in corynebacterium glutamicum is facilitated by the putative channel protein CgIK, which is essential for $\mathrm{pH}$ homeostasis and growth at acidic $\mathrm{pH} . " \underline{\mathrm{J} \text { Bacteriol 191(9): }}$ 2944-2952.

Foti, M., S. Ma, D. Y. Sorokin, J. L. Rademaker, J. G. Kuenen and G. Muyzer (2006). "Genetic diversity and biogeography of haloalkaliphilic sulphur-oxidizing bacteria belonging to the genus Thioalkalivibrio." FEMS Microbiol Ecol 56(1): 95-101.

Foti, M., D. Y. Sorokin, B. Lomans, M. Mussman, E. E. Zacharova, N. V. Pimenov, J. G. Kuenen and G. Muyzer (2007). "Diversity, activity, and abundance of sulfate-reducing bacteria in saline and hypersaline soda lakes." Appl Environ Microbiol 73(7): 2093-2100.

Foti, M. J., D. Y. Sorokin, E. E. Zacharova, N. V. Pimenov, J. G. Kuenen and G. Muyzer (2008). "Bacterial diversity and activity along a salinity gradient in soda lakes of the Kulunda Steppe (Altai, Russia)." Extremophiles 12(1): 133-145.

Fox, G. E., K. R. Pechman and C. R. Woese (1977). "Comparative Cataloging of 16s Ribosomal Ribonucleic-Acid - Molecular Approach to Procaryotic Systematics." International Journal of Systematic Bacteriology 27(1): 44-57.

Franzmann, P. D., Y. Liu, D. L. Balkwill, H. C. Aldrich, E. Conway de Macario and D. R. Boone (1997). "Methanogenium frigidum sp. nov., a psychrophilic, H2-using methanogen from Ace Lake, Antarctica." Int J Syst Bacteriol 47(4): 1068-1072.

Fredriksson, K., A. Dube, D. J. Milton and M. S. Balasundaram (1973). "Lonar lake, India: an impact crater in basalt." Science 180(4088): 862-864.

Fudali, R. F., D. J. Milton, K. Fredriksson and A. Dube (1980). "Morphology of Lonar Crater, India: Comparisons and implications." The Moon and the Planets 23(4): 493-515.

Fudou, R., Y. Jojima, T. lizuka and S. Yamanaka (2002). "Haliangium ochraceum gen. nov., sp. nov. and Haliangium tepidum sp. nov.: novel moderately halophilic myxobacteria isolated from coastal saline environments." J Gen Appl Microbiol 48(2): 109-116. 
Ganzert, L., J. Schirmack, M. Alawi, K. Mangelsdorf, W. Sand, A. Hillebrand-Voiculescu and D. Wagner (2014). "Methanosarcina spelaei sp. nov., a methanogenic archaeon isolated from a floating biofilm of a subsurface sulphurous lake." Int J Syst Evol Microbiol 64(Pt 10): 3478-3484.

Garnova, E. S., T. N. Zhilina, T. P. Tourova and A. M. Lysenko (2003). "Anoxynatronum sibiricum gen.nov., sp.nov. alkaliphilic saccharolytic anaerobe from cellulolytic community of Nizhnee Beloe (Transbaikal region)." Extremophiles 7(3): 213-220.

Ghosh, W. and B. Dam (2009). "Biochemistry and molecular biology of lithotrophic sulfur oxidation by taxonomically and ecologically diverse bacteria and archaea." FEMS Microbiol Rev 33(6): 999-1043.

Giggenbach, W. F. (1995). "Variations in the chemical and isotopic composition of fluids discharged from the Taupo Volcanic Zone, New Zealand." Journal of Volcanology and Geothermal Research 68(1-3): 89-116.

Gomila, M., B. Bowien, E. Falsen, E. R. Moore and J. Lalucat (2007). "Description of Pelomonas aquatica sp. nov. and Pelomonas puraquae sp. nov., isolated from industrial and haemodialysis water." Int J Syst Evol Microbiol 57(Pt 11): 2629-2635.

Gorlenko, V. M., I. A. Briantseva, E. E. Panteleeva, T. P. Turova, T. V. Kolganova, Z. K. Makhneva and A. A. Moskalenko (2004). "[Ectothiorhodosinus mongolicum gen. nov., sp. nov.,--a new purple sulfur bacterium from soda lake in Mongolia]." Mikrobiologiia 73(1): 80-88.

Gorlenko, V. M., I. A. Bryantseva, S. Rabold, T. P. Tourova, D. Rubtsova, E. Smirnova, V. Thiel and J. F. Imhoff (2009). "Ectothiorhodospira variabilis sp. nov., an alkaliphilic and halophilic purple sulfur bacterium from soda lakes." Int J Syst Evol Microbiol 59(Pt 4): 658-664.

Grant, S., D. Y. Sorokin, W. D. Grant, B. E. Jones and S. Heaphy (2004). "A phylogenetic analysis of Wadi el Natrun soda lake cellulase enrichment cultures and identification of cellulase genes from these cultures." Extremophiles 8(5): 421-429.

Grant, W. and B. Jones (1992). "Alkaline Environments." Encyclopedia of Microbiology 1: 126-133.

Grant, W. D., C. Gerday and N. Glansdorff (2006). "Alkaline environments and biodiversity." Extremophilies in Encyclopedia of Life Support System (EOLSS).

Grant, W. D., A. A. Mills and A. K. Schofield (1979). "An Alkalophilic Species of Ectothiorhodospira from a Kenyan Soda Lake." Journal of General Microbiology 110(1): 137-142.

Grant, W. D., W. E. Mwatha and B. E. Jones (1990). "Alkaliphiles: Ecology, diversity and applications." FEMS Microbiology Letters 75(2-3): 255-269.

Grant, W. D. and D. Y. Sorokin (2011). Distribution and Diversity of Soda Lake Alkaliphiles. New York, Springer.

Gregory R. Warnes, B. B., Lodewijk Bonebakker, Robert Gentleman, Wolfgang Huber Andy Liaw, Thomas Lumley, Martin Maechler, Arni Magnusson, Steffen Moeller, Marc Schwartz, Bill Venables, (2015). gplots: Various R Programming Tools for Plotting Data.

Grimm, F., B. Franz and C. Dahl (2011). "Regulation of dissimilatory sulfur oxidation in the purple sulfur bacterium allochromatium vinosum." Front Microbiol 2: 51.

Groth, I., P. Schumann, F. A. Rajney, K. Martin, B. Schuetze and K. Augsten (1997). "Bogoriella caseilytica gen. nov., sp. nov., a new alkaliphilic actinomycete from a soda lake in Africa." Int J Syst Bacteriol 47(3): 788-794.

Guerrero, R. and M. Berlanga (2006). "Life's unity and flexibility: the ecological link." Int Microbiol 9(3): 225-235.

Gupta, R. S. and B. Gao (2009). "Phylogenomic analyses of clostridia and identification of novel protein signatures that are specific to the genus Clostridium sensu stricto (cluster I)." Int J Syst Evol Microbiol 59(Pt 2): 285-294. 
Gutierrez, M. C., A. M. Castillo, P. Corral, M. Kamekura and A. Ventosa (2011). "Halorubrum aquaticum sp. nov., an archaeon isolated from hypersaline lakes." Int J Syst Evol Microbiol 61(Pt 5): 1144-1148.

Gutierrez, M. C., A. M. Castillo, P. Corral, H. Minegishi and A. Ventosa (2010). "Natronorubrum sediminis sp. nov., an archaeon isolated from a saline lake." Int J Syst Evol Microbiol 60(Pt 8): 1802-1806.

Gutierrez, M. C., A. M. Castillo, M. Kamekura and A. Ventosa (2008). "Haloterrigena salina sp. nov., an extremely halophilic archaeon isolated from a salt lake." Int J Syst Evol Microbiol 58(Pt 12): 2880-2884.

Hakemian, A. S. and A. C. Rosenzweig (2007). "The biochemistry of methane oxidation." Annu Rev Biochem 76: 223-241.

Hallam, S. J., P. R. Girguis, C. M. Preston, P. M. Richardson and E. F. DeLong (2003). "Identification of methyl coenzyme $M$ reductase $A$ ( $\mathrm{mcr} A$ ) genes associated with methane-oxidizing archaea." Appl Environ Microbiol 69(9): 5483-5491.

Han, B., Y. Chen, G. Abell, H. Jiang, L. Bodrossy, J. Zhao, J. C. Murrell and X. H. Xing (2009). "Diversity and activity of methanotrophs in alkaline soil from a Chinese coal mine." $\underline{\text { FEMS }}$ Microbiol Ecol 70(2): 40-51.

Hedderich, R., N. Hamann and M. Bennati (2005). "Heterodisulfide reductase from methanogenic archaea: a new catalytic role for an iron-sulfur cluster." Biol Chem 386(10): 961-970.

Henson, B. J., L. E. Watson and S. R. Barnum (2004). "The evolutionary history of nitrogen fixation, as assessed by NifD." J Mol Evol 58(4): 390-399.

Hezayen, F. F., B. J. Tindall, A. Steinbuchel and B. H. Rehm (2002). "Characterization of a novel halophilic archaeon, Halobiforma haloterrestris gen. nov., sp. nov., and transfer of Natronobacterium nitratireducens to Halobiforma nitratireducens comb. nov." Int J Syst Evol Microbiol 52(Pt 6): 2271-2280.

Hoeft, S. E., J. S. Blum, J. F. Stolz, F. R. Tabita, B. Witte, G. M. King, J. M. Santini and R. S. Oremland (2007). "Alkalilimnicola ehrlichii sp. nov., a novel, arsenite-oxidizing haloalkaliphilic gammaproteobacterium capable of chemoautotrophic or heterotrophic growth with nitrate or oxygen as the electron acceptor." Int J Syst Evol Microbiol 57(Pt 3): 504-512.

Hollibaugh, J. T., C. Budinoff, R. A. Hollibaugh, B. Ransom and N. Bano (2006). "Sulfide oxidation coupled to arsenate reduction by a diverse microbial community in a soda lake." Appl Environ Microbiol 72(3): 2043-2049.

Horikoshi, K. (1999). "Alkaliphiles: Some Applications of Their Products for Biotechnology." Microbiology and Molecular Biology Reviews 63(4): 735-750.

Hu, L., H. Pan, Y. Xue, A. Ventosa, D. A. Cowan, B. E. Jones, W. D. Grant and Y. Ma (2008). "Halorubrum luteum sp. nov., isolated from Lake Chagannor, Inner Mongolia, China." Int J Syst Evol Microbiol 58(Pt 7): 1705-1708.

Huang, H., J. Lv, Y. Hu, Z. Fang, K. Zhang and S. Bao (2008). "Micromonospora rifamycinica sp. nov., a novel actinomycete from mangrove sediment." Int J Syst Evol Microbiol 58(Pt 1): 17-20.

Humayoun, S. B., N. Bano and J. T. Hollibaugh (2003). "Depth distribution of microbial diversity in Mono Lake, a meromictic soda lake in California." Appl Environ Microbiol 69(2): 10301042.

Huse, S. M., J. A. Huber, H. G. Morrison, M. L. Sogin and D. M. Welch (2007). "Accuracy and quality of massively parallel DNA pyrosequencing." Genome Biol 8(7): R143. 
Hyatt, D., G. L. Chen, P. F. Locascio, M. L. Land, F. W. Larimer and L. J. Hauser (2010). "Prodigal: prokaryotic gene recognition and translation initiation site identification." BMC Bioinformatics 11(1): 119.

Hyman, E. D. (1988). "A new method of sequencing DNA." Anal Biochem 174(2): 423-436.

lino, T., K. Mori and K. Suzuki (2010). "Methanospirillum lacunae sp. nov., a methane-producing archaeon isolated from a puddly soil, and emended descriptions of the genus Methanospirillum and Methanospirillum hungatei." Int J Syst Evol Microbiol 60(Pt 11): 2563-2566.

Imachi, H., S. Sakai, J. S. Lipp, M. Miyazaki, Y. Saito, Y. Yamanaka, K. U. Hinrichs, F. Inagaki and K. Takai (2014). "Pelolinea submarina gen. nov., sp. nov., an anaerobic, filamentous bacterium of the phylum Chloroflexi isolated from subseafloor sediment." Int J Syst Evol Microbiol 64(Pt 3): 812-818.

Imamura, S., M. Terashita, M. Ohnuma, S. Maruyama, A. Minoda, A. P. Weber, T. Inouye, Y. Sekine, Y. Fujita, T. Omata and K. Tanaka (2010). "Nitrate assimilatory genes and their transcriptional regulation in a unicellular red alga Cyanidioschyzon merolae: genetic evidence for nitrite reduction by a sulfite reductase-like enzyme." Plant Cell Physiol 51(5): 707-717.

Imhoff, J. F., H. G. Sahl, G. S. H. Soliman and H. G. Trüper (2009). "The Wadi Natrun: Chemical composition and microbial mass developments in alkaline brines of Eutrophic Desert Lakes." Geomicrobiology Journal 1(3): 219-234.

Imhoff, J. F., B. J. Tindall, W. D. Grant and H. G. Trüper (1981). "Ectothiorhodospira vacuolata sp. nov., a new phototrophic bacterium from soda lakes." Archives of Microbiology 130(3): 238-242.

Infante-Dominguez, C., P. Corral, C. Sanchez-Porro and A. Ventosa (2015). "Halovenus salina sp. nov., an extremely halophilic archaeon isolated from a saltern." Int J Syst Evol Microbiol 65(9): 3016-3023.

Ishikawa, M., S. Tanasupawat, K. Nakajima, H. Kanamori, S. Ishizaki, K. Kodama, A. OkamotoKainuma, Y. Koizumi, Y. Yamamoto and K. Yamasato (2009). "Alkalibacterium thalassium sp. nov., Alkalibacterium pelagium sp. nov., Alkalibacterium putridalgicola sp. nov. and Alkalibacterium kapii sp. nov., slightly halophilic and alkaliphilic marine lactic acid bacteria isolated from marine organisms and salted foods collected in Japan and Thailand." Int J Syst Evol Microbiol 59(Pt 5): 1215-1226.

Itoh, T., T. Yamaguchi, P. Zhou and T. Takashina (2005). "Natronolimnobius baerhuensis gen. nov., sp. nov. and Natronolimnobius innermongolicus sp. nov., novel haloalkaliphilic Archaea isolated from soda lakes in Inner Mongolia, China." Extremophiles 9(2): 111-116.

Jeon, C. O., J. M. Lim, S. S. Lee, B. S. Chung, D. J. Park, L. H. Xu, C. L. Jiang and C. J. Kim (2009). "Paenibacillus harenae sp. nov., isolated from desert sand in China." Int J Syst Evol Microbiol 59(Pt 1): 13-17.

Jetten, M. S., O. Sliekers, M. Kuypers, T. Dalsgaard, L. van Niftrik, I. Cirpus, K. van de Pas-Schoonen, G. Lavik, B. Thamdrup, D. Le Paslier, H. J. Op den Camp, S. Hulth, L. P. Nielsen, W. Abma, K. Third, P. Engstrom, J. G. Kuenen, B. B. Jorgensen, D. E. Canfield, J. S. Sinninghe Damste, N. P. Revsbech, J. Fuerst, J. Weissenbach, M. Wagner, I. Schmidt, M. Schmid and M. Strous (2003). "Anaerobic ammonium oxidation by marine and freshwater planctomycete-like Bacteria." Appl Microbiol Biotechnol 63(2): 107-114.

Jetten, M. S., M. Strous, K. T. van de Pas-Schoonen, J. Schalk, U. G. van Dongen, A. A. van de Graaf, S. Logemann, G. Muyzer, M. C. van Loosdrecht and J. G. Kuenen (1998). "The anaerobic oxidation of ammonium." FEMS Microbiol Rev 22(5): 421-437. 
Jones, B. E., W. D. Grant, A. W. Duckworth and G. G. Owenson (1998). "Microbial diversity of soda lakes." Extremophiles 2(3): 191-200.

Joshi, A. A., P. P. Kanekar, A. S. Kelkar, Y. S. Shouche, A. A. Vani, S. B. Borgave and S. S. Sarnaik (2008). "Cultivable bacterial diversity of alkaline Lonar lake, India." Microb Ecol 55(2): 163172.

Kaluzhnaya, M., V. Khmelenina, B. Eshinimaev, N. Suzina, D. Nikitin, A. Solonin, J. L. Lin, I. McDonald, C. Murrell and Y. Trotsenko (2001). "Taxonomic characterization of new alkaliphilic and alkalitolerant methanotrophs from soda lakes of the Southeastern Transbaikal region and description of Methylomicrobium buryatense sp.nov." Syst Appl Microbiol 24(2): 166-176.

Kan, J., S. Clingenpeel, R. E. Macur, W. P. Inskeep, D. Lovalvo, J. Varley, Y. Gorby, T. R. McDermott and K. Nealson (2011). "Archaea in Yellowstone Lake." ISME J 5(11): 1784-1795.

Kanal, H., T. Kobayashi, R. Aono and T. Kudo (1995). "Natronococcus amylolyticus sp. nov., a haloalkaliphilic archaeon." Int J Syst Bacteriol 45(4): 762-766.

Kanehisa, M., Y. Sato and K. Morishima (2016). "BlastKOALA and GhostKOALA: KEGG Tools for Functional Characterization of Genome and Metagenome Sequences." J Mol Biol 428(4): 726-731.

Kanekar, P. P., S. S. Sarnaik and A. S. Kelkar (1998). "Bioremediation of phenol by alkaliphilic bacteria isolated from alkaline lake of Lonar, India." J Appl Microbiol 85 Suppl 1: 128S1335 .

Kendall, M. M., G. D. Wardlaw, C. F. Tang, A. S. Bonin, Y. Liu and D. L. Valentine (2007). "Diversity of Archaea in marine sediments from Skan Bay, Alaska, including cultivated methanogens, and description of Methanogenium boonei sp. nov." Appl Environ Microbiol 73(2): 407414.

Kevbrin, V. V., T. N. Zhilina, F. A. Rainey and G. A. Zavarzin (1998). "Tindallia magadii gen. nov., sp. nov.: an alkaliphilic anaerobic ammonifier from soda lake deposits." Curr Microbiol 37(2): 94-100.

Khmelenina, Y. N., B. T. Eshinimaev, M. G. Kalyuzhnaya and Y. A. Trotsenko (2000). "Potential activity of methane and ammonium oxidation by methanotrophic communities from the soda lakes of southern Transbaikal." Microbiology 69(4): 460-465.

Kim, J. and D. C. Rees (1994). "Nitrogenase and biological nitrogen fixation." Biochemistry 33(2): 389-397.

King-Thom, C. and F. D. Hunter (1996). "Martinus Willem Beijerinck (1852-1931) Pioneer of general microbiology." ASM News 62(10): 539-543.

Klindworth, A., E. Pruesse, T. Schweer, J. Peplies, C. Quast, M. Horn and F. O. Glockner (2013). "Evaluation of general $16 \mathrm{~S}$ ribosomal RNA gene PCR primers for classical and nextgeneration sequencing-based diversity studies." Nucleic Acids Res 41(1): e1.

Kompantseva, E. I. (2007). "[The effect of the pH level on the communities of anoxygenic phototrophic bacteria of soda lakes of the southeastern Transbaikal region]." Mikrobiologiia 76(6): 872-878.

Kompantseva, E. I., D. Sorokin, V. M. Gorlenko and B. B. Namsaraev (2005). "[The phototrophic community found in Lake Khilganta (an alkaline saline lake located in the southeastern Transbaikal region)]." Mikrobiologiia 74(3): 410-419.

Kong, D., Y. Wang, B. Zhao, Y. Li, J. Song, Y. Zhai, C. Zhang, H. Wang, X. Chen, B. Zhao and Z. Ruan (2014). "Lysinibacillus halotolerans sp. nov., isolated from saline-alkaline soil." Int J Syst Evol Microbiol 64(Pt 8): 2593-2598. 
Kormas, K. A., M. G. Pachiadaki, H. Karayanni, E. R. Leadbetter, J. M. Bernhard and V. P. Edgcomb (2015). "Inter-comparison of the potentially active prokaryotic communities in the halocline sediments of Mediterranean deep-sea hypersaline basins." Extremophiles 19(5): 949-960.

Kovaleva, O. L., T. P. Tourova, G. Muyzer, T. V. Kolganova and D. Y. Sorokin (2011). "Diversity of RuBisCO and ATP citrate lyase genes in soda lake sediments." FEMS Microbiol Ecol 75(1): 37-47.

Krienitz, L., P. K. Dadheech and K. Kotut (2012). "Mass developments of the cyanobacteria Anabaenopsis and Cyanospira (Nostocales) in the soda lakes of Kenya: ecological and systematic implications." Hydrobiologia 703(1): 79-93.

Krulwich, T. A., A. A. Guffanti, R. F. Bornstein and J. Hoffstein (1982). "A sodium requirement for growth, solute transport, and pH homeostasis in Bacillus firmus RAB." J Biol Chem 257(4): 1885-1889.

Kulp, T. R., S. Han, C. W. Saltikov, B. D. Lanoil, K. Zargar and R. S. Oremland (2007). "Effects of imposed salinity gradients on dissimilatory arsenate reduction, sulfate reduction, and other microbial processes in sediments from two California soda lakes." Appl Environ Microbiol 73(16): 5130-5137.

Kulp, T. R., S. E. Hoeft, L. G. Miller, C. Saltikov, J. N. Murphy, S. Han, B. Lanoil and R. S. Oremland (2006). "Dissimilatory arsenate and sulfate reduction in sediments of two hypersaline, arsenic-rich soda lakes: Mono and Searles Lakes, California." Appl Environ Microbiol 72(10): 6514-6526.

Kunin, V., A. Engelbrektson, H. Ochman and P. Hugenholtz (2010). "Wrinkles in the rare biosphere: pyrosequencing errors can lead to artificial inflation of diversity estimates." Environ Microbiol 12(1): 118-123.

Kunte, H., H. G. Trüper and H. Stan-Lotter (2002). Halophilic Microorganisms. Astrobiology. G. Horneck and C. Baumstark-Khan, Springer Berlin Heidelberg: 185-200.

Kurahashi, M., Y. Fukunaga, Y. Sakiyama, S. Harayama and A. Yokota (2010). "Euzebya tangerina gen. nov., sp. nov., a deeply branching marine actinobacterium isolated from the sea cucumber Holothuria edulis, and proposal of Euzebyaceae fam. nov., Euzebyales ord. nov. and Nitriliruptoridae subclassis nov." Int J Syst Evol Microbiol 60(Pt 10): 2314-2319.

Kuroki, M., Y. Igarashi, M. Ishii and H. Arai (2014). "Fine-tuned regulation of the dissimilatory nitrite reductase gene by oxygen and nitric oxide in Pseudomonas aeruginosa." Environ Microbiol Rep 6(6): 792-801.

Kurth, D., C. Belfiore, M. F. Gorriti, N. Cortez, M. E. Farias and V. H. Albarracin (2015). "Genomic and proteomic evidences unravel the UV-resistome of the poly-extremophile Acinetobacter sp. Ver3." Front Microbiol 6: 328.

Labrenz, M., E. Sintes, F. Toetzke, A. Zumsteg, G. J. Herndl, M. Seidler and K. Jurgens (2010). "Relevance of a crenarchaeotal subcluster related to Candidatus Nitrosopumilus maritimus to ammonia oxidation in the suboxic zone of the central Baltic Sea." ISME J 4(12): 1496-1508.

Lambert, R. J. (2011). "A new model for the effect of $\mathrm{pH}$ on microbial growth: an extension of the Gamma hypothesis." J Appl Microbiol 110(1): 61-68.

Lambert, R. J. and R. Lambert (2003). "A model for the efficacy of combined inhibitors." J Appl Microbiol 95(4): 734-743.

Lambert, R. J. and J. Pearson (2000). "Susceptibility testing: accurate and reproducible minimum inhibitory concentration (MIC) and non-inhibitory concentration (NIC) values." J Appl Microbiol 88(5): 784-790. 
Lanzen, A., A. Simachew, A. Gessesse, D. Chmolowska, I. Jonassen and L. Ovreas (2013). "Surprising prokaryotic and eukaryotic diversity, community structure and biogeography of Ethiopian soda lakes." PLoS One 8(8): e72577.

Leadbetter, J. R., L. D. Crosby and J. A. Breznak (1998). "Methanobrevibacter filiformis sp. nov., A filamentous methanogen from termite hindguts." Arch Microbiol 169(4): 287-292.

Leamon, J. H., W. L. Lee, K. R. Tartaro, J. R. Lanza, G. J. Sarkis, A. D. deWinter, J. Berka, M. Weiner, J. M. Rothberg and K. L. Lohman (2003). "A massively parallel PicoTiterPlate based platform for discrete picoliter-scale polymerase chain reactions." Electrophoresis 24(21): 3769-3777.

LeBlanc, J. G., M. S. Garro and G. Savoy de Giori (2004). "Effect of pH on Lactobacillus fermentum growth, raffinose removal, alpha-galactosidase activity and fermentation products." Appl Microbiol Biotechnol 65(1): 119-123.

Lee, J. S., K. C. Lee, Y. H. Chang, S. G. Hong, H. W. Oh, Y. R. Pyun and K. S. Bae (2002). "Paenibacillus daejeonensis sp. nov., a novel alkaliphilic bacterium from soil." Int J Syst Evol Microbiol 52(Pt 6): 2107-2111.

Lemon, J. (2006). Plotrix: a package in the red light district of R.

Lennon, J. T. and S. E. Jones (2011). "Microbial seed banks: the ecological and evolutionary implications of dormancy." Nat Rev Microbiol 9(2): 119-130.

Li, L. and K. Hong (2015). "Micromonospora ovatispora sp. nov. isolated from mangrove soil." Int J Syst Evol Microbiol.

Li, Q., F. Wang, Z. Chen, X. Yin and X. Xiao (2012). "Stratified active archaeal communities in the sediments of Jiulong River estuary, China." Front Microbiol 3: 311.

Li, Z., W. Jin, Z. Liang, Y. Yue and J. Lv (2013). "Abundance and diversity of ammonia-oxidizing Archaea in response to various habitats in Pearl River Delta of China, a subtropical maritime zone." J Environ Sci (China) 25(6): 1195-1205.

Liang, B., P. Lu, H. Li, R. Li, S. Li and X. Huang (2009). "Biodegradation of fomesafen by strain Lysinibacillus sp. ZB-1 isolated from soil." Chemosphere 77(11): 1614-1619.

Lin, J. L., S. Radajewski, B. T. Eshinimaev, Y. A. Trotsenko, I. R. McDonald and J. C. Murrell (2004). "Molecular diversity of methanotrophs in Transbaikal soda lake sediments and identification of potentially active populations by stable isotope probing." Environ Microbiol 6(10): 1049-1060.

Liu, Y., L. L. Beer and W. B. Whitman (2012). "Sulfur metabolism in Archaea reveals novel processes." Environ Microbiol 14(10): 2632-2644.

Lizama, C., M. Monteoliva-Sanchez, A. Suarez-Garcia, R. Rosello-Mora, M. Aguilera, V. Campos and A. Ramos-Cormenzana (2002). "Halorubrum tebenquichense sp. nov., a novel halophilic archaeon isolated from the Atacama Saltern, Chile." Int J Syst Evol Microbiol 52(Pt 1): 149-155.

Loffler, F. E., J. Yan, K. M. Ritalahti, L. Adrian, E. A. Edwards, K. T. Konstantinidis, J. A. Muller, H. Fullerton, S. H. Zinder and A. M. Spormann (2013). "Dehalococcoides mccartyi gen. nov., sp. nov., obligately organohalide-respiring anaerobic bacteria relevant to halogen cycling and bioremediation, belong to a novel bacterial class, Dehalococcoidia classis nov., order Dehalococcoidales ord. nov. and family Dehalococcoidaceae fam. nov., within the phylum Chloroflexi." Int J Syst Evol Microbiol 63(Pt 2): 625-635.

Lopez-Archilla, A. I., D. Moreira, P. Lopez-Garcia and C. Guerrero (2004). "Phytoplankton diversity and cyanobacterial dominance in a hypereutrophic shallow lake with biologically produced alkaline pH." Extremophiles 8(2): 109-115. 
Lyimo, T. J., A. Pol, M. S. Jetten and H. J. den Camp (2009). "Diversity of methanogenic Archaea in a mangrove sediment and isolation of a new Methanococcoides strain." $\underline{\text { FEMS Microbiol }}$ Lett 291(2): 247-253.

Ma, Y., W. Zhang, Y. Xue, P. Zhou, A. Ventosa and W. D. Grant (2004). "Bacterial diversity of the Inner Mongolian Baer Soda Lake as revealed by 16S rRNA gene sequence analyses." Extremophiles 8(1): 45-51.

Madadi-Kahkesh, S., E. C. Duin, S. Heim, S. P. Albracht, M. K. Johnson and R. Hedderich (2001). "A paramagnetic species with unique EPR characteristics in the active site of heterodisulfide reductase from methanogenic archaea." Eur J Biochem 268(9): 2566-2577.

Makhdoumi-Kakhki, A., M. A. Amoozegar and A. Ventosa (2012). "Halovenus aranensis gen. nov., sp. nov., an extremely halophilic archaeon from Aran-Bidgol salt lake." Int J Syst Evol Microbiol 62(Pt 6): 1331-1336.

Mancinelli, R. L., T. F. Fahlen, R. Landheim and M. R. Klovstad (2004). "Brines and evaporites: analogs for Martian life." Advances in Space Research 33(8): 1244-1246.

Mander, G. J., E. C. Duin, D. Linder, K. O. Stetter and R. Hedderich (2002). "Purification and characterization of a membrane-bound enzyme complex from the sulfate-reducing archaeon Archaeoglobus fulgidus related to heterodisulfide reductase from methanogenic archaea." Eur J Biochem 269(7): 1895-1904.

Marco, P., C. C. Pacheco, A. R. Figueiredo and P. Moradas-Ferreira (2004). "Novel pollutantresistant methylotrophic bacteria for use in bioremediation." FEMS Microbiology Letters 234(1): 75-80.

Martin, M. (2011). Cutadapt removes adapter sequences from high-throughput sequencing reads.

Martinez-Espinosa, R. M., B. Lledo, F. C. Marhuenda-Egea and M. J. Bonete (2007). "The effect of ammonium on assimilatory nitrate reduction in the haloarchaeon Haloferax mediterranei." Extremophiles 11(6): 759-767.

Martins, R. F., W. Davids, W. Abu Al-Soud, F. Levander, P. Radstrom and R. Hatti-Kaul (2001). "Starch-hydrolyzing bacteria from Ethiopian soda lakes." Extremophiles 5(2): 135-144.

Masters, C. I., R. G. Murray, B. E. Moseley and K. W. Minton (1991). "DNA polymorphisms in new isolates of 'Deinococcus radiopugnans'." J Gen Microbiol 137(7): 1459-1469.

Matsumoto, A., Y. Takahashi, M. Shinose, A. Seino, Y. Iwai and S. Omura (2003). "Longispora albida gen. nov., sp. nov., a novel genus of the family Micromonosporaceae." Int J Syst Evol Microbiol 53(Pt 5): 1553-1559.

Mauffrey, F., C. Martineau and R. Villemur (2015). "Importance of the Two Dissimilatory (Nar) Nitrate Reductases in the Growth and Nitrate Reduction of the Methylotrophic Marine Bacterium Methylophaga nitratireducenticrescens JAM1." Front Microbiol 6: 1475.

McKay, A. L. and A. C. Peters (1995). "The effect of sodium chloride concentration and pH on the growth of Salmonella typhimurium colonies on solid medium." J Appl Bacteriol 79(4): 353359.

Mcsween, H. Y. (1994). "What We Have Learned About Mars from Snc Meteorites." Meteoritics 29(6): 757-779.

McSween, H. Y. (2002). "The rocks of Mars, from far and near." Meteoritics \& Planetary Science 37: 7-25.

Melack, J. and P. Kilham (1974). "Photosynthetic activity of phytoplankton in tropical African soda lakes." Limnology and Oceanography 19(5): 743-755.

Melamade, R. J. (1985). Automatable process for sequencing nucleotide. 
Melton, E. D., C. Schmidt and A. Kappler (2012). "Microbial Iron(II) Oxidation in Littoral Freshwater Lake Sediment: The Potential for Competition between Phototrophic vs. Nitrate-Reducing Iron(II)-Oxidizers." Front Microbiol 3: 197.

Mesbah, N. M., S. H. Abou-El-Ela and J. Wiegel (2007). "Novel and unexpected prokaryotic diversity in water and sediments of the alkaline, hypersaline lakes of the Wadi An Natrun, Egypt." Microb Ecol 54(4): 598-617.

Mesbah, N. M. and J. Wiegel (2009). "Natronovirga wadinatrunensis gen. nov., sp. nov. and Natranaerobius trueperi sp. nov., halophilic, alkalithermophilic micro-organisms from soda lakes of the Wadi An Natrun, Egypt." Int J Syst Evol Microbiol 59(Pt 8): 2042-2048.

Mesbah, N. M. and J. Wiegel (2012). "Life under multiple extreme conditions: diversity and physiology of the halophilic alkalithermophiles." Appl Environ Microbiol 78(12): 40744082.

Metzker, M. L. (2005). "Emerging technologies in DNA sequencing." Genome Res 15(12): 17671776.

Metzker, M. L. (2010). "Sequencing technologies - the next generation." Nat Rev Genet 11(1): 3146.

Mikucki, J. A., Y. Liu, M. Delwiche, F. S. Colwell and D. R. Boone (2003). "Isolation of a methanogen from deep marine sediments that contain methane hydrates, and description of Methanoculleus submarinus sp. nov." Appl Environ Microbiol 69(6): 3311-3316.

Milford, A. D., L. A. Achenbach, D. O. Jung and M. T. Madigan (2000). "Rhodobaca bogoriensis gen. nov. and sp. nov., an alkaliphilic purple nonsulfur bacterium from African Rift Valley soda lakes." Arch Microbiol 174(1-2): 18-27.

Mills, H. J., B. K. Reese, A. K. Shepard, N. Riedinger, S. E. Dowd, Y. Morono and F. Inagaki (2012). "Characterization of Metabolically Active Bacterial Populations in Subseafloor Nankai Trough Sediments above, within, and below the Sulfate-Methane Transition Zone." Front Microbiol 3: 113.

Mizukami, S., K. Takeda, S. Akada and T. Fujita (2006). "Isolation and characteristics of methanosaeta in paddy field soils." Biosci Biotechnol Biochem 70(4): 828-835.

Mochimaru, H., H. Tamaki, S. Hanada, H. Imachi, K. Nakamura, S. Sakata and Y. Kamagata (2009). "Methanolobus profundi sp. nov., a methylotrophic methanogen isolated from deep subsurface sediments in a natural gas field." Int J Syst Evol Microbiol 59(Pt 4): 714-718.

Montalvo-Rodriguez, R., J. Lopez-Garriga, R. H. Vreeland, A. Oren, A. Ventosa and M. Kamekura (2000). "Haloterrigena thermotolerans sp. nov., a halophilic archaeon from Puerto Rico." Int J Syst Evol Microbiol 50 Pt 3: 1065-1071.

Mori, K., T. lino, K. Suzuki, K. Yamaguchi and Y. Kamagata (2012). "Aceticlastic and NaCl-requiring methanogen "Methanosaeta pelagica" sp. nov., isolated from marine tidal flat sediment." Appl Environ Microbiol 78(9): 3416-3423.

Mosier, A. C., E. E. Allen, M. Kim, S. Ferriera and C. A. Francis (2012). "Genome sequence of "Candidatus Nitrosopumilus salaria" BD31, an ammonia-oxidizing archaeon from the San Francisco Bay estuary." J Bacteriol 194(8): 2121-2122.

Mtimet, N., S. Guegan, L. Durand, A. G. Mathot, L. Venaille, I. Leguerinel, L. Coroller and O. Couvert (2016). "Effect of $\mathrm{pH}$ on Thermoanaerobacterium thermosaccharolyticum DSM 571 growth, spore heat resistance and recovery." Food Microbiol 55: 64-72.

Muyzer, G., A. Teske, C. Wirsen and H. Jannasch (1995). "Phylogenetic relationships of Thiomicrospira species and their identification in deep-sea hydrothermal vent samples by denaturing gradient gel electrophoresis of 16S rDNA fragments." Archives of Microbiology 164(3): 165-172. 
Mwirichia, R., S. Cousin, A. W. Muigai, H. I. Boga and E. Stackebrandt (2010). "Archaeal diversity in the haloalkaline Lake Elmenteita in Kenya." Curr Microbiol 60(1): 47-52.

Mwirichia, R., A. W. Muigai, B. Tindall, H. I. Boga and E. Stackebrandt (2010). "Isolation and characterisation of bacteria from the haloalkaline Lake Elmenteita, Kenya." Extremophiles 14(4): 339-348.

Nakamura, T., S. Kawasaki and T. Unemoto (1992). "Roles of $\mathrm{K}+$ and $\mathrm{Na}+$ in $\mathrm{pH}$ homeostasis and growth of the marine bacterium Vibrio alginolyticus." J Gen Microbiol 138(6): 1271-1276.

Nayak, V. K. (1972). "Glassy objects (Impactite Glasses?) A possible new evidence for meteoritic origin of the Lonar Crater, Maharashtra State, India." Earth and Planetary Science Letters 14: 1-6.

Nercessian, O., E. Noyes, M. G. Kalyuzhnaya, M. E. Lidstrom and L. Chistoserdova (2005). "Bacterial populations active in metabolism of C1 compounds in the sediment of Lake Washington, a freshwater lake." Appl Environ Microbiol 71(11): 6885-6899.

Neumann, S., A. Wynen, H. G. Truper and C. Dahl (2000). "Characterization of the cys gene locus from Allochromatium vinosum indicates an unusual sulfate assimilation pathway." Mol Biol Rep 27(1): 27-33.

Newsom, H. E. (1980). "Hydrothermal alteration of impact melt sheets with implications for Mars." Icarus 44(1): 207-216.

Ng, F., S. Kittelmann, M. L. Patchett, G. T. Attwood, P. H. Janssen, J. Rakonjac and D. Gagic (2015). "An adhesin from hydrogen-utilizing rumen methanogen Methanobrevibacter ruminantium M1 binds a broad range of hydrogen-producing microorganisms." Environ Microbiol.

Ni, S. S. and D. R. Boone (1991). "Isolation and characterization of a dimethyl sulfide-degrading methanogen, Methanolobus siciliae HI350, from an oil well, characterization of M. siciliae T4/MT, and emendation of M. siciliae." Int J Syst Bacteriol 41(3): 410-416.

Nielsen, A. K., K. Gerdes, H. Degn and J. C. Murrell (1996). "Regulation of bacterial methane oxidation: transcription of the soluble methane mono-oxygenase operon of Methylococcus capsulatus (Bath) is repressed by copper ions." Microbiology 142 ( Pt 5): 1289-1296.

Nissenbaum, A. (1975). "The microbiology and biogeochemistry of the Dead Sea." Microb Ecol 2(2): 139-161.

Nolla-Ardevol, V., M. Strous, D. Y. Sorokin, A. Y. Merkel and H. E. Tegetmeyer (2012). "Activity and diversity of haloalkaliphilic methanogens in Central Asian soda lakes." J Biotechnol 161(2): 167-173.

Nossa, C. W., W. E. Oberdorf, L. Yang, J. A. Aas, B. J. Paster, T. Z. Desantis, E. L. Brodie, D. Malamud, M. A. Poles and Z. Pei (2010). "Design of 16S rRNA gene primers for 454 pyrosequencing of the human foregut microbiome." World J Gastroenterol 16(33): 4135-4144.

Ntougias, S. and N. J. Russell (2001). "Alkalibacterium olivoapovliticus gen. nov., sp. nov., a new obligately alkaliphilic bacterium isolated from edible-olive wash-waters." Int J Syst Evol Microbiol 51(Pt 3): 1161-1170.

Nuianzina-Boldareva, E. N. and V. M. Gorlenko (2014). "[Roseibacula alcaliphilum gen. nov. sp. nov., a new alkaliphilic aerobic anoxygenic phototrophic bacterium from a meromictic soda Lake Doroninskoe (East Siberia, Russia)]." Mikrobiologiia 83(4): 456-466.

Nurk, S., A. Bankevich, D. Antipov, A. Gurevich, A. Korobeynikov, A. Lapidus, A. Prjibelsky, A. Pyshkin, A. Sirotkin, Y. Sirotkin, R. Stepanauskas, J. McLean, R. Lasken, S. R. Clingenpeel, T. Woyke, G. Tesler, M. A. Alekseyev and P. A. Pevzner (2013). Assembling Genomes and Mini-metagenomes from Highly Chimeric Reads. Research in Computational Molecular 
Biology: 17th Annual International Conference, RECOMB 2013, Beijing, China, April 7-10, 2013. Proceedings. M. Deng, R. Jiang, F. Sun and X. Zhang. Berlin, Heidelberg, Springer Berlin Heidelberg: 158-170.

Ochsenreiter, T., F. Pfeifer and C. Schleper (2002). "Diversity of Archaea in hypersaline environments characterized by molecular-phylogenetic and cultivation studies." Extremophiles 6(4): 267-274.

Ohlendorf, B., D. Schulz, P. Beese, A. Erhard, R. Schmaljohann and J. F. Imhoff (2012). "Diacidene, a polyene dicarboxylic acid from a Micromonospora isolate from the German Wadden Sea." Z Naturforsch C 67(9-10): 445-450.

Oladipo, I. C., D. T. Adeleke and A. O. Adebiyi (2010). "The effect of $\mathrm{pH}$ and chemical preservatives on the growth of bacterial isolates from some Nigerian packaged fruit juices." Pak J Biol Sci 13(1): 16-21.

Olsen, G. J., N. R. Pace, M. Nuell, B. P. Kaine, R. Gupta and C. R. Woese (1985). "Sequence of the 16S rRNA gene from the thermoacidophilic archaebacterium Sulfolobus solfataricus and its evolutionary implications." Journal of molecular evolution 22(4): 301-307.

Olson, J. M. (2006). "Photosynthesis in the Archean era." Photosynth Res 88(2): 109-117.

Oremland, R. S. (1990). "Nitrogen fixation dynamics of two diazotrophic communities in mono lake, california." Appl Environ Microbiol 56(3): 614-622.

Oremland, R. S., J. E. Cloern, R. L. Smith, C. W. Culbertson, J. Zehr, L. Miller, B. Cole, R. Harvey, Z. Sofer, N. Iversen, M. Klug, D. J. Des Marais and G. Rau (1988). "Microbial and biogeochemical processes in Big Soda Lake, Nevada." Geological Society, London, Special Publications 40(1): 59-75.

Oremland, R. S., L. Marsh and D. J. Desmarais (1982). "Methanogenesis in big soda lake, nevada: an alkaline, moderately hypersaline desert lake." Appl Environ Microbiol 43(2): 462-468.

Ovreås, L., L. Forney, F. Daae and V. Torsvik (1997). "Distribution of bacterioplankton in meromictic Lake Saelenvannet, as determined by denaturing gradient gel electrophoresis of PCR-amplified gene fragments coding for 16S rRNA." Applied and Environmental Microbiology 63(9): 3367-3373.

Pace, N. R. (1995). "Opening the door onto the natural microbial world: molecular microbial ecology." Harvey lectures 91: 59-78.

Pace, N. R., D. A. Stahl and G. J. Olsen (1985). Analyzing natural microbial populations by rRNA sequences.

Park, S. J., J. G. Kim, M. Y. Jung, S. J. Kim, I. T. Cha, K. Kwon, J. H. Lee and S. K. Rhee (2012). "Draft genome sequence of an ammonia-oxidizing archaeon, "Candidatus Nitrosopumilus koreensis" AR1, from marine sediment." J Bacteriol 194(24): 6940-6941.

Patel, R. N. and A. Felix (1976). "Microbial oxidation of methane and methanol: crystallization and properties of methanol dehydrogenase from Methylosinus sporium." J Bacteriol 128(1): 413-424.

Paul, D., S. V. Kumbhare, S. S. Mhatre, S. P. Chowdhury, S. A. Shetty, N. P. Marathe, S. Bhute and Y. S. Shouche (2015). "Exploration of Microbial Diversity and Community Structure of Lonar Lake: The Only Hypersaline Meteorite Crater Lake within Basalt Rock." Front Microbiol 6: 1553.

Peck, H. D., Jr. (1961). "Enzymatic basis for assimilatory and dissimilatory sulfate reduction." J Bacteriol 82: 933-939.

Pedersen, K., E. Nilsson, J. Arlinger, L. Hallbeck and A. O'Neill (2004). "Distribution, diversity and activity of microorganisms in the hyper-alkaline spring waters of Maqarin in Jordan." Extremophiles 8(2): 151-164. 
Phongsopitanun, W., T. Kudo, M. Mori, K. Shiomi, P. Pittayakhajonwut, K. Suwanborirux and S. Tanasupawat (2015). "Micromonospora fluostatini sp. nov., isolated from marine sediment." Int J Syst Evol Microbiol 65(12): 4417-4423.

Pikuta, E. V., R. B. Hoover, A. K. Bej, D. Marsic, E. N. Detkova, W. B. Whitman and P. Krader (2003). "Tindallia californiensis sp. nov., a new anaerobic, haloalkaliphilic, spore-forming acetogen isolated from Mono Lake in California." Extremophiles 7(4): 327-334.

Pikuta, E. V., R. B. Hoover, A. K. Bej, D. Marsic, W. B. Whitman, D. Cleland and P. Krader (2003). "Desulfonatronum thiodismutans sp. nov., a novel alkaliphilic, sulfate-reducing bacterium capable of lithoautotrophic growth." Int J Syst Evol Microbiol 53(Pt 5): 1327-1332.

Pikuta, E. V., T. Itoh, P. Krader, J. Tang, W. B. Whitman and R. B. Hoover (2006). "Anaerovirgula multivorans gen. nov., sp. nov., a novel spore-forming, alkaliphilic anaerobe isolated from Owens Lake, California, USA." Int J Syst Evol Microbiol 56(Pt 11): 2623-2629.

Pino, C., F. Olmo-Mira, P. Cabello, M. Martinez-Luque, F. Castillo, M. D. Roldan and C. MorenoVivian (2006). "The assimilatory nitrate reduction system of the phototrophic bacterium Rhodobacter capsulatus E1F1." Biochem Soc Trans 34(Pt 1): 127-129.

Plugge, C. M., M. Balk, E. G. Zoetendal and A. J. Stams (2002). "Gelria glutamica gen. nov., sp. nov., a thermophilic, obligately syntrophic, glutamate-degrading anaerobe." Int J Syst Evol Microbiol 52(Pt 2): 401-407.

Podosokorskaya, O. A., E. A. Bonch-Osmolovskaya, A. A. Novikov, T. V. Kolganova and I. V. Kublanov (2013). "Ornatilinea apprima gen. nov., sp. nov., a cellulolytic representative of the class Anaerolineae." Int J Syst Evol Microbiol 63(Pt 1): 86-92.

Poser, A., R. Lohmayer, C. Vogt, K. Knoeller, B. Planer-Friedrich, D. Sorokin, H. H. Richnow and K. Finster (2013). "Disproportionation of elemental sulfur by haloalkaliphilic bacteria from soda lakes." Extremophiles 17(6): 1003-1012.

Presser, K. A., D. A. Ratkowsky and T. Ross (1997). "Modelling the growth rate of Escherichia coli as a function of $\mathrm{pH}$ and lactic acid concentration." Applied and environmental ....

Pruesse, E., C. Quast, K. Knittel, B. M. Fuchs, W. Ludwig, J. Peplies and F. O. Glockner (2007). "SILVA: a comprehensive online resource for quality checked and aligned ribosomal RNA sequence data compatible with ARB." Nucleic Acids Res 35(21): 7188-7196.

Quast, C., E. Pruesse, P. Yilmaz, J. Gerken, T. Schweer, P. Yarza, J. Peplies and F. O. Glockner (2013). "The SILVA ribosomal RNA gene database project: improved data processing and web-based tools." Nucleic Acids Res 41(Database issue): D590-596.

Quentmeier, A., P. Hellwig, F. Bardischewsky, G. Grelle, R. Kraft and C. G. Friedrich (2003). "Sulfur oxidation in Paracoccus pantotrophus: interaction of the sulfur-binding protein SoxYZ with the dimanganese SoxB protein." Biochem Biophys Res Commun 312(4): 1011-1018.

Quinn, M. J., C. T. Resch, J. Sun, E. J. Lind, P. Dibrov and C. C. Hase (2012). "NhaP1 is a $\mathrm{K}+(\mathrm{Na}+) / \mathrm{H}+$ antiporter required for growth and internal $\mathrm{pH}$ homeostasis of Vibrio cholerae at low extracellular pH." Microbiology 158(Pt 4): 1094-1105.

R Core Team (2015). R: A Language and Environment for Statistical Computing. Vienna, Austria, R Foundation for Statistical Computing.

Raddadi, N., A. Cherif, D. Daffonchio and F. Fava (2013). "Halo-alkalitolerant and thermostable cellulases with improved tolerance to ionic liquids and organic solvents from Paenibacillus tarimensis isolated from the Chott El Fejej, Sahara desert, Tunisia." Bioresour Technol 150: 121-128.

Raevuori, M. and C. Genigeorgis (1975). "Effect of pH and sodium chloride on growth of Bacillus cereus in laboratory media and certain foods." Appl Microbiol 29(1): 68-73. 
Rahman, A., N. Nahar, N. N. Nawani, J. Jass, S. Ghosh, B. Olsson and A. Mandal (2015). "Comparative genome analysis of Lysinibacillus B1-CDA, a bacterium that accumulates arsenics." Genomics 106(6): 384-392.

Rai, S. K., J. K. Roy and A. K. Mukherjee (2010). "Characterisation of a detergent-stable alkaline protease from a novel thermophilic strain Paenibacillus tezpurensis sp. nov. AS-S24-II." Appl Microbiol Biotechnol 85(5): 1437-1450.

Rainey, F. A., N. L. Ward, H. W. Morgan, R. Toalster and E. Stackebrandt (1993). "Phylogenetic analysis of anaerobic thermophilic bacteria: aid for their reclassification." Journal of Bacteriology 175(15): 4772-4779.

Reddy, S. V., M. Thirumala, M. Farooq, C. Sasikala and C. V. Ramana (2015). "Bacillus lonarensis sp. nov., an alkalitolerant bacterium isolated from a soda lake." Arch Microbiol 197(1): $27-$ 34.

Reed, D. W., Y. Fujita, M. E. Delwiche, D. B. Blackwelder, P. P. Sheridan, T. Uchida and F. S. Colwell (2002). "Microbial communities from methane hydrate-bearing deep marine sediments in a forearc basin." Appl Environ Microbiol 68(8): 3759-3770.

Rees, H. C., W. D. Grant, B. E. Jones and S. Heaphy (2004). "Diversity of Kenyan soda lake alkaliphiles assessed by molecular methods." Extremophiles 8(1): 63-71.

Reichenbecher, W. and B. Schink (1997). "Desulfovibrio inopinatus, sp. nov., a new sulfatereducing bacterium that degrades hydroxyhydroquinone." Arch Microbiol 168(4): 338344.

Romano, I., A. Poli, I. Finore, F. J. Huertas, A. Gambacorta, S. Pelliccione, G. Nicolaus, L. Lama and B. Nicolaus (2007). "Haloterrigena hispanica sp. nov., an extremely halophilic archaeon from Fuente de Piedra, southern Spain." Int J Syst Evol Microbiol 57(Pt 7): 1499-1503.

Ronaghi, M., S. Karamohamed, B. Pettersson, M. Uhlen and P. Nyren (1996). "Real-time DNA sequencing using detection of pyrophosphate release." Anal Biochem 242(1): 84-89.

Ronaghi, M., M. Uhlen and P. Nyren (1998). "A sequencing method based on real-time pyrophosphate." Science 281(5375): 363, 365.

Rospert, S., J. Breitung, K. Ma, B. Schworer, C. Zirngibl, R. K. Thauer, D. Linder, R. Huber and K. O. Stetter (1991). "Methyl-coenzyme $M$ reductase and other enzymes involved in methanogenesis from $\mathrm{CO} 2$ and $\mathrm{H} 2$ in the extreme thermophile Methanopyrus kandleri." Arch Microbiol 156(1): 49-55.

Ross, M. G., C. Russ, M. Costello, A. Hollinger, N. J. Lennon, R. Hegarty, C. Nusbaum and D. B. Jaffe (2013). "Characterizing and measuring bias in sequence data." Genome Biol 14(5): R51.

Rosso, L., J. R. Lobry, S. Bajard and J. P. Flandrois (1995). "Convenient Model To Describe the Combined Effects of Temperature and pH on Microbial Growth." Appl Environ Microbiol 61(2): 610-616.

Roy, A. and A. K. Chatterjee (1998). " Deccan basalts and its mineralogical alterations in the central and western Peninsular India." Clay Research 17(2): 72-89.

Rozanov, A. S., A. V. Bryanskaya, T. K. Malup, A. V. Kotenko and S. E. Peltek (2015). "Draft genome sequence of a halorubrum h3 strain isolated from the burlinskoye salt lake (altai krai, Russia)." Genome Announc 3(3).

Ruiz-Romero, E., C. Valenzuela-Encinas, M. P. Lopez-Ramirez, M. de los Angeles Coutino-Coutino, R. Marsch and L. Dendooven (2013). "Natronorubrum texcoconense sp. nov., a haloalkaliphilic archaeon isolated from soil of the former lake Texcoco (Mexico)." Arch Microbiol 195(2): 145-151.

Russell, J. B. and D. B. Dombrowski (1980). "Effect of pH on the efficiency of growth by pure cultures of rumen bacteria in continuous culture." Appl Environ Microbiol 39(3): 604-610. 
Salka, I., A. Srivastava, M. Allgaier and H. P. Grossart (2014). "The Draft Genome Sequence of Sphingomonas sp. Strain FukuSWIS1, Obtained from Acidic Lake Grosse Fuchskuhle, Indicates Photoheterotrophy and a Potential for Humic Matter Degradation." Genome Announc 2(6).

Sass, H., M. Berchtold, J. Branke, H. Konig, H. Cypionka and H. D. Babenzien (1998). "Psychrotolerant sulfate-reducing bacteria from an oxic freshwater sediment, description of Desulfovibrio cuneatus sp. nov. and Desulfovibrio litoralis sp. nov." Syst Appl Microbiol 21(2): 212-219.

Savant, D. V., Y. S. Shouche, S. Prakash and D. R. Ranade (2002). "Methanobrevibacter acididurans sp. nov., a novel methanogen from a sour anaerobic digester." Int J Syst Evol Microbiol 52(Pt 4): 1081-1087.

Schagerl, M., A. Burian, M. Gruber-Dorninger, S. O. Oduor and M. N. Kaggwa (2015). "Algal communities of Kenyan soda lakes with a special focus on Arthrospira fusiformis." Fottea 15(2): 245-257.

Schalk, J., S. de Vries, J. G. Kuenen and M. S. Jetten (2000). "Involvement of a novel hydroxylamine oxidoreductase in anaerobic ammonium oxidation." Biochemistry 39(18): 5405-5412.

Schirmack, J., K. Mangelsdorf, L. Ganzert, W. Sand, A. Hillebrand-Voiculescu and D. Wagner (2014). "Methanobacterium movilense sp. nov., a hydrogenotrophic, secondary-alcoholutilizing methanogen from the anoxic sediment of a subsurface lake." Int J Syst Evol Microbiol 64(Pt 2): 522-527.

Schloss, P. D. and J. Handelsman (2005). "Introducing DOTUR, a computer program for defining operational taxonomic units and estimating species richness." Appl Environ Microbiol 71(3): 1501-1506.

Selim, S. and N. Hagagy (2016). "Genome sequence of carboxylesterase, carboxylase and xylose isomerase producing alkaliphilic haloarchaeon Haloterrigena turkmenica WANU15." Genom Data 7: 70-72.

Shannon, C. E. (2001). "A mathematical theory of communication." ACM SIGMOBILE Mobile Computing and Communications Review 5(1): 3.

Shao, M. F., T. Zhang and H. H. Fang (2010). "Sulfur-driven autotrophic denitrification: diversity, biochemistry, and engineering applications." Appl Microbiol Biotechnol 88(5): 1027-1042.

Shapovalova, A. A., T. V. Khijniak, T. P. Tourova, G. Muyzer and D. Y. Sorokin (2008). "Heterotrophic denitrification at extremely high salt and $\mathrm{pH}$ by haloalkaliphilic Gammaproteobacteria from hypersaline soda lakes." Extremophiles 12(5): 619-625.

Shapovalova, A. A., T. V. Khijniak, T. P. Tourova and D. Y. Sorokin (2009). "Halomonas chromatireducens sp. nov., a new denitrifying facultatively haloalkaliphilic bacterium from solonchak soil capable of aerobic chromate reduction." Microbiology 78(1): 102-111.

Sharp, C. E., A. L. Brady, G. H. Sharp, S. E. Grasby, M. B. Stott and P. F. Dunfield (2014). "Humboldt's spa: microbial diversity is controlled by temperature in geothermal environments." ISME J 8(6): 1166-1174.

Shenderov, B. A. (2013). "Metabiotics: novel idea or natural development of probiotic conception." Microb Ecol Health Dis 24.

Shetty, S., N. Marathe, H. Munot, C. Antony, D. Dhotre, J. Murrell and Y. Shouche (2013). "Draft Genome Sequence of Methylophaga lonarensis MPLT, a Haloalkaliphilic (Non-MethaneUtilizing) Methylotroph." Genome announcements 1(3).

Shiratori-Takano, H., K. Yamada, T. Beppu and K. Ueda (2011). "Longispora fulva sp. nov., isolated from a forest soil, and emended description of the genus Longispora." Int J Syst Evol Microbiol 61(Pt 4): 804-809. 
Siddiqi, S. Z. (2007). Limnological Profile of High-Impact Meteor Crater Lake Lonar, Buldana, Maharashtra, India, an Extreme Hyperalkaline, Saline Habitat. The 12th World Lake Conference.

Simankova, M. V., S. N. Parshina, T. P. Tourova, T. V. Kolganova, A. J. Zehnder and A. N. Nozhevnikova (2001). "Methanosarcina lacustris sp. nov., a new psychrotolerant methanogenic archaeon from anoxic lake sediments." Syst Appl Microbiol 24(3): 362-367.

Simon, C., A. Wiezer, A. W. Strittmatter and R. Daniel (2009). "Phylogenetic diversity and metabolic potential revealed in a glacier ice metagenome." Appl Environ Microbiol 75(23): 7519-7526.

Singh, N., M. M. Kendall, Y. Liu and D. R. Boone (2005). "Isolation and characterization of methylotrophic methanogens from anoxic marine sediments in Skan Bay, Alaska: description of Methanococcoides alaskense sp. nov., and emended description of Methanosarcina baltica." Int J Syst Evol Microbiol 55(Pt 6): 2531-2538.

Sirajuddin, S. and A. C. Rosenzweig (2015). "Enzymatic oxidation of methane." Biochemistry 54(14): 2283-2294.

Smith, C. J., D. B. Nedwell, L. F. Dong and A. M. Osborn (2007). "Diversity and abundance of nitrate reductase genes (narG and napA), nitrite reductase genes (nirS and nrfA), and their transcripts in estuarine sediments." Appl Environ Microbiol 73(11): 3612-3622.

Smith, R. L., J. K. Bohlke, B. Song and C. R. Tobias (2015). "Role of Anaerobic Ammonium Oxidation (Anammox) in Nitrogen Removal from a Freshwater Aquifer." Environ Sci Technol 49(20): 12169-12177.

Soemphol, W., M. Tatsuno, T. Okada, M. Matsutani, N. Kataoka, T. Yakushi and K. Matsushita (2015). "A novel $\mathrm{Na}(+)(\mathrm{K}(+)) / \mathrm{H}(+)$ antiporter plays an important role in the growth of Acetobacter tropicalis SKU1100 at high temperatures via regulation of cation and $\mathrm{pH}$ homeostasis." J Biotechnol 211: 46-55.

Sogin, M. L., H. G. Morrison, J. A. Huber, D. M. Welch, S. M. Huse, P. R. Neal, J. M. Arrieta and G. J. Herndl (2006). "Microbial diversity in the deep sea and the underexplored "rare biosphere"." Proceedings of the National Academy of Sciences 103(32): 12115-12120.

Sogin, S. J., M. L. Sogin and C. R. Woese (1971). "Phylogenetic measurement in procaryotes by primary structural characterization." J Mol Evol 1(1): 173-184.

Solé, M., J. G. Lorén and N. Rius (2010). "Rapid extracellular acidification induced by glucose metabolism in non-proliferating cells of Serratia marcescens." International Microbiology.

Sorensen, K. B. and A. Teske (2006). "Stratified communities of active Archaea in deep marine subsurface sediments." Appl Environ Microbiol 72(7): 4596-4603.

Sorokin, D. and J. Kuenen (2005). "Haloalkaliphilic sulfur-oxidizing bacteria in soda lakes." FEMS Microbiology Reviews 29(4): 685-702.

Sorokin, D., T. Tourova, M. C. Schmid, M. Wagner, H. P. Koops, J. G. Kuenen and M. Jetten (2001). "Isolation and properties of obligately chemolithoautotrophic and extremely alkalitolerant ammonia-oxidizing bacteria from Mongolian soda lakes." Arch Microbiol 176(3): 170-177.

Sorokin, D., T. P. Turova, B. B. Kuznetsov, I. A. Briantseva and V. M. Gorlenko (2000). "[Roseinatronobacter thiooxidans Gen. Nov., sp. Nov., a new alkaliphilic aerobic bacteriochlorophyll-alpha-containing bacteria from a soda lake]." Mikrobiologiia 69(1): 89-97.

Sorokin, D. Y., B. Abbas, M. Geleijnse, G. N. V. Pimenov, M. V. Sukhacheva and M. C. M. van Loosdrecht (2015). "Methanogenesis at extremely haloalkaline conditions in soda lakes of Kulunda Steppe (Altai, Russia)." FEMS Microbiology Ecology. 
Sorokin, D. Y., B. Abbas, M. Geleijnse, N. V. Pimenov, M. V. Sukhacheva and M. C. van Loosdrecht (2015). "Methanogenesis at extremely haloalkaline conditions in the soda lakes of Kulunda Steppe (Altai, Russia)." FEMS Microbiol Ecol 91(4).

Sorokin, D. Y., B. Abbas, A. Y. Merkel, W. I. Rijpstra, J. S. Damste, M. V. Sukhacheva and M. C. van Loosdrecht (2015). "Methanosalsum natronophilum sp. nov., and Methanocalculus alkaliphilus sp. nov., haloalkaliphilic methanogens from hypersaline soda lakes." Int J Syst Evol Microbiol 65(10): 3739-3745.

Sorokin, D. Y., H. Banciu, L. A. Robertson, J. G. Kuenen, M. S. Muntyan and G. Muyzer (2013). Halophilic and Haloalkaliphilic Sulfur-Oxidizing Bacteria. The Prokaryotes: Prokaryotic Physiology and Biochemistry. E. Rosenberg, E. F. DeLong, S. Lory, E. Stackebrandt and F. Thompson. Berlin, Heidelberg, Springer Berlin Heidelberg: 529-554.

Sorokin, D. Y., T. Berben, E. D. Melton, L. Overmars, C. D. Vavourakis and G. Muyzer (2014). "Microbial diversity and biogeochemical cycling in soda lakes." Extremophiles 18(5): 791809.

Sorokin, D. Y., E. N. Detkova and G. Muyzer (2010). "Propionate and butyrate dependent bacterial sulfate reduction at extremely haloalkaline conditions and description of Desulfobotulus alkaliphilus sp. nov." Extremophiles 14(1): 71-77.

Sorokin, D. Y., E. N. Detkova and G. Muyzer (2011). "Sulfur-dependent respiration under extremely haloalkaline conditions in soda lake 'acetogens' and the description of Natroniella sulfidigena sp. nov." FEMS Microbiol Lett 319(1): 88-95.

Sorokin, D. Y., M. Foti, H. C. Pinkart and G. Muyzer (2007). "Sulfur-oxidizing bacteria in Soap Lake (Washington State), a meromictic, haloalkaline lake with an unprecedented high sulfide content." Appl Environ Microbiol 73(2): 451-455.

Sorokin, D. Y., J. Gijs Kuenen and M. S. M. Jetten (2001). "Denitrification at extremely high pH values by the alkaliphilic, obligately chemolithoautotrophic, sulfur-oxidizing bacterium Thioalkalivibrio denitrificans strain ALD." Archives of Microbiology 175(2): 94-101.

Sorokin, D. Y., V. M. Gumerov, A. L. Rakitin, A. V. Beletsky, J. S. Damste, G. Muyzer, A. V. Mardanov and N. V. Ravin (2014). "Genome analysis of Chitinivibrio alkaliphilus gen. nov., sp. nov., a novel extremely haloalkaliphilic anaerobic chitinolytic bacterium from the candidate phylum Termite Group 3." Environ Microbiol 16(6): 1549-1565.

Sorokin, D. Y., B. E. Jones and J. G. Kuenen (2000). "An obligate methylotrophic, methaneoxidizing Methylomicrobium species from a highly alkaline environment." Extremophiles 4(3): 145-155.

Sorokin, D. Y. and J. G. Kuenen (2005). "Chemolithotrophic haloalkaliphiles from soda lakes." FEMS Microbiol Ecol 52(3): 287-295.

Sorokin, D. Y. and J. G. Kuenen (2005). "Haloalkaliphilic sulfur-oxidizing bacteria in soda lakes." FEMS Microbiol Rev 29(4): 685-702.

Sorokin, D. Y., J. G. Kuenen and M. S. Jetten (2001). "Denitrification at extremely high pH values by the alkaliphilic, obligately chemolithoautotrophic, sulfur-oxidizing bacterium Thioalkalivibrio denitrificans strain ALD." Arch Microbiol 175(2): 94-101.

Sorokin, D. Y., J. G. Kuenen and G. Muyzer (2011). "The microbial sulfur cycle at extremely haloalkaline conditions of soda lakes." Front Microbiol 2: 44.

Sorokin, D. Y., A. M. Lysenko, L. L. Mityushina, T. P. Tourova, B. E. Jones, F. A. Rainey, L. A. Robertson and G. J. Kuenen (2001). "Thioalkalimicrobium aerophilum gen. nov., sp. nov. and Thioalkalimicrobium sibericum sp. nov., and Thioalkalivibrio versutus gen. nov., sp. nov., Thioalkalivibrio nitratis sp.nov., novel and Thioalkalivibrio denitrificancs sp. nov., 
novel obligately alkaliphilic and obligately chemolithoautotrophic sulfur-oxidizing bacteria from soda lakes." Int J Syst Evol Microbiol 51(Pt 2): 565-580.

Sorokin, D. Y., M. S. Muntyan, A. N. Panteleeva and G. Muyzer (2012). "Thioalkalivibrio sulfidiphilus sp. nov., a haloalkaliphilic, sulfur-oxidizing gammaproteobacterium from alkaline habitats." Int J Syst Evol Microbiol 62(Pt 8): 1884-1889.

Sorokin, D. Y. and G. Muyzer (2010). "Desulfurispira natronophila gen. nov. sp. nov.: an obligately anaerobic dissimilatory sulfur-reducing bacterium from soda lakes." Extremophiles 14(4): 349-355.

Sorokin, D. Y. and G. Muyzer (2010). "Haloalkaliphilic spore-forming sulfidogens from soda lake sediments and description of Desulfitispora alkaliphila gen. nov., sp. nov." Extremophiles 14(3): 313-320.

Sorokin, D. Y., G. Muyzer, T. Brinkhoff, J. G. Kuenen and M. S. Jetten (1998). "Isolation and characterization of a novel facultatively alkaliphilic Nitrobacter species, N. alkalicus sp. nov." Arch Microbiol 170(5): 345-352.

Sorokin, D. Y., A. N. Panteleeva, T. P. Tourova, E. N. Kaparullina and G. Muyzer (2011). "Natronoflexus pectinivorans gen. nov. sp. nov., an obligately anaerobic and alkaliphilic fermentative member of Bacteroidetes from soda lakes." Extremophiles 15(6): 691-696.

Sorokin, D. Y., Rusanov, II, N. V. Pimenov, T. P. Tourova, B. Abbas and G. Muyzer (2010). "Sulfidogenesis under extremely haloalkaline conditions in soda lakes of Kulunda Steppe (Altai, Russia)." FEMS Microbiol Ecol 73(2): 278-290.

Sorokin, D. Y., T. P. Tourova, B. Abbas, M. V. Suhacheva and G. Muyzer (2012). "Desulfonatronovibrio halophilus sp. nov., a novel moderately halophilic sulfate-reducing bacterium from hypersaline chloride-sulfate lakes in Central Asia." Extremophiles 16(3): 411-417.

Sorokin, D. Y., T. P. Tourova, A. M. Henstra, A. J. Stams, E. A. Galinski and G. Muyzer (2008). "Sulfidogenesis under extremely haloalkaline conditions by Desulfonatronospira thiodismutans gen. nov., sp. nov., and Desulfonatronospira delicata sp. nov. - a novel lineage of Deltaproteobacteria from hypersaline soda lakes." Microbiology 154(Pt 5): 1444-1453.

Sorokin, D. Y., T. P. Tourova, T. V. Kolganova, E. N. Detkova, E. A. Galinski and G. Muyzer (2011). "Culturable diversity of lithotrophic haloalkaliphilic sulfate-reducing bacteria in soda lakes and the description of Desulfonatronum thioautotrophicum sp. nov., Desulfonatronum thiosulfatophilum sp. nov., Desulfonatronovibrio thiodismutans sp. nov., and Desulfonatronovibrio magnus sp. nov." Extremophiles 15(3): 391-401.

Sorokin, D. Y., T. P. Tourova, T. V. Kolganova, K. A. Sjollema and J. G. Kuenen (2002). "Thioalkalispira microaerophila gen. nov., sp. nov., a novel lithoautotrophic, sulfuroxidizing bacterium from a soda lake." Int J Syst Evol Microbiol 52(Pt 6): 2175-2182.

Sorokin, D. Y., T. P. Tourova, A. M. Lysenko, L. L. Mityushina and J. G. Kuenen (2002). "Thioalkalivibrio thiocyanoxidans sp. nov. and Thioalkalivibrio paradoxus sp. nov., novel alkaliphilic, obligately autotrophic, sulfur-oxidizing bacteria capable of growth on thiocyanate, from soda lakes." Int J Syst Evol Microbiol 52(Pt 2): 657-664.

Sorokin, D. Y., T. P. Tourova, M. Mussmann and G. Muyzer (2008). "Dethiobacter alkaliphilus gen. nov. sp. nov., and Desulfurivibrio alkaliphilus gen. nov. sp. nov.: two novel representatives of reductive sulfur cycle from soda lakes." Extremophiles 12(3): 431-439.

Sorokin, D. Y., T. P. Tourova, A. N. Panteleeva, E. N. Kaparullina and G. Muyzer (2012). "Anaerobic utilization of pectinous substrates at extremely haloalkaline conditions by 
Natranaerovirga pectinivora gen. nov., sp. nov., and Natranaerovirga hydrolytica sp. nov., isolated from hypersaline soda lakes." Extremophiles.

Sorokin, D. Y., T. P. Tourova, A. N. Panteleeva and G. Muyzer (2012). "Desulfonatronobacter acidivorans gen. nov., sp. nov. and Desulfobulbus alkaliphilus sp. nov., haloalkaliphilic heterotrophic sulfate-reducing bacteria from soda lakes." Int J Syst Evol Microbiol 62(Pt 9): 2107-2113.

Sorokin, D. Y., T. P. Tourova, M. V. Sukhacheva, A. V. Mardanov and N. V. Ravin (2012). "Bacterial chitin utilisation at extremely haloalkaline conditions." Extremophiles 16(6): 883-894.

Sorokin, D. Y., T. P. Tourova, M. V. Sukhacheva and G. Muyzer (2012). "Desulfuribacillus alkaliarsenatis gen. nov. sp. nov., a deep-lineage, obligately anaerobic, dissimilatory sulfur and arsenate-reducing, haloalkaliphilic representative of the order Bacillales from soda lakes." Extremophiles 16(4): 597-605.

Sorokin, D. Y., P. L. van den Bosch, B. Abbas, A. J. Janssen and G. Muyzer (2008). "Microbiological analysis of the population of extremely haloalkaliphilic sulfur-oxidizing bacteria dominating in lab-scale sulfide-removing bioreactors." Appl Microbiol Biotechnol 80(6): 965-975.

Sorokin, D. Y., S. van Pelt, T. P. Tourova and L. I. Evtushenko (2009). "Nitriliruptor alkaliphilus gen. nov., sp. nov., a deep-lineage haloalkaliphilic actinobacterium from soda lakes capable of growth on aliphatic nitriles, and proposal of Nitriliruptoraceae fam. nov. and Nitriliruptorales ord. nov." Int J Syst Evol Microbiol 59(Pt 2): 248-253.

Sorokin, D. Y., D. Vejmelkova, S. Lucker, G. M. Streshinskaya, W. I. Rijpstra, J. S. Sinninghe Damste, R. Kleerbezem, M. van Loosdrecht, G. Muyzer and H. Daims (2014). "Nitrolancea hollandica gen. nov., sp. nov., a chemolithoautotrophic nitrite-oxidizing bacterium isolated from a bioreactor belonging to the phylum Chloroflexi." Int J Syst Evol Microbiol 64(Pt 6): 1859-1865.

Sorokin, D. Y., T. N. Zhilina, A. M. Lysenko, T. P. Tourova and E. M. Spiridonova (2006). "Metabolic versatility of haloalkaliphilic bacteria from soda lakes belonging to the AlkalispirillumAlkalilimnicola group." Extremophiles 10(3): 213-220.

Sorokin, I. D., I. K. Kravchenko, E. V. Doroshenko, E. S. Boulygina, E. V. Zadorina, T. P. Tourova and D. Y. Sorokin (2008). "Haloalkaliphilic diazotrophs in soda solonchak soils." FEMS Microbiol Ecol 65(3): 425-433.

Sorokin, I. D., I. K. Kravchenko, T. P. Tourova, T. V. Kolganova, E. S. Boulygina and D. Y. Sorokin (2008). "Bacillus alkalidiazotrophicus sp. nov., a diazotrophic, low salt-tolerant alkaliphile isolated from Mongolian soda soil." Int J Syst Evol Microbiol 58(Pt 10): 2459-2464.

Sorokin, I. D., E. V. Zadorina, I. K. Kravchenko, E. S. Boulygina, T. P. Tourova and D. Y. Sorokin (2008). "Natronobacillus azotifigens gen. nov., sp. nov., an anaerobic diazotrophic haloalkaliphile from soda-rich habitats." Extremophiles 12(6): 819-827.

Stahl, D. and R. Amann (1991). Development and application of nucleic acid probes in bacterial systematics. Nucleic acid techniques in bacterial systematics. E. Stackebrandt and M. Goodfellow. New York, John Wiley and Sons: 205-248.

Sun, B., J. R. Cole, R. A. Sanford and J. M. Tiedje (2000). "Isolation and characterization of Desulfovibrio dechloracetivorans sp. nov., a marine dechlorinating bacterium growing by coupling the oxidation of acetate to the reductive dechlorination of 2-chlorophenol." Appl Environ Microbiol 66(6): 2408-2413.

Supong, K., C. Suriyachadkun, S. Tanasupawat, K. Suwanborirux, P. Pittayakhajonwut, T. Kudo and C. Thawai (2013). "Micromonospora sediminicola sp. nov., isolated from marine sediment." Int J Syst Evol Microbiol 63(Pt 2): 570-575. 
Surakasi, V. P., C. P. Antony, S. Sharma, M. S. Patole and Y. S. Shouche (2010). "Temporal bacterial diversity and detection of putative methanotrophs in surface mats of Lonar crater lake." J Basic Microbiol 50(5): 465-474.

Surakasi, V. P., A. A. Wani, Y. S. Shouche and D. R. Ranade (2007). "Phylogenetic analysis of methanogenic enrichment cultures obtained from Lonar Lake in India: isolation of Methanocalculus sp. and Methanoculleus sp." Microb Ecol 54(4): 697-704.

Suzuki, D., A. Ueki, A. Amaishi and K. Ueki (2009). "Desulfovibrio portus sp. nov., a novel sulfatereducing bacterium in the class Deltaproteobacteria isolated from an estuarine sediment." J Gen Appl Microbiol 55(2): 125-133.

Takii, S., S. Hanada, Y. Hase, H. Tamaki, Y. Uyeno, Y. Sekiguchi and K. Matsuura (2008). "Desulfovibrio marinisediminis sp. nov., a novel sulfate-reducing bacterium isolated from coastal marine sediment via enrichment with Casamino acids." Int J Syst Evol Microbiol 58(Pt 10): 2433-2438.

Tamegai, H., E. Ikeda, C. Kato and K. Horikoshi (2007). "Identification of the functional periplasmic nitrate reductase (nap) gene cluster from the deep-sea denitrifier Pseudomonas sp. strain MT-1." Biosci Biotechnol Biochem 71(8): 2041-2045.

Tetu, S. G., K. Breakwell, L. D. Elbourne, A. J. Holmes, M. R. Gillings and I. T. Paulsen (2013). "Life in the dark: metagenomic evidence that a microbial slime community is driven by inorganic nitrogen metabolism." ISME J 7(6): 1227-1236.

Thakker, C. D. and Ranade (2002). "An alkalophilic Methanosarcina isolated from Lonar crater." Current science 82(4): 455-458.

Thorat, M. N., R. Mawlankar, V. V. Sonalkar, V. Venkata Ramana, N. Joseph, Y. S. Shouche and S. G. Dastager (2015). "Deinococcus enclensis sp. nov., isolated from a marine sediment sample." Antonie Van Leeuwenhoek 107(1): 141-148.

Tiago, I., A. P. Chung and A. Verissimo (2004). "Bacterial diversity in a nonsaline alkaline environment: heterotrophic aerobic populations." Appl Environ Microbiol 70(12): 73787387.

Ticak, T., D. Hariraju, M. B. Arcelay, B. A. Arivett, S. E. Fiester and D. J. Ferguson, Jr. (2015). "Isolation and characterization of a tetramethylammonium-degrading Methanococcoides strain and a novel glycine betaine-utilizing Methanolobus strain." Arch Microbiol 197(2): 197-209.

Tienungoon, S. and D. A. Ratkowsky (2000). "Growth limits of Listeria monocytogenesas a function of temperature, $\mathrm{pH}, \mathrm{NaCl}$, and lactic acid." Applied and ....

Tindall, B. J., A. A. Mills and W. D. Grant (1980). "An Alkalophilic Red Halophilic Bacterium with a Low Magnesium Requirement from a Kenyan Soda Lake." Microbiology 116(1): 257-260.

Tokura, M., K. Tajima and K. Ushida (1999). "Isolation of Methanobrevibacter sp. as a ciliateassociated ruminal methanogen." J Gen Appl Microbiol 45(1): 43-47.

Torres, M. J., M. I. Rubia, E. J. Bedmar and M. J. Delgado (2011). "Denitrification in Sinorhizobium meliloti." Biochem Soc Trans 39(6): 1886-1889.

Torres, M. J., M. I. Rubia, T. C. de la Pena, J. J. Pueyo, E. J. Bedmar and M. J. Delgado (2014). "Genetic basis for denitrification in Ensifer meliloti." BMC Microbiol 14: 142.

Tourova, T. P., M. A. Grechnikova, V. V. Kuznetsov and D. Y. Sorokin (2014). "[Phylogenetic diversity of bacteria in soda lake stratified sediments]." Mikrobiologiia 83(6): 730-742.

Tourova, T. P., N. V. Slobodova, B. K. Bumazhkin, T. V. Kolganova, G. Muyzer and D. Y. Sorokin (2013). "Analysis of community composition of sulfur-oxidizing bacteria in hypersaline and soda lakes using soxB as a functional molecular marker." FEMS Microbiol Ecol 84(2): 280289. 
Tourova, T. P., E. M. Spiridonova, I. A. Berg, N. V. Slobodova, E. S. Boulygina and D. Y. Sorokin (2007). "Phylogeny and evolution of the family Ectothiorhodospiraceae based on comparison of $16 \mathrm{~S}$ rRNA, cbbL and nifH gene sequences." Int J Syst Evol Microbiol 57(Pt 10): 2387-2398.

Tsubouchi, T., S. Koyama, K. Mori, Y. Shimane, K. Usui, M. Tokuda, A. Tame, K. Uematsu, T. Maruyama and Y. Hatada (2014). "Brevundimonas denitrificans sp. nov., a denitrifying bacterium isolated from deep subseafloor sediment." Int J Syst Evol Microbiol 64(Pt 11): 3709-3716.

Tsubouchi, T., Y. Shimane, K. Usui, S. Shimamura, K. Mori, T. Hiraki, A. Tame, K. Uematsu, T. Maruyama and Y. Hatada (2013). "Brevundimonas abyssalis sp. nov., a dimorphic prosthecate bacterium isolated from deep-subsea floor sediment." Int J Syst Evol Microbiol 63(Pt 6): 1987-1994.

Van de Peer, Y., S. Chapelle and R. De Wachter (1996). "A quantitative map of nucleotide substitution rates in bacterial rRNA." Nucleic Acids Res 24(17): 3381-3391.

van de Wijngaard, W. M., J. Creemers, G. D. Vogels and C. van der Drift (1991). "Methanogenic pathways in Methanosphaera stadtmanae." FEMS Microbiol Lett 64(2-3): 207-211.

Vargas, V. A., O. D. Delgado, R. Hatti-Kaul and B. Mattiasson (2005). "Bacillus bogoriensis sp. nov., a novel alkaliphilic, halotolerant bacterium isolated from a Kenyan soda lake." Int J Syst Evol Microbiol 55(Pt 2): 899-902.

Vasileiadis, S., E. Puglisi, M. Arena, F. Cappa, P. S. Cocconcelli and M. Trevisan (2012). "Soil bacterial diversity screening using single 16S rRNA gene $V$ regions coupled with multimillion read generating sequencing technologies." PLoS One 7(8): e42671.

Ventosa, A., M. C. Gutierrez, M. Kamekura and M. L. Dyall-Smith (1999). "Proposal to transfer Halococcus turkmenicus, Halobacterium trapanicum JCM 9743 and strain GSL-11 to Haloterrigena turkmenica gen. nov., comb. nov." Int J Syst Bacteriol 49 Pt 1: 131-136.

Vilo, C. and Q. Dong (2012). "Evaluation of the RDP Classifier Accuracy Using 16S rRNA Gene Variable Regions." Metagenomics 1: 1-5.

Vishnuvardhan Reddy, S., M. Thirumala and M. Farooq (2015). "Bacillus caseinilyticus sp. nov., an alkali- and thermotolerant bacterium isolated from a soda lake." Int J Syst Evol Microbiol 65(8): 2441-2446.

Vissers, E. W., F. S. Anselmetti, P. L. Bodelier, G. Muyzer, C. Schleper, M. Tourna and H. J. Laanbroek (2013). "Temporal and spatial coexistence of archaeal and bacterial amoA genes and gene transcripts in Lake Lucerne." Archaea 2013: 289478.

Wang, B., S. Q. Ji, X. X. Tian, L. Y. Qu and F. L. Li (2015). "Brassicibacter thermophilus sp. nov., a thermophilic bacterium isolated from coastal sediment." Int J Syst Evol Microbiol 65(9): 2870-2874.

Wang, G., X. Huang, T. B. Ng, J. Lin and X. Y. Ye (2014). "High phylogenetic diversity of glycosyl hydrolase family 10 and 11 xylanases in the sediment of Lake Dabusu in China." PLoS One 9(11): e112798.

Wang, J. P., B. Liu, G. H. Liu, C. B. Ge, Q. Q. Chen, Y. J. Zhu and Z. Chen (2015). "Genome Sequence of Anaerobacillus macyae JMM-4T (DSM 16346), the First Genomic Information of the Newly Established Genus Anaerobacillus." Genome Announc 3(4).

Wang, S., Q. Yang, Z. H. Liu, L. Sun, D. Wei, J. Z. Zhang, J. Z. Song and H. F. Yuan (2010). "Haloterrigena daqingensis sp. nov., an extremely haloalkaliphilic archaeon isolated from a saline-alkaline soil." Int J Syst Evol Microbiol 60(Pt 10): 2267-2271. 
Wani, A. A., V. P. Surakasi, J. Siddharth, R. G. Raghavan, M. S. Patole, D. Ranade and Y. S. Shouche (2006). "Molecular analyses of microbial diversity associated with the Lonar soda lake in India: an impact crater in a basalt area." Res Microbiol 157(10): 928-937.

Ward, B. B., D. P. Martino, M. C. Diaz and S. B. Joye (2000). "Analysis of ammonia-oxidizing bacteria from hypersaline Mono Lake, California, on the basis of 16S rRNA sequences." Appl Environ Microbiol 66(7): 2873-2881.

Wei, S., T. Wang, H. Liu, C. Zhang, J. Guo, Q. Wang, K. Liang and Z. Zhang (2015). "Sphingomonas hengshuiensis sp. nov., isolated from lake wetland." Int J Syst Evol Microbiol 65(12): 46444649.

Wemheuer, B., R. Taube, P. Akyol, F. Wemheuer and R. Daniel (2013). "Microbial diversity and biochemical potential encoded by thermal spring metagenomes derived from the Kamchatka Peninsula." Archaea 2013: 136714.

Wemheuer, B., F. Wemheuer and R. Daniel (2012). "RNA-based assessment of diversity and composition of active archaeal communities in the German Bight." Archaea 2012: 695826.

Weng, C. Y., S. C. Chen, M. C. Lai, S. Y. Wu, S. Lin, T. F. Yang and P. C. Chen (2015). "Methanoculleus taiwanensis sp. nov., a methanogen isolated from deep marine sediment at the deformation front area near Taiwan." Int J Syst Evol Microbiol 65(Pt 3): 1044-1049.

Whitby, C. B., J. R. Saunders, R. W. Pickup and A. J. McCarthy (2001). "A comparison of ammoniaoxidiser populations in eutrophic and oligotrophic basins of a large freshwater lake." Antonie Van Leeuwenhoek 79(2): 179-188.

Wodara, C., S. Kostka, M. Egert, D. P. Kelly and C. G. Friedrich (1994). "Identification and sequence analysis of the soxB gene essential for sulfur oxidation of Paracoccus denitrificans GB17." J Bacteriol 176(20): 6188-6191.

Woese, C. R., G. E. Fox, L. Zablen, T. Uchida, L. Bonen, K. Pechman, B. J. Lewis and D. Stahl (1975). "Conservation of primary structure in 16S ribosomal RNA." Nature 254(5495): 83-86.

Wood, S. A., A. Rueckert, D. A. Cowan and S. C. Cary (2008). "Sources of edaphic cyanobacterial diversity in the Dry Valleys of Eastern Antarctica." ISME J 2(3): 308-320.

Wu, X. Y., K. L. Shi, X. W. Xu, M. Wu, A. Oren and X. F. Zhu (2010). "Alkaliphilus halophilus sp. nov., a strictly anaerobic and halophilic bacterium isolated from a saline lake, and emended description of the genus Alkaliphilus." Int J Syst Evol Microbiol 60(Pt 12): 2898-2902.

Wu, X. Y., G. Zheng, W. W. Zhang, X. W. Xu, M. Wu and X. F. Zhu (2010). "Amphibacillus jilinensis sp. nov., a facultatively anaerobic, alkaliphilic bacillus from a soda lake." Int J Syst Evol Microbiol 60(Pt 11): 2540-2543.

Xie, Q. Y., Z. Qu, H. P. Lin, L. Li and K. Hong (2012). "Micromonospora haikouensis sp. nov., isolated from mangrove soil." Antonie Van Leeuwenhoek 101(3): 649-655.

Xiong, J., Y. Liu, X. Lin, H. Zhang, J. Zeng, J. Hou, Y. Yang, T. Yao, R. Knight and H. Chu (2012). "Geographic distance and $\mathrm{pH}$ drive bacterial distribution in alkaline lake sediments across Tibetan Plateau." Environmental Microbiology 14(9): 2457-2466.

Xiong, J., Y. Liu, X. Lin, H. Zhang, J. Zeng, J. Hou, Y. Yang, T. Yao, R. Knight and H. Chu (2012). "Geographic distance and $\mathrm{pH}$ drive bacterial distribution in alkaline lake sediments across Tibetan Plateau." Environ Microbiol 14(9): 2457-2466.

Xu, X. W., S. J. Liu, D. Tohty, A. Oren, M. Wu and P. J. Zhou (2005). "Haloterrigena saccharevitans sp. nov., an extremely halophilic archaeon from Xin-Jiang, China." Int J Syst Evol Microbiol 55(Pt 6): 2539-2542.

Xu, X. W., M. Wu, P. J. Zhou and S. J. Liu (2005). "Halobiforma lacisalsi sp. nov., isolated from a salt lake in China." Int J Syst Evol Microbiol 55(Pt 5): 1949-1952. 
Xu, X. W., Y. H. Wu, H. B. Zhang and M. Wu (2007). "Halorubrum arcis sp. nov., an extremely halophilic archaeon isolated from a saline lake on the Qinghai-Tibet Plateau, China." Int J Syst Evol Microbiol 57(Pt 5): 1069-1072.

Xu, Y., Z. Wang, Y. Xue, P. Zhou, Y. Ma, A. Ventosa and W. D. Grant (2001). "Natrialba hulunbeirensis sp. nov. and Natrialba chahannaoensis sp. nov., novel haloalkaliphilic Archaea from soda lakes in Inner Mongolia Autonomous Region, China." Int J Syst Evol Microbiol 51(Pt 5): 1693-1698.

Xu, Y., P. Zhou and X. Tian (1999). "Characterization of two novel haloalkaliphilic Archaea Natronorubrum bangense gen. nov., sp. nov. and Natronorubrum tibetense gen. nov., sp. nov." Int J Syst Bacteriol 49 Pt 1: 261-266.

Yakimov, M. M., L. Giuliano, T. N. Chernikova, G. Gentile, W. R. Abraham, H. Lunsdorf, K. N. Timmis and P. N. Golyshin (2001). "Alcalilimnicola halodurans gen. nov., sp. nov., an alkaliphilic, moderately halophilic and extremely halotolerant bacterium, isolated from sediments of soda-depositing Lake Natron, East Africa Rift Valley." Int J Syst Evol Microbiol 51(Pt 6): 2133-2143.

Yamamoto, E., H. Muramatsu and K. Nagai (2014). "Vulgatibacter incomptus gen. nov., sp. nov. and Labilithrix luteola gen. nov., sp. nov., two myxobacteria isolated from soil in Yakushima Island, and the description of Vulgatibacteraceae fam. nov., Labilitrichaceae fam. nov. and Anaeromyxobacteraceae fam. nov." Int J Syst Evol Microbiol 64(Pt 10): 3360-3368.

Yan, Y., J. Yang, L. Chen, F. Yang, J. Dong, Y. Xue, X. Xu, Y. Zhu, Z. Yao, M. Lin, Y. Wang and Q. Jin (2005). "Structural and functional analysis of denitrification genes in Pseudomonas stutzeri A1501." Sci China C Life Sci 48(6): 585-592.

Yang, Z., X. Meng, F. Breidt, Jr., L. L. Dean and F. M. Arritt (2015). "Effects of acetic acid and arginine on $\mathrm{pH}$ elevation and growth of Bacillus licheniformis in an acidified cucumber juice medium." J Food Prot 78(4): 728-737.

Yeates, C., M. R. Gillings, A. D. Davison, N. Altavilla and D. A. Veal (1998). "Methods for microbial DNA extraction from soil for PCR amplification." Biological procedures online 1: 40-47.

Yeates, C., M. R. Gillings, A. D. Davison, N. Altavilla and D. A. Veal (1998). "Methods for microbial DNA extraction from soil for PCR amplification." Biol Proced Online 1: 40-47.

Yilmaz, P., L. W. Parfrey, P. Yarza, J. Gerken, E. Pruesse, C. Quast, T. Schweer, J. Peplies, W. Ludwig and F. O. Glockner (2014). "The SILVA and "All-species Living Tree Project (LTP)" taxonomic frameworks." Nucleic Acids Res 42(Database issue): D643-648.

Yin, H., X. Zhang, X. Li, Z. He, Y. Liang, X. Guo, Q. Hu, Y. Xiao, J. Cong, L. Ma, J. Niu and X. Liu (2014). "Whole-genome sequencing reveals novel insights into sulfur oxidation in the extremophile Acidithiobacillus thiooxidans." BMC Microbiol 14: 179.

Yoon, J. H., S. J. Kang, J. S. Lee and T. K. Oh (2006). "Brevundimonas terrae sp. nov., isolated from an alkaline soil in Korea." Int J Syst Evol Microbiol 56(Pt 12): 2915-2919.

Yoon, J. H., S. J. Kang, H. W. Oh, J. S. Lee and T. K. Oh (2006). "Brevundimonas kwangchunensis sp. nov., isolated from an alkaline soil in Korea." Int J Syst Evol Microbiol 56(Pt 3): 613617.

Yoon, J. H., S. J. Kang, S. H. Yeo and T. K. Oh (2005). "Paenibacillus alkaliterrae sp. nov., isolated from an alkaline soil in Korea." Int J Syst Evol Microbiol 55(Pt 6): 2339-2344.

Zakharyuk, A. G., L. P. Kozyreva, T. V. Khijniak, B. B. Namsaraev and V. A. Shcherbakova (2015). "Desulfonatronum zhilinae sp. nov., a novel haloalkaliphilic sulfate-reducing bacterium from soda Lake Alginskoe, Trans-Baikal Region, Russia." Extremophiles 19(3): 673-680. 
Zavarzin, G. A. and T. N. Zhilina (2000). Anaerobic Chemotrophic Alkaliphiles. Journey to Diverse Microbial Worlds: Adaptation to Exotic Environments. J. Seckbach. Dordrecht, Springer Netherlands: 191-208.

Zavarzin, G. A., T. N. Zhilina and V. V. Kevbrin (1999). "The alkaliphilic microbial community and its functional diversity." Microbiologiya 68(5): 579-599.

Zavarzina, D. G., T. V. Kolganova, E. S. Bulygina, N. A. Kostrikina, T. P. Turova and G. A. Zavarzin (2006). "[Geoalkalibacter ferrihydriticus gen. nov., sp. nov., the first alkaliphilic representative of the family Geobacteraceae, isolated from a soda lake]." Mikrobiologiia 75(6): 775-785.

Zavarzina, D. G., T. P. Tourova, T. V. Kolganova, E. S. Boulygina and T. N. Zhilina (2009). "Description of Anaerobacillus alkalilacustre gen. nov., sp. nov.-Strictly anaerobic diazotrophic bacillus isolated from soda lake and transfer of Bacillus arseniciselenatis, Bacillus macyae, and Bacillus alkalidiazotrophicus to Anaerobacillus as the new combinations A. arseniciselenatis comb. nov., A. macyae comb. nov., and A. alkalidiazotrophicus comb. nov." Microbiology 78(6): 723-731.

Zavarzina, D. G., T. N. Zhilina, B. B. Kuznetsov, T. V. Kolganova, G. A. Osipov, M. S. Kotelev and G. A. Zavarzin (2013). "Natranaerobaculum magadiense gen. nov., sp. nov., an anaerobic, alkalithermophilic bacterium from soda lake sediment." Int J Syst Evol Microbiol 63(Pt 12): 4456-4461.

Zeleke, J., S. L. Lu, J. G. Wang, J. X. Huang, B. Li, A. V. Ogram and Z. X. Quan (2013). "Methyl coenzyme $M$ reductase $A$ ( $m c r A$ ) gene-based investigation of methanogens in the mudflat sediments of Yangtze River estuary, China." Microb Ecol 66(2): 257-267.

Zellner, G., E. Stackebrandt, P. Messner, B. J. Tindall, E. Conway de Macario, H. Kneifel, U. B. Sleytr and J. Winter (1989). "Methanocorpusculaceae fam. nov., represented by Methanocorpusculum parvum, Methanocorpusculum sinense spec. nov. and Methanocorpusculum bavaricum spec. nov." Arch Microbiol 151(5): 381-390.

Zeng, J., D. Y. Zhao, R. Huang and Q. L. Wu (2012). "Abundance and community composition of ammonia-oxidizing Archaea and bacteria in two different zones of Lake Taihu." Can J Microbiol 58(8): 1018-1026.

Zhai, L., T. Liao, Y. Xue and Y. Ma (2012). "Bacillus daliensis sp. nov., an alkaliphilic, Gram-positive bacterium isolated from a soda lake." Int J Syst Evol Microbiol 62(Pt 4): 949-953.

Zhang, G., N. Jiang, X. Liu and X. Dong (2008). "Methanogenesis from methanol at low temperatures by a novel psychrophilic methanogen, "Methanolobus psychrophilus" sp. nov., prevalent in Zoige wetland of the Tibetan plateau." Appl Environ Microbiol 74(19): 6114-6120.

Zhang, H., Y. Sekiguchi, S. Hanada, P. Hugenholtz, H. Kim, Y. Kamagata and K. Nakamura (2003). "Gemmatimonas aurantiaca gen. nov., sp. nov., a gram-negative, aerobic, polyphosphateaccumulating micro-organism, the first cultured representative of the new bacterial phylum Gemmatimonadetes phyl. nov." Int J Syst Evol Microbiol 53(Pt 4): 1155-1163.

Zhang, Y. Z., M. X. Fang, W. W. Zhang, T. T. Li, M. Wu and X. F. Zhu (2013). "Salimesophilobacter vulgaris gen. nov., sp. nov., an anaerobic bacterium isolated from paper-mill wastewater." Int J Syst Evol Microbiol 63(Pt 4): 1317-1322.

Zhao, F., Y. Feng, R. Chen, J. Zhang and X. Lin (2015). "Lysinibacillus alkaliphilus sp. nov., an extremely alkaliphilic bacterium, and emended description of genus Lysinibacillus." Int J Syst Evol Microbiol 65(8): 2426-2431. 
Zhao, Y., Y. Dong, Y. Zhang, L. Che, H. Pan and H. Zhou (2016). "Draft Genome Sequence of a Selenite- and Tellurite-Reducing Marine Bacterium, Lysinibacillus sp. Strain ZYM-1." Genome Announc 4(1).

Zhilina, T. N., R. Appel, C. Probian, E. L. Brossa, J. Harder, F. Widdel and G. A. Zavarzin (2004). "Alkaliflexus imshenetskii gen. nov. sp. nov., a new alkaliphilic gliding carbohydratefermenting bacterium with propionate formation from a soda lake." Arch Microbiol 182(23): $244-253$.

Zhilina, T. N., E. N. Detkova, F. A. Rainey, G. A. Osipov, A. M. Lysenko, N. A. Kostrikina and G. A. Zavarzin (1998). "Natronoincola histidinovorans gen. nov., sp. nov., A new alkaliphilic acetogenic anaerobe." Curr Microbiol 37(3): 177-185.

Zhilina, T. N., V. V. Kevbrin, T. P. Turova, A. M. Lysenko, N. A. Kostrikina and G. A. Zavarzin (2005). "[Clostridium alkalicellum sp. nov., an obligately alkaliphilic cellulolytic bacterium from a soda lake in the Baikal region]." Mikrobiologiia 74(5): 642-653.

Zhilina, T. N., G. A. Zavarzin, E. N. Detkova and F. A. Rainey (1996). "Natroniella acetigena gen. nov. sp. nov., an Extremely Haloalkaliphilic, Homoacetic Bacterium: A New Member of Haloanaerobiales." Curr Microbiol 32(6): 320-326.

Zhilina, T. N., G. A. Zavarzin, F. A. Rainey, E. N. Pikuta, G. A. Osipov and N. A. Kostrikina (1997). "Desulfonatronovibrio hydrogenovorans gen. nov., sp. nov., an alkaliphilic, sulfatereducing bacterium." Int J Syst Bacteriol 47(1): 144-149.

Zhilina, T. N., D. G. Zavarzina, V. V. Kevbrin and T. V. Kolganov (2013). "[Methanocalculus natronophilus sp. nov., a new alkaliphilic hydrogenotrophic methanogenic archaeon from a soda lake, and proposal of the new family Methanocalculaceae]." Mikrobiologiia 82(6): 681-690.

Zhilina, T. N., D. G. Zavarzina, T. V. Kolganova, A. M. Lysenko and T. P. Tourova (2009). "Alkaliphilus peptidofermentans sp. nov., a new alkaliphilic bacterial soda lake isolate capable of peptide fermentation and Fe(III) reduction." Microbiology 78(4): 445-454.

Zhilina, T. N., D. G. Zavarzina, J. Kuever, A. M. Lysenko and G. A. Zavarzin (2005). "Desulfonatronum cooperativum sp. nov., a novel hydrogenotrophic, alkaliphilic, sulfatereducing bacterium, from a syntrophic culture growing on acetate." Int J Syst Evol Microbiol 55(Pt 3): 1001-1006.

Zhilina, T. N., D. G. Zavarzina, G. A. Osipov, N. A. Kostrikina and T. P. Tourova (2009). "Natronincola ferrireducens sp. nov., and Natronincola peptidovorans sp. nov., new anaerobic alkaliphilic peptolytic iron-reducing bacteria isolated from soda lakes." Microbiology 78(4): 455-467.

Zhilina, T. N., D. G. Zavarzina, A. N. Panteleeva, G. A. Osipov, N. A. Kostrikina, T. P. Tourova and G. A. Zavarzin (2012). "Fuchsiella alkaliacetigena gen. nov., sp. nov., an alkaliphilic, lithoautotrophic homoacetogen from a soda lake." Int J Syst Evol Microbiol 62(Pt 7): 16661673.

Zhou, L., X. Liu and X. Dong (2014). "Methanospirillum psychrodurum sp. nov., isolated from wetland soil." Int J Syst Evol Microbiol 64(Pt 2): 638-641.

Zhou, X., J. O. Zeitz, L. Meile, M. Kreuzer and A. Schwarm (2015). "Influence of pH and the degree of protonation on the inhibitory effect of fatty acids in the ruminal methanogen Methanobrevibacter ruminantium strain M1." J Appl Microbiol 119(6): 1482-1493.

Zhou, Z., J. Chen, H. Cao, P. Han and J. D. Gu (2014). "Analysis of methane-producing and metabolizing archaeal and bacterial communities in sediments of the northern South China Sea and coastal Mai Po Nature Reserve revealed by PCR amplification of mcrA and pmoA genes." Front Microbiol 5: 789. 
Zhu, J., X. Liu and X. Dong (2011). "Methanobacterium movens sp. nov. and Methanobacterium flexile sp. nov., isolated from lake sediment." Int J Syst Evol Microbiol 61(Pt 12): 29742978.

Zvereva, E. A., T. V. Fedorova, V. V. Kevbrin, T. N. Zhilina and M. L. Rabinovich (2006). "Cellulase activity of a haloalkaliphilic anaerobic bacterium, strain Z-7026." Extremophiles 10(1): 5360. 
$\underline{\text { Supplements }}$ 


\section{SUPPLEMENTS}

\section{SUPPLEMENT-A: AUTHORIZATION FOR SAMPLING}

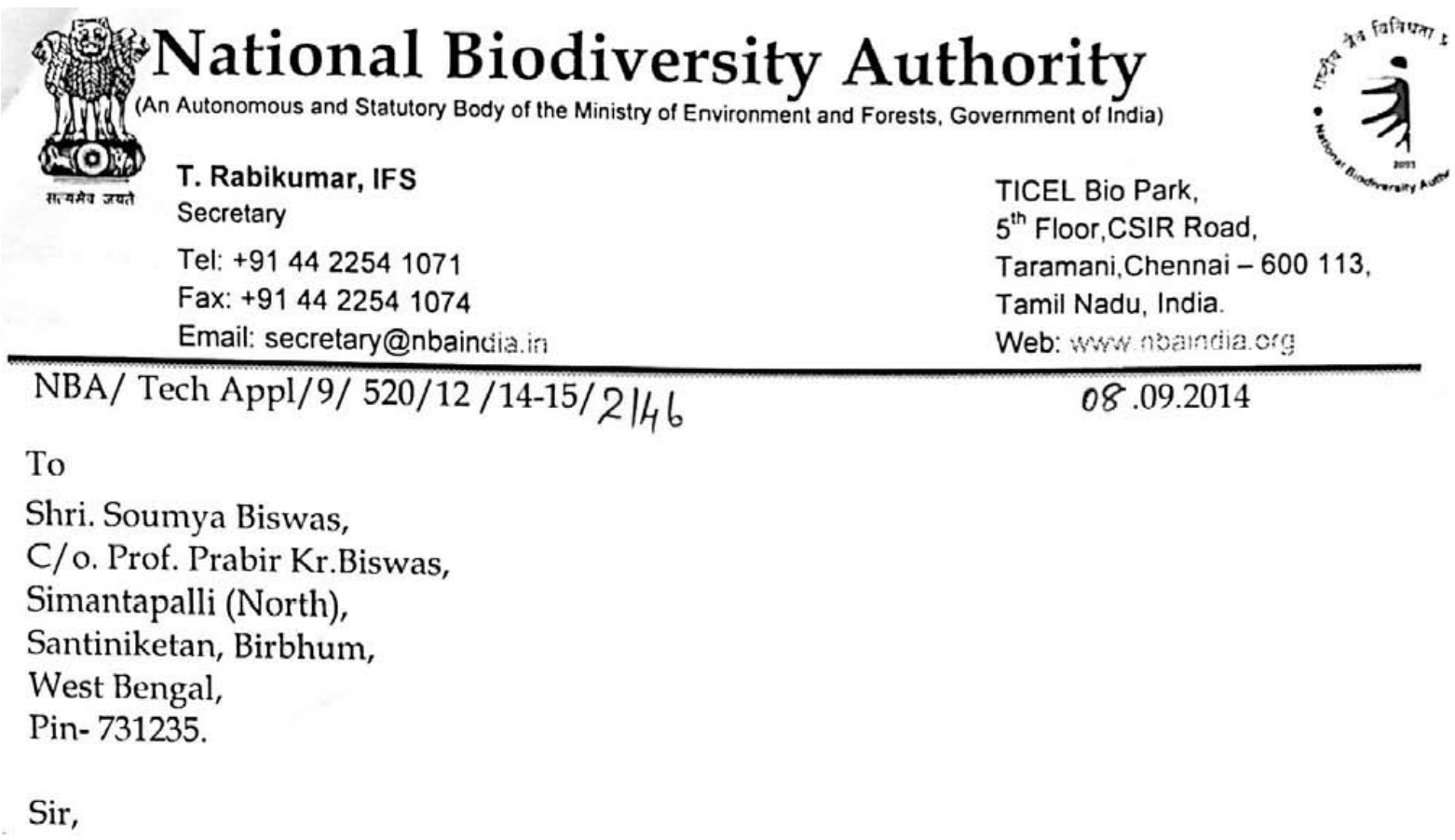

Sub: Approval for Access of Bioresource for Research/Bio- survey and Bioutilization (Form-I) application under Section 3 read with Section 19(1) of the Biological Diversity Act, 2002 and Rule 14 of the Biological Diversity Rules, 2004-reg.

Ref- Your application in Form - I dated 01.06.2012.

With reference to your application cited in reference on the subject cited above to facilitate "Collect the soil sediment (Microbial life form) from Lonar lake and carrying to Germany for research purpose" has been approved by the National Biodiversity Authority subject to the condition that the applicant should not transfer any material to other persons without obtaining prior approval of National Biodiversity Authority and no application for patents in any country should be submitted without obtaining prior permission from the National Biodiversity Authority.

I am enclosing herewith one mutually signed stamp paper Agreement executed between National Biodiversity Authority and the applicant for the applicant's reference compliance. It is also to inform you that breach of the terms 
of agreement and provisions of the Biological Diversity Act, 2002 and Biological Diversity Rule, 2004 made there under will invite imposition of penalties as per Section 55, 56 \& 57 of the Biological Diversity Act, 2002.

Please acknowledge receipt of this communication.

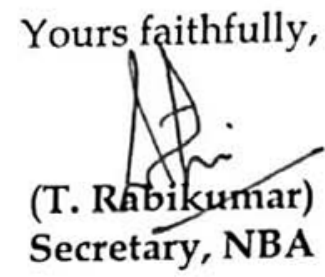

Encl: One Mutually Signed agreement (Original)

Copy to: Member Secretary, Shri. Jose. T. Mathew, IFS, West Bengal Biodiversity Board, Poura Bhawan (4th Floor),FD-415A, Sector - III, Bidhan Nagar, Kolkata - 700106. 


\section{SUPPLEMENT-B: THE TOTAL AND THE ACTIVE ARCHAEAL DIVERSITY TABLE}

TABle 33: Relative ABUNDANCE OF the totAl AND the ACtiVe ARCHAEAL ORDER. Lonar 1, Lonar 2 and Lonar 3 represent 3 different samples, and the values are average of 3 separate experiments.

cd:|supplements\suppliment-B.pdf

Table 34: Relative abundance of the total and the active archaeal genera. Lonar 1, Lonar 2 and Lonar 3 represent 3 different samples, and the values are average of 3 separate experiments.

cd:\supplements\suppliment-B.pdf

\section{SUPPLEMENT-C: THE TOTAL AND THE ACTIVE BACTERIAL DIVERSITY TABLE}

Table 35: Relative abundance of the total and the ACtive bacterial Phylum. Lonar 1, Lonar 2 and Lonar 3 represent 3 different samples, and the values are average of 3 separate experiments.

cd:|supplements\suppliment-C.pdf

TABle 36: Relative abundance of the total AND the ACtive bacterial genera. Lonar 1, Lonar 2 and Lonar 3 represent 3 different samples, and the values are average of 3 separate experiments.

cd:|supplements\suppliment-C.pdf

\section{SUPPLEMENT-D: ADDITIONAL TOTAL DIVERSITY OF ARCHAEA AND BACTERIA}

Table 37: Relative abundance of ArChaea and Bacteria from additional assessment. Lonar 1, Lonar 2 and Lonar 3 represent 3 different samples, and the values are average of 3 separate experiments.

cd:\supplements\suppliment-D.pdf 


\section{Supplement-E: Changing Relative ABundANCE Of ARCHAEA AND BACTERIA IN SUBOPTIMAL AND SUPEROPTIMAL PH SYSTEMS}

Table 38: Relative Abundance of Prokaryotes. to to t5 represents time points from day zero to day 25. All the values are average of 3 separate experiment and only up to 5 decimal points are shown.

cd:\supplements\suppliment-E.pdf

\section{SUPPLEMENT-F: DIVERSITY OF FUNCTIONAL GENES OBSERVED BY DIRECT METAGENOME ANALYSIS}

Table 39: Relative Abundance of ORF in Functional Categories

cd:\supplements\suppliment-F.pdf

TABle 40: Results of Reconstructed BRIte anAlysis.

cd:|supplements\suppliment-F.pdf

Table 41: Reconstructed Pathway Module

cd:\supplements\suppliment-F.pdf

Table 42: Results of Reconstructed Pathway Analysis.

cd:\supplements\suppliment-F.pdf

\section{SUPPLEMENT-G: DETAILS OF THE SEQUENCE SUBMITTED TO NCBI}

All the sequences generated during this thesis will be uploaded to NCBI Sequence Read Archive under accession number SRA437941. 


\section{SUPPLEMENT-H: RESULTS FROM CONSTRUCTION AND SCREENING OF METAGENOMIC LIBRARIES}

TABle 43: Characterization of Constructed Metagenomic libraries (SMALl inSERT Library) AND SCREENING FOR FUNCTIONAL GENES

cd:|supplements\suppliment-H.pdf 


\section{ACKNOWLEDGEMENTS}

I would like to express my most sincere gratitude to my supervisor and thesis committee member Prof. Dr. Rolf Daniel for letting me work on my idea and for allowing me to mature as a research scientist. Your guidance for both research as well as on my career has been invaluable. I would also like to thank my co-supervisor and thesis committee member, PD. Dr. Michael Hoppert and all the Members of the Examination Board, Prof. Dr. Burkhard Morgenstern, PD Dr. Fabian Commichau, Prof. Dr. Kai Heimel, PD Dr. Wilfried Kramer. I also want to thank my thesis committee and examination board for letting my defense be a pleasing moment, and for your brilliant observations and recommendations, thanks to you. I am thankful to Dr. Bernd Wemheuer, Dr. Heiko Nacke, Dr. Dominik Schneider and Dr. Romano Mwirichia. Special thanks to Dr. Andrea Thürmer and all the stuff of sequencing laboratory. I would especially like to thank all the personals of Administration, especially Daniela Dreykluft and all the Technical Assistants, especially Melanie Heinemann. I am also grateful to all the members of the Department of Genomic and Applied Microbiology, The Institute of Microbiology and Genetics and all the members of Courant Research Centre, Geobiology of the Georg-August-Universität Göttingen. I would also like to thank Mareike Jakobi for her contribution towards my thesis while working on her Bachelor Thesis under my supervision. Also a very special thanks to Kajori Parial, Senior Research Fellow, Radioactivity and Radon Modelling Laboratory, Department of Geology and Geophysics, Indian Institute of Technology (IIT) Kharagpur, India for creating the map of the global distribution of soda lakes (Figure 39).

I am also thankful to Erasmus Mundus External Cooperation Window Lot 13, EURINDIA and Director, Goettingen International, Georg-August-Universität Göttingen, Germany for the scholarship and the contract. Field work permit was given by National Biodiversity Authority of India (An Autonomous and Statutory Body of the Ministry of Environment and Forests, Government of India), Chennai, India. I am thankful for their cooperation.

I would also like to take this opportunity to express my regards for my most encouraging mentor from my earlier education and research Professor Narayan C. 
Mandal, Department of Botany, Siksha-Bhavana, Visva-Bharati University, Santiniketan, India for his encouragement to pursue my ideas.

Finally, a very special thanks to my family. Words cannot express how grateful I am to my father, Prof. Prabir Kr. Biswas; my mother, Bani Biswas for all of the sacrifices that you've made on my behalf. Your support for me has what sustained me this far. I would also like to thank my dear friend and philosopher Supratik Bose and Mary K for their help and support. In the end, I would like to express my appreciation to my beloved wife Abhirupa Biswas who spent nightmarish sleepless nights with me and kept me from losing my mind during perpetual stressful situations one after the other. 